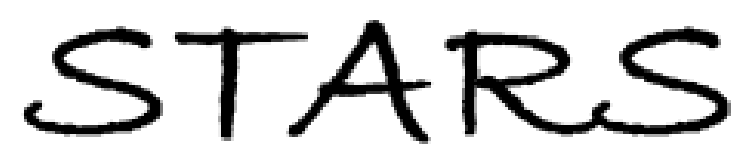

University of Central Florida

STARS

2013

\title{
Early And Intermediate Hospital-to-home Transition Outcomes Of Older Adults Diagnosed With Diabetes
}

Jacqueline Lamanna

University of Central Florida

Part of the Nursing Commons

Find similar works at: https://stars.library.ucf.edu/etd

University of Central Florida Libraries http://library.ucf.edu

This Doctoral Dissertation (Open Access) is brought to you for free and open access by STARS. It has been accepted for inclusion in Electronic Theses and Dissertations, 2004-2019 by an authorized administrator of STARS. For more information, please contact STARS@ucf.edu.

\section{STARS Citation}

Lamanna, Jacqueline, "Early And Intermediate Hospital-to-home Transition Outcomes Of Older Adults Diagnosed With Diabetes" (2013). Electronic Theses and Dissertations, 2004-2019. 2648.

https://stars.library.ucf.edu/etd/2648

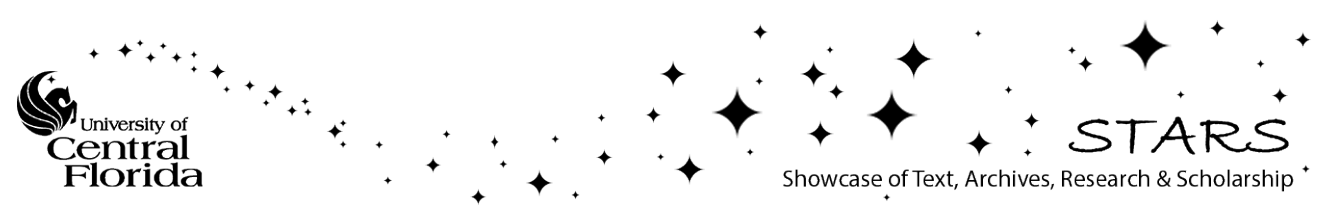




\title{
EARLY AND INTERMEDIATE HOSPITAL-TO-HOME TRANSITION OUTCOMES OF OLDER ADULTS DIAGNOSED WITH DIABETES
}

\author{
by
}

JACQUELINE BURTON LaMANNA

B.S.N. Purdue University, 1985

M.S.N. University of Florida, 1991

\begin{abstract}
A dissertation submitted in partial fulfillment of the requirements for the degree of Doctor of Philosophy in the College of Nursing at the University of Central Florida Orlando, Florida
\end{abstract}

Summer Term 2013

Major Professor: Angeline Bushy 
(C) 2013 Jacqueline Burton LaManna 


\begin{abstract}
Over 5 million older adults with diabetes are hospitalized each year. Though typically not the index condition that leads to hospitalization, diabetes control often decompensates during the course of an admission and necessitates changes in home self-management plans. The specific transitional care needs of older adults with diabetes have been largely unstudied.

Transition theory provided the guiding framework for this research and proposes that each transition is a complex process created by the continuous interaction of personal, community, and societal-level conditions that facilitate or inhibit the health of a transition. Hospitalization has been described as a series of three successive, interrelated transitions.

The aims of this study were to determine whether personal and community transition conditions impacted the early and intermediate post-discharge outcomes in a sample of older adults with diabetes. A simultaneous quantitative/qualitative mixed method design was used to identify factors that impacted the home recovery transition experiences in a sample of 96 older adults with a mean age of 75 years.
\end{abstract}

A supplementary content analysis of free-response data gathered during administration of the Post-Discharge Coping Difficulty Scale (PDCDS) clarified difficulties encountered by elders and caregivers during in the first 30 days following discharge. Four overarching themes emerged: "the daily stuff is difficult”; “engineering care at home is difficult”; "life is stressful” and “difficulty managing complex health problems”.

Difficulties managing a complex medication regimen, regulating blood glucose, and managing a non-diabetes chronic health problem such as hypertension and chronic lung disease were subthemes that emerged during qualitative data analyses. These subthemes were transposed 
into discrete nominal level variables and served as additional indicators of post-discharge coping difficulty in the descriptive correlational core component of the research project.

Participants in this study who experienced an event of recidivism had lower pre-discharge assessments of readiness on the Readiness for Hospital Discharge Scale (RHDS) $(t=2.274$, $\mathrm{df}=48, p=.028)$. Higher PDCDS scores were observed in patients who experienced an event of recidivism within 30 days of discharge $(t=-3.363, \mathrm{df}=24.7, p=.003)$ and also in respondents who described difficulties with managing medications, controlling diabetes, and managing a chronic illness. Binary logistic regression was used to identify factors that may predict recidivism risk. No condition-specific predictor variables were identified. A statistically significant three-variable model $\left(X^{2}=26.737, \mathrm{df}=3, p<.001\right)$ revealed that PDCDS scores at 7 days (Wald $X^{2}=3.671, \mathrm{df}=1, p=.050$ ), PDCDS scores at 30 days $\left(\right.$ Wald $X^{2}=6.723, \mathrm{df}=1$, $p=.010$ ), and difficulty managing a chronic health condition (Wald $X^{2}=8.200, \mathrm{df}=1, p=.004$ ) were predictive of an event of recidivism within 30 days of discharge. Difficulty managing a chronic health problem other than diabetes was particularly predictive of recidivism.

The nurse's skill in delivering discharge education was a factor in limiting early postdischarge difficulties. Elders with residual information needs on the day of discharge as measured by scores the Quality of Discharge Teaching Scale (QDTS) reported a lower readiness for discharge $(r=-.314, p=.003)$ and experienced greater difficulties with early post-discharge coping ( $r=.288, p=.023)$. Greater satisfaction with the post-discharge transition was noted in participants with higher QDTS scores $(r=.444, p<.001)$.

Outcomes of the hospital-to-home transition experience were impacted by a variety of personal, hospital, and community factors. Findings of this study suggest that there is a need to better understand the sequential nature of the home recovery transition and the fluid needs of 
older adults during this high-risk phase of care. The environments in which older adults receive post-discharge care are complex and need to be thoroughly considered when planning the postdischarge transition. Metrics of institutional performance of transitional care practices need to extend beyond events to recidivism and include evaluations of post-discharge coping and transition satisfaction. The nurse as the primary provider of discharge education has the potential to significantly promote positive transition outcomes for older adults and their family care providers. 
This dissertation is dedicated to my mother, Marilyn Burton, RN, who was my inspiration to pursue a career in nursing and my partner in data collection for this study. Thank you for the hundreds of phone calls she made and the patience she exhibited as each elder shared his or her story. I could not have completed the study without her help and support and would not be the nurse I am today without her caring example of professional nursing practice 


\section{ACKNOWLEDGMENTS}

I would first like to thank my husband, Tony, for his loving support during this journey. He has helped me to keep my eye on the ball and has been there to celebrate each success and push me during each challenge in my doctoral journey. My children, Beth and Dan, shared the UCF experience with me. I have watched them graduate from high school, excel in college and begin careers during our time at UCF. I am very proud of them both. My parents, Marilyn and Warren Burton, have also been tremendous supports in my dissertation journey.

Special thanks are offered to Dr. Angeline Bushy, who was a member of my original committee and stepped up to serve as chair as I completed data collection. I appreciate her counsel and guidance through the difficult part of this process and tremendous insight on qualitative methodology.

I also would like to thank Drs. Diane Wink and Denise Gammonley for their guidance in designing a study that targeted older adults with special needs and for their support during the dissertation process. Special thanks to Dr. Anne Norris for her assistance with statistical analysis and for recommending the mixed methods design. I believe this added to richness of the data. Additionally, I would like to thank Dr. Karen Dennis for her assistance in proposal development and the University of Central Florida’s Knightingale Society for partial funding of this research.

Thanks are also extended to Bonnie Rudolph, RN, MS, who assisted me with gaining access to the study site. I appreciate the friendship and support in this process and the time that she spent introducing me to key hospital personnel. I would also like to thank the unit nurses who assisted me in recruitment and who encouraged me in this process.

Finally, I would like to thank the study respondents who were so willing to share their stories on the challenges of returning home after a hospitalization. 


\section{TABLE OF CONTENTS}

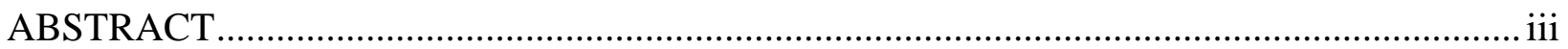

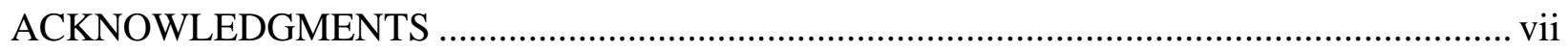

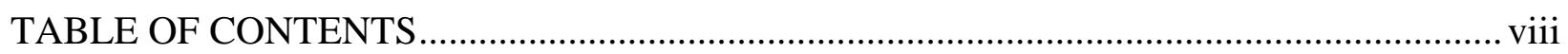

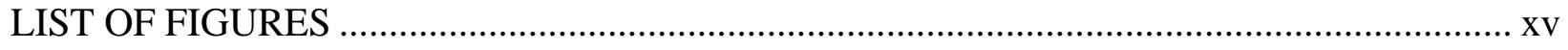

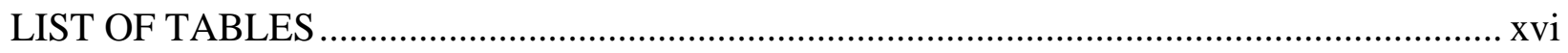

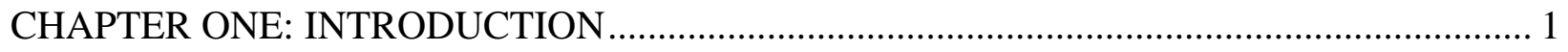

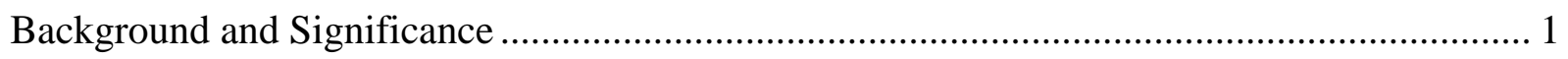

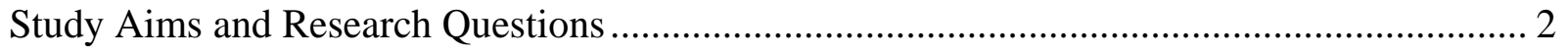

Theoretical Framework …………………………………...................................................... 3

Home Recovery Transition Experiences ............................................................................ 8

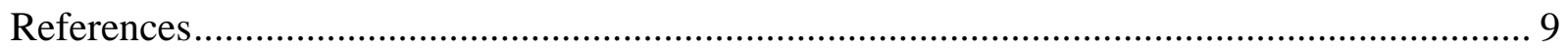

CHAPTER TWO: HOSPITAL-TO-HOME TRANSITION OUTCOMES OF OLDER ADULTS WITH DIABETES — STATE OF THE SCIENCE ………………………………....... 13

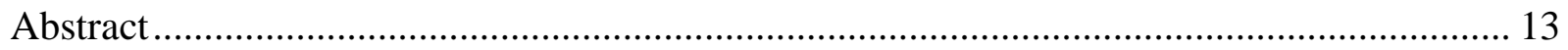

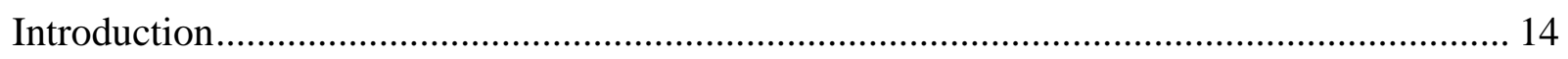

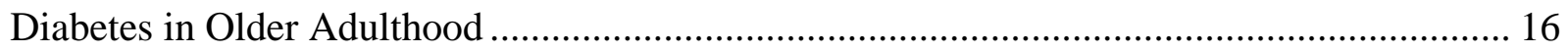

Chronic Illness and Hospitalization in Older Adulthood..................................................... 17

Hospital-to-Home Transition Experiences of Older Adults ....................................................... 19

Hospital Discharge as a Transition ...................................................................................... 21

Medical Error Risk and Hospital Discharge ....................................................................... 23

Provider Issues and Hospital Discharge ........................................................................... 24

Perceived Discharge Readiness and Coping Difficulties After Discharge ............................ 25 


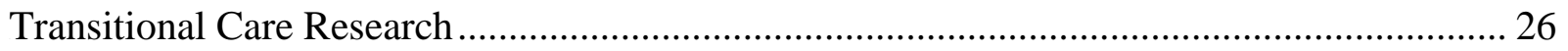

Care Transition Intervention ....................................................................................... 28

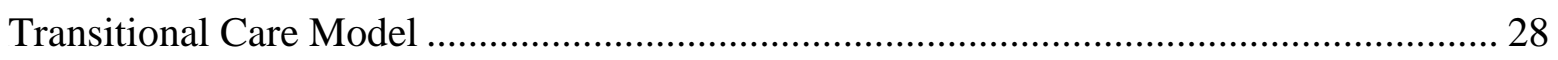

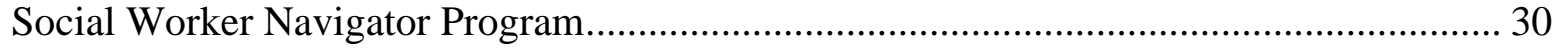

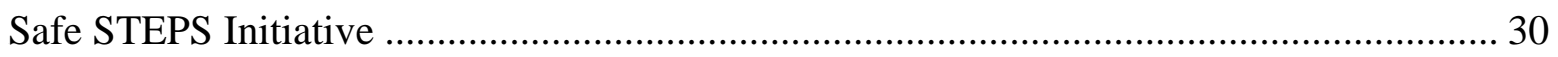

BOOSTing Care Transitions........................................................................................ 31

Hospitalization of Elders with Diabetes ............................................................................... 32

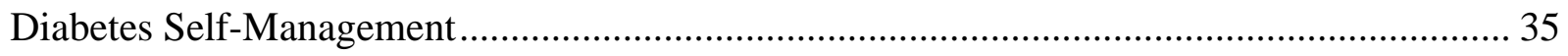

Health Policy Implications of Hospital Transitions..................................................................... 37

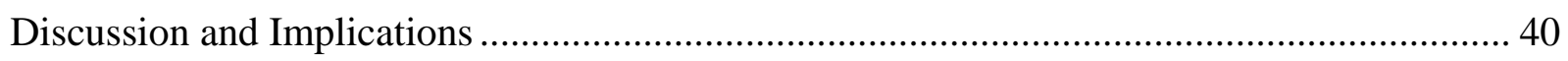

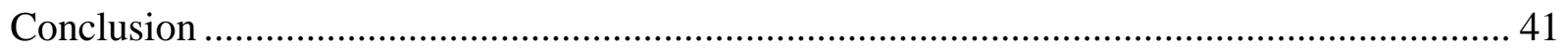

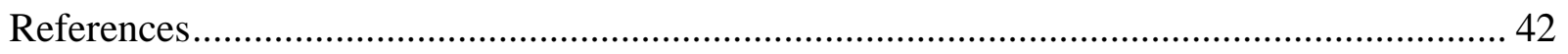

CHAPTER THREE: EARLY AND INTERMEDIATE HOSPITAL-TO-HOME TRANSITION OUTCOMES OF OLDER ADULTS WITH DIABETES — FINDINGS ........................ 55

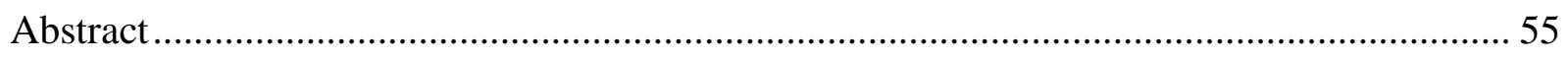

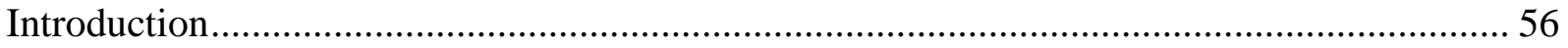

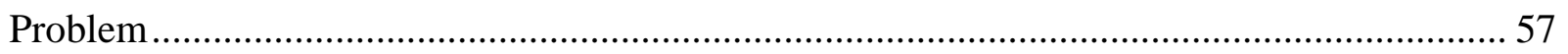

Background and Significance ………………………...................................................... 57

Conceptual Framework …………………………………................................................ 60

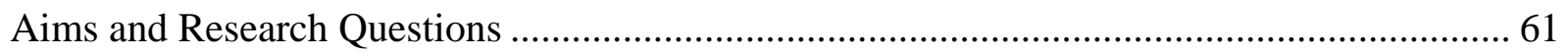

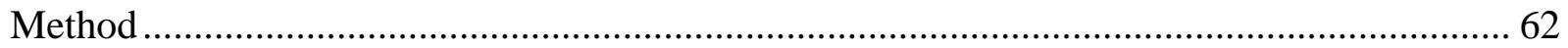

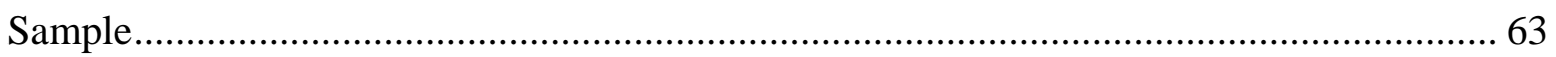

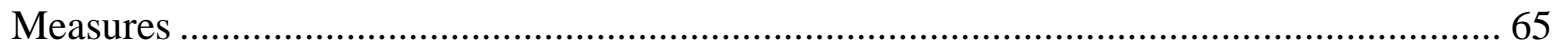




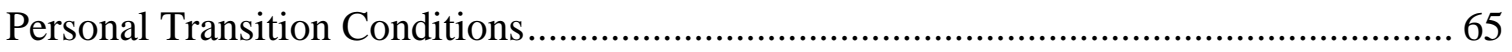

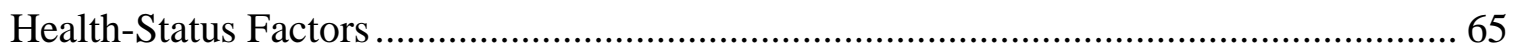

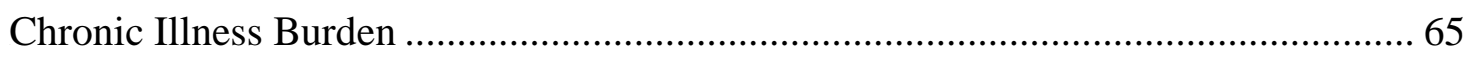

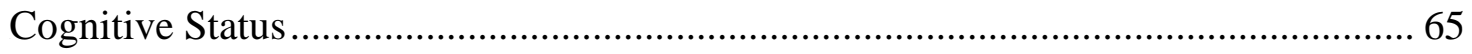

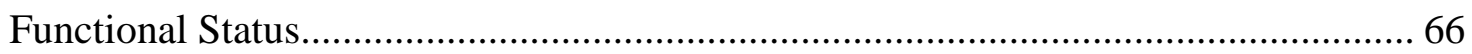

Diabetes-Related Personal Factors ................................................................................ 66

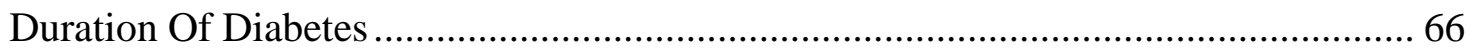

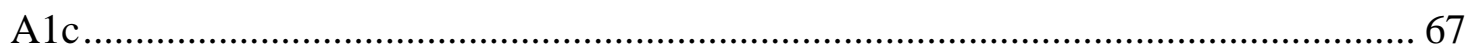

Diabetes-Related Health Complications ........................................................................ 67

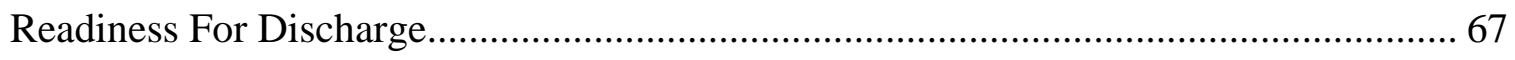

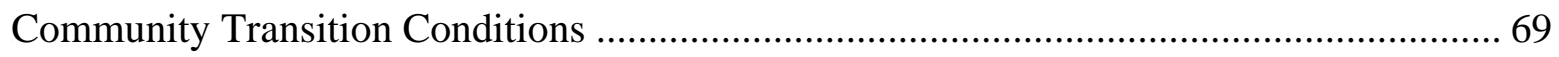

Hospital Discharge Factors ......................................................................................... 69

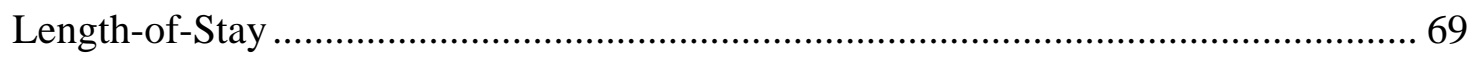

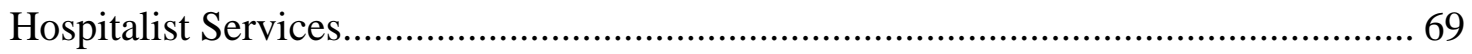

Quality of Discharge Teaching Scale Score …………………….................................. 69

Family Involvement in Post-Discharge Care ...................................................................... 70

Community Service Providers …………………………........................................... 70

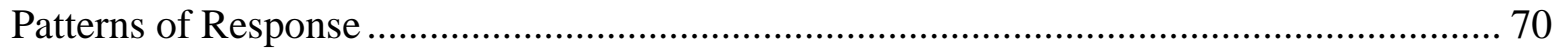

Measures of Recidivism............................................................................................ 71

Care Transition Measure-15 .................................................................................... 71

Post-Discharge Coping Difficulty Scale.......................................................................... 72

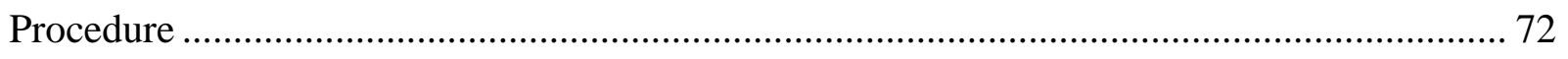

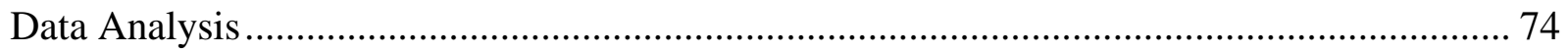




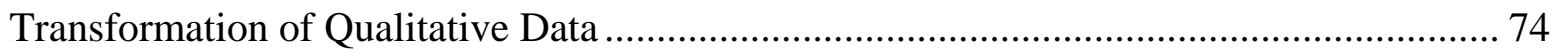

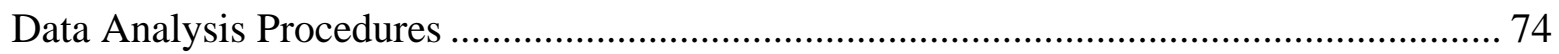

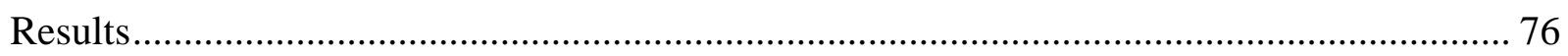

Sample Characteristics ................................................................................................. 76

Personal Transition Conditions.................................................................................... 77

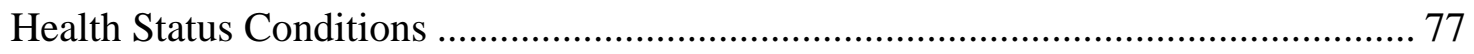

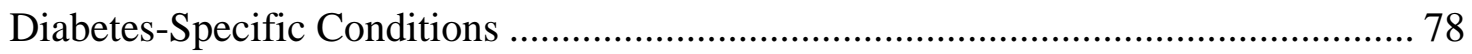

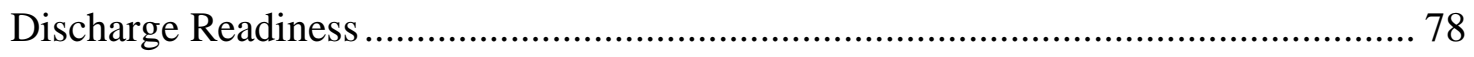

Community Transition Conditions …………………….................................................. 79

Hospitalization-Related Transition Conditions ....................................................... 79

Family and Community Support Resources .............................................................. 80

Prediction of Post-Discharge Difficulties ....................................................................... 81

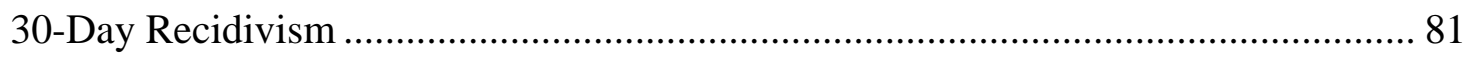

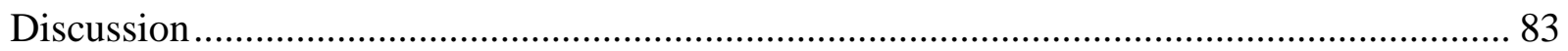

Demographic and Health Status Transition Conditions......................................................... 83

Diabetes-Specific Personal Transition Conditions ............................................................. 84

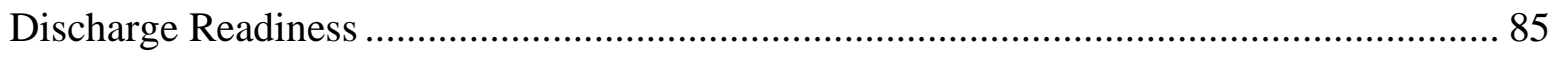

Discharge Preparation and Education .................................................................................. 85

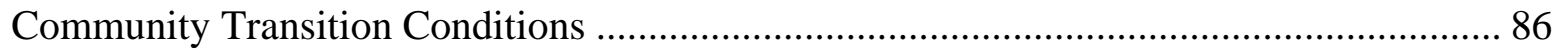

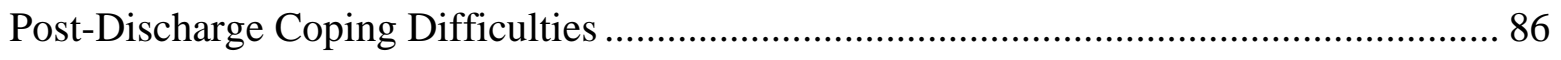

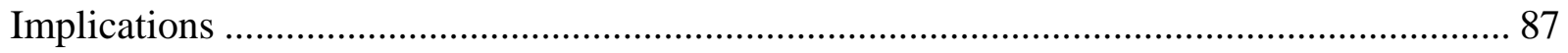

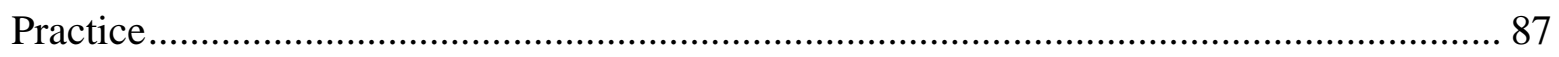

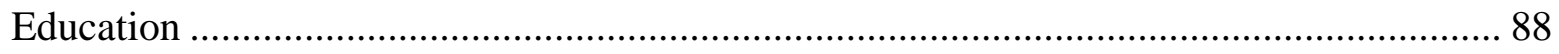




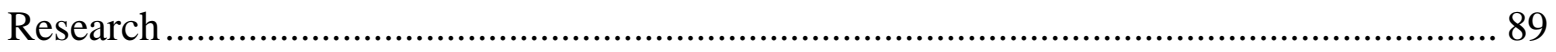

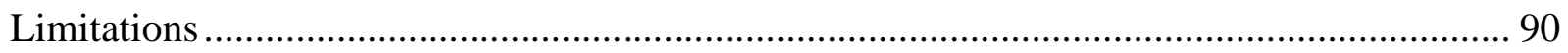

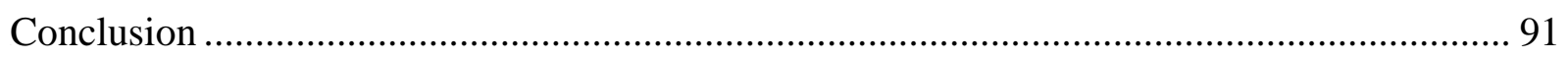

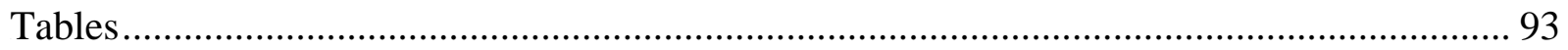

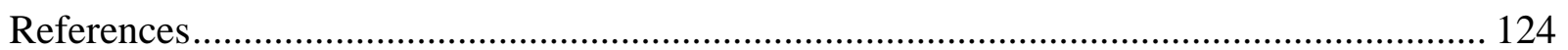

CHAPTER FOUR: HOSPITAL-TO-HOME TRANSITION EXPERIENCES OF OLDER ADULTS DIAGNOSED WITH DIABETES — ANALYSIS OF QUALITATIVE DATA

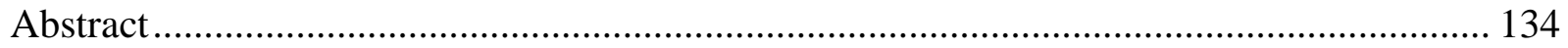

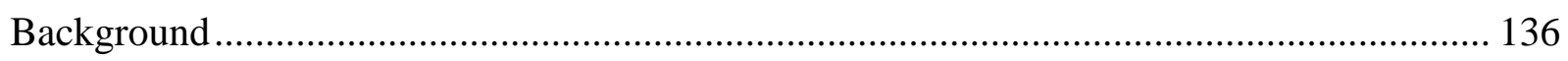

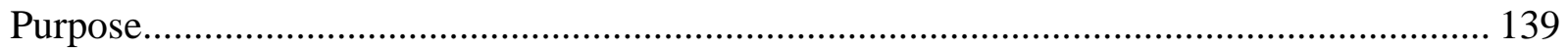

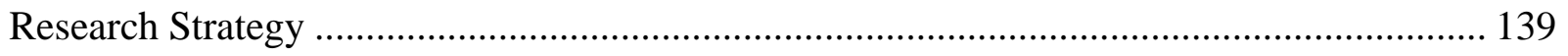

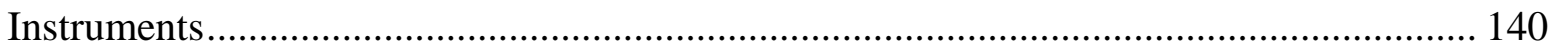

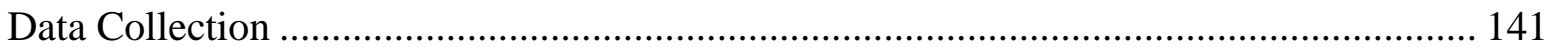

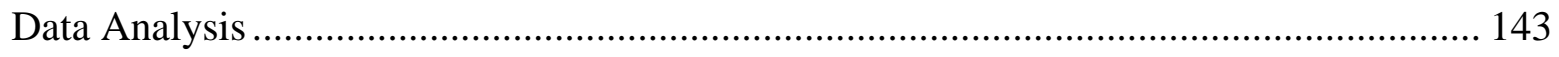

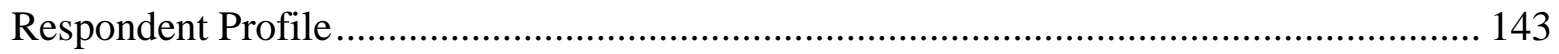

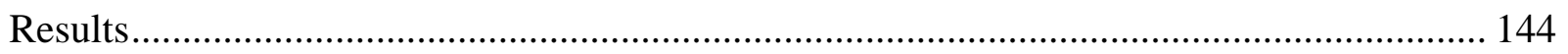

The Daily Stuff is Difficult ............................................................................................. 145

Engineering Care at Home is Difficult ............................................................................ 146

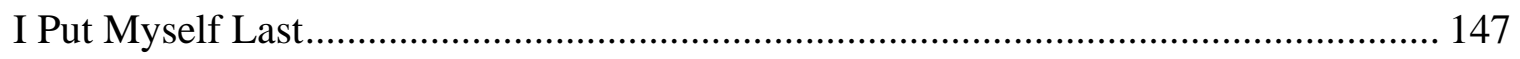

Doing It Alone Is Difficult......................................................................................... 149

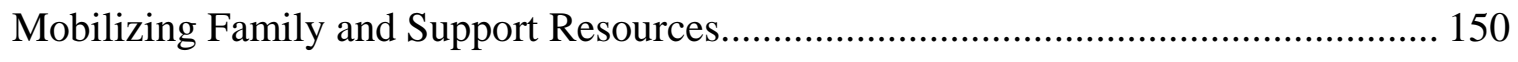

This Is Rough on My Family …………………………....................................... 150 


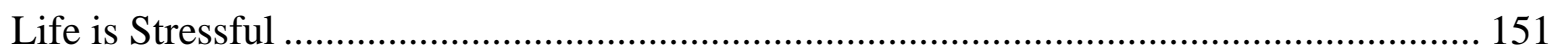

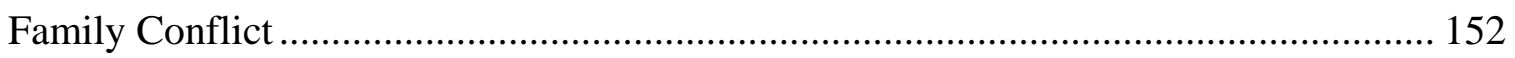

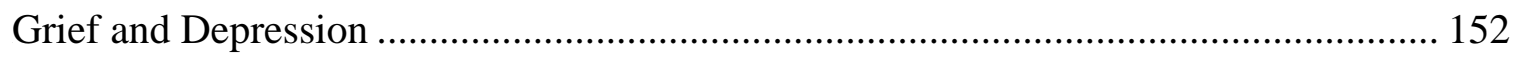

Anxiety and Frustration ........................................................................................... 153

Difficulties Managing Complex Health Problems.............................................................. 154

Difficulty Controlling or Managing Diabetes............................................................... 155

Difficulty Managing Other Chronic Health Problems..................................................... 156

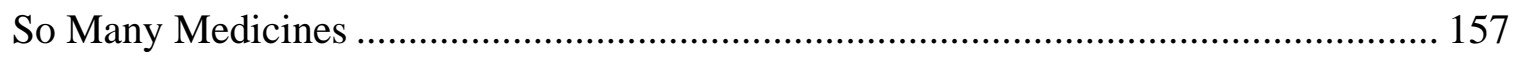

I Needed More Information ....................................................................................... 158

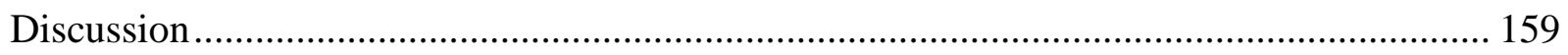

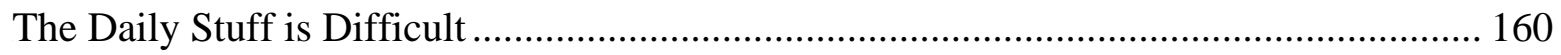

Engineering Care at Home Is Complex ............................................................................. 160

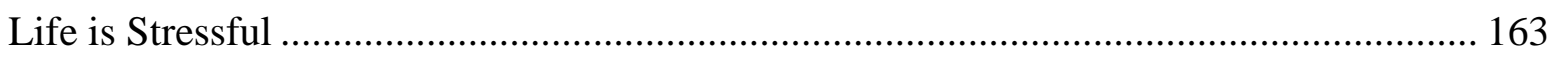

Managing Multiple Complex Health Problems is Difficult............................................... 164

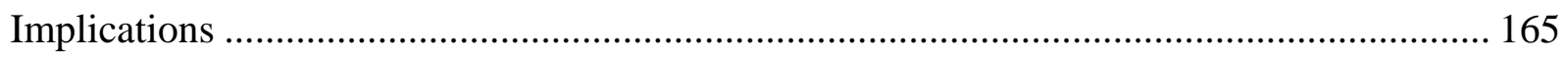

Clinical Practice ................................................................................................................. 165

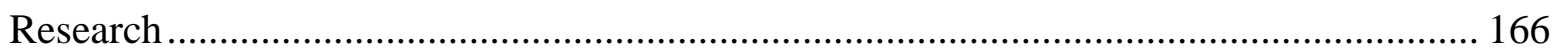

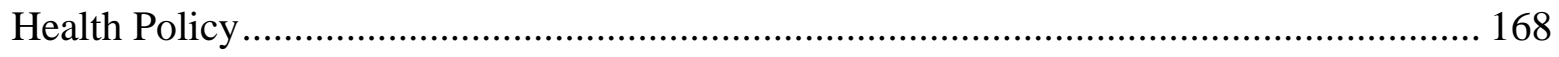

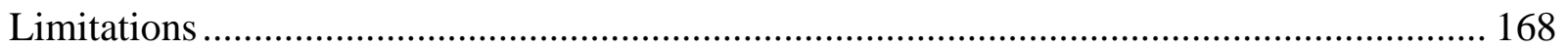

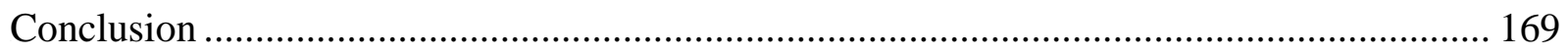

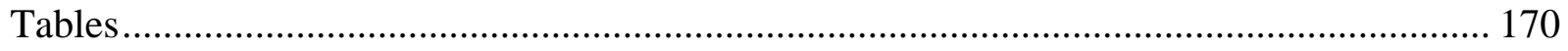

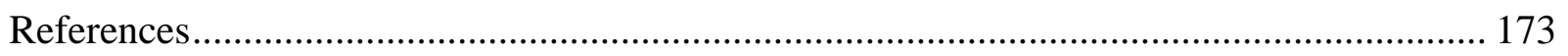

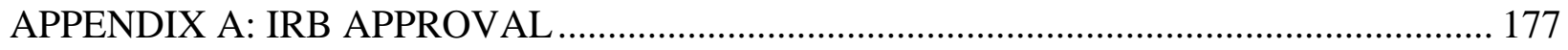




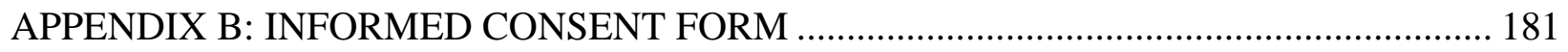

APPENDIX C: HUMAN SUBJECTS PROTECTION TRAINING ………………................. 189

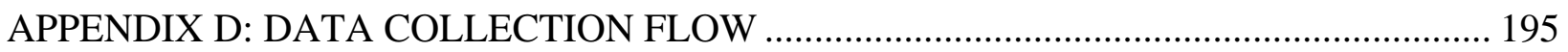

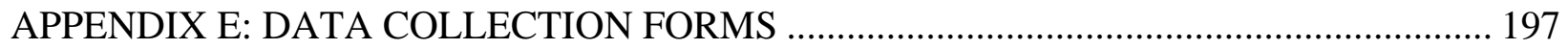

APPENDIX F: DIABETES COMPLICATION INDEX AND PERMISSION TO USE ........... 203

APPENDIX G: PERMISSION TO USE INSTRUMENTS ....................................................... 207

APPENDIX H: READINESS FOR HOSPITAL DISCHARGE SURVEY AND SCORING

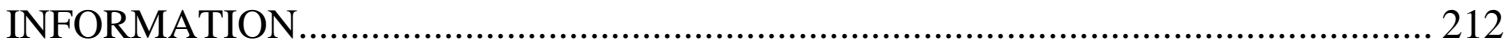

APPENDIX I: QUALITY OF DISCHARGE TEACHING SCALE AND SCORING

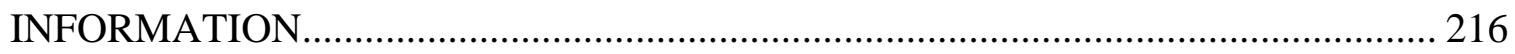

APPENDIX J: POST-DISCHARGE COPING DIFFICULTY SCALE AND SCORING

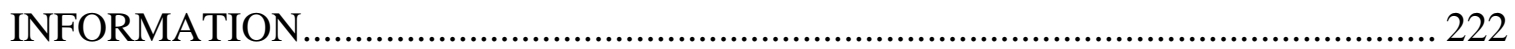

APPENDIX K: CARE TRANSITION MEASURE AND SCORING INFORMATION........... 226

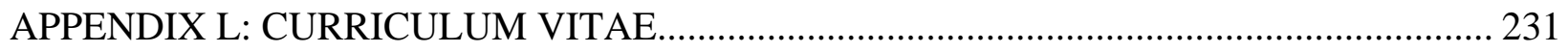




\section{LIST OF FIGURES}

Figure 1. Adapted Model of Transition (Meleis et al., 2000) p. 17.......................................... 5 


\section{LIST OF TABLES}

Table 1. Home Recovery Transition Variables Defined...................................................... 93

Table 2. General Demographic and Health-Illness Characteristics ....................................... 96

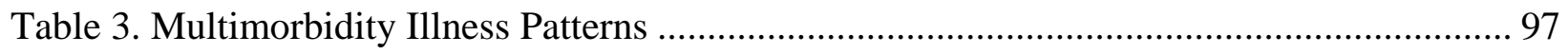

Table 4. Diabetes-specific Health Illness Characteristics ................................................... 98

Table 5. Hospitalization-related Transition Conditions........................................................ 99

Table 6. Post-Discharge Support-related Transition Conditions ............................................ 99

Table 7. Hospital-to-Home Transition Outcomes .............................................................. 100

Table 8. Chi $\left(X^{2}\right)$ Analysis of Dichotomous Variables with Recidivism within 7 Days of Hospital

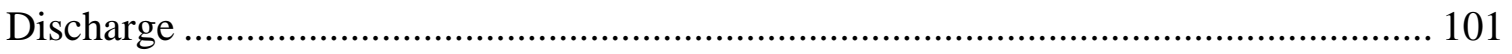

Table 9. Chi $\left(X^{2}\right)$ Analysis of Dichotomous Variables with Recidivism within 8 to 30 Days of

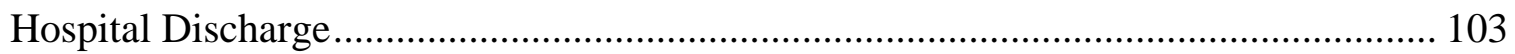

Table 10. Chi $\left(X^{2}\right)$ Analysis of Dichotomous Variables with Recidivism within 30 Days of

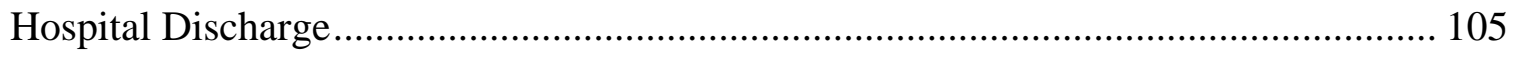

Table 11. Chi $\left(X^{2}\right)$ Analysis of Dichotomous Variables Associated with Participant-reported

Difficulty with Glucose Control or Diabetes Management after Discharge................... 107

Table 12. Chi $\left(X^{2}\right)$ Analysis of Dichotomous Variables Associated with Participant-reported

Difficulty with Management of a Non-diabetes Chronic Illness after Discharge .......... 109

Table 13. Chi $\left(X^{2}\right)$ Analysis of Dichotomous Variables Associated with Participant-reported

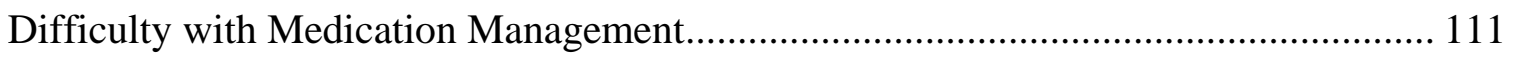

Table 14. $t$ tests of Continuous Variables Associated with Recidivism in First 30 Days Following

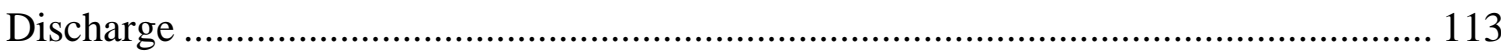

Table 15. $t$ tests of Continuous Variables Associated with Difficulties Managing Medications 115 
Table 16. $t$ tests of Continuous Variables Associated with Difficulties Controlling or Managing Diabetes 117

Table 17. $t$ tests of Continuous Variables Associated with Difficulties Managing Other Chronic

Illness 119

Table 18. Bivariate Correlations of Continuous Transition-Related Variables.... 121

Table 19. Logistic Regression and Odds Ratios for Individual Chronic Condition Variables Total 30-Day Post-Discharge Recidivism 123

Table 20. Final Logistic Regression Model with Significant Predictors for Event of Recidivism within 30 Days of Discharge. 123

Table 21. Classification Table for Logistic Regression Predicting Event of Recidivism 123

Table 22. Summary of Themes and Subthemes by Frequency and Response Period 170

Table 23. General Demographic and Health-Illness Characteristics of 7-day and 30-day Respondents 172 


\section{CHAPTER ONE: INTRODUCTION}

\section{Background and Significance}

Older adults experience the highest rates of acute care hospitalization (Hall, DeFrances, Williams, Golosinskiy, \& Swartzman, 2010). Individuals over the age of 65 comprise $13 \%$ of the United States population, but generate over one-third of in-patient hospital stays (Levit, Wier, Stranges, Ryan, \& Elixhauser, 2009). While utilization of in-patient services for most age groups has declined over the past 30 years, rates of hospitalization for older adults have not decreased (Hall et al., 2010).

Multimorbidity, the occurrence of three or more chronic illnesses in one individual, affects over 50\% of older adults (American Geriatrics Society [AGS], 2012). Chronic health conditions such as heart failure, hypertension, and diabetes are factors in $74 \%$ of hospitalizations. Exacerbations of chronic illnesses are the primary cause of over one-third of hospital admissions and potentially complicate another 35\% of in-patient stays (Levit et al., 2009). A patient’s chronic disease self-management abilities largely determine whether a chronic illness is a primary cause or a contributing factor to a hospitalization.

Diabetes mellitus is a chronic health condition that has a profound impact on the health and well-being of millions of older Americans (Centers for Disease Control and Prevention [CDC], 2011). Over one-fourth of people over the age of 65 are affected by diabetes, and diabetes prevalence in the aged is expected to increase significantly over the next several decades (Narayan, Boyle, Geiss, Saaddine, \& Thompson, 2006). Due to the coexistence of age-associated chronic conditions and disease-related complications, hospitalization rates of elders with diabetes exceed those of the general population (Bethel, Sloan, Belsky, \& Feinglos, 2007). 
The home recovery transitions of older adults with diabetes are intricate and involve the interaction between physiological, psychosocial, and environmental factors. Elders become particularly susceptible to poor outcomes when transitioning from the acute care setting because they are often discharged with ongoing care needs that exceed those that preceded the hospitalization (Miller, Piacentine, \& Weiss, 2008; Mistiaen, Francke, \& Poot, 2007; Murtaugh \& Litke, 2002). Older adults with diabetes experience higher rates of post-discharge recidivism in the forms of readmission, emergency room utilization, and unplanned provider visits (Jiang, Stryker, Friedman, \& Andrews, 2003).

Although elders with diabetes are frequent consumers of acute-care services, there is little known about the post-discharge transition needs of this high-risk patient population (American Diabetes Association [ADA], 2013). Enhanced understanding of the experiences and difficulties encountered by older adults with complex, pre-existing health conditions such as diabetes may assist in identifying patients at risk-for poor home recovery transitions and in developing preemptive interventions to support elders and family caregivers as they enter this vulnerable phase of care.

\section{Study Aims and Research Questions}

The specific aims of this study were to:

1. Determine what factors are associated with the development of home recovery transition difficulties in a sample of older adults with a pre-existing diagnosis of diabetes.

2. Describe common transition difficulties encountered by older adults with diabetes and their family caregivers during the early (7-day) and intermediate (30-day) post-discharge transition periods. 
3. Determine if post-discharge difficulties encountered by older adults and family caregivers differ in the early (7-day) and intermediate (30-day) transitional periods following an acute hospitalization.

4. Determine if any of these factors are predictive of development of poor transition outcomes during the home recovery transition.

The research questions regarding older adults with pre-existing diabetes who were newlydischarged to home from an in-patient setting were:

1. What personal transition conditions (health-illness factors, diabetes-related factors, and perceived discharge readiness) impact early and intermediate transition outcomes?

2. What hospital-related community transition conditions (length-of-stay, discharge teaching quality, perceived discharge quality) impact early and intermediate transition outcomes?

3. Does the availability of post-discharge community support resources (family and home health care) impact early and intermediate transition outcomes of older adults with diabetes?

4. Are any of the identified personal, hospital-based, or community support transition conditions predictive of risk for 30-day recidivism?

\section{Theoretical Framework}

Transition is defined as "a passage from one state, place, stage, or subject to another; a change” (Transition, 2013). Transitions occur during periods of instability and may be precipitated by significant developmental, situational, and/or health and illness events (Schumacher, Jones, \& Meleis, 1999; Schumacher \& Meleis, 1994). Individuals in the process of 
transition experience a heightened state of vulnerability (Meleis, Sawyer, Im, Messias, \& Schumacher, 2000). Hospitalization has been described as a series of three overlapping transition processes in which an individual attempts to return to a state of normalcy (Miller et al., 2008). During the discharge and home recovery transition periods, in particular, patients and family caregivers often struggle to redefine their self-concepts, resume prior roles, and employ the new knowledge and skills required to manage condition-associated changes in health and wellness (Miller et al., 2008). Nurses are often primary providers of interventions that support patients and families during these vulnerable periods.

The middle range theory of transitions provided the guiding framework for this study. The theory conceptualizes transition as both a process and an outcome and provides a theoretical construct for the development of nursing therapeutics that meet the individual needs of patients and families during the throes of transition (Meleis et al., 2000). Aging is characterized by a series of gains and losses that may prompt interrelated changes in the health, function, and roles of elders and individuals within their social networks. Transition theory is particularly applicable in the care of aging families because age-related transitions that may result in hospitalization of an older adult often precipitate the need for nursing care for the elder and associated family members (Schumacher et al., 1999). An adapted model of transitions used in this study is depicted in Figure 1. 


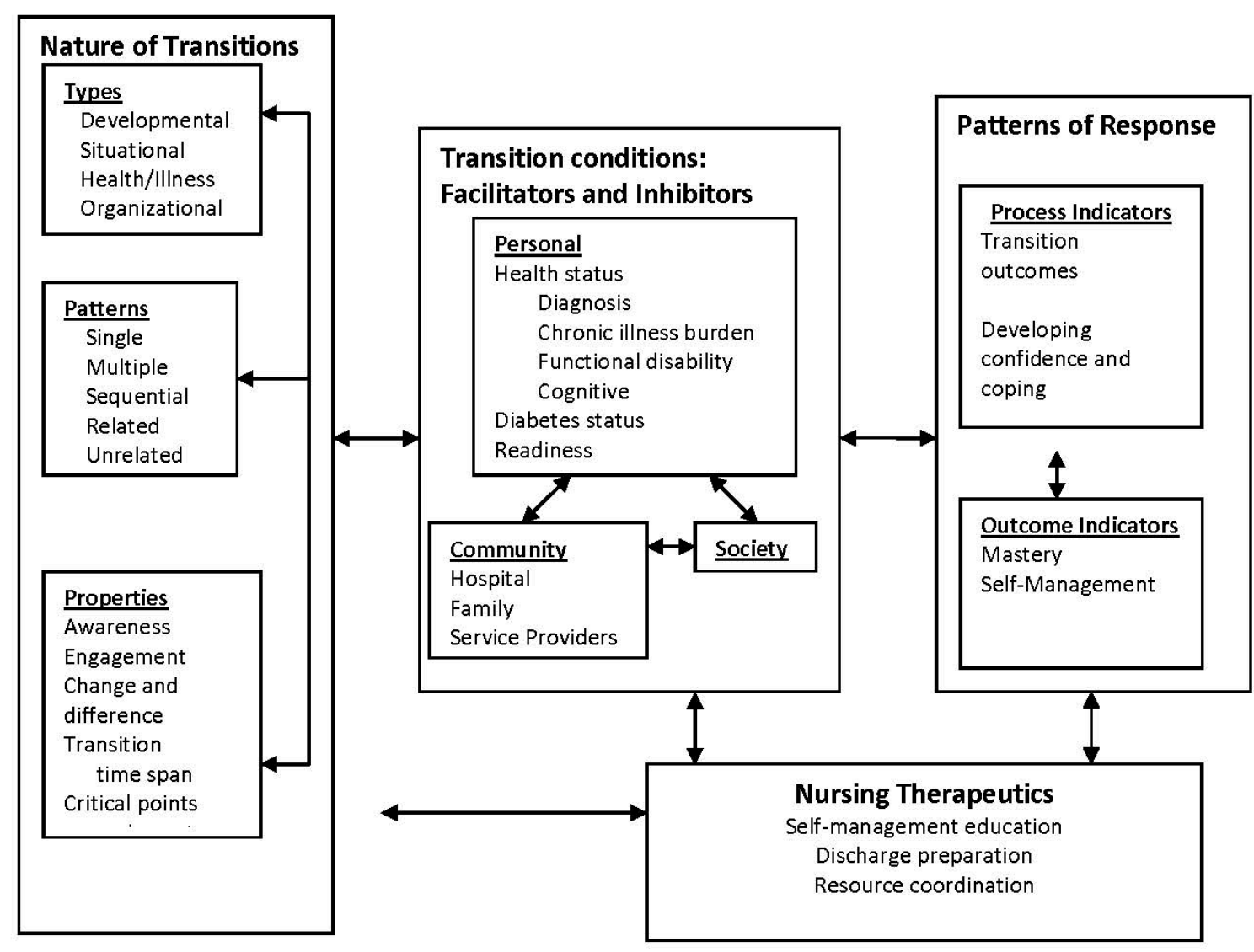

Figure 1. Adapted Model of Transition (Meleis et al., 2000) p. 17

Meleis et al. (2000) assert that transition is a complex phenomenon and that the nature of a transition is a product of various types, patterns and properties of change that may or may not be related. A transition may affect multiple individuals and must be understood from the point of view of each person impacted by the situation. Hospitalization of an older adult potentially creates a multidimensional transition experience for the elder and all affected family members (Meleis et al., 2000; Schumacher et al., 1999). Because transitions such as home recovery may occur over a period of time, the health of a transition may require reassessment during several critical points in the process. 
Transition conditions are created by the continuous interaction of personal, community, and societal level factors that facilitate or inhibit the health of the transition (Meleis et al., 2000). The depiction of transition conditions as an interacting triangle in the center of the model illustrates the potential for these factors to significantly influence the nature of a transition as well as transition outcomes (Meleis et al., 2000).

Personal transition conditions in a hospitalized, chronically-ill older adult are jointly created by age-related health changes and disease-specific concerns (Meleis et al., 2000; Schumacher \& Meleis, 1994). Health instability, functional disabilities, cognitive deficits, and chronic illness burdens contribute to the personal conditions that may significantly impact the well-being and subsequent transition outcomes of hospitalized older adults. The degree of glycemic control, the presence of diabetes-related macrovascular and microvascular complications, and the complexity of the self-management regimen are disease-specific personal conditions that also may particularly affect home recovery transition experiences in older adults with diabetes (Munshi et al., 2006; Suhl \& Bonsignore, 2006). Because the burden for most postdischarge care rests with elders and their family caregivers, the perceived readiness to assume these responsibilities at the time of discharge creates another personal transition condition (Weiss \& Piacentine, 2006; Weiss et al., 2007).

Older adults often rely upon formal and informal support from family, social networks, and community resources when navigating the home recovery transition (Schumacher et al., 1999). Changes in physical and functional status that may follow an acute hospitalization of an elder often necessitate the inclusion of family and community supports after discharge. The placement of these community-level transition conditions at the base of the model's triangle depicts the need for stability in these resources in order to attain and maintain a healthy, safe 
environment for home recovery (Schumacher et al., 1999). Changes in a critical support resource such as illness or relocation of a family caregiver may require reallocation of care resources or supplemental referrals. Hospital discharge planning services, family caregivers, and home care utilization comprise the frequently-used community-level transition conditions that facilitate the post-discharge phase of care. Elders who lack access to a family caregiver are more likely to require at least temporary relocation to a skilled nursing facility (SNF) after discharge and are at higher risk for a poor transition outcome (Mahoney, Eisner, Havighurst, Gray, \& Palta, 2000). Societal transition conditions such as cultural background and governmental factors may facilitate or inhibit a transition (Meleis et al., 2000). Although societal conditions were not examined in the current study, it should be noted that that they may have significant influence on the older adult's transition experience. Cultural and other family factors may drive a family's decision to support an elder in home care efforts (Quadagno, 2008). Additionally, most thirdparty payers including Medicare do not reimburse for discharge planning interventions, transitional care services, or unskilled personal care making the availability of many of these supports limitedly available to many elders (Coleman, 2008; Parrish, O'Malley, Adams, Adams, \& Coleman, 2009). Recent changes in hospital reimbursement structures have tied payment to readmission for high-risk diagnoses and patient satisfaction. These policies are driving changes in hospital transition practices (Goldfield et al., 2008; Medicare Payment Advisory Committee, 2007).

Patterns of response depicted in the model of transitions include those process and outcome indicators that are suggestive of an individual's movement toward restored health and away from vulnerability (Schumacher et al., 1999). Outcomes that reflect achievement of a successful home recovery transition include confidence in self-care and restoration of physical, 
social, and environmental stability. Recidivism, medical errors, difficulties coping, and troubles managing existing or newly-emerging health problems are markers of poor hospital-to-home transition outcomes.

Nursing therapeutics traverse the duration of a transition and have the ability to impact or be impacted by the other components of the model (Meleis et al., 2000). Assessment of readiness, role supplementation in the form of discharge preparation including self-management education, and mobilization of community resources are common nursing therapeutics that are provided in the course of preparing an elder and family for the home recovery phase of care.

\section{Home Recovery Transition Experiences}

Post-hospitalization transitions of older adults with chronic illnesses are complex processes that place millions of elders and their family caregivers at risk for poor outcomes each year. The dynamic nature of post-discharge transitions suggests that experiences and needs of older adults and individuals within their support system may change as the transition progresses. Current system-level metrics of transition quality center around 30-day readmission rates for high-risk diagnoses such as heart failure and have given little consideration to the individual physical, social, and environmental factors that may precipitate a poor home recovery transition in a patient affected by multiple chronic illnesses.

This research study used a mixed-methods approach to investigate factors associated with early and intermediate transition outcomes of recently-discharged older adults with diabetes. Following receipt of Institutional Review Board approval, 96 consenting, hospitalized older adults with diabetes participated in face-to-face interviews within several hours of discharge. Participants were contacted by phone 7 and 30 days following discharge and provided 
information on events of recidivism and experiences with post-discharge coping difficulty. Participants were afforded the opportunity to offer free-response comments describing specific difficulties encountered with regard to stress, recovery, self-management, and family concerns. A summary of the qualitative supplementary component of this research project is provided in Chapter Four.

The following three recurring post-discharge coping problems encountered by elders or caregivers during the early and intermediate phases of transition emerged during qualitative data analyses: difficulty managing medications; difficulty controlling blood glucose or managing diabetes; and difficulty managing other chronic health conditions. Nominal level variables were created to represent each of these subthemes. The problem-specific variables were included in analyses that examined statistical relationships of factors associated with the development of post-discharge coping difficulties. Specific descriptions of the core component of this research project and associated findings are provided in Chapter Three.

\section{References}

American Diabetes Association. (2013). Standards of medical care in diabetes - 2013. Diabetes Care, 36(Suppl 1), S12-S66.

American Geriatrics Society. (2012). Guiding principles for the care of older adults with multimorbidity: An approach for clinicians. Journal of the American Geriatrics Society, 60, E1-E-25.

Bethel, M. A., Sloan, F. A., Belsky, D., \& Feinglos, M. N. (2007). Longitudinal incidence and prevalence of adverse outcomes of diabetes mellitus in elderly patients. Archives of Internal Medicine, 167, 921-927. 
Centers for Disease Control and Prevention. (2011). National diabetes fact sheet: National estimates and general information on diabetes and prediabetes, 2011. Atlanta, GA: U. S. Department of Health and Human Services.

Coleman, E. A. (2008, July). Person-centered models for assuring quality and safety during transitions across care settings. Testimony to United States Senate Special Committee on Aging. Washington, DC.

Goldfield, N. I., McCullough, N. C., Hughes, J. S., Tang, A. M., Eastman, B., Rawlins, L. K., et al. (2008). Identifying potentially preventable readmission. Healthcare Financing Review, 30, 75-91.

Hall, M. J., DeFrances, C. J., Williams, S. N., Golosinskiy, A., \& Swartzman, A. (2010). National Hospital Discharge Survey: 2007 summary. National Health Statistics Reports, 29. Hyattsville, MD: National Center for Health Statistics.

Jiang, H. J., Stryker, D., Friedman, B., \& Andrews, R. (2003). Multiple hospitalizations for people with diabetes. Diabetes Care, 26, 1421-1426.

Levit, K., Wier, L., Stranges, E., Ryan, K., \& Elixhauser, A. (2009). HCUP facts and figures: Statistics on hospital-based care in the United States, 2007. Rockville, MD: Agency for Healthcare Research and Quality.

Mahoney, J. E., Eisner, J., Havighurst, T., Gray, S., \& Palta, M. (2000). Problems of older adults living alone after hospitalization. Journal of General Internal Medicine, 15, 611-619.

Medicare Payment Advisory Committee. (2007). Report to Congress: Promoting greater efficiency in Medicare. Washington, DC: MedPac.

Meleis, A. I., Sawyer, L. M., Im, E., Messias, D. K. H., \& Schumacher, K. (2000). Experiencing transitions: An emerging middle-range theory. Advances in Nursing Science, 23, 12-28. 
Miller, J. F., Piacentine, L. B., \& Weiss, M. (2008). Coping difficulties after hospitalization. Clinical Nursing Research, 17, 278-296.

Mistiaen, P., Francke, A. L., \& Poot, E. (2007). Interventions aimed at reducing problems in adult patients discharged from hospital to home: A systematic meta-review. BMC Health Services Research, 7:47.

Munshi, M., Grande, L., Hayes, M., Ayres, D., Suhl, E., Capelson, R., et al. (2006). Cognitive dysfunction is associated with poor diabetes control in older adults. Diabetes Care, 29, 1794-1799.

Murtaugh, C. M., \& Litke, A. (2002). Transitions through post-acute and long-term care settings: Patterns of use and outcomes for a national cohort of elders. Medical Care, 40, 227-236.

Narayan, K. M. V., Boyle, J. P., Geiss, L. S., Saaddine, J. B., \& Thompson, T. J. (2006). Impact of recent increase in incidence on future diabetes burden: United States 2005-2050. Diabetes Care, 29, 2114-2116.

Parrish, M. M., O'Malley, K., Adams, R. I., Adams, S. R., \& Coleman, E. A. (2009). Implementation of the Care Transitions Intervention: Sustainability and lessons learned. Professional Case Management, 14, 282-295.

Quadagno, J. (2008). Aging and the life course: An introduction to social gerontology (4th ed.). New York: McGraw Hill.

Schumacher, K. L., Jones, P. S., \& Meleis, A. I. (1999). Helping elderly persons in transition: A framework for research and practice. In E. A. Swanson \& T. Tripp-Reimer (Eds.), Life transitions in the older adult: Issues for nurses and other health professionals (pp. 1-26). New York: Springer. 
Schumacher, K. L., \& Meleis, A. I. (1994). Transitions: A central concept in nursing. Image: Journal of Nursing Scholarship, 26, 119-127.

Suhl, E., \& Bonsignore, P. (2006). Diabetes self-management education for older adults: General principles and practical application. Diabetes Spectrum, 19, 234-240.

Transition. (2013). The Merriam-Webster Dictionary On-Line: Dictionary and Thesaurus. Retrieved from http://www.merriam-webster.com/dictionary/transition

Weiss, M. E., \& Piacentine, L. B. (2006). Psychometric properties of the Readiness for Hospital Discharge Scale. Journal of Nursing Measurement, 14, (163-180).

Weiss, M. E., Piacentine, L. B., Lokken, L., Ancona, J., Archer, J., Gresser, S., et al. (2007). Perceived readiness for hospital discharge in adult medical-surgical patients. Clinical Nurse Specialist: The Journal for Advanced Nursing Practice, 21, 31-42. 


\title{
CHAPTER TWO: HOSPITAL-TO-HOME TRANSITION OUTCOMES OF OLDER ADULTS WITH DIABETES — STATE OF THE SCIENCE
}

\begin{abstract}
Over five million older adults with a prior history of diabetes are hospitalized each year. Older adults with diabetes are at high-risk for multimorbidity related to chronic health changes secondary to long-standing diabetes and experience a greater prevalence of geriatric syndromes including cognitive dysfunction, functional impairment, incontinence, and pain. These factors contribute to the higher in-patient utilization seen in older adults with diabetes. Individuals with diabetes are at higher risk for poor hospital-to-home transition outcomes. Readmission rates for elders with diabetes may approach 30\%, and adverse drug reactions also occur with greater frequency. Current transition research has focused on identification of predictors for readmission in disease-specific populations such as heart failure. The needs of individuals who live with chronic illnesses that exert heavy self-management burdens such as diabetes are not well-studied.

Hospitalization has been described as a series of three overlapping transitions: the hospitalization; the period surrounding discharge; and the home recovery. During this time, elders and individuals within their family network become particularly vulnerable to poor transition outcomes. Because elders leave the hospital with ongoing care needs, they are often reliant on supplemental help from family and support services during the home recovery transition. Older adults and family caregivers have described unmet needs during the postdischarge transition. Diabetes self-management skills serve as mainstays in optimizing the health of elders with diabetes. Changes in diabetes treatment plan that accompany hospitalization may necessitate new approaches in diabetes management. The unique post-discharge discharge needs of individuals with diabetes have been largely unstudied.
\end{abstract}




\section{Introduction}

Diabetes mellitus has a profound impact on the health and well-being of millions of older Americans (American Diabetes Association [ADA], 2013a). Over one-fourth of people over the age of 65 are affected by diabetes, and diabetes prevalence in the aged is expected to increase significantly over the next several decades (ADA, 2013a; Centers for Disease Control and Prevention [CDC], 2011). Due to the coexistence of age-associated chronic conditions and disease-related complications, hospitalization rates of elders with diabetes exceed those of the general population (Bethel, Sloan, Belsky, \& Feinglos, 2007; DeFrances, Lucas, Bluie, \& Golosinskiy, 2008; Jiang, Stryker, Friedman, \& Andrews, 2003). Older adults with diabetes also experience higher rates of post-discharge recidivism in the forms of readmission, emergency room utilization, and unplanned provider visits (Jencks, Williams, \& Coleman, 2009; Jiang et al., 2003).

Diabetes is a common contributor to the multimorbidity of many older adults (Marengoni, Rizzuto, Wang, Winbland, \& Fratiglioni, 2009; Steinman et al., 2012). Though typically not the index condition that leads to a hospitalization, diabetes may complicate the course of treatment. In-patient diabetes care for patients of all ages frequently focuses on glycemic control during the acute episode of illness (ADA, 2013a). Modifications to diabetes treatment regimens during the course of a hospitalization are common and often result in substantial changes to home diabetes treatment plans (ADA, 2013a). Diabetes self-management skills serve as mainstays in achieving long-term glycemic control and limiting the development of acute and chronic disease-related complications.

Hospitalization has been described as a series of three overlapping transition processes in which one strives to biographically reconstruct a sense of normalcy (Miller, Piacentine, \& Weiss, 
2008). During the hospitalization, discharge, and home recovery transition periods, patients and family caregivers attempt to restructure their self-concepts, resume prior roles, and integrate the knowledge and skills required to manage health and illness and associated changes (Miller et al., 2008). At discharge, day-to-day responsibility for health management including diabetes care is returned back to patients and their family caregivers. Because older adults often leave hospitals with residual health problems and new functional deficits, the ability to independently manage intricate diabetes care skills at time of discharge may be limited, increasing the risk for poor transition outcomes (Suhl \& Bonsignore, 2006).

Individuals experience a heightened state of vulnerability during times of change, including the transition periods that surround a hospitalization. The interaction between personal, community and societal transition conditions may positively or negatively impact transition outcomes (Meleis, Sawyer, Im, Messias, \& Schumacher, 2000; Schumacher \& Meleis, 1994; Schumaker, Jones, \& Meleis, 1999). The intensified care needs of recently-discharged older adults and their family support systems are often unmet by healthcare providers ( Bull, Hansen, \& Gross, 2000; LeClerc, Wells, Craig, \& Wilson, 2002; Mistiaen, Duijunhouwer, Wijkel, de Bont, \& Veeger, 1997) Recidivism, medical errors, and caregiving difficulties are poor transition outcomes that are commonly experienced by older adults (Coleman, 2003; Coleman \& Boult, 2003; Coleman, Mahoney, \& Parry, 2005; Coleman, Parry, Chalmers, Chugh, \& Mahoney, 2007) Extensive research has been conducted on post-discharge experiences of older adults and their caregivers (Bobay, Jerofke, Weiss, \& Yakusheva, 2010; Brooten et al., 2002; Bull et al., 2000; Bull, Hansen, \& Gross, 2000; Bull \& Jervis, 1997; Coleman et al., 2005; Coleman, Min, Chomiak, \& Kramer, 2004; Coleman, Parry, Chalmers, \& Min, 2006; Coleman et al., 2002; Jencks et al., 2009; Miller et al., 2008; Naylor et al., 2004; Parry, Coleman, Smith, Frank, \& 
Kramer, 2003; Parry, Mahoney, Chalmers, \& Coleman, 2008; Saleh, Freire, Morris-Dickinson, \& Shannon, ; Shyu, 2000; Watkins, Hall, \& Kring, 2012). There is, however, a paucity of literature that specifically addresses the impact of pre-existing chronic illnesses on transition outcomes in combination with resumption of disease-specific self-management behaviors. Diabetes serves as a prototype of a chronic condition that carries significant lifelong personal self-management burdens that may be significantly impacted following a hospitalization.

\section{Diabetes in Older Adulthood}

Diabetes affects 10.9 million or $26.9 \%$ of Americans over the age of 65 (CDC, 2011). By the year 2050, the prevalence rate of diabetes is expected to increase by $220 \%$ for individuals age 65 to 74 and by $449 \%$ for those age 75 or greater (Narayan, Boyle, Geiss, Saaddine, \& Thompson, 2006). Older adults with diabetes present clinically and functionally as a heterogeneous population that exists on a continuum from physically robust to medically frail (ADA, 2013b; California Healthcare Foundation \& American Geriatrics Society on Improving Care for Elders with Diabetes, 2003; Durso, 2006; Norris \& Olson, 2004; Olson \& Norris, 2004; Selvin, Coresh, \& Brancati, 2006). Elders with diabetes carry an increased risk for premature death, functional disability, and development of co-morbid health conditions, particularly cardiovascular disease (ADA, 2013a; California Healthcare Foundation \& American Geriatrics Society on Improving Care for Elders with Diabetes, 2003). Elders with diabetes also are at greater risk for the development of geriatric syndromes in the form of cognitive impairment, depression, urinary incontinence, falls, and pain (California Healthcare Foundation \& American Geriatrics Society on Improving Care for Elders with Diabetes, 2003; Hewer, Mussell, Rist, Kulzer, \& Bergis, 2003; Munshi et al., 2006; Travis, Buchanan, Wang, \& Kim, 2004). Acute and 
chronic changes in health and declines in cognitive and functional status that often accompany the aging process additionally have the potential to impair an elder's ability to independently self-manage diabetes care. Dependence on family and other support resources, therefore, may be increased in the period following a health-illness transition that resulted in hospitalization (Mistiaen et al., 1997; Schumaker et al., 1999).

\section{Chronic Illness and Hospitalization in Older Adulthood}

Older adults experience the highest rates of acute care hospitalization (DeFrances et al., 2008; Levit, Wier, Stranges, Ryan, \& Elixhauser, 2009). Individuals over the age of 65 comprise 13\% of the United States population but generate 33\% of acute-care hospital visits (Levit et al., 2009). Elders over the age of 75 utilize approximately $25 \%$ of all hospital encounters (Hall, DeFrances, Williams, Golosinskiy, \& Swartzman, 2010). Rates of hospitalization for adults over the age of 65 have shown an upward trend over the past 30 years, while rates of all other age groups have significantly declined (Hall et al., 2010).

Over $40 \%$ of non-institutionalized people, most of whom are middle or older-aged, are affected by at least one chronic health problem (Paez, Zhao, \& Whang, 2009). Multimorbidity, the presence of two acute or chronic medical conditions in the same individual, may affect more than 50\% of older adults (Marengoni et al., 2011; Steinman et al., 2012). Multimorbidity is a major contributor to national health care expenditures. In a study of over 2 million elderly veterans, a mean of 5.5 chronic conditions per veteran was reported (Steinman et al., 2012). Over three-fourths of Medicare spending is generated by the $50 \%$ of Medicare beneficiaries who are affected by five or more chronic conditions (Medicare Payment Advisory Committee, 2007). 
Multimorbidity typically presents in patterns. Hypertension, hyperlipidemia, and coronary heart disease occurred in combination in $37.4 \%$ of elderly male veterans (Steinman et al., 2012). Diabetes was a contributing factor in several chronic condition triplets that primarily included hypertension, hyperlipidemia and coronary heart disease. Individuals affected by multimorbidity are more likely to be affected by functional impairments, disability, and poor quality of life (Marengoni et al., 2011). Twenty-five percent of elders with one or more chronic health conditions additionally experience at least one geriatric syndrome (Lee, Cigolle, \& Blaum, 2009). The presence of multimorbidity increases the complexity of an elder's treatment plan and heightens the risk for drug-disease and drug-drug interactions (Steinman et al., 2012). Diabetes is a complicating factor in many hospital admissions of older adults but is rarely the index condition that precipitates admission. Clinical practice guidelines typically have not given consideration to the impact of multimorbidity on chronic disease management practices (Marengoni et al., 2011; Marengoni et al., 2009; Steinman et al., 2012).

Chronic health conditions such as heart failure (HF), hypertension, and diabetes are factors in 74\% of hospitalizations (Levit et al., 2009). Exacerbations of chronic illnesses are the primary cause of $37 \%$ of hospitalizations and potentially complicate another $35 \%$ of admissions (Levit et al., 2009). A patient’s chronic disease self-management abilities largely determine whether the health condition is a primary cause or a contributing factor to a hospitalization (Levit et al., 2009). Functional deficits associated with aging, such as degenerative joint disease, also drive the high in-patient utilization rates in the older adult population (DeFrances et al., 2008; Hall et al., 2010; Levit et al., 2009).

Hospital readmission has been identified as an indicator of poor care quality. Over 17\% of Medicare beneficiaries who are discharged from acute care facilities are readmitted within 30 
days (Hall et al., 2010; Medicare Payment Advisory Committee [Med-Pac], 2007). The risk for poor hospital-to-home transition outcomes has been associated with the following factors: advanced age, multimorbidity, polypharmacy, impaired cognition, depression, functional disabilities, prior hospital admission, extended length-of-stay, and inadequate social support (Preyde \& Brassard, 2011). Readmission rates for patients who have chronic kidney disease, a common sequela of diabetes, are almost twice those of the general Medicare population (MedPac, 2007). Med-Pac estimates that approximately $84 \%$ of 7 -day readmissions and $76 \%$ of 30 day readmissions may be preventable (Med-Pac, 2007).

\section{Hospital-to-Home Transition Experiences of Older Adults}

Older adults and family care providers frequently report unmet transitional care needs as they leave the hospital (Brazil, Roberts, Hode, \& VanderBent, 2000; Bull \& Jervis, 1997; Clark, Steinberg, \& Bischoff, 1997; Coleman, 2003; Coleman et al., 2007; Congdon, 1994; LeClerc et al., 2002; Naylor \& Keating, 2008; Naylor, 2002; Tsilimingras \& Bates, 2008). Most elders are discharged to the home environment following a hospitalization, the majority of them without home care supervision (Levit et al., 2009). Current hospital-based discharge planning processes typically address the immediate relocation needs of the patient within the confines of an individual admission (Holland \& Harris, 2007). These services often occur in isolation and are often ineffective because elder health-illness transitions are complex, have profound effects on elders and families, and extend well beyond the walls of institutions (Bull \& Jervis, 1997;

Kripalani, Jackson, Schnipper, \& Coleman, 2007; LeClerc et al., 2002).

Older adults become particularly susceptible to poor outcomes when transitioning from the acute care setting because they are often discharged with ongoing care demands that exceed 
those that preceded the hospitalization (Levine et al., 2006; Miller et al., 2008; Mistiaen, Francke, \& Poot, 2007; Murtaugh \& Litke, 2002). The health-illness, role, and relocation transitions that follow hospitalizations of older adults, particularly those with chronic conditions such as diabetes, are intricate and involve the interaction between physiological, psychosocial, and environmental factors. Difficulties arise because many of these discharges are poorly planned, are coordinated by clinicians without ongoing relationships with patients or families, lack effective communication between members of the healthcare team, fail to consider all ongoing medical and social needs, and occur abruptly with limited preparation time for the patient and family care providers (Coleman \& Berenson, 2004; Greenwald, Denham, \& Jack, 2007; Preyde \& Brassard, 2011). Discharge planning processes often inadequately address psychosocial factors that may impede or support function and post-discharge adjustment (Preyde \& Brassard, 2011). Many hospitalized patients are discharged with ongoing care needs at an intermediate stage of recovery (Weiss \& Piacentine, 2006). The complexity of many diabetes self-management plans increases the risk that these elders will experience poor transitions as they move from the hospital to the home environments.

Mortality, readmission, emergency room utilization, unplanned provider visits, medical errors, living situation instability, and coping difficulties are potential consequences of poorly executed transitions (Coleman, 2003; Greenwald et al., 2007; Preyde \& Brassard, 2011). Common post-discharge difficulties encountered by older patients in the home setting include: increased dependence on others to meet personal and self-care needs; greater reliance on others to perform household tasks; difficulty with reading medication labels and basic medication management; lack of information on appropriate support services and how to engage them; unmet informational needs; poor understanding of symptom control; social instability; and 
coping issues including fatigue, anxiety, and depression (Preyde \& Brassard, 2011; Mistiaen et al., 2007).

Weekend discharges, which are typically characterized by limited service availability, are more apt to result in poor discharge outcomes (Cumbler, Carter, \& Kutner, 2008). Additionally, timely acquisition of discharge medications is a problem faced by many older adults and may contribute to compromise of the elder's health status on the first days following discharge (Cumbler et al., 2008). Elders with diabetes may be more vulnerable to poor outcomes from these discharge scenarios because they are often released from the hospital with new prescriptions for self-management supplies such a blood glucose testing equipment and injectable medications such as insulin. Elders may be unable to fully operationalize a diabetes treatment plan if they lack necessary supplies or self-management skill competence.

Failures of community and family support systems contribute to readmission. Many family caregivers experience unrealistic expectations of the post-discharge experience and may experience difficulty in caregiving as well as emotional burdens in the form of stress and depression (Preyde \& Brassard, 2011). Elders who live alone are at particular risk for poor discharge outcomes (Lysack, Neufeld, MacNeil, \& Lichtenberg, 2001; Preyde \& Brassard, 2011).

\section{Hospital Discharge as a Transition}

The middle range theory of transitions provides a framework for understanding the complexity of the post-hospital transition experience on elders, families, and their support systems. The theory conceptualizes transition as both a process and an outcome and provides a theoretical construct for the development of nursing therapeutics that meet the individual needs 
of patients and families (Meleis et al., 2000). Because aging is characterized by a series of gains and losses that may prompt multiple changes in the health, function, and roles of elders and individuals within their social networks, transition theory is particularly applicable in the care of aging families (Schumacher et al., 1999). Age-related transitions that result in hospitalization often precipitate the need for nursing care for both elders and their families (Schumacher et al., 1999).

Meleis et al. assert that transition is a complex phenomenon with a final desired outcome of mastery of the new situation (Meleis et al., 2000). The nature of a transition is a product of various types, patterns and properties of change that may or may not be related (Schumacher \& Meleis, 1994). A transition may impact multiple individuals and must be understood from the point of view of each person affected by the transition (Schumacher \& Meleis, 1994). Hospitalization of an older adult potentially creates a multidimensional transition experience for the elder, involved family members, and social supports (Schumacher \& Meleis, 1994; Schumaker et al., 1999).

Process indicators provide a means by which the quality of a transition or attainment of new physical, psychosocial, self-care, and environmental states can be assessed over time (Meleis et al., 2000). Development of confidence as one progresses through a transition reflects a movement toward adaptation to a new situation. Hospitalization frequently results in changes of established disease-specific self-care routines and may require an elder to gain confidence with new or changing self-management skills upon return to the home environment. Comprehension of the disease process, treatment, and recovery, appropriate resource utilization, and the acquisition of effective coping skills are indicators of attainment of confidence and reflect a healthy transition outcome (Meleis et al., 2000). 
Mastery occurs later in the transition process and is indicative of the healthy completion of a transition. Attainment of mastery suggests that an individual has achieved competency with new self-management skills and coping behaviors that facilitate a healthy transition experience (Meleis et al., 2000). Mastery reflects attainment of confidence and a return to stability. Traditional measures of hospital-to-home transition quality have not focused on attainment of mastery. Instead indicators that reflect movement away from health and toward heightened vulnerability such as recidivism, unplanned use of healthcare resources, and medical errors rates have been used in evaluation of transitional care interventions and are currently being used as indicators of quality care by payers such Medicare.

\section{Medical Error Risk and Hospital Discharge}

Each care transition places the patient at risk for medical errors, duplication of services, and poorly-relayed plans of care (Clark et al., 1997; Greenwald et al., 2007). Adverse event rates following discharge are estimated to be five to six times higher than those reported in hospitalized patients (Tsilimingras \& Bates, 2008). In a study of 328 Canadian adults, the incidence, severity, preventability and ameliorability of adverse events were examined (Forster et al., 2004). Twenty-three study participants experienced at least one post-discharge medical error, most of which were adverse drug events (ADE's) (Forster et al., 2004). A history of type 2 diabetes, a diagnosis of pneumonia and female gender were associated with higher prevalence of adverse events (Forster et al., 2004). In a similar study conducted in the United States, one in nine patients experienced an ADE following discharge (Forster, Murff, Peterson, Gandhi, \& Bates, 2005). One-third of patients who reported receipt of incomplete medication information at 
discharge suffered an ADE (Forster et al., 2005). Additionally, the risk for an ADE increased as the number of medications prescribed at discharge rose (Forster et al., 2005).

Medication regimen continuity and adherence during the period immediately following a hospitalization were studied in a sample of 198 Israeli elders with a mean age of 80.7 years (Mansur, Weiss, Hoffman, Gruenewald, \& Beloosesky, 2008). Non-adherence with medication regimens was observed in 30\% of elders, typically secondary to under-adherence with one medication. Under-adherence was noted with elders prescribed a variety of medications including antihyperglycemic agents. Non-adherence was most common in patients who had medication regimen changes following discharge, those prescribed seven or more medications, and those who failed to follow-up with a physician in the first month after discharge (Mansur et al., 2008).

\section{Provider Issues and Hospital Discharge}

The acute care delivery model has recently evolved to include the role of the hospitalist, a physician who manages the care of a patient during the hospital phase of an illness. While the emergence of the hospitalist role has resulted in physician specialists with expertise in acute care patient management, it has also created a new element of transition because care must be transferred back to the primary care provider at discharge (Greenwald et al., 2007; Kripalani et al., 2007). The addition of a provider who has no prior knowledge of a patient increases the risk for delays and error in information exchange (Greenwald et al., 2007; Kripalani et al., 2007). Poor transition outcomes commonly result from discontinuity of care between hospitalists and follow-up care providers, modification of medication regimens with poor medication reconciliation practices, changes in self-management plans that may require additional care 
resources, and the complexity of discharge instructions (Greenwald et al., 2007; Kripalani et al., 2007).

\section{Perceived Discharge Readiness and Coping Difficulties After Discharge}

Transition theory and research in the area of transitional care emphasize the import of preparation, knowledge acquisition, and communication as facilitators of healthy or wellexecuted transitions (Coleman, 2003; Coleman \& Berenson, 2004; Coleman \& Fox, 2004; Coleman et al., 2005; Coleman et al., 2002; Naylor, 2002, 2006; Parry et al., 2003; Parry et al., 2008; Weiss \& Piacentine, 2006) Readiness is potentially a reflection of preparedness and knowledge attainment and thus functions as a facilitator of healthy discharge.

Elders and caregivers commonly describe disparities between perceived discharge readiness prior to leaving the hospital and lived transition experiences (Brazil et al., 2000; Bull \& Jervis, 1997; Clark et al., 1997; Congdon, 1994; LeClerc et al., 2002; Reilly et al., 1996; Shyu, 2000; Weiss, Yakusheva, \& Bobay, 2010). Significant discrepancies between nurses’ perceptions of discharge knowledge of medications and actual patient understanding have been reported (Reilly et al., 1996). In a study of 97 patient/nurse dyads, 95\% of nurses assumed that discharged patients understood their medication teaching while only $57 \%$ of patients confirmed understanding of medication side effects (Reilly et al., 1996). In an additional study of 162 medical surgical patients, a low correlation between nurse and patient assessment of discharge readiness was reported (Weiss et al., 2010). Nurses’ assessments of discharge readiness, however, were most closely correlated with post-discharge utilization of healthcare resources.

Problems with pain management, complication recognition, mobility, and fatigue were frequently reported coping difficulties in a qualitative study of transition experiences of 113 
hospitalized medical-surgical patients (Miller et al., 2008). The desire to return to normalcy and a dependency on family members were added concerns of study participants. Respondents desired supplemental information on the recovery process, diagnosis, and treatment plan (Miller et al., 2008). A lack of clarity on diabetes management was also specifically reported as a postdischarge care difficulty in the study.

\section{Transitional Care Research}

Because elders experience heightened vulnerability as they move between care environments, transitional care is emerging as a priority in geriatric research (Coleman \& Boult, 2003). The American Geriatrics Society (AGS) defines transitional care as "a set of actions designed to ensure the coordination and continuity of health care as patients transfer between different locations or different levels of care within the same location” (Coleman \& Boult, 2003, p. 556).

Transitional care research has identified five factors that are integral to effective posthospitalization transitions. These include: (1) accurate provider communication; (2) preparation of the patient and caregiver for the next level of care; (3) reconciliation of the pre and post transition medication regimens; (4) patient and caregiver involvement in decision making; and (5) education on signs and symptoms of significant clinical changes (Coleman et al., 2004; Coleman et al., 2007). The need to reengineer discharge planning processes to better delineate roles and responsibilities of each care team member, to initiate discharge education early and continue it throughout the course of the hospitalization, and to adapt patient education interventions to match a patient's health literacy level and primary language has been reported in the literature (Coleman \& Fox, 2004). 
A 2007 meta-review of 15 meta-analyses concluded that comprehensive programs that combine effective discharge planning with post-discharge support are most effective in improving transition outcomes. The review provided little evidence to support the benefits of individual discharge support interventions on patient discharge status, post-discharge functioning, cost, or utilization (Mistiaen et al., 2007). A 2010 Cochrane review of 21 hospitalto-home discharge planning studies arrived at similar conclusions (Shepperd et al., 2010). In both reviews, traditional system-level evaluations such length-of-stay, emergency department utilization, and readmission were used to gauge the effectiveness of discharge planning interventions. None of the studies evaluated self-management or post-hospital coping outcomes of patients with pre-existing chronic health conditions (Shepperd et al., 2010). In general, there is an absence of transition literature that specifically addresses the needs or experiences of individuals with diabetes (ADA, 2013b).

More recently, several studies have suggested that the inclusion of a nurse or social worker in the post-discharge phase of care may improve discharge outcomes when metrics are broadened to include geriatric-specific or psychosocial metrics. Model programs have been implemented to address the transitional care needs of older adults. The Community Based-Care Transition Program (CCTP) has been included as a provision of the Affordable Care Act and will provide funding to evaluate the effectiveness of various care transition initiatives (Centers for Medicare and Medicaid, 2012). The program is an element of the Partnership for Patients initiative which seeks to reduce hospital readmission by 20\% by 2013 (Centers for Medicare and Medicaid, 2012). 


\section{Care Transition Intervention}

The Care Transitions Intervention (CTI) is a four-week program that pairs a medically complex adult with a “transitions coach”, often an advanced practice nurse (APN) (Care Transitions Program, 2007; Coleman et al., 2006; Coleman et al., 2004; Parrish, O'Malley, Adams, Adams, \& Coleman, 2009; Parry et al., 2003). Pre-discharge identification of elders atrisk for poor transition outcomes is combined with home and telephonic follow-up support of elders’ self-management efforts in this delivery model. "Pillar interventions” included in this intervention are medication self-management teaching, a dynamic patient-centered record, timely post-discharge provider follow-up, and education on warning signs of condition deterioration (Care Transitions Program [CTI], 2007). Diabetes has been identified as a chronic health condition that may trigger referral for CTI services (Coleman et al., 2006). The CTI has been adopted by over 600 health care organizations in 39 states (Coleman, 2012). CTI participants have experienced lower rates of readmission 30 days, 90 days, and six months after discharge (CTI, 2007; Coleman et al., 2006). Sustainability of the CTI in a resource-limited health care system has been identified as a constraint in maintaining the program (Parrish et al., 2009). CTI interventions have been incorporated into the care transition test programs funded under the CCTP.

\section{Transitional Care Model}

The University of Pennsylvania has twenty years of experience with a transitional care model that is delivered by APN’s (Brooten et al., 2002; Naylor \& Keating, 2008; Naylor, 2000, 2002; Naylor, Bowles, \& Brooten, 2000; Naylor et al., 2004; Transitional Care Model [TCM], 2009). The Transitional Care Model (TCM) or Naylor model is targeted at high-risk, cognitively 
intact elders who are returning home following a hospitalization, many with cardiovascular diagnoses such as HF. APN's, known as Transitional Care Nurses (TCNs), coordinate transition preparation during the course of the hospitalization and follow the elder after discharge by means of home visits, telephonic case management, and participation in post-discharge medical appointments (Naylor, 2002; Naylor et al., 2004; TCM, 2009).

The TCM program supports the patient and family for a period of one to three months following discharge. Key elements of the program include: in-patient and home-based patient and family education with a focus on understanding discharge instructions; facilitation of patient self-management skills with an emphasis on early recognition of changes in health status and prevention of decline; medication reconciliation and management; and development of a longterm transition planned based upon patient/family goals (TCM, 2009). The TCN serves as the patient's care coordinator during and immediately following an acute hospitalization. The TCN initiates interaction with the patient during the hospitalization and works with the patient and family to establish an evidence-based plan of care. The TCN subsequently visits the patient in the home environment and maintains phone contact for the duration of the intervention. The TCN serves as a liaison between the patient, family caregiver, community providers, and professionals.

Reported outcomes of the TCM include reduced rehospitalization, decreased health care costs, and improved patient satisfaction (Naylor \& Keating, 2008; Naylor et al., 2004). The developers contend that refinement of the current model is required to include an expanded focus that addresses the needs of family caregivers during transition periods (Naylor \& Keating, 2008). Relationships with third party payers have been established, and the program is typically offered as a covered health benefit (TCM, 2009). 


\section{Social Worker Navigator Program}

In an interventional transition study of 298 high-risk elders, the inclusion of a social worker “navigator” resulted in improvements in discharge outcomes (Watkins et al., 2012). “Navigator” interventions included identification of at-risk elders; coordination of post-discharge services; a home visit within 72 hours of discharge; and telephone follow-up. To be eligible for the program a patient was required to be age 65 years or older, reside in the geographic catchment area of the hospital, and meet at least two high-risk criteria (Watkins et al., 2012). The navigator had the ability to refer the patient to supplemental community health services including housekeeping, transportation, prescription pick-up, and grocery shopping.

Program participants experienced fewer post-discharge emergency room visits and a readmission rate $61 \%$ lower than the local norm (Watkins et al., 2012). They additionally demonstrated post-intervention improvements in the vitality, social functioning, emotional, and mental health subscales of the SF-36 and high patient satisfaction scores (Watkins et al., 2012). Cost-savings of over $\$ 600,000$ to the healthcare network were realized, much less than the program cost. Patients in this program were followed for a period of 30 days to 4 months.

\section{Safe STEPS Initiative}

The Safe and Successful Transition of Elderly Patients Study (Safe STEPS) utilized a multidisciplinary, geriatric-specific, pre-discharge intervention program to improve discharge outcomes of high-risk elders (Dedhia et al., 2009). Program interventions were initiated when the elder was admitted to the in-patient care unit. The first element of the program included hospitalist training on geriatric care principles and introduction of a "geriatricized" (Dedhia et al., 2009) history and physical form into routine care. The revised intake assessment addressed 
fall risk, sleep habits, ADL performance, cognition, functional abilities, caregiver considerations, home medication administration practices, and advanced directive requests (Dedhia et al., 2009). Early admission notification of the patient's primary care provider was accomplished by case managers, and daily interdisciplinary rounds addressing patient-specific needs were instituted. Collaboration between the pharmacist and hospitalist on medication management began upon admission. A coordinated pre-discharge meeting that included the case manager, hospitalist and patient and development of a discharge contract between all parties occurred during the course of each admission. Additionally, written discharge instructions were revised to include easy-tounderstand lay language and large font. The intervention did not include any formal postdischarge follow-up interventions. Statistically significant improvements in 7-day and 30-day emergency department utilization, hospital readmission rates, discharge quality measures, and patient-perceived health status were reported following implementation of the program (Dedhia et al., 2009).

\section{BOOSTing Care Transitions}

The Better Outcomes for Older Adults through Safe Transitions (BOOSTing) Care Transitions program was developed by the Society of Hospital Medicine to provide resources to support improvement in hospital-based discharge planning processes (Society of Hospital Medicine [SHM], 2008). The program provides tools that assist providers in improving discharge risk assessment and stratification, implementing teach-back methods of patient education, a patient-focused transition record, risk-specific interventions and discharge/patient education tools.

Risk assessment is based upon identification of the “8P's," which include: 
- Problem medicines such as warfarin, aspirin and insulin

- Psychological problems, particularly depression

- Principal diagnoses placing the patient at risk for readmission including cancer, stroke, diabetes, COPD, and heart failure

- Polypharmacy

- Poor health literacy

- Patient support (lack of)

- Prior hospitalizations in the six months preceding the index admission

- Palliative care [SHM, 2008)

Evidence-based risk-specific interventions are then linked with each positive risk factor. Followup telephone contact within 72 hours of discharge is recommended for patients prescribed highrisk medications or 5 or more regular medications and those with histories of readmission, poor health literacy and poor post-discharge support (SHM, 2008). Specific outcomes of the initiative were not reported, but the Society recommends that participating organizations monitor lengthof-stay, readmission rates, patient satisfactions scores, and discharge summary completion rates (SHM, 2008).

\section{Hospitalization of Elders with Diabetes}

Over five-million individuals with diabetes, the majority of whom are age $\geq 75$, are discharged from acute care hospitals annually (CDC, 2011). Approximately 43\% of hospital and 52\% of nursing home admissions are initiated by patients with diabetes (Russell et al., 2005). Hospitalizations of elders with diabetes most commonly are precipitated by diagnoses other than diabetes, particularly cardiovascular disorders such as ischemic heart disease and HF (ADA, 
2013a; Hall et al., 2010; Russell et al., 2005;). Elders with diabetes typically experience longer lengths-of-stay and significantly higher hospital costs than other patient groups (ADA, 2013a; CDC 2011; Moghissi et al., 2009). Recidivism is common in older adults with diabetes. In a study of hospitalized individuals with diabetes, over $30 \%$ of older adults returned to the inpatient setting after discharge (Jiang et al., 2003). Rehospitalization rates were highest amongst Hispanic and non-Hispanic black elders (Jiang et al., 2003).

Recent trials examining outcomes of intensive glycemic control in hospitalized patients have produced conflicting findings (Kavanagh \& McCowen, 2010). Ideal glucose targets for hospitalized patients are a subject of debate in the diabetes community (ADA, 2013b; Kavanagh \& McCowen, 2010; NICE-SUGAR Study Investigators, 2009). Despite this, glucose control during an acute episode of illness remains an in-patient care priority, particularly in critically ill patients (ADA, 2013b). Although age-specific glucose targets for hospitalized elders with diabetes have not been identified, standardized hospital protocols are commonly used in the care of older adults.

AGS guidelines for improving care of elders with diabetes suggest that long-term glycemic targets in older adults must be individualized due to the heterogeneity of the aged diabetes population (ADA, 2013b; California Healthcare Foundation \& American Geriatrics Society on Improving Care for Elders with Diabetes, 2003). Guidelines recommend that older adults with longer life expectancies, functional independence, and intact cognition receive diabetes care consistent with established general diabetes treatment guidelines (ADA, 2013b; California Healthcare Foundation \& American Geriatrics Society on Improving Care for Elders with Diabetes, 2003). Conversely, elders with limited life expectancy, diabetes complications such as autonomic neuropathy, or advanced cognitive deficits may be safer with higher glucose 
targets (California Healthcare Foundation \& American Geriatrics Society on Improving Care for Elders with Diabetes, 2003).

Recent clinical investigations such as Action to Control Cardiovascular Risk in Diabetes (ACCORD), Action in Diabetes and Vascular Disease: Preterax and Diamicron Modified Release Controlled Evaluation (ADVANCE), and Veterans Affairs Diabetes Trial (VADT) have examined the outcomes of intensive glycemic control in older populations. The studies each included large samples of elders, many with pre-existing cardiovascular disease. Findings of these studies have been conflicting with several demonstrating increased mortality in intensively controlled, high-risk elders (Action to Control Cardiovascular Risk in Diabetes Study Group, 2008; ADVANCE Collaborative Group, 2008; ADA, 2013b; Duckworth et al., 2009).

Most elders with diabetes will ultimately return to the home environment following a hospitalization (Levit et al., 2009; Russell et al., 2005). Disparities between recommended glucose targets in the hospital and home settings as well as changes in physician providers during the course of a hospitalization raise the risk that diabetes treatment plans will be altered at discharge. Illness-related health status changes may require the recently hospitalized older adult to modify existing home diabetes self-management regimens in order to achieve new glucose targets (Chau \& Edelman, 2001).

There is a lack of evidence-based guidance on how to best promote resumption of a modified chronic disease self-management regimen during the transition from hospital to home (ADA, 2013b). Inadequate knowledge of meal planning skills, lack of knowledge of medications, limited access to disease-related equipment, and lack of coordinated care are barriers faced by community-dwelling elders with diabetes (Nagelkerk, Reick, \& Meengs, 2006). These problems are frequently worsened by a change in care setting (Nagelkerk et al., 2006). 
Frequent capillary blood glucose testing, complex insulin dosing regimens, use of supplemental injectable medications such as exanatide (Byetta ${ }^{\circledR}$ ), and intricate meal plans are additional care demands placed on many elders with diabetes (Chau \& Edelman, 2001). These treatment modalities often increase the risk of hypoglycemia and further heighten discharge safety risk (ADA, 2013b). The AGS has issued a position statement supporting the need to improve the process of transitional care for individuals with complex needs such as diabetes selfmanagement.(Chau \& Edelman, 2001)

\section{Diabetes Self-Management}

The Institute of Medicine (IOM) defines self-management as "the tasks that an individual must undertake to live well with one or more chronic health conditions. These tasks include having the confidence to deal with medical management, role management, and emotional management of their conditions” (Adams, Greinger, \& Corrigan, 2004, p. 57). Patients and family caregivers are recognized as principal managers of chronic conditions such as diabetes (Adams, 2006). Diabetes care, which falls within the "living with illness and disability" domain of the IOM's organizational framework, has been identified as a priority for health care improvement activities (Adams \& Corrigan, 2003).

Diabetes self-management education (DSME), defined as "the ongoing process of facilitating the knowledge, skill, and ability necessary for pre-diabetes and diabetes self-care,” is essential in supporting an elder's mastery of a life that includes diabetes (Haas et al., 2013, p. S101). The American Association of Diabetes Educators (AADE) and AGS have developed guidelines on care of the elders with diabetes (Suhl \& Bonsignore, 2006). The guidelines are largely based on expert consensus secondary to the dearth of DSME research on older adults 
.(Suhl \& Bonsignore, 2006) General tenets outlined in the guidelines include the need to: (1) individualize DSME with consideration to clinical variables, functional variables, and personal preferences; (2) weigh benefits and risks of therapies with attention to quality of life and life expectance; (3) involve multiple disciplines; and (4) involve a care partner as needed (Suhl \& Bonsignore, 2006). Clinical elements addressed in the guidelines include baseline diabetes knowledge, nutritional status, physical activity factors, comorbidities, and polypharmacy (Suhl \& Bonsignore, 2006). Functional considerations to be evaluated in the development of a diabetes self-management plan are cognitive dysfunction, depression, and physical disability. Care partners such as family caregivers and friends are particularly important in optimizing self-care when the elder is unable to do this independently (Suhl \& Bonsignore, 2006).

DSME in the acute care setting is often problematic. The fast-paced hospital environment is generally not conducive to the individualized, time-consuming education required by many elders (Bobay et al., 2010). Acutely ill older adults are often too infirmed and stressed to actively participate in DSME activities while hospitalized (ADA, 2013b). These factors often necessitate the active involvement of lay family caregivers, many of whom have limited knowledge of diabetes and its treatment, in the coordination and delivery of diabetes care after discharge. Self-management education in the hospital environment is primarily directed toward “survival skill” training (ADA, 2013b). Discharge content ideally addresses the following: (1) blood glucose monitoring procedures and use of results; (2) definition, prevention, recognition and treatment of hyperglycemia and hypoglycemia; (3) follow-up care information; (4) information on consistent eating patterns; (5) instruction on medication regimens with content on potential side effects of each agent; (6) sick day management; and (7) proper use and disposal of insulin syringes (ADA, 2013b). In a patient with pre-existing diabetes this content must be 
delivered with attention to modifications in the treatment plan and acquisition of new skills. Much of this teaching is provided by the bedside nurse at as part of the discharge process.

Follow-up with an out-patient DSME program is frequently recommended as a discharge intervention. These referrals, however, are often completed sometime after discharge and do not address immediate transition needs of elders and their caregivers. Although many elders qualify for Medicare intermittent, skilled home health care after discharge, coordination of diabetes care in the period after discharge largely rests with the elder and family care provider, even when supplemental services are in place (Fortinsky, Madigan, Sheehan, Tullai-McGuinness, \& Fenster, 2006). In a study of 922 older adults admitted to home care services in Ohio, patients with a primary home care admitting diagnosis of diabetes were almost three times more likely to experience an unplanned hospitalization than other patients (Fortinsky et al., 2006).

Hospital-to-home transition experiences of elders with pre-existing chronic conditions that impose a significant self-care burden on the individual including diabetes have been limitedly reported in the literature. Current literature has not described how individuals with chronic illnesses such as diabetes integrate new and established self-management behaviors following a hospitalization.

\section{Health Policy Implications of Hospital Transitions}

Poorly executed transitions place significant strain on the United States health care system. Costs associated with readmission are \$15 billion annually (Med-Pac, 2007). In an effort to reduce readmission and incentivize effective transitional care practices, significant changes in Medicare funding structures and pay-for-performance initiatives have been incorporated into the Affordable Care Act. The Hospital Readmission Reduction Program, the National Pilot Program 
on Payment Bundling, and CCTP are being implemented in an effort to improve the quality of post-hospital care transitions (Naylor et al., 2012).

Effective October, 2013, hospitals identified as creating excessive readmission in Medicare beneficiaries will face financial penalties. Readmission for the index conditions of HF, myocardial infarction, and pneumonia will be initially targeted with additional conditions added in 2015 (Centers for Medicare and Medicaid, 2013). There is concern that a concerted focus on programs that target specific disease-states such as HF may not adequately address the transition problems experienced by patients who are unaffected by the targeted condition but who experience significant multimorbidity (Naylor et al., 2012).

Identification of risk factors for potentially preventable readmissions (PPRs) and development of programs to reduce 30-day readmission rates has become a focus of health policy research. An analysis of a large Florida administrative data set that included information on over 5 million hospitalizations and 300,000 PPR's suggested that many readmissions may not be preventable (Goldfield et al., 2008). PPR's were examined by diagnostic-related group classifications for all discharge dispositions as investigators attempted to identify a chain of interrelated diagnoses that precipitated a readmission. PPR's in this analysis were typically a byproduct of instability of the index condition if they occurred in close proximity to the first hospitalization (Goldfield et al., 2008). The interrelationship of two admissions was more difficult to establish later in the post-discharge period. PPR's most commonly were associated with the following diagnoses: HF; chronic obstructive pulmonary disease (COPD); schizophrenia; pneumonia; major depression; and coronary artery disease (CAD).

Local hospitals are introducing the use of bedside assessment tools that identify risk for readmission into nursing workflows. The "LACE" index is one example of a risk assessment 
screen that is being used to identify patients at potential risk for readmission. Analysis of hospitalization data from over 4800 Canadian adults determined that the following four variables were predictive of readmission from the community or mortality within 30 days of discharge: (L) length of stay; (A) acuity; (C) comorbidity as calculated using the Charlson comorbidity index; and (E) events of emergency department utilization within the past six months (van Walraven et al., 2010).

Payment bundling that encompasses the costs associated with an entire episode of care rather than individual provider payments has also been proposed as a pilot program. Under current prospective payment structures, providers are incentivized to control length-of-stay and thus move the patient to the next level of care as quickly as possible (Med-Pac, 2007). Transitional care services are currently not a covered benefit making the cost prohibitive to many organizations. Proposed payment bundles will potentially incorporate the costs incurred in the three days prior to admission through 30 or 90 days post discharge. Thus, the payment bundle would cover the costs of acute care expenditures, physicians’ fees, care management, and postdischarge services such as short-term rehabilitation, telemonitoring, and home care (Naylor et al., 2012). Ideally, providers will effectively collaborate to better coordinate care with community partners and maintain an optimal standard of care across settings. This payment model, if poorly implemented, has the potential to result in withholding of services and a reduction in the availability of long term care providers.

The CTTP promotes the partnership of acute care facilities with transition services provided by Community Based Organizations (CBO’s). The goals of the initiative are to reduce costs, to promote positive post-discharge outcomes, and to improve the care experience for patients and families (Centers for Medicare and Medicaid, 2012). Medicare beneficiaries 
assessed as high-risk based upon health factors including a specified set of diagnosed chronic conditions are eligible for the program. Patients with minimal multimorbidity but high degrees of functional impairment thus may not qualify under current guidelines (Naylor et al., 2012). Performance indicators for CCTP's will include 30, 90 and 180 day readmission rates, mortality rates, acute care observation status utilization, and emergency department utilization (Centers for Medicare and Medicaid, 2012). Currently, 47 organizations have been approved for participation in the CCTP initiative. Three of these organizations are based in Florida.

\section{Discussion and Implications}

Although home recovery transition experiences of older adults have been previously investigated, prior studies have not focused on the impact of a pre-existing chronic health problem such as diabetes on transition outcomes. There is limited literature that explains how recently hospitalized elders with chronic illnesses integrate changing care demands into chronic disease self-management routines following discharge. With the rising prevalence of multimorbidity in the older population, the need to understand the interaction of chronic conditions and their effect on care at home is needed. Additionally, the current focus on 30-day readmission directed at condition-specific risk identification fails to capture the fluid nature of the hospital-to-home transition experience from the perspective of the elder and associated family care providers. In order to develop interventions that promote healthy hospital-to-home transitions, there is a need to investigate if the care needs and problems experienced at different phases of the home recovery transition vary. There is also a need to develop transition risk models that expand the definition of poor transition beyond readmission and incorporate nonmedical predictors of risk. 
Hospital-to home transitions do not occur in a vacuum. The transition model suggests that significant transitions such as hospitalization are multidimensional and impact and are impacted by many factors. There is therefore a need to study the hospital-to-home transition experience from various perspectives and to identify potential hospital-related, caregiver-related, family-driven, and resource-related factors that may promote or inhibit a healthy transition.

\section{Conclusion}

The prevalence of chronic health conditions such as diabetes is escalating as America ages. Many chronic illnesses are characterized by complex treatment regimens that are directed at controlling symptoms, preventing complications, and maintaining quality of life. Affected individuals and family caregivers are the primary daily care managers of chronic illnesses and are often dependent upon health care providers, particularly nurses, to acquire condition-specific knowledge and skills. Chronic illnesses such as diabetes often prolong or complicate diseaserelated and non-disease related hospitalizations. The chronically ill consume significant healthcare resources and may be at higher risk for recidivism and coping difficulties during the home recovery phase of transition.

Transitions such as hospitalization of an older adult ultimately affect people who live within complex family systems. Thus, there is a need to broaden the definition of "successful transition" beyond an event of recidivism that affects an individual to establishment of a healthy, safe post-discharge care environment that reduces the vulnerability of the older adult and family support structures. Because nurses are so integral in planning and delivering care during the hospital-to-home transition period, they are in an excellent position to drive patient-focused research that improves outcomes during home recovery transitions. 


\section{References}

Action to Control Cardiovascular Risk in Diabetes Study Group. (2008). Effects of intensive glucose lowering in type 2 diabetes. New England Journal of Medicine, 358, 2545-2459.

Adams, K., \& Corrigan, J. M. (Eds.). (2003). Priority areas for national action: Transforming health care quality. Washington, DC: National Academies Press.

Adams, K., Greinger, A. C., \& Corrigan, J. M. (Eds.). (2004). Report of a summit. The 1st annual crossing the quality chasm summit: A focus on communities. Washington, DC: National Academies Press.

Adams, K. B. (2006). The transition to caregiving: The experience of family members embarking on the dementia caregiving career. Journal of Gerontological Social Work, 47, 3-29.

ADVANCE Collaborative Group. (2008). Intensive blood glucose control and vascular outcomes in patients with type 2 diabetes New England Journal of Medicine, 358, 2560-2572.

American Diabetes Association. (2013a). Economic costs of diabetes in the U. S. in 2012. Diabetes Care, 36, 1033-1046.

American Diabetes Association. (2013b). Standards of medical care in diabetes - 2013. Diabetes Care, 36(Suppl 1), S12-S66.

Bethel, M. A., Sloan, F. A., Belsky, D., \& Feinglos, M. N. (2007). Longitudinal incidence and prevalence of adverse outcomes of diabetes mellitus in elderly patients. Archives of Internal Medicine, 167, 921-927.

Bobay, K., Jerofke, T. A., Weiss, M. E., \& Yakusheva, O. (2010). Age-related differences in perception of quality of discharge teaching and readiness for hospital discharge. Geriatric Nursing, 31, 178-187. 
Brazil, K., Roberts, J., Hode, M., \& VanderBent, S. D. (2000). Managing the transition from hospital to home for family caregivers of stroke survivors. National Academies of Practice Forum, 2, 259-266.

Brooten, D., Naylor, M. D., York, R., Brown, L. P., Munro, B. H., Hollingsworth, A. O., et al. (2002). Lessons learned from testing the quality cost model of advanced practice nursing (APN) transitional Care. Journal of Nursing Scholarship, 34, 369-375.

Bull, M. J., Hansen, H. E., \& Gross, C. R. (2000). Differences in family caregiver outcomes by their level of involvement in discharge planning. Applied Nursing Research, 13, 76-82.

Bull, M. J., Hansen, H. E., \& Gross, C. R. (2000). Predictors of elder and family caregiver satisfaction with discharge planning. Journal of Cardiovascular Nursing, 14(3), 76-87.

Bull, M. J., \& Jervis, L. L. (1997). Strategies used by chronically ill older women and their caregiving daughters in managing post-hospital care. Journal of Advanced Nursing, 25, 541-547.

California Healthcare Foundation \& American Geriatrics Society on Improving Care for Elders with Diabetes. (2003). Guidelines for improving the care of the older person with diabetes mellitus. Journal of American Geriatrics Society, 51(Suppl), S265-S279.

Care Transitions Program. (2007). The care transitions program: Improving quality and safety during care hand-offs. Retrieved July 15, 2010, from http://www.caretransitions.org/ Centers for Disease Control and Prevention. (2011). National diabetes fact sheet: National estimates and general information on diabetes and prediabetes, 2011. Atlanta: GA: U. S. Department of Health and Human Services. 
Centers for Medicare and Medicaid. (2012). Community-Based Care Transition Fact Sheet.

Retrieved November 22, 2012, from http://innovation.cms.gov/Files/fact-sheet/CCTPFact-Sheet.pdf

Centers for Medicare and Medicaid. (2013). Readmission Reduction Program. Retrieved May 5, 2013, from http://www.cms.gov/Medicare/Medicare-Fee-for-ServicePayment/AcuteInpatientPPS/Readmissions-Reduction-Program.html

Chau, D., \& Edelman, S. V. (2001). Clinical management of diabetes in the elderly. Clinical Diabetes, 19, 172-175.

Clark, M., Steinberg, M., \& Bischoff, N. (1997). Patient readiness for return to home: Discord between expectations and reality. Australian Occupational Therapy Journal, 44, 132141.

Coleman, E. A. (2003). Falling through the cracks: Challenges and opportunities for improving transitional care for persons with continuous complex care needs. Journal of the American Geriatrics Society, 51, 549-555.

Coleman, E. A. (2012). The Care Transition Program. Retrieved November 25, 2012, from http://www.caretransitions.org/

Coleman, E. A., \& Berenson, R. A. (2004). Improving patient care. Lost in transition: Challenges and opportunities for improving the quality of transitional care. Annals of Internal Medicine, 141, 533-536.

Coleman, E. A., \& Boult, C. (2003). Improving the quality of transitional care for persons with complex care needs. Journal of the American Geriatrics Society, 51, 556-557. 
Coleman, E. A., \& Fox, P. D. (2004). One patient, many places: Managing health care transitions, part I: Introduction, accountability, information for patients in transition... three-part series. Annals of Long Term Care, 12, 25-32.

Coleman, E. A., Mahoney, E., \& Parry, C. (2005). Assessing the quality of preparation for posthospital care from the patient's perspective: The care transitions measure. Medical Care, 43, 246-255.

Coleman, E. A., Min, S., Chomiak, A., \& Kramer, A. M. (2004). Post-hospital care transitions: Patterns, complications, and risk identification. Health Services Research, 39, 1449-1465.

Coleman, E. A., Parry, C., Chalmers, S., \& Min, S. (2006). The care transitions intervention: Results of a randomized controlled trial. Archives of Internal Medicine, 166, 1822-1828.

Coleman, E. A., Parry, C., Chalmers, S. A., Chugh, A., \& Mahoney, E. (2007). The central role of performance measurement in improving the quality of transitional care. Home Health Care Services Quarterly, 26(4), 93-104.

Coleman, E. A., Smith, J. D., Frank, J., Eilersten, T. B., Thiare, J. N., \& Kramer, A. M. (2002). Development and testing of a measure designed to assess the quality of care transitions. International Journal of Integrated Care, 2, 1-9.

Coleman, E. A., Smith, J. D., Frank, J. C., Min, S., Parry, C., \& Kramer, A. M. (2004). Preparing patients and caregivers to participate in care delivered across settings: The care transitions intervention. Journal of the American Geriatrics Society, 52, 1817-1825.

Congdon, J. G. (1994). Managing the incongruities: The hospital discharge experience for elderly patients, their families, and nurses. Applied Nursing Research, 7(3), 125-131.

Cumbler, E., Carter, J., \& Kutner, J. (2008). Failure of transition of care: Challenges in the discharge of the vulnerable elderly patient. Journal of Hospital Medicine, 3, 349-352. 
Dedhia, P., Kravet, S., Bulger, J., Hinson, T., Sridharan, A., Kolodner, K., et al. (2009). A quality improvement intervention to facilitate the transition of older adults from hospitals back to their homes. Journal of the American Geriatrics Society, 57, 1540-1546.

DeFrances, C. J., Lucas, C. A., Bluie, V. C., \& Golosinskiy, A. (2008). 2006 National Hospital Discharge Survey. National Health Statistics Reports, 5, 1-20.

Duckworth, W., Abraira, C., Moritz, T., Reda, D., Emanuele, N., Reaven, P. D., et al. (2009). Glucose control and vascular complications in veterans with type 2 diabetes. New England Journal of Medicine, 360, 129-139.

Durso, S. C. (2006). Using clinical guidelines designed for older adults with diabetes mellitus and complex health status. Journal of the American Medical Association, 295, 19351940.

Forster, A. J., Clark, H., D., Menard, A., Dupuis, N., Chernish, R., Chandok, N., et al. (2004). Adverse events among medical patients after discharge from hospital. Canadian Medical Association Journal, 170, 345-349.

Forster, A. J., Murff, H. J., Peterson, J. F., Gandhi, T. K., \& Bates, D. W. (2005). Adverse drug events occurring following hospital discharge. Journal of Internal Medicine, 20, 317-323.

Fortinsky, R. H., Madigan, E. A., Sheehan, T. J., Tullai-McGuinness, S., \& Fenster, J. (2006). Risk factors for hospitalization among Medicare home care patients. Western Journal of Nursing Research, 28, 902-917.

Goldfield, N. I., McCullough, N. C., Hughes, J. S., Tang, A. M., Eastman, B., Rawlins, L. K., et al. (2008). Identifying potentially preventable readmission. Healthcare Financing Review, 30, 75-91. 
Greenwald, J. L., Denham, C. R., \& Jack, B. W. (2007). The hospital discharge: A review of high risk transition with highlights of a reengineered discharge processes. Journal of Patient Safety, 3, 97-106.

Haas, L., Maryniuk, M., Beck, J., Cox, C. E., Duker, P., Edwards, L., Fisher, E. B, et al. (2013). National Standards of Diabetes Self-Management Education and Support. Diabetes Care, 36 (Suppl). 1, S100-108.

Hall, M. J., DeFrances, C. J., Williams, S. N., Golosinskiy, A., \& Swartzman, A. (2010). National Hospital Discharge Survey: 2007 summary. National Health Statistics Reports, 29. Hyattsville, MD: National Center for Health Statistics

Hewer, W., Mussell, M., Rist, F., Kulzer, B., \& Bergis, K. (2003). Short-term effects of improved glycemic control on cognitive function in patients with type 2 diabetes. Gerontology, 49, 86-92.

Holland, D. E., \& Harris, M. R. (2007). Discharge planning, transitional care, coordination of care, and continuity of care: Clarifying concepts and terms from the hospital perspective. Home Health Care Services Quarterly, 26(4), 3-19.

Jencks, S. F., Williams, M. V., \& Coleman, E. A. (2009). Rehospitalizations among patients in the Medicare fee-for-service program. New England Journal of Medicine, 360, 14181428.

Jiang, H. J., Stryker, D., Friedman, B., \& Andrews, R. (2003). Multiple hospitalizations for people with diabetes. Diabetes Care, 26, 1421-1426.

Kavanagh, B. P., \& McCowen, K. (2010). Glycemic control in the ICU. New England Journal of Medicine, 363, 2540-2546. 
Kripalani, S., Jackson, A. T., Schnipper, J. L., \& Coleman, E. A. (2007). Promoting effective transitions of care at hospital discharge: A review of key issues for hospitalists. Journal of Hospital Medicine, 2, 314-323.

LeClerc, C. M., Wells, D. L., Craig, D., \& Wilson, J. L. (2002). Falling short of the mark: Tales of life after hospital discharge. Clinical Nursing Research, 11, 242-266.

Lee, P. G., Cigolle, C., \& Blaum, C. (2009). The co-occurrence of chronic diseases and geriatric syndromes: The health and retirement study. Journal of the American Geriatric Society, 57, 511-516.

Levine, C., Albert, S. M., Hokenstad, A., Halper, D. E., Hart, A. Y., \& Gould, D. A. (2006). "This case is closed": Family caregivers and the termination of home health care services for stroke patients. Milbank Quarterly, 84, 305-331.

Levit, K., Wier, L., Stranges, E., Ryan, K., \& Elixhauser, A. (2009). HCUP facts and figures: Statistics on hospital-based care in the United States, 2007. Rockville, MD: Agency for Healthcare Research and Quality.

Lysack, C. L., Neufeld, S. W., MacNeil, S. E., \& Lichtenberg, P. A. (2001). At risk in old age: Elderly men who live alone. Clinical Gerontologist, 24, 77-91.

Mansur, N., Weiss, A., Hoffman, A., Gruenewald, T., \& Beloosesky, Y. (2008). Continuity and adherence to long-term drug treatment by geriatric patients after hospital discharge: A prospective cohort study. Drugs \& Aging, 25, 861-870.

Marengoni, A., Angleman, S., Melis, R., Manglialasche, F., Karp, A., Garmen, A., et al. (2011). Aging with multimorbidity: A systematic review of the literature. Aging Research Reviews, 10, 430-439. 
Marengoni, A., Rizzuto, D., Wang, H.-X., Winbland, B., \& Fratiglioni, L. (2009). Patterns of chronic multimorbidity in the elderly population. Journal of the American Geriatric Society, $57,225-230$.

Medicare Payment Advisory Committee. (2007). Report to Congress: Promoting greater efficiency in Medicare. Washington, DC: Medicare Payment Advisory Committee.

Meleis, A. I., Sawyer, L. M., Im, E., Messias, D. K. H., \& Schumacher, K. (2000). Experiencing transitions: An emerging middle-range theory. Advances in Nursing Science, 23, 12-28.

Miller, J. F., Piacentine, L. B., \& Weiss, M. (2008). Coping difficulties after hospitalization. Clinical Nursing Research, 17, 278-296.

Mistiaen, P., Duijunhouwer, E., Wijkel, D., de Bont, M., \& Veeger, A. (1997). The problems of elderly people at home one week after discharge from the acute care setting. Journal of Advanced Nursing, 25, 1233-1240.

Mistiaen, P., Francke, A. L., \& Poot, E. (2007). Interventions aimed at reducing problems in adult patients discharged from hospital to home: A systematic meta-review. BMC Health Services Research, 7(47).

Moghissi, E. S., Korytkowski, M. T., DiNardo, M., Einhorn, D., Hellman, R., Hirsch, I. B., et al. (2009). American Association of Clinical Endocrinologists and American Diabetes Association consensus statement on inpatient glycemic control. Diabetes Care, 32, 11191131.

Munshi, M., Grande, L., Hayes, M., Ayres, D., Suhl, E., Capelson, R., et al. (2006). Cognitive dysfunction is associated with poor diabetes control in older adults. Diabetes Care, 29, 1794-1799. 
Murtaugh, C. M., \& Litke, A. (2002). Transitions through post-acute and long-term care settings: Patterns of use and outcomes for a national cohort of elders. Medical Care, 40, 227-236. Nagelkerk, J., Reick, K., \& Meengs, L. (2006). Perceived barriers and effective strategies to diabetes self-management. Journal of Advanced Nursing, 54, 151-158.

Narayan, K. M. V., Boyle, J. P., Geiss, L. S., Saaddine, J. B., \& Thompson, T. J. (2006). Impact of recent increase in incidence on future diabetes burden: United States, 2005-2050. Diabetes Care, 29, 2114-2116.

Naylor, M., \& Keating, S. A. (2008). Transitional care. American Journal of Nursing, 108(9), 58-63.

Naylor, M. D. (2000). A decade of transitional care research with vulnerable elders. Journal of Cardiovascular Nursing, 14(3), 1-14.

Naylor, M. D. (2002). Transitional care of older adults. Annual Review of Nursing Research, 20, $127-147$.

Naylor, M. D. (2006). Transitional care: A critical dimension of the home healthcare quality agenda. Journal for Healthcare Quality: Promoting Excellence in Healthcare, 28(1), 4854.

Naylor, M. D., Bowles, K. H., \& Brooten, D. (2000). Patient problems and advanced practice nurse interventions during transitional care. Public Health Nursing, 17(2), 94-102.

Naylor, M. D., Brooten, D. A., Campbell, R. L., Maislin, G., McCauley, K. M., \& Schwartz, J. S. (2004). Transitional care of older adults hospitalized with heart failure: A randomized, controlled trial. Journal of the American Geriatrics Society, 52, 675-684. 
Naylor, M. D., Kurtzman, E. T., Grabowski, D. C., Harrington, C., McClellan, M., \& Reinhard, S. C. (2012). Unintended consequences of steps to cut readmissions and reform payment may threaten care of vulnerable older adults. Health Affairs, 31, 1623-1632.

NICE-SUGAR Study Investigators. (2009). Intensive verses convention glucose control in critically ill patients. New England Journal of Medicine, 360, 1283-1297.

Norris, S. L., \& Olson, D. E. (2004). Implementing evidence-based diabetes care in geriatric populations. Geriatrics, 59(6), 35-40.

Olson, D. E., \& Norris, S. L. (2004). Diabetes in older adults: Overview of AGS guidelines for the treatment of diabetes mellitus in geriatric populations. Geriatrics, 59(4), 18-25.

Paez, K. A., Zhao, L., \& Whang, W. (2009). Rising out-of-pocket spending for chronic conditions: A ten-year trend. Health Affairs, 28(1), 15-25.

Parrish, M. M., O'Malley, K., Adams, R. I., Adams, S. R., \& Coleman, E. A. (2009). Implementation of the Care Transitions Intervention: Sustainability and lessons learned. Professional Case Management, 14(6), 282-295.

Parry, C., Coleman, E. A., Smith, J. D., Frank, J., \& Kramer, A. M. (2003). The care transitions intervention: A patient-centered approach to ensuring effective transfers between sites of geriatric care. Home Health Care Services Quarterly, 22(3), 1-17.

Parry, C., Mahoney, E., Chalmers, S. A., \& Coleman, E. A. (2008). Assessing the quality of transitional care: Further applications of the care transitions measure. Medical Care, 46, 317-322.

Preyde, M., \& Brassard, K. (2011). Evidence-based risk factors for adverse health outcomes in older patients after discharge home and assessment tools: A systematic review. Journal of Evidence-Based Social Work, 8, 445-468. 
Reilly, P., Iezzoni, L. I., Phillips, R., Davis, R. B., Tuchin, L. I., \& Calkins, D. (1996). Discharge planning: Comparison of patients' and nurses' perceptions of patients following hospital discharge. Image: Journal of Nursing Scholarship, 28, 143-147.

Russell, L. B., Valiyeva, E., Roman, S. H., Pogach, L. M., Suh, L. M., \& Safford, M. M. (2005). Hospitalizations, nursing home admissions, and deaths attributable to diabetes. Diabetes Care, 28, 1611-1617.

Saleh, S. S., Freire, C., Morris-Dickinson, G., \& Shannon, T. An effectiveness and cost-benefit analysis of a hospital-based discharge transition program for elderly Medicare recipients. Journal of the American Geriatrics Society, 60, 1051-1056.

Schumacher, K. L., \& Meleis, A. I. (1994). Transitions: A central concept in nursing. Image: Journal of Nursing Scholarship, 26, 119-127.

Schumaker, K. L., Jones, P. S., \& Meleis, A. I. (1999). Helping elderly persons in transition: A framework for research and practice. In E. A. Swanson \& T. Tripp-Reimer (Eds.), Life transitions in the older adult: Issues for nurses and other health professionals (pp. 1-26). New York: Springer.

Selvin, E., Coresh, J., \& Brancati, F. L. (2006). The burden and treatment of diabetes in elderly individuals in the U.S. Diabetes Care, 29, 2415-2419.

Shepperd, S., McClaren, J., Phillips, C., Lannin, N. A., Clemson, L. M., McCluskey, A., et al. (2010). Discharge planning from hospital to home: Cochrane Collaboration.

Shyu, Y. L. (2000). The needs of family caregivers of frail elders during the transition from hospital to home: A Taiwanese sample. Journal of Advanced Nursing, 32, 619-625. 
Society of Hospital Medicine. (2008). BOOSTing Care Transitions. Retrieved November 25, 2012, from http://www.hospitalmedicine.org/ResourceRoomRedesign/RR_ CareTransitions/CT_Home.cfm

Steinman, M. A., Lee, S. J., Boscardin, W. J., Miao, Y., Fung, K. Z., Moore, K. L., et al. (2012). Patterns of multimorbidity in elderly veterans. Journal of the American Geriatrics Society, 60, 1872-1880.

Suhl, E., \& Bonsignore, P. (2006). Diabetes self-management education for older adults: General principles and practical application. Diabetes Spectrum, 19, 234-240.

Transitional Care Model. (2009). Transitional Care Model. Retrieved November 25, 2012, from http://www.transitionalcare.info/index.html

Travis, S. S., Buchanan, R. J., Wang, S., \& Kim, M. (2004). Analyses of nursing home residents with diabetes at admission. Journal of the American Medical Directors Association, 5, 320-327.

Tsilimingras, D., \& Bates, D. W. (2008). Performance improvement: Addressing post-discharge adverse events: A neglected area. Joint Commission Journal on Quality \& Patient Safety, 34, 85-97.

van Walraven, C. J., Dhalla, I. A., Bell, C., Etchells, E., Stiell, I. G., Zarnke, K., et al. (2010). Derivation and validation of an index to predict early death or unplanned readmission from hospital to the community. Canadian Medical Association Journal, 182, 551-557.

Watkins, L., Hall, C., \& Kring, D. (2012). Hospital to home: A transition program for frail older adults. Professional Case Management, 17, 117-125.

Weiss, M., Yakusheva, O., \& Bobay, K. (2010). Nurse and patient perceptions of discharge readiness in relation to postdischarge utilization. Medical Care, 48, 482-486. 
Weiss, M. E., \& Piacentine, L. B. (2006). Psychometric properties of the Readiness for Hospital Discharge Scale. Journal of Nursing Measurement, 14, 163-180. 


\title{
CHAPTER THREE: EARLY AND INTERMEDIATE HOSPITAL-TO-HOME TRANSITION OUTCOMES OF OLDER ADULTS WITH DIABETES — FINDINGS
}

\begin{abstract}
Over five million older adults with diabetes are hospitalized each year. Complex diseasespecific, self-management demands and the high prevalence of multimorbidity make older adults with chronic illnesses such as diabetes particularly vulnerable for poor hospital-to home transition outcomes including recidivism, medical errors, and excessive resource utilization.

A simultaneous quantitative/qualitative mixed method design was used to identify factors that impacted the home recovery transition experiences of 96 older adults (mean age $=75$ years) with pre-existing diabetes, most of whom were affected by multimorbidity. Although diabetes was typically well-controlled upon admission, deterioration of glycemic control during course of the hospitalization necessitated changes in home self-management plan for $40 \%$ of participants.

Binary logistic regression was used to identify factors that may predict 30-day recidivism risk. A statistically significant predictor model $\left(X^{2}=26.767, \mathrm{df}=3, p<.001\right)$ correctly classified 78.3\% of cases. Post Discharge Coping Difficulty Scale (PDCDS) scores 7 days (Wald $X^{2}=$ 3.671, $\mathrm{df}=1, p=.050$ ) and 30 days following discharge (Wald $X^{2}=6.723, \mathrm{df}=1, p=.010$ ) and participant-reported difficulty managing a non-diabetes chronic health condition ( Wald $X^{2}=$ 8.200, $\mathrm{df}=1, p=.004$ ) were predictive of recidivism. No diagnosis-specific predictor variables were identified.
\end{abstract}

The nurse's skill in delivering discharge education was an important factor in promoting discharge readiness and preventing early difficulties in coping and promoting positive patient satisfaction. Unmet post-discharge information needs as measured on the Quality of Discharge Teaching Scale (QDTS) were associated with lower Readiness for Hospital Discharge scores 
( $r=-.314, p=.003$ ), while higher QDTS scores were associated with better overall perceptions of the transition experience $(r=.444, p<.001)$.

The findings of this study suggest that elders at risk for hospital-to-home transition problems may be pre-identified by assessing readiness for discharge and targeting these patients for follow-up interventions. Older adults describing difficulties within 7 days of discharge may be at higher risk for readmission and may require more intensive follow-up during the first month after discharge. The nurse's role in discharge education is critical in promoting a successful early home transmission and may play a role in promoting patient satisfaction with care.

\section{Introduction}

Hospitalization rates are highest among individuals who are age 65 and older and typically result from an acute change in the health status of the older adult. In the most recent National Hospital Discharge Survey, 37\% of annual hospital visits and 43\% of hospital days of care were amassed by individuals who were age 65 and older (Hall, DeFrances, Williams, Golosinskiy, \& Swartzman, 2010). Thirty percent of visits in this age group were due to an exacerbation of a chronic cardiovascular condition such as coronary artery disease (CAD), heart failure (HF), or a cardiac arrhythmia (Hall et al., 2010). In a large, national study that examined chronic illness patterns in older adulthood, veterans age 65 and older were found to have a mean of 5.5 chronic health conditions (Steinman et al., 2012). Chronic illnesses such HF, hypertension, and diabetes contribute to medical treatment complexity in $74 \%$ of hospitalizations, even when

they are not the index condition that precipitates the admission (Levit, Wier, Stranges, Ryan, \& Elixhauser, 2009). Clinical practice guidelines that drive patient care decision making on 
complex health conditions often fail to incorporate the unique transition needs of individuals with pre-existing chronic health problems such as diabetes (Marengoni et al., 2011; Marengoni, Rizzuto, Wang, Winbland, \& Fratiglioni, 2009; Steinman et al., 2012).

\section{Problem}

More than 25\% of people over the age of 65 are affected by diabetes (Centers for Disease Control and Prevention [CDC], 2011). Hospitalization rates of older adults with diabetes significantly exceed the rates of elders who are unaffected by the condition. In 2012, elders with diabetes utilized more than 16.5 million hospital days (American Diabetes Association [ADA], 2013a). Diabetes, does not typically precipitate hospital admission of an elder, but often will decompensate during the course of a hospitalization and necessitate a change in treatment plan at discharge (ADA, 2013b). Older adults with diabetes are most commonly admitted with cardiovascular and general medical diagnoses and may suffer deterioration of a chronic diabetesrelated complication such as chronic kidney disease (CKD) during an admission (ADA, 2013a). Although older adults with diabetes are frequent consumers of acute care services, the postdischarge needs of this high-risk patient population have been only limitedly studied (ADA, 2013b).

\section{Background and Significance}

Multimorbidity is defined as "the simultaneous presence of diseases/symptoms, cognitive, and physical functional limitations” (Marengoni et al., 2011, p. 431). Multimorbidity is a particular concern for older adults because more than $50 \%$ are affected by three or more chronic conditions (American Geriatrics Society [AGS], 2012). Diabetes and it attendant chronic complications including atherosclerosis, nephropathy, neuropathy, and retinopathy contribute 
significantly to the multimorbidity of individuals age 65 and older. Additionally, older adults with diabetes are at higher risk for the development of geriatric syndromes such as cognitive impairment, depression, urinary incontinence, falls, and pain (California Healthcare Foundation \& American Geriatrics Society on Improving Care for Elders with Diabetes, 2003; Munshi et al., 2006; Travis, Buchanan, Wang, \& Kim, 2004). Each year individuals with diabetes, most of whom are $\geq 75$ years of age, generate over 5 million hospital admissions (CDC, 2007). Nationally, $42 \%$ of acute care hospitalizations and 52\% of nursing home admissions may be attributed to individuals affected with diabetes (Russell et al., 2005).

The transition from hospital-to home is complex for many elders with diabetes. At discharge, day-to-day responsibility for diabetes care is returned back to patients and their family caregivers. Because older adults often leave hospitals with residual health problems and new functional deficits, the ability to independently manage intricate diabetes care skills at the time of discharge may be limited, increasing the risk for poor transition outcomes (Weiss et al., 2007; Suhl \& Bonsignore, 2006). Older adults with diabetes experience higher rates of post-discharge recidivism in the forms of unplanned provider visits, emergency room utilization, and readmission (Jencks, Williams, \& Coleman, 2009).

Research on post-hospitalization experiences of older adults and their caregivers has revealed that discharge needs of aging families are often unmet (Bull, Hansen, \& Gross, 2000a; LeClerc, Wells, Craig, \& Wilson, 2002; Mistiaen, Duijunhouwer, Wijkel, de Bont, \& Veeger, 1997). Recidivism, medical errors, and caregiving difficulties are poor transition outcomes that are frequently experienced by older adults (Coleman, 2003; Coleman \& Boult, 2003; Coleman, Mahoney, \& Parry, 2005; Coleman, Parry, Chalmers, Chugh, \& Mahoney, 2007). The imminent implementation of Medicare’s Readmission Reduction Program (RRP) as part of the Affordable 
Care Act is motivating hospitals to reevaluate current transitional care practices (Centers for Medicare and Medicaid, 2013). The RRP mandates public reporting of readmission rates and exacts financial penalties on hospitals with excessive readmission for HF, myocardial infarction (MI), and pneumonia. In response, many hospitals are developing condition-specific initiatives in an effort to reduce readmission rates on these diagnoses. The condition-specific concentration of these initiatives has raised concerns that patients with complex needs who are unaffected by a targeted condition will continue to have unmet transition needs and remain at-risk for poor postdischarge outcomes (Naylor et al., 2012).

Identification of risk factors for potentially preventable readmissions (PPRs) and development of programs to reduce 30-day readmission rates has become a focus of transition research. Risk-assessment studies have most commonly used large data sets rather than individual patient experiences to identify PPR predictor variables and have not necessarily focused on unique risks of patients who are discharged directly to home (Goldfield et al., 2008; van Walraven et al., 2010). Goldfield et al. (2008) assert that many readmissions may not be preventable and are a byproduct of instability of the index condition when they occur soon after discharge. The interrelationship of two admissions may be more difficult to establish later in the post-discharge period. Hospitals are currently introducing the use of bedside tools that identify risk for readmission into general patient care workflows.

Transition theory proposes that individuals become particularly vulnerable during times of change, such as an event of hospitalization, and that the interplay between personal, community and societal transition conditions facilitate or inhibit transition outcomes (Meleis, Sawyer, Im, Messias, \& Schumacher, 2000; Schumacher \& Meleis, 1994; Schumaker, Jones, \& Meleis, 1999). While extensive research has been conducted on the post-discharge experiences 
of older adults and their caregivers, there is a lack of literature that specifically addresses the impact of a chronic illness with heavy self-management burdens, such as diabetes, on transition outcomes (Brooten et al., 2002; Bull, Hansen et al., 2000a; Bull, Hansen, \& Gross, 2000b; Bull \& Jervis, 1997; Coleman et al., 2005; Coleman, Min, Chomiak, \& Kramer, 2004; Coleman, Parry, Chalmers, \& Min, 2006; Coleman et al., 2002;; Jencks et al., 2009; Naylor et al., 2004; Parry, Coleman, Smith, Frank, \& Kramer, 2003; Parry, Mahoney, Chalmers, \& Coleman, 2008). Current hospitalization-related transition literature has primarily focused on 30-day recidivism and has not given consideration to the unique, evolving needs of elders and family care providers that may present in the early and intermediate periods of the home recovery transition.

\section{Conceptual Framework}

Hospitalization of an older adult is a multidimensional phenomenon that creates challenges for millions of elders each year. Changes in the physical and functional status of an older adult frequently follow an acute hospitalization and often necessitate the care integration of family and community resources following discharge. The middle range theory of transitions was selected as the framework for this research study because it appropriately conceptualizes the complexity of the many interrelated personal and support conditions that may facilitate or inhibit an effective home recovery transition for an aging family (Meleis et al., 2000; Schumaker et al., 1999). Personal transition conditions in this study incorporated characteristics of the older adult that were reflective of current health status, diabetes status, and readiness for discharge. Community transition conditions represented those factors external to the patient that potentially supported a successful post-hospital transition including hospital-driven processes such as 
discharge education, the availability of a caregiver at home, and utilization of home care services. The model of transitions as adapted for this study is presented in Figure 1.

Hospitalization has been described as a complex process that incorporates three sequential transition periods: the hospitalization; the period surrounding discharge; and the home recovery (Miller, Piacentine, \& Weiss, 2008). During the home recovery transition, the focus of this study, elders and their caregivers attempt to assimilate new knowledge and behaviors in order to manage health changes, restructure self-concepts and resume prior roles (Miller et al., 2008). Assessment of discharge readiness, discharge preparation and education, and community resource coordination are common nursing therapeutics that are provided in the course of supporting an elder and family through the hospital-to-home transition process (Schumacher \& Meleis, 1994; Schumaker et al., 1999).

Patterns of response depicted in the transition model include process and outcome indicators that represent an individual's movement away from vulnerability and toward restored health (Meleis et al., 2000). Knowledge of the disease process and treatment plan, appropriate resource utilization, and the acquisition of effective coping skills are indicators of attainment of confidence and reflect a healthy transition outcome (Meleis et al., 2000). In this study, posthospitalization transition effectiveness was evaluated during the early and intermediate stages of the home recovery transition using variables that measured events of recidivism, perceived quality of the post-hospitalization transition, and the presence of post-discharge coping difficulties.

\section{Aims and Research Questions}

The specific aims of this study were to: 
1. Determine whether personal health transition conditions and community transition conditions impact the early and intermittent home recovery transition outcomes of recidivism, perceived transition quality, and post-discharge coping difficulty in a sample of older adults with a pre-existing diagnosis of diabetes.

2. Determine if any of the above factors are predictive of development of poor transition outcomes during the home recovery transition.

The research questions regarding older adults with pre-existing diabetes who were newlydischarged to home from an in-patient setting were:

1. What personal transition conditions (health-illness factors, diabetes-related factors and perceived discharge readiness, specific post-discharge coping difficulties) impact early (7-day) and intermediate transition (30-day) outcomes?

2. What hospital-related community transition conditions (length-of-stay, discharge teaching quality, hospitalist) impact early and intermediate transition outcomes?

3. Does the availability of post-discharge community support resources (family and home health care) impact early and intermediate transition outcomes of older adults with diabetes?

4. Are any of the identified personal, hospital-based, or community support transition conditions predictive of risk for 30-day recidivism?

\section{Method}

A mixed-methods quantitative-qualitative design was used in this research study. The core component of the project utilized a descriptive, correlational design and included variables that were transposed from qualitative findings (Morse \& Liehaus, 2007). This preliminary study 
addressed gaps in the literature relative to the impact of a chronic illness with heavy selfmanagement burden on post-hospitalization transition outcomes and provided initial data on factors that may impact outcomes at different phases of the home recovery transition. A summary of independent and dependent variables examined in this study are included in Table 1.

\section{Sample}

This study included a convenience sample of 96 hospitalized older adults age 65 or older who had a pre-existing diagnosis of diabetes. All participants had a planned home discharge disposition at the time of enrollment and had been hospitalized for at least 48 hours for a medical/surgical diagnosis. A planned discharge to hospice services, rehabilitation, or an assisted living facility excluded an elder from participation. Participants were also excluded if their medical record indicated a history of cognitive deficit or treatment with medications used in the management of dementia.

This study was open to men and women of all racial and ethnic groups. Participants were also required to hear, speak, and understand English and have access to a telephone for 30 days following discharge. Participants were enrolled between March, 2012 and January, 2013 at 560bed tertiary medical center located in east, central Florida.

Because this study specifically targeted high-risk, recently-hospitalized, older adults with chronic illnesses and required two follow-up contacts, the risk of attrition related to loss-tofollow-up and mortality was a consideration in study design. Recommendations from the literature to reduce the risk of attrition with older adult research participants include shortening follow-up interviews, decreasing the time between follow-up contacts, and including the use of proxy respondents (Chatfield, Brayne, \& Matthews, 2005; Deeg, van Tilberg, Smit, \& de Leeuw, 
2002). All of these suggestions were incorporated into the research protocol, and participants were additionally mailed reminder follow-up appointment letters which included copies of study instruments. To increase engagement with an older-patient population, a retired registered nurse with extensive experience in health-related telephone survey of older adults conducted the postdischarge interviews.

Family care providers were permitted to serve as alternate study respondents for enrolled elders. Proxy report is appropriate when an objective outcome measure is available, when the study participant cannot provide an accurate report, or when an alternative respondent, in this case the family caregiver, has the ability to provide important information on the phenomenon under investigation (Snow, Cook, Lin, Morgan, \& Magaziner, 2005). In this study, the proxy’s report of discharge difficulties is a viable substitute for that of the older adult. Outcomes under investigation in this study such as reports of recidivism, perceived discharge quality, and discharge coping difficulties were readily observable by a proxy care provider, and as such, met criteria for use of a proxy responder.

Six participants experienced a change in discharge disposition or had a discharge cancelled after enrollment and were excluded from the follow-up phases of the study. Of the 90 participants who were discharged to home, 74 (82\%) completed the 7-day follow-up, and 70\% ( $n$ = 63) contributed data during the 30-day follow-up interview. Eleven participants were not reached by telephone or declined further study participation without comment. Four participants deferred additional follow-up after describing deterioration in their post-discharge health status. Another seven participants subsequently declined study participation secondary to caregiver fatigue, primarily in the later follow-up phase of the study. Five participants were actively hospitalized at the time of a follow-up appointment. No participants were lost to mortality. 


\section{Measures}

\section{Personal Transition Conditions}

Personal transition conditions were evaluated using measures of health status, diabetesrelated factors, and readiness for hospital discharge (Table 1). A copy of the demographic data collection form is included in Appendix E.

\section{Health-Status Factors}

\section{Chronic Illness Burden}

The Charlson Comorbidity Index (CCI) was used as a proxy measure of multimorbidity. The CCI provides an estimate of the chronic illness burden associated with the combined number and weighted severity of a variety of health conditions (Charlson, Pompei, Ales, \& MacKenzie, 1987) The tool affords a means of discriminating patients with low, medium and high chronic illness burdens, including the burden associated with diabetes and diabetes with end-organ damage (Charlson et al., 1987). The CCI score been identified as a significant predictor of oneyear survival $(p<.0001)$ (Charlson et al., 1987). In this study, CCI scores were established through review of each participant's hospital record.

\section{Cognitive Status}

The Mini-Cog was used to screen for the potential presence of previously unrecognized cognitive dysfunction (Borson, Scanlan, Brush, Vitallano, \& Dokmak, 2000) The Mini-Cog is constructed as a three-item, learning-recall test combined with a clock drawing exercise that

additionally serves as a memory distractor (Borson, Scanlan, Chen, \& Ganguli, 2003; Borson, Scanlan, Watanabe, Tu, \& Lessig, 2005, 2006). The Mini-Cog is easy to use and interpret and 
has a reported sensitivity of 76\% and specificity of 89\% (Borson et al., 2003). The Mini-Cog performs well in individuals of varied cultural, literacy, and language backgrounds (Borson \& Scanlan, 2006; Borson et al., 2003; Borson et al., 2005). Administration time for the Mini-Cog is approximately two to four minutes. The Mini-Cog was administered during the initial intake phase of the study.

\section{Functional Status}

The Katz Index of Independence with ADLs was used to determine an elder's baseline functional status at the time of discharge. The index provides a cumulative, dichotomous (dependent/independent) rating of six basic ADLs: (1) bathing; (2) dressing; (3) toileting; (4) transferring; (5) continence; and (6) feeding (Katz, Downs, Cash, \& Grotz, 1970; Wallace \& Shelkey, 2007, 2008). Lower scores are reflective of greater difficulty performing ADL's. The Katz ADL has been widely used in a variety of clinical settings since its development in the 1960’s and has been administered by direct observation, personal interview, mailed questionnaire, and by telephone (Ciesla et al., 1993). In this study, the Katz ADL was administered by interview of the elder participant.

\section{Diabetes-Related Personal Factors}

\section{Duration Of Diabetes}

Duration of diabetes data were reported in years and obtained by participant report during the initial enrollment interview. 


\section{A1c}

The A1c value provided a measure of glycemic control during the three months that preceded hospitalization (ADA, 2013b). The most recent report of the A1c value was obtained from the medical record.

\section{Diabetes-Related Health Complications}

The Diabetes Complication Index (DCI) functioned as a proxy measure of diabetesassociated multimorbity in this study. The DCI is a 17-item questionnaire that uses self-report to assess for a patient history the following type 2 diabetes-related complications and/or conditionspecific symptoms: (1) CAD; (2) cerebrovascular disease (CVD); (3) peripheral vascular disease

(PVD); (4) neuropathy; (5) foot problems; and (6) eye problems (Frincke et al., 2005). Two types of questions, one based upon physician-provided diagnostic information and the other based upon symptom report, are used to collect data on each complication. A positive response to any condition-specific question is scored with a value of 1 . DCI scores may range from 0 to 6 with higher scores suggesting a greater diabetes-related complication burden. DCI scores have been positively correlated with perceived diabetes-related reductions in health; diabetes-related resource utilization; physician visits; and duration of diabetes (Frincke et al., 2005). The DCI was administered during the enrollment interview phase of the study. A copy of the questionnaire is provided in Appendix F.

\section{Readiness For Discharge}

The Readiness for Hospital Discharge Scale (RHDS) adult version provided an assessment of a patient's perceived readiness to leave the hospital (Weiss et al., 2008; Weiss \& Piacentine, 2006; Weiss et al., 2007). The first item on the RHDS is an unscored, dichotomous 
question that assesses the respondent's self-perceived discharge readiness. The remaining 22 items provide a unidimensional measure of the construct of discharge readiness within the following four subscales: Personal Status (6 items); Knowledge (9 items); Coping Ability (3 items); and Expected Support (4 items). Each item is graded on a scale of 0 to 10 with lower scores indicating a lesser degree of readiness. Question 3 assesses the participant's pain level and is reverse coded for scoring. Developers reported Cronbach's $\alpha$ values of .86 to .91 in a large sample of adults age 55 or older (Bobay, Jerofke, Weiss, \& Yakusheva, 2010). The Cronbach’s alpha coefficient for the entire instrument was .82 in the current study sample. In a recent communication, the developer recommended deletion of the item on stress and exclusion of this item from scoring (M. Weiss, personal communication, February 11, 2011). These revised scoring recommendations were used in the current study, and the potential range of scores in the current study was 0 to 210 .

The RHDS is positively predictive for development of post-discharge coping difficulties in older adults, particularly those over the age of 85 years (Bobay et al., 2010). No differences in mean RHDS scores have been noted relative to gender, socioeconomic status, or race in a variety of patient demographics (Weiss \& Piacentine, 2006). The instrument has a reading grade level of 8.5 and the estimated questionnaire administration time is five to ten minutes (Weiss \& Piacentine, 2006; Weiss et al., 2007). Participants completed the RHDS within four hours of a planned discharge. A copy of the adult medical-surgical RHDS and scoring grid is included in Appendix H. 


\section{Community Transition Conditions}

Community transition conditions examined in this study included hospital-related discharge factors, family involvement in the post-discharge phase of care, and use of community-based services such as home care.

\section{Hospital Discharge Factors}

\section{Length-of-Stay}

Duration of hospitalization was measured as the length-of-stay. The day of admission marked Day 1 of the hospitalization. Days were "added” at midnight each evening and totaled on the day of discharge.

\section{Hospitalist Services}

The inclusion of a hospitalist, a physician with specialization in the in-patient management of complex medical problems, in the care of a participant was established through review of the hospital record.

\section{Quality of Discharge Teaching Scale Score}

The Quality of Discharge Teaching Scale (QDTS) measured the participant’s perception of nurse-provided discharge-related education and served as a nurse-sensitive indicator of discharge effectiveness (Bobay et al., 2010; Weiss, 2012; Weiss, Yakusheva, \& Bobay, 2010; Weiss et al., 2007). The QDTS includes 24 items that are scored on a 0 to 10 scale using the anchors none or not at all and always or a great deal. The two major subscales of content and delivery contribute to 54\% of the variance (Maloney \& Weiss, 2008; Weiss, 2012). “Content” responses describe a patient's perspective on both needed and received discharge information 
(Maloney \& Weiss, 2008). “Delivery” items address the patient’s perception of nurses’ effectiveness in providing all discharge education. QDTS scores are calculated by adding Content Received and Delivery subscale scores.

A Cronbach’s alpha coefficient of .88 to .93 in a sample of adults age 55 and older was reported for the entire scale (Bobay et al., 2010; Maloney \& Weiss, 2008). Cronbach’s alpha coefficients observed in the current study sample were .804 (Content Needed), .677 (Content Received), .775 (Delivery); and .775 (Total scale). Based upon findings of a currently unpublished study of 1800 patients, the developer is recommending the use of subscales in predictive analyses rather than total instrument scores (M. Weiss, personal communication, February 11, 2011). The QDTS was administered within four hours of the projected discharge. A copied is provided in Appendix I.

\section{Family Involvement in Post-Discharge Care}

The availability of an in-home family caregiver to support the elder during the immediate discharge period was assessed during the intake interview and subsequent telephone contacts.

\section{Community Service Providers}

Use of intermittent home care services was established through participant interview during intake and during two follow-up telephone contacts.

\section{Patterns of Response}

Early and intermediate outcome measures of the hospital-to-home transition experience included events of recidivism and assessment of post-discharge coping difficulty. Participantperceived quality with the care transition was also examined. 


\section{Measures of Recidivism}

Data on emergency department utilization, hospital readmission, and unplanned provider visits were gathered during two telephone follow-up interviews. All events of recidivism were combined as a single variable for outcome analyses in this study.

\section{Care Transition Measure-15}

The Care Transition Measure (CTM)-15 provided an assessment of a participant’s perceived quality with the post-discharge transition (Coleman et al., 2002). The CTM-15 includes 15 items that measure the construct of transition within the context of the acute healthillness relocation (Parry et al., 2008). Items are scored on a four-level Likert scale that uses the anchor descriptions of strongly disagree and strongly agree. Lower scores are reflective of poor transition experiences (Coleman et al., 2002; Parry et al., 2008).

Internal consistency reliability of the CTM-15 has been established with Cronbach’s alpha coefficients in excess of .90 (Parry et al., 2008). Cronbach's $\alpha$ for the CTM-15 was .966 for the current sample. The CTM-15 has demonstrated reliability in varied patient samples with respect to age, educational level, language, and self-reported health status (Parry et al., 2008). Scores on CTM-15 have shown an excellent ability to discriminate between patients who do and do not access emergency department services following a hospital discharge (Coleman et al., 2005). The CTM-15 may be administered in written or telephone formats (Coleman, 2006). Optimal timing of instrument administration has not been specified. Patient or family members respond to the CTM-15, but variations in performance of the measure between these two respondent types have not been discussed in the literature. The CTM-15 was administered by telephone interview 7 days following discharge in the current study. CTM-15 scores were 
calculated and transformed following developer guidelines (Coleman, 2006). Copies of the CTM-15, scoring procedures, and scoring grids are included in Appendix K.

\section{Post-Discharge Coping Difficulty Scale}

The Post-Discharge Coping Difficulty Scale (PDCDS) was used to gain insight into problems encountered during the early and intermediate stages of the home recovery transition (Miller et al., 2008; Weiss \& Piacentine, 2006). The PDCDS includes ten close-ended items that rate potential transition concerns such as stress, recovery difficulties, self-sufficiency, emotional needs, and family difficulties on a scale of 0 to 10 (Miller et al., 2008). Items 8, 9, and 10 of the PDCDS assess perceived confidence, self-management abilities, and post-hospitalization adjustment and are reverse coded for data analysis (M. Weiss, personal communication February 18, 2011). Higher PDCDS scores are indicative of greater difficulty with post-discharge coping. Five open-ended questions afford respondents the opportunity to explicate specific problems encountered in the home setting. A Cronbach's $\alpha$ of .87 has been reported in an adult medicalsurgical sample of patients (Miller et al., 2008). Cronbach’s alpha coefficients were .916 for the 7-day follow-up sample and .921 for the 30-day post-discharge sample in this study. Copies of the PDCDS and scoring criteria are included in Appendix J.

\section{Procedure}

Approval to conduct this study was received from the University of Central Florida Institutional Review Board and administrative authorities at the study site. Screening for potential participants who met inclusion criteria was accomplished by the principal investigator through consultation with nursing staff and case managers, participation in unit discharge planning rounds, and use of hospital informatics systems. Patients meeting first-level screening 
criteria were approached by the investigator, and those agreeing to participate provided written consent using the document provided in Appendix B. Only competent elders were permitted to provide consent for study participation. They could, however, designate a proxy respondent who could participate in follow-up interviews.

The initial study interview was conducted by the principal investigator. Participants provided demographic and health-related data, diabetes-specific history and treatment information, and plans for anticipated post-discharge support. Additionally, the Mini-Cog, KatzADL, and DCI instruments were completed. The RHDS and QDTS were administered within four hours of the estimated discharge. Due to the age and fragility of the study sample, the principal investigator stayed in the room during survey completion and was available for standby assistance as needed. Hospital records were reviewed to gather data on age, admitting diagnosis, length-of-stay, use of hospitalist services, A1c values, admitting and discharge treatment plans, and a history of diagnoses included on the Charlson comorbidity index. A copy of the data collection form is included in Appendix E. Upon completion of the intake interview, the participant's follow-up contact information was confirmed, and an appointment for a 7-day follow-up interview was made.

Telephone follow-up interviews were conducted by the study's research assistant 7 and 30 days following discharge. During each interview, post-discharge utilization data were gathered, and the closed-ended and free response items of the PDCDS were administered. The research assistant recorded participants' verbatim responses to the open-ended questions on the PDCDS. Responses to the CTM-15 were also gathered during the 7-day follow-up interview. Participants who were not reached on the first attempt were contacted every other day for a 
period of seven days. Those who were not reached during that time period were considered lostto-follow-up. The data collection process is outlined in Appendix D.

\section{Data Analysis}

\section{Transformation of Qualitative Data}

Analysis of qualitative data from the supplementary component of the study revealed that respondents regularly reported difficulties managing complex medication regimens, regulating blood glucose, and managing other chronic health problems during the home recovery transition. Qualitative data were transformed to create discrete nominal-level variables that reflected the presence or absence of each of these difficulties. These newly-created variables were analyzed as post-discharge transition outcomes during statistical testing.

\section{Data Analysis Procedures}

All statistical analyses were performed using Statistical Package for Social Services (SPSS) for windows (Version 19.0). Pre-analysis screening of data for accuracy, missing data, outliers and the assumptions of normality and linearity were completed. Data provided by the six participants who experienced a change in discharge disposition or discharge cancellation on the day of enrollment were deleted from the final data file that was used for analyses of transition outcomes. Additionally, data from individuals who were lost to follow-up during the course of the study were excluded from subsequent analyses. Because it was felt that failure to complete a follow-up interview may be a meaningful data point, a nominal level variable was created to identify participants who had not completed all phases of data collection and was used in statistical analyses. Data from 74 of the original 96 participants were available for analysis of 7- 
day post-discharge transition outcomes, while 63 participants contributed data to 30-day analyses.

Review of plots and normality assessments of the continuous RHDS scores and both sets of PDCDS scores revealed that these variables lacked normality and linearity. These three variables were transformed using log transformation with a resultant improvement in normality plots. Transformed variables were used in statistical tests where assumptions of normality and linearity are required such as differences in means testing and bivariate correlations.

Descriptive statistics including means, medians, modes and standard deviations were calculated for each continuous variable. Frequency counts and percentages were computed for each categorical variable. Multimorbidity profiles of the sample were evaluated by generating counts of each possible combination of common medical conditions that were identified while gathering data for the Charleson comorbidity index and the DCI. Multimorbidity patterns were evaluated for the following diagnoses: CAD; HF; CKD; chronic obstructive pulmonary disease (COPD); CVD; PVD; and neuropathy. $X^{2}$ tests of independence were calculated to determine if there was a difference in the occurrence of an event of 30-day recidivism based upon the presence or absence of one of these diagnoses or multimorbidity patterns. Because CKD was so prevalent in the sample and was excluded from the DCI, a separate variable was created to represent the total diabetes-related comorbidity burden by combining the following diseaserelated variables: CAD; HF; CKD; CVD; PVD; and neuropathy. Due to the age of the sample and frequency of reports of cataracts, which are a common variant in older adults, eye problems were not included in this count. Diabetes-specific medication patterns were evaluated using the same count procedures. 
Multiple $X^{2}$ analyses were performed to determine if a relationship existed between dichotomous variables that portrayed personal health-related transition conditions, diabetesspecific transition conditions, community transition conditions, and common discharge conditions and 7-day recidivism, 30-day recidivism, and common post-discharge difficulties. $t$ tests were conducted to determine if differences in recidivism, difficulties managing medications, problems regulating glucose, and complications managing other chronic health conditions were related to the following variables: age; total diabetes-related conditions; lengthof-stay; RHDS scores; QDTS scores; CTM-15 scores; and 7 and 30-day PDCDS scores. Bivariate correlations were performed to assess if statistically significant relationships existed between continuous variables that measured personal factors (age, total chronic health conditions), diabetes transition conditions (A1c), readiness (RHDS), hospital-related transition factors (LOS, QDTS subscale and total scores), and home recovery transition outcomes (CTM15, 7-day and 30 day PDCDS).

Logistic regression models were analyzed to determine if chronic illness burdens (total diabetes-related complications, COPD and interaction between both variables), early and intermediate presentation of post-discharge difficulty (7 and 30-day PDCDS scores) and reports of specific post-discharge difficulties were predictive of risk for 30-day post-discharge recidivism. Statistical tests and regression predictors were deemed significant if $p \leq .05$.

\section{Results}

\section{Sample Characteristics}

The initial sample included 96 hospitalized adults, age 65 or older, who had plans to leave the hospital within four hours of study enrollment. 


\section{Personal Transition Conditions}

\section{Health Status Conditions}

Characteristics of the sample's health status-related transition conditions are summarized in Table 2. The median age of participants was 75 years (range 65 to 90 years), and the sample was equally represented by males and females. Study participants were primarily Caucasian $(84.4 \%, n=81)$ which is consistent with the demographic of the study site. Participants in this study were hospitalized for a variety of conditions. Non-cardiovascular medical diagnoses initiated 49.8\% $(n=47)$ of hospitalizations, and 34.4\% $(n=33)$ of admissions resulted from a cardiovascular condition. Twenty participants were admitted for non-cardiovascular surgical procedures.

Although prospective study participants were screened for a history of dementia during recruitment, 6.3\% $(n=6)$ of enrolled participants produced a Minicog score of $<3$, which may be suggestive of cognitive dysfunction. Only 11.4\% $(n=11)$ of the enrolled elders were experiencing difficulties performing basic ADLS’s at discharge. Most participants who reported functional deficits during intake had undergone surgical procedures and were on activity or wound-related precautions at the time of discharge.

Multimorbidity was evident in 75\% $(n=72)$ of enrolled elders due to the additive effects of diabetes and its associated chronic complications. (Marengoni et al., 2011). The most commonly occurring chronic illness dyads were representative of blends of diabetes-related macrovascular and microvascular conditions such as CAD and neuropathy $(33.3 \%, n=32)$, CAD and CKD (30.2\%, $n=29)$, CKD and neuropathy (28.1\%, $n=27)$, CAD and HF (28.1\%, $n=27)$, CKD and neuropathy (28.1, $n=27)$, and CKD and PVD $(25 \%, n=24)$. A summary of the multimorbidity profile of the sample is contained in Table 3. A relationship existed between a 
history of CKD $\left(X^{2}=3.927, p=.048\right)$ and 7-day recidivism and PVD $\left(X^{2}=4.591, p=.048\right)$ and 30-day recidivism. Neither of these conditions was independently predictive of recidivism. No significant relationships were established between chronic condition dyads and development of problems managing complex medication regimens, glycemic control and regulation, and treatment of other chronic conditions.

\section{Diabetes-Specific Conditions}

Most participants in this study had a long duration of diabetes (Mdn $=11$ years, range 1 to 49 years). The mean A1c was $6.9 \%(S D=1.043)$ with a range of 5.2 to $11.7 \%$. Nine $(11 \%)$ participants had recorded A1c values of $\geq 8 \%$ indicating poor glycemic control prior to admission. Changes in the established home diabetes regimen were recommended for $40 \%$ ( $n=$ 36) of participants prior to discharge, and 35.6\% $(n=32)$ of respondents were discharged on insulin. Only two participants were new to insulin when they returned home. Diabetes-specific characteristics of the sample are presented in Table 4.

\section{Discharge Readiness}

All but two of the 96 original study participants, including those who experienced a lastminute change in discharge disposition, reported that they were ready for discharge at the time of enrollment. RHDS scores of the total sample were skewed to indicate higher levels of perceived discharge readiness $(M=186.65, S D=19.64, M d n=194)$. Scores of the total sample ranged from 105 to 210 (Table 2).

Healthy perceptions of discharge readiness were associated with positive patient perceptions of the overall transition experience $(r=.403, p<.001)$ (Table 18). Perceived discharge readiness scores were lower in elders who experienced an event of recidivism 
$(t=2.274, \mathrm{df}=48, p=.028)$ within the first 30 days of discharge (Table 14). No differences in readiness scores were associated with development of difficulties in managing medications (Table 15) or diabetes (Table 16), though differences in readiness scores in patients who later reported difficulty managing a chronic health problem (Table 17) did approach statistical significance $(t=1.942, \mathrm{df}=66.2, \mathrm{p}=.056)$.

\section{Community Transition Conditions}

\section{Hospitalization-Related Transition Conditions}

The mean LOS for study participants was 6.27 days $(S D=3.643)$ (Table 5). LOS was not correlated with perceived discharge readiness, quality of discharge teaching, the perceived quality of the post-discharge transition, and post-discharge coping difficulty scores. Additionally, no age-related differences in the occurrence of 30-day post discharge recidivism were noted in this sample of older adults.

Hospitalists were involved in the acute care management of $32.3 \%(n=21)$ study participants. The inclusion of a hospitalist in care was not related to an occurrence of recidivism or reports of post-discharge management of conditions. A relationship existed between difficulties managing medications at home and non-use of hospitalist services $(p=.020)$ (Table 13).

The nurses’ effectiveness in delivery of discharge teaching was identified as a critical element in the success of the home recovery transition (Table 5). High residual needs for discharge information were associated with reduced readiness for discharge $(r=-.314, p=.003)$ and greater early post-discharge coping difficulty $(r=.288, p=.023)$ (Table 18). The quality of discharge teaching was positively correlated with participant perceptions of transition quality 
$(r=.444, p<.001)$. Specifically, the quality of the discharge information $(r=.333, p=.004)$ and the skill of the nurse in delivering discharge education $(r=.451, p<.001)$ were associated with better perceptions of transition quality (Table 18). Lower CTM-15 scores were associated with higher levels of post-discharge coping difficulty $(r=-.286, p=.027)$ in the early phase of the home recovery transition. Patient perception of post-discharge transition quality did not significantly vary in elders who did or did not experience an event or recidivism $(t=1.661, \mathrm{df}=$ $66, p=.101$ ) (Table 14). Individuals with lower CTM-15 scores reported more difficulty managing medications $(t=2.123, \mathrm{df}=71, p=.037)$ following discharge (Table 15).

\section{Family and Community Support Resources}

Eighty percent $(n=72)$ of participants reported access to a caregiver who resided in the home during the initial stages of recovery (Table 6). Twelve respondents lived alone, and eight of these elders returned home with no family supervision. Ultimately, five of the participants who lived alone dropped out of the study. The availability of a caregiver was not associated with reports of recidivism, but these findings need to be interpreted cautiously in view of the small sample of independently-dwelling elders in the sample. Six participants were required to resume the role of caregiver for another immediately after their own discharge.

Almost 50\% $(n=44)$ of respondents were referred to home care services at the time of discharge. Utilization of home care services was not associated with post-discharge recidivism in the early phase of the home recovery transition or in variations in PDCDS scores during both data periods (Table 10). There were no statistically significant relationships established between use of home care service and the development of difficulties with medication complexity, glycemic control, or chronic illness management. 


\section{Prediction of Post-Discharge Difficulties}

\section{0-Day Recidivism}

A summary of outcome-related data is provided in Table 7. A series of $X^{2}$ analyses were conducted to determine if occurrences of 7-day (Table 8), 8 to 30-day (Table 9), and 30-day recidivism (Table 10) were related to nominal-level variables that were representative of chronic health conditions, diabetes-related health conditions, hospitalization-related transition conditions, and access to community support resources. The relationship of these variables to participantreported difficulties with medication complexity, managing glucose or diabetes, and managing a chronic health problem were also examined. A series of $t$ tests were calculated to ascertain if significant differences in scored measures of discharge readiness, quality of discharge teaching, perceived discharge quality, 7-day post-discharge coping difficulty, and 30-day post-discharge coping difficulty could be attributed to 30-day recidivism (Table 14), difficulty with medication complexity (Table 15), difficulty with controlling diabetes (Table 16), and difficulty in managing other chronic health problems (Table 16).

A history of CKD was the only condition-specific variable that was associated with an early event of recidivism $\left(X^{2}=3.927, p=.048\right)$. Statistically significant associations between 30 day recidivism were observed with the following variables (Table 10): history of PVD $\left(X^{2}=\right.$ 4.591, $p=.032)$; difficulty managing medications $\left(X^{2}=4.653, p=.031\right)$; difficulty managing diabetes $\left(X^{2}=4.384, p=.036\right)$; and difficulty managing a chronic illness other than diabetes $\left(X^{2}=13.830, p<.001\right)$. Continuous variables that were significantly related to 30-day recidivism included perceived discharge readiness scores $(t=2.274$, $\mathrm{df}=48, p=.028)$ and 30-day postdischarge coping difficulty scores $(t=-3.363$, $\mathrm{df}=24.7, p=.003)$ (Table 14). Differences in 7day PDCDS scores were also observed in relation to each of the specified post-discharge 
difficulties which led to a decision to include this variable in predictive assessment of the risk for 30-day recidivism.

Binary logistic regression was used to explore the impact of multimorbidity on early and latent recidivism. Total diabetes-related complications, COPD, and the interactions of the two variables were run as predictors for the occurrence of recidivism during three post-discharge time periods within one month following discharge (Table 19). No chronic illness specific variables emerged as predictors of 30-day recidivism.

Six predictors were entered into a regression model with 30-day recidivism as the outcome: RHDS scores; 7-day PDCDS scores; 30-day PDCDS scores; difficulty managing medications; difficulty controlling blood glucose; and difficulty managing other chronic illnesses. Three of the six predictors contributed significantly to the initial model, and a model was re-run using these three variables. A final three-predictor model was found to be statistically significant $\left(X^{2}=26.737, \mathrm{df}=3, p<.001\right)$. The following variables contributed to an event of recidivism within 30 days of discharge: 7-day PDCDS scores (Wald $X^{2}=3.671, \mathrm{df}=1, p=.05$ ); 30-day PDCDS scores (Wald $X^{2}=6.723, \mathrm{df}=1, p=.010$ ); and difficulty managing other chronic illnesses (Wald $X^{2}=8.200, \mathrm{df}=1, p=.004$ ). The Hosmer-Lemeshow goodness-of-fit statistic $\left(X^{2}=7.061\right)$ was insignificant $(p=.530, \mathrm{df}=8)$ indicating that the final model had a good fit with the data. The Nagelkerke $R$ square statistic indicated that the model contributed to $49.9 \%$ of the variance. The model correctly predicted $85 \%$ of participants who did not have an event of recidivism and $65 \%$ of people who did experience recidivism and was able to correctly predict discharge transition outcomes in $78.3 \%$ of cases (Table 21). The odds of experiencing recidivism within 30 days of hospital discharge was particularly high if the elder was experiencing difficulty managing a non-diabetes related chronic illness $(\mathrm{OR}=10.666, p=.004)$. 


\section{Discussion}

This study examined the impact of personal health transition conditions (health-illness factors, diabetes-related factors, and discharge readiness) and community transition conditions (hospital-related discharge factors, family caregiver status, and utilization of home care resources) on the early and intermediate recovery transition outcomes of recidivism and postdischarge coping difficulty in a sample of older adults with a pre-existing diagnosis of diabetes. Study findings provided preliminary insight into the multidimensional nature of the early and intermediate home recovery transition experience from the perspective of the older adult and family care providers. The free-responses provided by older adults and their care providers in the supplementary qualitative component of the study provided an opportunity to better understand specific problems encountered during the early and later phases of the home transition and to explore their potential value in predicting the risk for recidivism.

\section{Demographic and Health Status Transition Conditions}

The study sample closely mirrored the descriptions of hospitalized older patients that were provided in the literature. Over one-third of participants were admitted for a cardiovascular diagnosis which is consistent with the $30 \%$ reported in the most recent National Discharge Survey (Hall et al., 2010). Hospitalization causes in the sample were similar to those that were

previously reported in the older diabetes population (ADA, 2013a). Age and length-of-stay were not associated with difficulties encountered in home recovery transition period.

The additive effects of diabetes and diabetes-related conditions suggested that at least $73 \%(n=70)$ of participants met baseline criteria for multimorbidity, and as in the VA study (Steinman et al., 2012), over 30\% ( $n=30)$ of participating elders suffered from at least five 
comorbid conditions. Because this study was diabetes-focused and did not specifically address other common conditions that affect elders such as arthritis, hypertension, and gastrointestinal disorders it can be assumed that the multimorbidity burden of the sample is even higher. Multimorbidity patterns identified in this study were similar to those seen in the VA study (Steinman et al., 2012). A relationship was seen between CKD and early recidivism and PVD and 30-day recidivism, but these conditions were not independent predictors of overall 30-day recidivism. Because of the high prevalence of stage 3 or higher CKD in this sample $(45.8 \%, n=$ 44) and participant-generated free-response descriptions of difficulty with home-management of CKD, additional study of this condition is warranted with larger patient samples. The preliminary findings of this study suggest that the current condition-specific approach to readmission reduction may inadequately predict patients who are at higher risk for recidivism.

\section{Diabetes-Specific Personal Transition Conditions}

Most of the older adults in this study sample had a long duration of diabetes and were affected by multiple chronic complications that are often associated with poor diabetes control. Although, the multimorbidity profile of the sample established that participating elders were afflicted by several chronic diabetes-related complications, A1c values indicated that glycemic control for most participants met current guidelines for older adults at the time of admission (ADA, 2013b; Huang, Sachs, \& Chin, 2006). These findings suggest that older adults with diabetes may experience acceptable glycemic control prior to hospitalization. Over one-third of participants were discharged on insulin, and over $40 \%$ of participants experienced changes in their diabetes treatment regimen at discharge. In the qualitative component of this study, elders reported difficulty maintaining glycemic control during the early and later home recovery phases 
of transition. Participants regularly reported adjustments to their diabetes treatment regimens following discharge, and a few reported glucoses in excess of $300 \mathrm{mg} / \mathrm{dL}$. Although it was not a significant predictor in the final regression model, difficulty controlling diabetes following discharge was a common frustration reported by participants.

\section{Discharge Readiness}

An elder's perceived readiness for discharge was related to post-hospitalization transition outcomes. Though not statistically significant, scores on the RDHS were lower in patients who reported specific difficulties with handling medications, controlling glucose, and managing a chronic health problem at home. Differences in readiness scores were statistically significant with regard to recidivism - lower scores were seen in patients who experienced an event of recidivism within 30-days of discharge. Because patient satisfaction is a reportable quality metric and is now attached to hospital reimbursement equations (Medicare Payment Advisory Committee, 2007), it should be noted that higher perceived readiness for discharge was positively correlated with patient perceptions of post-discharge transition quality. Perceived readiness for discharge may have bearing in how patients describe their hospital experiences in patient satisfaction surveys and is an important consideration in evaluating the overall hospital experience.

\section{Discharge Preparation and Education}

Perceived discharge readiness was positively correlated with the patient-perceived quality of discharge teaching. Participants who reported unmet discharge information needs had a lower perceived readiness for discharge. Additionally, failure to meet an elder's information needs was correlated with higher levels of post-discharge coping difficulty in the first week following 
hospitalization. These findings are supported by the qualitative responses provided to PDCDS free-response items. Effective delivery of discharge teaching by the nurse was correlated with higher levels of readiness and improved perceptions of transition quality. Although quality of discharge teaching was not a significant predictor of post-discharge recidivism, the skill of the nurse in delivering discharge education clearly influenced the patients' overall perception of the home recovery transition.

\section{Community Transition Conditions}

Transition support resources such as a caregiver who was residing in the home at the time of discharge and receipt of home care services were not associated with an event of recidivism. It should be noted, however, that recruitment of individuals who were discharged home with no inhome supervision was limited, and statistical analyses may not have adequately captured the true experience of elders who lived alone. Content analyses of the free response comments to the PDCDS of individuals who lived alone suggested that returning home after a hospitalization without formal support is extremely difficult. It was noted during study screening activities that individuals who lived alone often were transferred to intermediate care facilities following discharge. A better understanding of the transition from skilled rehabilitation to home is needed particularly for older adults with limited community support resources.

\section{Post-Discharge Coping Difficulties}

Common post-discharge coping difficulties appeared to be interrelated. Associations between medication management and difficulty controlling glucose or regulating another chronic health condition were observed. Additionally, a report of difficulty regulating glucose was significantly associated with difficulty in managing another chronic health problem. These 
findings suggest that multimorbidity may play a role in the evolution of post-discharge coping difficulties during the home recovery phase of transition.

PDCDS scores were predictive of the risk for an event of recidivism in the early and later phases of the home recovery transition. Specific difficulties with management of a complex chronic health condition such as hypertension, cardiac rhythm abnormalities, or renal failure were described by almost 52\% of respondents during the first week following discharge and $78 \%$ of participants who provided comments during 30-day post-hospitalization interviews. Although PDCDS scores were lower during the second interview, multiple elders did report that they were undergoing modifications to chronic illness treatment plans or work-ups for decompensated health problems.

\section{Implications}

\section{Practice}

The findings of this study suggest that sequential screening for the presence of postdischarge coping difficulties and early intervention for emerging problems is critical for the duration of the home recovery transition. Seven-day follow-up assessment of recently discharged older adults may be particularly helpful in identifying older adults and families who are struggling at home. Inclusion of these assessments during routine post-hospital provider visits may be particularly helpful in identifying elders who are actively experiencing post-discharge difficulties and may have heightened risk for recidivism. The addition of transitional care interventions within the context of evolving medical home models may be helpful in limiting problems during the home recovery transition. 
Changes in the approach to hospital-to-home transitional care may improve the experience and transition outcomes of older adults and their family support systems. Structured post-discharge follow-up of recently-hospitalized older adults may be more effective if it is driven by individual patient assessment rather than condition-specific protocols. Research findings have shown that involvement of an advanced practice nurse or social worker significantly improves transitional care outcomes. Interventions that include assessment of all elders for discharge readiness and structured follow-up interventions may be particularly beneficial in identifying elder at-risk for poor home recovery transition outcomes (Naylor, 2000; Naylor et al., 2004; Watkins, Hall, \& Kring, 2012). Additionally, telehealth interventions that incorporate inclusion of mobile technologies such as Facebook, tablets, and mobile videoconferencing such as Skype may provide support in post-discharge support.

\section{Education}

During data collection procedures, the principal investigator noted that older adults often stated that they knew "what to do" to care for themselves because they had "done it before." Participants additionally routinely stated that they were "sure" they would be told what care was needed at home prior to leaving the hospital. Because data were collected within four hours of discharge, there is suggestion that the patient education was not interwoven into daily care during the course of the hospitalization.

This study did find that high residual information needs at discharge were correlated with higher rates of post-discharge coping difficulties and lower perceived satisfaction with care transitions. Data from this study support prior findings that diabetes treatment plans frequently change following a hospitalization. Changes in treatment plans may increase the risk for 
medication errors at home and necessitate effective communication between patients, family care providers and the health care team at time of discharge. Because older adults relied upon prior knowledge when organizing post-discharge care, assessments of current home self-management practices are critical. Better understanding of a patient's pre-admission self-care practices, may assist the bedside nurse in developing clear discharge instructions that clarify new or changing elements of care. Consideration must be given to preparing nurses who are effective patient educators and affording time in care delivery models to meet the "survival needs" of high-risk patient populations such as elders with chronic illnesses.

\section{Research}

Qualitative data gathered during the course of this research study provided insight into the specific areas that created problems for patients and caregivers during the immediate and later phases of the home recovery transition. The current focus on prevention of 30-day recidivism fails to address the concerns, trials and difficulties encountered by older adults and their families during this period of heightened vulnerability. There is a need to better understand evolving needs of older adults as they progress through the home recovery transition. This study did provide for proxy response by family care providers. Qualitative data associated with this study suggest that needs of elders and family caregivers may vary and require further study. Replication studies are required.

This research study focused on hospital-to-home transition experiences of older adults with diabetes. In addition to using acute care services, individuals with diabetes also are frequent consumers of skilled rehabilitation care (ADA, 2013b). It can be assumed that older adults leaving these facilities, particularly if they live alone, have residual transition needs. There is an 
absence of literature on the hospital-to-rehabilitation and post-rehabilitation transition experiences of older adults and extensive opportunities for study in this area. The higher rates of dependency observed in older adults with diabetes supports study of the post-hospitalization transitions of older adults who reside in assisted living facilities.

\section{Limitations}

Attrition is a common issue faced in longitudinal studies that include elderly participants. Age, cognitive deficit, frailty, and higher acuity increase the risk of study attrition (Chatfield et al., 2005). Because this study included elders who were recently hospitalized, the risk of attrition was high and, due to changes in discharge disposition, actually presented before several participants had even left the hospital. The study design did incorporate recommendations to reduce attrition in an elderly patient sample and even included the use of a peer interviewer. Because common causes of attrition were rehospitalization, participant-reported changes in health status, and caregiver fatigue, it is possible that findings of this study actually underestimated the prevalence of post-discharge caregiving difficulties in participants with more complex physical conditions or social situations. Attrition potentially contributed to loss of statistical power and may have impacted interpretation of findings. In this exploratory study the risk for a Type II error with the associated failure to recognize a significant relationship was a greater concern.

This study excluded individuals with a documented history of cognitive dysfunction or a medication profile that included agents used to treat dementia. The care and supervisory needs of individuals with cognitive function may well exceed those of unaffected individuals and also may increase the need for support service following discharge. Exclusion of this high-risk 
sample may underestimate the prevalence of post-discharge coping difficulties in recentlydischarged older adults.

Due to the demographic make-up of the research site, there was limited inclusion of nonCaucasian participants in the study. Motivation and resources to provide care to an older adult at home may be partially culturally driven (Quadagno, 2008). Findings could vary in a sample with a different ethnic/cultural distribution. Additionally, socioeconomic indicators such as income, education level and insurance were not evaluated in this study.

The study did not specifically evaluate the type, amount, or duration of home care and potentially did not capture the impact of homecare on discharge outcomes.

\section{Conclusion}

Older adults with chronic health problems such as diabetes are a growing population and nationally experience the highest rates of hospitalization. Multimorbidity impacts over 50\% of adults over the age of 65 and contributes to the complexity of the hospital-to-home transition as the elder attempts to integrate modifications in complicated treatment plans and monitor for evolving changes in diverse health problems. Hospitalization has been described as a series of three sequential transitions in which the patient is particularly vulnerable to medical errors, declines in functional status, and physiologic and social stressors. Elders typically leave the hospital with residual recovery needs and often must elicit the support of family, friends, or formal resources in order to optimize transition outcomes.

Recent changes in hospital reimbursement structures have tied post-discharge transition outcomes to payment. The current focus on readmission and recidivism has led to a national research agenda that attempts to "target” high risk patient populations based upon pre-identified 
risk profiles that are typically condition or disease-focused. The intended outcome of these interventions is decreased costs, reduced service utilization, and limitation of PPR within the first 30 days of discharge. Risk identification strategies have typically utilized large datasets and have given little consideration to the dynamic needs of elders and their family caregivers as they progress through the hospital recovery transition experience. Better understanding of the evolving needs of elders in the early and later stages of transition may assist in identifying elders who are at risk for or in the throes of an unhealthy home recovery transition and developing time-appropriate interventions that address the complexity of individual patients and their families. 


\section{Tables}

Table 1. Home Recovery Transition Variables Defined

\begin{tabular}{|c|c|c|}
\hline \multirow[b]{2}{*}{ Variable } & \multicolumn{2}{|c|}{ Definition } \\
\hline & Conceptual & Operational \\
\hline \multirow{2}{*}{\multicolumn{3}{|c|}{$\begin{array}{l}\text { Personal Transition Conditions } \\
\text { Health Status }\end{array}$}} \\
\hline & & \\
\hline Age & Chronological age & $\begin{array}{l}\text { Documented age on day of } \\
\text { admission }\end{array}$ \\
\hline Admitting diagnosis & $\begin{array}{l}\text { Primary reason for } \\
\text { hospitalization }\end{array}$ & $\begin{array}{l}\text { Documented reason for } \\
\text { admission classified as } \\
\text { cardiovascular, non- } \\
\text { cardiovascular medical, and } \\
\text { surgical }\end{array}$ \\
\hline $\begin{array}{l}\text { History of chronic } \\
\text { health condition }\end{array}$ & $\begin{array}{l}\text { Chronic medical condition for } \\
\text { which the elder is receiving } \\
\text { treatment }\end{array}$ & $\begin{array}{l}\text { Documented medical history } \\
\text { of various chronic illnesses - } \\
\text { each treated individually as } \\
\text { nominal level yes/no variable }\end{array}$ \\
\hline Comorbidity burden & $\begin{array}{l}\text { Combined weighted burden of } \\
\text { illness contributed chronic } \\
\text { health condition }\end{array}$ & $\begin{array}{l}\text { Charleson Comorbidity } \\
\text { Index score }\end{array}$ \\
\hline Multimorbidity profile & $\begin{array}{l}\text { Dyad combinations of } \\
\text { identified chronic health } \\
\text { conditions seen in same } \\
\text { participant }\end{array}$ & $\begin{array}{l}\text { Presence of pre-identified } \\
\text { combinations of chronic } \\
\text { illnesses in one elder as } \\
\text { identified in medical record - } \\
\text { each combination treated as } \\
\text { nominal level yes/no variable }\end{array}$ \\
\hline Functional status & $\begin{array}{l}\text { Ability of elder to self- } \\
\text { perform basic activities of } \\
\text { daily living }\end{array}$ & $\begin{array}{l}\text { Total Katz-ADL score based } \\
\text { on data obtained by } \\
\text { participant self-report }\end{array}$ \\
\hline Readiness for discharge & $\begin{array}{l}\text { Patient-perceived readiness } \\
\text { for hospital discharge }\end{array}$ & $\begin{array}{l}\text { Participant-provided } \\
\text { Readiness for Hospital } \\
\text { Discharge Scale Score }\end{array}$ \\
\hline \multicolumn{3}{|l|}{$\begin{array}{l}\text { Diabetes-related Personal } \\
\text { Factors }\end{array}$} \\
\hline Duration of diabetes & $\begin{array}{l}\text { Time period elder has been } \\
\text { aware of diabetes }\end{array}$ & $\begin{array}{l}\text { Participant-reported duration } \\
\text { of time of known diabetes in } \\
\text { years }\end{array}$ \\
\hline A1c (\%) & $\begin{array}{l}\text { Degree of glycemic control at } \\
\text { time of admission }\end{array}$ & $\begin{array}{l}\text { Recorded lab value in patient } \\
\text { hospital record }\end{array}$ \\
\hline Change in diabetes plan? & $\begin{array}{l}\text { Modifications in diabetes } \\
\text { treatment plan at time of } \\
\text { discharge }\end{array}$ & $\begin{array}{l}\text { Dissimilarities noted between } \\
\text { recorded diabetes plan on } \\
\text { admitting history and } \\
\text { discharge documents - } \\
\text { yes/no }\end{array}$ \\
\hline
\end{tabular}




\begin{tabular}{|c|c|c|}
\hline \multirow[b]{2}{*}{ Variable } & \multicolumn{2}{|c|}{ Definition } \\
\hline & Conceptual & Operational \\
\hline Insulin usage? & $\begin{array}{l}\text { Inclusion of insulin in the } \\
\text { elder's diabetes treatment } \\
\text { plan }\end{array}$ & $\begin{array}{l}\text { Mention of insulin use after } \\
\text { discharge in discharge } \\
\text { documents - yes/no }\end{array}$ \\
\hline Diabetes complication profile & $\begin{array}{l}\text { Total macrovascular and } \\
\text { microvascular disease burden } \\
\text { exacted by diabetes }\end{array}$ & $\begin{array}{l}\text { Diabetes Complication Index } \\
\text { score obtained during patient } \\
\text { interview }\end{array}$ \\
\hline \multicolumn{3}{|l|}{$\begin{array}{l}\text { Hospital-related Transition } \\
\text { Conditions }\end{array}$} \\
\hline Length-of-stay & Duration of hospitalization & $\begin{array}{l}\text { Total days patient was } \\
\text { hospitalized for current } \\
\text { admission as documented in } \\
\text { medical record }\end{array}$ \\
\hline Hospitalist? & $\begin{array}{l}\text { Hospital plan of care directed } \\
\text { by hospital-based physician } \\
\text { rather than elder's usual } \\
\text { provider }\end{array}$ & $\begin{array}{l}\text { Hospitalist is identified as } \\
\text { attending physician in } \\
\text { hospital record - yes/no }\end{array}$ \\
\hline Discharge content needed & $\begin{array}{l}\text { Participant-perceived unmet } \\
\text { informational needs at time of } \\
\text { discharge }\end{array}$ & $\begin{array}{l}\text { Score on Content Needed } \\
\text { subscale of the QDTS }\end{array}$ \\
\hline Discharge content received & $\begin{array}{l}\text { Total discharge-related } \\
\text { information received during } \\
\text { the course of a hospitalization }\end{array}$ & $\begin{array}{l}\text { Score on Content-Received } \\
\text { subscale of the QDTS }\end{array}$ \\
\hline Discharge content delivery & $\begin{array}{l}\text { Participant-perceived } \\
\text { effectiveness of nursing staff } \\
\text { in delivering discharge } \\
\text { education }\end{array}$ & $\begin{array}{l}\text { Score on Content-Delivered } \\
\text { subscale of the QDTS }\end{array}$ \\
\hline Discharge content quality & $\begin{array}{l}\text { Participant-perceived quality } \\
\text { of discharge content and } \\
\text { effectiveness of delivery } \\
\text { during the course of the } \\
\text { hospitalization }\end{array}$ & $\begin{array}{l}\text { Summed total of the Content- } \\
\text { Received and Content- } \\
\text { Delivered subscales of the } \\
\text { QTDS }\end{array}$ \\
\hline \multicolumn{3}{|l|}{ Community Support } \\
\hline Caregiver in home & $\begin{array}{l}\text { Inclusion of an in-residence } \\
\text { support person at the time } \\
\text { discharge }\end{array}$ & $\begin{array}{l}\text { Participant-reports of } \\
\text { anticipated caregiver support } \\
\text { at time of discharge - yes/no }\end{array}$ \\
\hline Home care & $\begin{array}{l}\text { Inclusion of intermittent } \\
\text { skilled home care services at } \\
\text { time of discharge }\end{array}$ & $\begin{array}{l}\text { Indication in case } \\
\text { management note of referral } \\
\text { to home care - yes/no }\end{array}$ \\
\hline \multicolumn{3}{|l|}{ Transition outcomes } \\
\hline Perceived quality of transition & $\begin{array}{l}\text { Patient-perceived quality of } \\
\text { the post-hospitalization } \\
\text { transition }\end{array}$ & $\begin{array}{l}\text { CTM-15 score obtained } 7 \\
\text { days following discharge }\end{array}$ \\
\hline Recidivism 7 day & Event of unplanned provider & Participant report of event of \\
\hline
\end{tabular}




\begin{tabular}{|c|c|c|}
\hline \multirow[b]{2}{*}{ Variable } & \multicolumn{2}{|c|}{ Definition } \\
\hline & Conceptual & Operational \\
\hline & $\begin{array}{l}\text { visit, emergency department } \\
\text { visit or rehospitalization } \\
\text { within } 7 \text { days of discharge }\end{array}$ & $\begin{array}{l}\text { recidivism within } 7 \text { days of } \\
\text { discharge - yes/no }\end{array}$ \\
\hline Recidivism 8 to 30 days & $\begin{array}{l}\text { Event of unplanned provider } \\
\text { visit, emergency department } \\
\text { visit or rehospitalization } \\
\text { during the } 8 \text { to } 10 \text { days } \\
\text { following discharge }\end{array}$ & $\begin{array}{l}\text { Participant report of event of } \\
\text { recidivism within } 8 \text { to } 30 \\
\text { days of discharge - yes/no }\end{array}$ \\
\hline Recidivism 30 days & $\begin{array}{l}\text { Event of unplanned provider } \\
\text { visit, emergency department } \\
\text { visit or rehospitalization } \\
\text { during the }\end{array}$ & $\begin{array}{l}\text { Participant report of } \\
\text { recidivism within } 30 \text { days of } \\
\text { discharge - yes/no }\end{array}$ \\
\hline $\begin{array}{l}\text { Post-discharge coping } \\
\text { difficulty } 7 \text { days }\end{array}$ & $\begin{array}{l}\text { Participant-reported } \\
\text { difficulties encountered } \\
\text { during the first week after } \\
\text { discharge }\end{array}$ & $\begin{array}{l}\text { PDCDS score obtained by } \\
\text { participant interview } 7 \text { days } \\
\text { following discharge }\end{array}$ \\
\hline $\begin{array}{l}\text { Post discharge coping } \\
\text { difficulty } 30 \text { days }\end{array}$ & $\begin{array}{l}\text { Participant-reported } \\
\text { difficulties encountered } \\
\text { during the } 8 \text { to } 30 \text { days } \\
\text { following discharge }\end{array}$ & $\begin{array}{l}\text { PDCDS score obtained by } \\
\text { participant interview } 30 \text { days } \\
\text { following discharge }\end{array}$ \\
\hline Problems with medicines & $\begin{array}{l}\text { Participant-reported } \\
\text { difficulties managing } \\
\text { medications or with } \\
\text { medication side-effects in the } \\
\text { first } 30 \text { days following } \\
\text { discharge }\end{array}$ & $\begin{array}{l}\text { Participant-described } \\
\text { difficulty with medication } \\
\text { management described in } \\
\text { PDCDS free-response } \\
\text { interviews - yes/no }\end{array}$ \\
\hline Problems with glucose control & $\begin{array}{l}\text { Participant-reported } \\
\text { difficulties with glucose } \\
\text { regulation or diabetes } \\
\text { management during the first } \\
30 \text { days following discharge }\end{array}$ & $\begin{array}{l}\text { Participant-described } \\
\text { difficulty with regulation of } \\
\text { glucose or management of } \\
\text { diabetes treatment plan } \\
\text { described in the PDCDS } \\
\text { free-response interviews - } \\
\text { yes/no }\end{array}$ \\
\hline $\begin{array}{l}\text { Problems with other chronic } \\
\text { condition }\end{array}$ & $\begin{array}{l}\text { Participant-reported } \\
\text { difficulties with managing a } \\
\text { chronic condition other than } \\
\text { diabetes during the first } 30 \\
\text { days following discharge }\end{array}$ & $\begin{array}{l}\text { Participant-described } \\
\text { difficulty with managing a } \\
\text { chronic health condition } \\
\text { other than diabetes described } \\
\text { in the PDCDS free-response } \\
\text { interviews - yes/no }\end{array}$ \\
\hline
\end{tabular}


Table 2. General Demographic and Health-Illness Characteristics

\begin{tabular}{lc}
\hline Age & $n=96$ \\
Mean (SD) years & $75.16(5.971)$ \\
Median years & 75.00 \\
64-74 years (\%) & 49.0 \\
$\geq 75$ years (\%) & 51.0 \\
\hline Gender & $n=96$ \\
Female (\%) & 51 \\
Male (\%) & 49 \\
\hline Ethnicity & $n=96$ \\
Asian (\%) & 2.1 \\
Black (\%) & 8.3 \\
Caucasian (\%) & 84.4 \\
Latino (\%) & 5.2 \\
\hline Comorbidity Profile & $n=96$ \\
Coronary artery disease (\%) & 61.5 \\
Chronic kidney disease (\%) & 45.8 \\
Chronic obstructive pulmonary disease (\%) & 22.9 \\
Cerebrovascular disease (\%) & 21.9 \\
Diabetes chronic complication (\%) & 81.3 \\
Foot problems (\%) & 8.3 \\
Heart failure (\%) & 38.5 \\
Malignancy history (\%) & 13.5 \\
Neuropathy (\%) & 57.3 \\
Peripheral vascular disease (\%) & 36.5 \\
\hline Charleson Comorbidity Score & 2.77 \\
Mean (SD) & $(1.762)$ \\
Median & 3 \\
\hline Diabetes Complication Index Score & 2.73 \\
Mean (SD) & $(1.285)$ \\
Median & 3 \\
\hline Minicog Score < 3 (\%) & $6.3 \%$ \\
\hline Katz Index of ADL Score <5 (\%) & $11.4 \%$ \\
\hline Readiness for Hospital Discharge score & $n=96$ \\
Mean (SD) & $186.65(19.64)$ \\
Median & 194.00 \\
Range & $105-210$ \\
\hline
\end{tabular}


Table 3. Multimorbidity Illness Patterns

\begin{tabular}{lcc}
\hline Common multimorbidity dyad combinations $(n=96)$ & $\%$ & Count \\
CAD and HF & 28.1 & 27 \\
CAD and CKD & 30.2 & 29 \\
CAD and COPD & 13.5 & 13 \\
CAD and PVD & 25.0 & 24 \\
CAD and CVD & 16.7 & 16 \\
CAD and neuropathy & 33.3 & 32 \\
HF and CKD & 25.0 & 24 \\
HF and COPD & 10.4 & 10 \\
HF and PVD & 20.8 & 20 \\
HF and CVD & 14.6 & 14 \\
HF and neuropathy & 22.9 & 22 \\
CKD and COPD & 12.5 & 12 \\
CKD and PVD & 25.0 & 24 \\
CKD and CVD & 11.5 & 11 \\
CKD and neuropathy & 28.1 & 27 \\
COPD and neuropathy & 12.5 & 12 \\
PVD and neuropathy & 21.9 & 21 \\
CVD and neuropathy & 11.5 & 11 \\
\hline Diabetes-related complication frequency per participant & $n=96$ & \\
Mean $(S D)$ conditions & $2.678(1.610)$ & \\
Median conditions & 2.0 & 2 \\
0 conditions $(\%, n)$ & 5.2 & 5 \\
1 conditions (\%, $n)$ & 19.8 & 19 \\
2 conditions $(\%, n)$ & 28.1 & 27 \\
3 conditions $(\%, n)$ & 15.6 & 15 \\
4 conditions $(\%, n)$ & 15.6 & 15 \\
5 conditions $(\%, n)$ & 10.4 & 10 \\
6 conditions $(\%, n)$ & 5.2 & 5 \\
\hline
\end{tabular}


Table 4. Diabetes-specific Health Illness Characteristics

\begin{tabular}{lc}
\hline Duration diabetes & $n=95$ \\
Mean (SD) years & $13.58(11.285)$ \\
Median years & 11 \\
Range & $1-49$ years \\
\hline A1c & $n=82$ \\
Mean (SD) \% & $6.857(1.043)$ \\
Median (\%) & 6.7 \\
Range & $5.2-11.7$ \\
$\geq 8 \%(\%)$ & 11.0 \\
\hline Diabetes treatment at discharge & $n=90$ \\
Change in diabetes treatment plan? (\%) & 40.0 \\
Insulin at discharge? (\%) & 35.6 \\
New to insulin? (\%) & 2.2 \\
\hline Number of diabetes-related medications & $n=95$ \\
None (\%) & 2.1 \\
$1(\%)$ & 63.2 \\
$2(\%)$ & 23.2 \\
$3(\%)$ & 11.6 \\
\hline
\end{tabular}


Table 5. Hospitalization-related Transition Conditions

\begin{tabular}{lc}
\hline Length-of-stay & $n=95$ \\
Mean (SD) days & $6.27(3.643)$ \\
Median days & 5.00 \\
Length-of-stay group & \\
$\leq 3$ days (\%, $n)$ & $25.0,24$ \\
4-7 day (\%, $n$ ) & $42.7,41$ \\
$\geq 7$ days (\%, n) & $31.3,30$ \\
Hospitalist provider (\%, n) & $32.3,31$ \\
Admitting diagnosis & $n=96$ \\
Cardiovascular (\%, n) & $34.4,33$ \\
Non-cardiovascular medical (\%, n) & $48.9,47$ \\
Non-cardiovascular surgical (\%, n) & $20.8,20$ \\
\hline Quality of Discharge Teaching Content Needed & $n=96$ \\
Mean (SD) & $9.03(10.681)$ \\
Median & 5.5 \\
Range & $0-47$ \\
Quality of Discharge Teaching Content Received & $n=96$ \\
Mean (SD) & $32.38(14.674)$ \\
Median & 33.50 \\
Range & $1-60$ \\
Quality of Discharge Teaching Delivery & $n=96$ \\
Mean $(S D)$ & $109.95(13.146)$ \\
Median & 112 \\
Range & $55-120$ \\
Quality of Discharge Teaching Total & $n=96$ \\
Mean (SD) & $142.32(23.968)$ \\
Median & 147.50 \\
Range & $56-180$ \\
\hline
\end{tabular}

Table 6. Post-Discharge Support-related Transition Conditions

\begin{tabular}{lcc}
\hline & $n=90$ & \\
Caregiver at home $(\%, n)$ & 80 & 72 \\
Lives alone $(\%, n)$ & 13.3 & 12 \\
Caregiver for another $(\%, n)$ & 6.7 & 6 \\
Homecare at discharge $(\%, n)$ & 48.9 & 44 \\
\hline
\end{tabular}


Table 7. Hospital-to-Home Transition Outcomes

\begin{tabular}{|c|c|c|}
\hline Perceived transition quality & $n=73$ & \\
\hline Mean $(S D)$ & $68.311(20.081)$ & \\
\hline Median & 66.67 & \\
\hline Range & $0-100$ & \\
\hline Post discharge coping difficulty -7 days & $n=73$ & \\
\hline Mean $(S D)$ & $19.23(22.027)$ & \\
\hline Median & 10 & \\
\hline Range & $0-95$ & \\
\hline Post discharge coping difficulty -30 days & $\mathrm{n}=62$ & \\
\hline Mean $(S D)$ & $15.85(21.198)$ & \\
\hline Median & 6.50 & \\
\hline Range & $0-82$ & \\
\hline Difficulty with diabetes control $(\%, n)$ & 38.7 & 29 \\
\hline Difficulty with other chronic health problem $(\%, n)$ & 50.6 & 39 \\
\hline Difficulty with medications $(\%, n)$ & 40.8 & 31 \\
\hline Recidivism - 7 days & $n=83$ & \\
\hline Event of recidivism $(\%, n)$ & 22.9 & 19 \\
\hline Unplanned provider visit $(\%, n)$ & 10.8 & 9 \\
\hline Emergency department visit $(\%, n)$ & 7.2 & 6 \\
\hline Readmission $(\%, n)$ & 9.6 & 8 \\
\hline Recidivism -8 to 30 days & $n=68$ & \\
\hline Event of recidivism $(\%, n)$ & 30.9 & 21 \\
\hline Unplanned provider visit $(\%, n))$ & 16.2 & 11 \\
\hline Emergency department visit $(\%, n)$ & 10.3 & 7 \\
\hline Readmission $(\%, n)$ & 16.2 & 11 \\
\hline Total recidivism 30 days post discharge & $n=73$ & \\
\hline Event of recidivism $(\%, n)$ & 41.1 & 30 \\
\hline Unplanned provider visit $(\%, n)$ & 26.0 & 19 \\
\hline Emergency department visit $(\%, n)$ & 16.4 & 12 \\
\hline Readmission $(\%, n)$ & 21.9 & 16 \\
\hline \multicolumn{3}{|l|}{ Study completion } \\
\hline Enrolled $(n)$ & & 96 \\
\hline Discharged to home after enrollment $(\%, n)$ & 93.8 & 90 \\
\hline Discharge cancelled $(\%, n)$ & 4.2 & 4 \\
\hline Discharge disposition changed $(\%, n)$ & 2.1 & 2 \\
\hline 7-day completion discharged participants $(\%, n)$ & 82.2 & 74 \\
\hline 30-day completion discharged participants $(\%, n)$ & 70.0 & 63 \\
\hline
\end{tabular}


Table 8. Chi $\left(X^{2}\right)$ Analysis of Dichotomous Variables with Recidivism within 7 Days of Hospital Discharge

\begin{tabular}{|c|c|c|c|c|c|c|}
\hline Variable & $X^{2}$ & $\mathrm{df}$ & No Recidivism & Recidivism & Total & $p$ \\
\hline \multicolumn{7}{|c|}{ Age $\geq 75$ years } \\
\hline No & .236 & & 31 (37.3\%) & $8(9.6 \%)$ & $46.9 \%$ & .627 \\
\hline Yes & & & $33(39.8 \%)$ & 11 (13.3\%) & $53.1 \%$ & \\
\hline \multicolumn{7}{|l|}{ Gender } \\
\hline Female & .929 & & $29(34.9 \%)$ & 11 (13.3\%) & $48.2 \%$ & .335 \\
\hline Male & & & $35(42.2 \%)$ & $8(9.6 \%)$ & $51.8 \%$ & \\
\hline \multicolumn{7}{|c|}{$\begin{array}{l}\text { Coronary artery } \\
\text { disease }\end{array}$} \\
\hline No & .030 & & 25 (30.1\%) & $7(8.4 \%)$ & $38.5 \%$ & .861 \\
\hline Yes & & & $39(47.0 \%)$ & 12 (14.5\%) & $61.5 \%$ & \\
\hline \multicolumn{7}{|c|}{ Heart failure } \\
\hline No & .003 & & $40(48.2 \%)$ & 12 (14.5\%) & $62.7 \%$ & .958 \\
\hline Yes & & & $24(28.9 \%)$ & $7(8.4 \%)$ & $37.3 \%$ & \\
\hline \multicolumn{7}{|l|}{ COPD } \\
\hline No & 2.717 & & $52(62.7 \%)$ & 12 (14.5\%) & $77.2 \%$ & .099 \\
\hline Yes & & & $12(14.5 \%)$ & $7(8.4 \%)$ & $22.9 \%$ & \\
\hline \multicolumn{7}{|c|}{ Chronic kidney } \\
\hline No & 3.927 & & $40(48.2 \%)$ & $7(8.4 \%)$ & $52.6 \%$ & .048 \\
\hline Yes & & & 24 (28.9\%) & 12 (14.5\%) & $43.4 \%$ & \\
\hline \multicolumn{7}{|c|}{$\begin{array}{l}\text { Cerebrovascular } \\
\text { disease }\end{array}$} \\
\hline No & & & $50(60.2 \%)$ & 15 (18.1\%) & $78.3 \%$ & 1.000 \\
\hline Yes & & & $14(16.9 \%)$ & $4(4.8 \%)$ & $21.7 \%$ & \\
\hline \multicolumn{7}{|c|}{$\begin{array}{l}\text { Peripheral vascular } \\
\text { disease }\end{array}$} \\
\hline No & & & $40(48.2 \%)$ & 15 (18.1\%) & $66.3 \%$ & .270 \\
\hline Yes & & & 24 (28.9\%) & $4(4.8 \%)$ & $33.7 \%$ & \\
\hline \multicolumn{7}{|c|}{ Neuropathy } \\
\hline No & .160 & & 27 (32.5\%) & $9(10.8 \%)$ & $43.3 \%$ & .689 \\
\hline Yes & & & 37 (44.6\%) & $10(12.0 \%)$ & $56.6 \%$ & \\
\hline \multicolumn{7}{|c|}{$\begin{array}{l}\text { Cardiovascular } \\
\text { admission }\end{array}$} \\
\hline No & .001 & & 44 (53.1\%) & 13 (15.7\%) & $68.8 \%$ & .978 \\
\hline Yes & & & $20(24.1 \%)$ & $6(7.2 \%)$ & $31.3 \%$ & \\
\hline \multicolumn{7}{|c|}{$\begin{array}{l}\text { General medical } \\
\text { admission }\end{array}$} \\
\hline No & & & 48 (57.8\%) & 16 (19.3\%) & $77.1 \%$ & .307 \\
\hline Yes & & & $16(19.3 \%)$ & $3(3.6 \%)$ & $22.9 \%$ & \\
\hline
\end{tabular}




\begin{tabular}{|c|c|c|c|c|c|c|}
\hline Variable & $X^{2}$ & $\mathrm{df}$ & No Recidivism & Recidivism & Total & $p$ \\
\hline \multicolumn{7}{|c|}{ Surgical admission } \\
\hline No & .466 & & 36 (43.4\%) & $9(10.8 \%)$ & $54.2 \%$ & .495 \\
\hline Yes & & & 28 (33.7\%) & 10 (12.0\%) & $45.7 \%$ & \\
\hline \multicolumn{7}{|c|}{ Hospitalist } \\
\hline No & .169 & & 44 (53.1\%) & 14 (16.9\%) & $70 \%$ & .681 \\
\hline Yes & & & $20(24.1 \%)$ & $5(6.0 \%)$ & $30.1 \%$ & \\
\hline \multicolumn{7}{|c|}{$\mathrm{A} 1 \mathrm{c}>8 \%$} \\
\hline No & & & 49 (67.1\%) & 17 (23.3\%) & $90.4 \%$ & .673 \\
\hline Yes & & & $6(8.2 \%)$ & $1(1.4 \%)$ & $9.6 \%$ & \\
\hline \multicolumn{7}{|c|}{$\begin{array}{l}\text { Change in diabetes } \\
\text { plan }\end{array}$} \\
\hline No & .013 & & 38 (45.8\%) & 11 (13.3\%) & $59.1 \%$ & .908 \\
\hline Yes & & & $26(31.3 \%)$ & $8(9.6 \%)$ & $40.9 \%$ & \\
\hline \multicolumn{7}{|c|}{ Insulin at discharge } \\
\hline No & & & 39 (47.0\%) & 15 (18.1\%) & $65.1 \%$ & .179 \\
\hline Yes & & & 25 (30.1\%) & $4(4.8 \%)$ & $34.9 \%$ & \\
\hline \multicolumn{7}{|c|}{ Caregiver in home } \\
\hline No & & & $12(14.5 \%)$ & $2(2.4 \%)$ & $16.9 \%$ & .506 \\
\hline Yes & & & $52(62.7 \%)$ & 17 (20.5\%) & $83.2 \%$ & \\
\hline \multicolumn{7}{|c|}{ Home care } \\
\hline No & .524 & & 31 (37.3\%) & 11 (13.3\%) & $50.6 \%$ & .469 \\
\hline Yes & & & $33(39.8 \%)$ & $8(9.6 \%)$ & $49.4 \%$ & \\
\hline \multicolumn{7}{|c|}{$\begin{array}{l}\text { Difficulty with } \\
\text { medications }\end{array}$} \\
\hline No & .220 & & $36(48.0 \%)$ & $8(10.7 \%)$ & $50.7 \%$ & .639 \\
\hline Yes & & & $24(32.0 \%)$ & $7(9.3 \%)$ & $49.3 \%$ & \\
\hline \multicolumn{7}{|c|}{$\begin{array}{l}\text { Difficulty with } \\
\text { diabetes }\end{array}$} \\
\hline No & .847 & & 38 (51.4\%) & $7(9.5 \%)$ & $61.9 \%$ & .357 \\
\hline Yes & & & 22 (29.7\%) & 7 (9.5\%) & $38.3 \%$ & \\
\hline \multicolumn{7}{|c|}{$\begin{array}{l}\text { Difficulty with other } \\
\text { chronic health } \\
\text { problem }\end{array}$} \\
\hline No & & & 33 (42.9\%) & $4(5.2 \%)$ & $48.1 \%$ & .028 \\
\hline Yes & & & $27(35.1 \%)$ & $13(16.9 \%)$ & $52.0 \%$ & \\
\hline
\end{tabular}


Table 9. Chi $\left(X^{2}\right)$ Analysis of Dichotomous Variables with Recidivism within 8 to 30 Days of Hospital Discharge

\begin{tabular}{|c|c|c|c|c|c|c|}
\hline Variable & $X^{2}$ & $d f$ & No Recidivism & Recidivism & Total & $p$ \\
\hline \multicolumn{7}{|c|}{ Age $\geq 75$ years } \\
\hline No & .215 & 1 & 23 (33.8\%) & 9 (13.3\%) & $47.1 \%$ & .643 \\
\hline Yes & & & 24 (35.3\%) & $12(17.6 \%)$ & $52.9 \%$ & \\
\hline \multicolumn{7}{|l|}{ Gender } \\
\hline Female & .180 & 1 & 25 (36.8\%) & 10 (14.7\%) & $51.5 \%$ & .671 \\
\hline Male & & & 22 (32.4\%) & $11(16.2 \%)$ & $48.6 \%$ & \\
\hline \multicolumn{7}{|c|}{$\begin{array}{l}\text { Coronary artery } \\
\text { disease }\end{array}$} \\
\hline No & 1.540 & 1 & 15 (22.1\%) & $10(14.7 \%)$ & $36.8 \%$ & .215 \\
\hline Yes & & & 32 (47.1\%) & $11(16.2 \%)$ & $63.3 \%$ & \\
\hline \multicolumn{7}{|c|}{ Heart failure } \\
\hline No & 1.993 & 1 & 25 (36.8\%) & 15 (22.1\%) & $58.9 \%$ & .158 \\
\hline Yes & & & 22 (32.4\%) & $6(8.8 \%)$ & $41.2 \%$ & \\
\hline \multicolumn{7}{|l|}{ COPD } \\
\hline No & & & 35 (51.5\%) & 18 (26.5\%) & $78.0 \%$ & .361 \\
\hline Yes & & & 12 (17.6\%) & $3(4.4 \%)$ & $22.0 \%$ & \\
\hline \multicolumn{7}{|c|}{$\begin{array}{l}\text { Chronic kidney } \\
\text { disease }\end{array}$} \\
\hline No & .051 & 1 & 26 (38.2\%) & $11(16.2 \%)$ & $54.4 \%$ & .882 \\
\hline Yes & & & 21 (30.9\%) & $10(14.7 \%)$ & $45.6 \%$ & \\
\hline \multicolumn{7}{|c|}{$\begin{array}{l}\text { Cerebrovascular } \\
\text { disease }\end{array}$} \\
\hline No & .001 & 1 & 36 (52.9\%) & 16 (23.5\%) & $76.4 \%$ & .971 \\
\hline Yes & & & $11(16.2 \%)$ & $5(7.4 \%)$ & $23.6 \%$ & \\
\hline \multicolumn{7}{|c|}{$\begin{array}{l}\text { Peripheral vascular } \\
\text { disease }\end{array}$} \\
\hline No & .601 & 1 & 29 (42.6\%) & 15 (22.1\%) & $64.7 \%$ & .438 \\
\hline Yes & & & $18(26.5 \%)$ & $6(8.8 \%)$ & $35.3 \%$ & \\
\hline \multicolumn{7}{|c|}{ Neuropathy } \\
\hline No & 447 & 1 & 22 (32.4\%) & 8 (11.8\%) & $44.2 \%$ & .504 \\
\hline Yes & & & 25 (36.8\%) & 13 (19.1\%) & $45.9 \%$ & \\
\hline \multicolumn{7}{|c|}{$\begin{array}{l}\text { Cardiovascular } \\
\text { admission }\end{array}$} \\
\hline No & .104 & 1 & 31 (45.6\%) & 13 (19.1\%) & $64.7 \%$ & .747 \\
\hline Yes & & & 16 (23.5\%) & $8(11.8 \%)$ & $35.3 \%$ & \\
\hline \multicolumn{7}{|c|}{$\begin{array}{l}\text { General medical } \\
\text { admission }\end{array}$} \\
\hline No & .054 & 1 & 37 (54.4\%) & 16 (23.5\%) & $77.9 \%$ & .816 \\
\hline Yes & & & 10 (14.7\%) & $5(7.4 \%)$ & $22.1 \%$ & \\
\hline
\end{tabular}




\begin{tabular}{|c|c|c|c|c|c|c|}
\hline Variable & $X^{2}$ & $d f$ & No Recidivism & Recidivism & Total & $p$ \\
\hline \multicolumn{7}{|c|}{ Surgical admission } \\
\hline No & .257 & 1 & 26 (38.2\%) & 13 (19.1\%) & $57.3 \%$ & .612 \\
\hline Yes & & & 21 (30.9\%) & $8(11.8 \%)$ & $42.7 \%$ & \\
\hline \multicolumn{7}{|c|}{ Hospitalist } \\
\hline No & .069 & 1 & 35 (51.5\%) & 15 (22.1\%) & $73.6 \%$ & .793 \\
\hline Yes & & & 12 (17.6\%) & $6(8.8 \%)$ & $26.4 \%$ & \\
\hline \multicolumn{7}{|c|}{$\mathrm{A} 1 \mathrm{c}>8 \%$} \\
\hline No & & & 39 (62.9\%) & $18(29.0 \%)$ & $91.9 \%$ & .654 \\
\hline Yes & & & $3(4.8 \%)$ & $2(3.2 \%)$ & $8.0 \%$ & \\
\hline \multicolumn{7}{|c|}{$\begin{array}{l}\text { Change in diabetes } \\
\text { plan }\end{array}$} \\
\hline No & .051 & 1 & 26 (38.2\%) & $11(16.2 \%)$ & $54.4 \%$ & .822 \\
\hline Yes & & & $21(30.9 \%)$ & $10(14.7 \%)$ & $45.6 \%$ & \\
\hline \multicolumn{7}{|c|}{ Insulin at discharge } \\
\hline No & 1.108 & 1 & 33 (48.5\%) & 12 (17.6\%) & $66.1 \%$ & .293 \\
\hline Yes & & & $14(20.6 \%)$ & $9(13.2 \%)$ & $33.8 \%$ & \\
\hline \multicolumn{7}{|c|}{ Caregiver in home } \\
\hline No & & & $4(5.9 \%)$ & $5(7.4 \%)$ & $13.3 \%$ & .122 \\
\hline Yes & & & $43(63.2 \%)$ & $16(20.6 \%)$ & $83.8 \%$ & \\
\hline \multicolumn{7}{|c|}{ Home care } \\
\hline No & .069 & 1 & 24 (35.3\%) & $10(14.7 \%)$ & $50.0 \%$ & .798 \\
\hline Yes & & & 23 (33.8\%) & $11(16.2 \%)$ & $50.0 \%$ & \\
\hline \multicolumn{7}{|c|}{$\begin{array}{l}\text { Difficulty with } \\
\text { medications }\end{array}$} \\
\hline No & 3.245 & 1 & 30 (44.8\%) & 8 (11.9\%) & $56.7 \%$ & .072 \\
\hline Yes & & & 17 (25.4\%) & 12 (17.9\%) & $43.3 \%$ & \\
\hline \multicolumn{7}{|c|}{$\begin{array}{l}\text { Difficulty with } \\
\text { diabetes }\end{array}$} \\
\hline No & 3.149 & 1 & $32(47.8 \%)$ & $9(13.4 \%)$ & $61.2 \%$ & .076 \\
\hline Yes & & & 15 (22.4\%) & 11 (16.4\%) & $38.8 \%$ & \\
\hline \multicolumn{7}{|c|}{$\begin{array}{l}\text { Difficulty with other } \\
\text { chronic health } \\
\text { problem }\end{array}$} \\
\hline No & & & 27 (39.7\%) & $4(5.9 \%)$ & $45.6 \%$ & .004 \\
\hline Yes & & & $20(29.4 \%)$ & $17(25.0 \%)$ & $54.4 \%$ & \\
\hline
\end{tabular}


Table 10. Chi $\left(X^{2}\right)$ Analysis of Dichotomous Variables with Recidivism within 30 Days of Hospital Discharge

\begin{tabular}{|c|c|c|c|c|c|c|}
\hline Variable & $X^{2}$ & $\mathrm{df}$ & No Recidivism & Recidivism & Total & $p$ \\
\hline \multicolumn{7}{|c|}{ Age $\geq 75$ years } \\
\hline No & \multirow[t]{2}{*}{.557} & \multirow[t]{2}{*}{1} & $21(28.8 \%)$ & 12 (16.4\%) & $45.2 \%$ & \multirow[t]{2}{*}{.455} \\
\hline Yes & & & $22(30.1 \%)$ & 18 (24.7\%) & $54.8 \%$ & \\
\hline \multicolumn{7}{|l|}{ Gender } \\
\hline Female & \multirow[t]{2}{*}{.329} & \multirow[t]{2}{*}{1} & 23 (31.5\%) & 14 (19.2\%) & $50.7 \%$ & \multirow[t]{2}{*}{.566} \\
\hline Male & & & $20(27.4 \%)$ & 16 (21.9\%) & $49.3 \%$ & \\
\hline \multicolumn{7}{|c|}{$\begin{array}{l}\text { Coronary artery } \\
\text { disease }\end{array}$} \\
\hline No & \multirow[t]{2}{*}{.198} & \multirow[t]{2}{*}{1} & 15 (20.5\%) & 12 (16.4\%) & $36.9 \%$ & \multirow[t]{2}{*}{.656} \\
\hline Yes & & & 28 (38.4\%) & 18 (24.7\%) & $63.1 \%$ & \\
\hline \multicolumn{7}{|c|}{ Heart failure } \\
\hline No & \multirow[t]{2}{*}{2.012} & \multirow[t]{2}{*}{1} & $23(31.5 \%)$ & 21 (28.8\%) & $60.3 \%$ & \multirow[t]{2}{*}{.156} \\
\hline Yes & & & 20 (27.4\%) & $9(12.3 \%)$ & $39.7 \%$ & \\
\hline \multicolumn{7}{|l|}{ COPD } \\
\hline No & \multirow[t]{2}{*}{.011} & \multirow[t]{2}{*}{1} & 32 (43.9\%) & 22 (30.1\%) & $74.0 \%$ & \multirow[t]{2}{*}{.917} \\
\hline Yes & & & $11(15.1 \%)$ & $8(11.0 \%)$ & $26.1 \%$ & \\
\hline \multicolumn{7}{|c|}{$\begin{array}{l}\text { Chronic kidney } \\
\text { disease }\end{array}$} \\
\hline No & \multirow[t]{2}{*}{.592} & \multirow[t]{2}{*}{1} & 24 (32.9\%) & 14 (19.2\%) & $52.1 \%$ & \multirow[t]{2}{*}{.441} \\
\hline Yes & & & $19(26.0 \%)$ & 16 (21.9\%) & $47.9 \%$ & \\
\hline \multicolumn{7}{|c|}{$\begin{array}{l}\text { Cerebrovascular } \\
\text { disease }\end{array}$} \\
\hline No & \multirow[t]{2}{*}{.060} & \multirow[t]{2}{*}{1} & 34 (46.6\%) & 23 (31.5\%) & $78.1 \%$ & \multirow[t]{2}{*}{.807} \\
\hline Yes & & & $9(12.3 \%)$ & $7(9.6 \%)$ & $21.9 \%$ & \\
\hline \multicolumn{7}{|c|}{$\begin{array}{l}\text { Peripheral vascular } \\
\text { disease }\end{array}$} \\
\hline No & 4.591 & 1 & 24 (32.9\%) & 24 (32.9\%) & $65.8 \%$ & .032 \\
\hline Yes & & & $19(26.0 \%)$ & $6(8.2 \%)$ & $34.3 \%$ & \\
\hline Neuropat & & & & & & \\
\hline No & .304 & 1 & 20 (27.4\%) & 12 (16.4\%) & $43.8 \%$ & .581 \\
\hline Yes & & & 23 (31.5\%) & 18 (24.7\%) & $56.2 \%$ & \\
\hline $\begin{array}{l}\text { Cardiovas } \\
\text { admissior }\end{array}$ & & & & & & \\
\hline No & .408 & 1 & 27 (37.0\%) & 21 (28.8\%) & $65.8 \%$ & .523 \\
\hline Yes & & & $16(21.9 \%)$ & $9(12.3 \%)$ & $34.3 \%$ & \\
\hline $\begin{array}{l}\text { General n } \\
\text { admissior }\end{array}$ & & & & & & \\
\hline No & .242 & 1 & 35 (47.9\%) & 23 (31.5\%) & $78.9 \%$ & .623 \\
\hline Yes & & & $8(11.0 \%)$ & 7 (10.0\%) & $21.0 \%$ & \\
\hline
\end{tabular}




\begin{tabular}{|c|c|c|c|c|c|c|}
\hline Variable & $X^{2}$ & $\mathrm{df}$ & No Recidivism & Recidivism & Total & $p$ \\
\hline \multicolumn{7}{|c|}{ Surgical admission } \\
\hline No & .044 & 1 & 24 (32.9\%) & 16 (21.9\%) & $54.8 \%$ & .834 \\
\hline Yes & & & 19 (26.0\%) & $14(19.2 \%)$ & $45.2 \%$ & \\
\hline \multicolumn{7}{|c|}{ Hospitalist } \\
\hline No & .961 & 1 & 30 (41.1\%) & 24 (32.9\%) & $74.0 \%$ & .327 \\
\hline Yes & & & 13 (17.8\%) & $6(8.2 \%)$ & $26.0 \%$ & \\
\hline \multicolumn{7}{|c|}{$\mathrm{A} 1 \mathrm{c}>8 \%$} \\
\hline No & & & 35 (53.0\%) & 25 (37.9\%) & $90.9 \%$ & 693 \\
\hline Yes & & & $3(4.5 \%)$ & $3(4.5 \%)$ & $9 \%$ & \\
\hline \multicolumn{7}{|c|}{$\begin{array}{l}\text { Change in diabetes } \\
\text { plan }\end{array}$} \\
\hline No & .005 & 1 & 24 (32.9\%) & 17 (23.3\%) & $56.2 \%$ & .942 \\
\hline Yes & & & $19(26.0 \%)$ & $13(17.8 \%)$ & $43.8 \%$ & \\
\hline \multicolumn{7}{|c|}{ Insulin at discharge } \\
\hline No & .191 & 1 & 28 (38.4\%) & $21(28.8 \%)$ & $67.2 \%$ & .662 \\
\hline Yes & & & 15 (20.5\%) & $9(12.3 \%)$ & $32.8 \%$ & \\
\hline \multicolumn{7}{|c|}{ Caregiver in home** } \\
\hline \multicolumn{7}{|c|}{$\begin{array}{l}\text { Multiple participants } \\
\text { without caregiver } \\
\text { dropped out }\end{array}$} \\
\hline No & & & $3(4.1 \%)$ & $7(9.6 \%)$ & $13.7 \%$ & .080 \\
\hline Yes & & & 40 (54.8\%) & 23 (31.5\%) & $86.3 \%$ & \\
\hline \multicolumn{7}{|c|}{ Home care } \\
\hline No & .592 & 1 & 24 (32.9\%) & $14(19.2 \%)$ & $52.1 \%$ & .441 \\
\hline Yes & & & $19(26.0 \%)$ & 16 (21.9\%) & $47.9 \%$ & \\
\hline \multicolumn{7}{|c|}{$\begin{array}{l}\text { Difficulty with } \\
\text { medications }\end{array}$} \\
\hline No & 4.653 & 1 & 28 (40.6\%) & 10 (14.5\%) & $55.1 \%$ & .031 \\
\hline Yes & & & 15 (21.7\%) & $16(23.2 \%)$ & $44.9 \%$ & \\
\hline \multicolumn{7}{|c|}{$\begin{array}{l}\text { Difficulty with } \\
\text { diabetes }\end{array}$} \\
\hline No & 4.384 & 1 & 30 (44.1\%) & $11(16.2 \%)$ & $60.3 \%$ & .036 \\
\hline Yes & & & 13 (19.1\%) & $14(20.6 \%)$ & $39.7 \%$ & \\
\hline \multicolumn{7}{|c|}{$\begin{array}{l}\text { Difficulty with other } \\
\text { chronic health } \\
\text { problem }\end{array}$} \\
\hline No & 13.830 & 1 & 27 (38.0\%) & $5(7.0 \%)$ & $45.0 \%$ & $<.001$ \\
\hline Yes & & & $16(22.5 \%)$ & $23(32.4 \%)$ & $55.9 \%$ & \\
\hline
\end{tabular}


Table 11. Chi $\left(X^{2}\right)$ Analysis of Dichotomous Variables Associated with Participant-reported Difficulty with Glucose Control or Diabetes Management after Discharge

\begin{tabular}{|c|c|c|c|c|c|c|}
\hline Variable & $X^{2}$ & $\mathrm{df}$ & No Difficulty & Difficulty & Total & $p$ \\
\hline \multicolumn{7}{|c|}{ Age $\geq 75$ years } \\
\hline No & .384 & 1 & $24(32.0 \%)$ & $13(17.3 \%)$ & $49.3 \%$ & .535 \\
\hline Yes & & & 22 (29.3\%) & $16(21.3 \%)$ & $50.6 \%$ & \\
\hline \multicolumn{7}{|l|}{ Gender } \\
\hline Female & .108 & 1 & 22 (29.3\%) & $15(20.0 \%)$ & $49.3 \%$ & .742 \\
\hline Male & & & $24(32.0 \%)$ & $14(18.7 \%)$ & $50.7 \%$ & \\
\hline \multicolumn{7}{|c|}{$\begin{array}{l}\text { Coronary artery } \\
\text { disease }\end{array}$} \\
\hline No & 1.161 & 1 & 20 (26.7\%) & $9(12.0 \%)$ & $38.7 \%$ & .281 \\
\hline Yes & & & $26(34.7 \%)$ & $20(26.7 \%)$ & $61.4 \%$ & \\
\hline \multicolumn{7}{|c|}{ Heart failure } \\
\hline No & 1.920 & 1 & $26(34.7 \%)$ & $21(28.0 \%)$ & $62.7 \%$ & .166 \\
\hline Yes & & & $20(26.7 \%)$ & $8(10.7 \%)$ & $37.4 \%$ & \\
\hline \multicolumn{7}{|l|}{ COPD } \\
\hline No & .014 & 1 & 37 (49.3\%) & $23(30.7 \%)$ & $80.0 \%$ & .906 \\
\hline Yes & & & $9(12.0 \%)$ & $6(8.0 \%)$ & $20.0 \%$ & \\
\hline \multicolumn{7}{|c|}{ Chronic kidney } \\
\hline No & 1.920 & 1 & 23 (30.7\%) & $19(25.3 \%)$ & $56.0 \%$ & .187 \\
\hline Yes & & & 23 (30.7\%) & $10(13.3 \%)$ & $44.0 \%$ & \\
\hline \multicolumn{7}{|c|}{$\begin{array}{l}\text { Cerebrovascular } \\
\text { disease }\end{array}$} \\
\hline No & .105 & 1 & 35 (46.7\%) & $23(30.7 \%)$ & $77.4 \%$ & .745 \\
\hline Yes & & & $11(14.7 \%)$ & $6(8.0 \%)$ & $22.7 \%$ & \\
\hline \multicolumn{7}{|c|}{$\begin{array}{l}\text { Peripheral vascular } \\
\text { disease }\end{array}$} \\
\hline No & 1.047 & 1 & 28 (37.3\%) & $21(28.0 \%)$ & $65.3 \%$ & .306 \\
\hline Yes & & & $18(24.0 \%)$ & 8 (10.7\%) & $34.7 \%$ & \\
\hline \multicolumn{7}{|c|}{ Neuropathy } \\
\hline No & .707 & 1 & 22 (29.3\%) & $11(14.7 \%)$ & $44.0 \%$ & .401 \\
\hline Yes & & & 24 (32.0\%) & $18(24.0 \%)$ & $56.0 \%$ & \\
\hline \multicolumn{7}{|c|}{$\begin{array}{l}\text { Cardiovascular } \\
\text { admission }\end{array}$} \\
\hline No & 1.343 & 1 & 29 (38.7\%) & $22(29.3 \%)$ & $68.0 \%$ & .246 \\
\hline Yes & & & 17 (22.7\%) & 7 (9.3\%) & $32.0 \%$ & \\
\hline \multicolumn{7}{|c|}{$\begin{array}{l}\text { General medical } \\
\text { admission }\end{array}$} \\
\hline No & $<.001$ & 1 & 35 (46.7\%) & 22 (29.3\%) & $76.0 \%$ & .982 \\
\hline Yes & & & $11(14.7 \%)$ & $7(9.3 \%)$ & $24.0 \%$ & \\
\hline
\end{tabular}




\begin{tabular}{|c|c|c|c|c|c|c|}
\hline Variable & $X^{2}$ & $\mathrm{df}$ & No Difficulty & Difficulty & Total & $p$ \\
\hline \multicolumn{7}{|c|}{ Surgical admission } \\
\hline No & 1.145 & 1 & 28 (37.3\%) & $14(18.7 \%)$ & $56.0 \%$ & .285 \\
\hline Yes & & & $18(24.0 \%)$ & $15(20.0 \%)$ & $44.0 \%$ & \\
\hline \multicolumn{7}{|c|}{ Hospitalist } \\
\hline No & 2.715 & 1 & $30(40.0 \%)$ & $24(32.0 \%)$ & $72.0 \%$ & .099 \\
\hline Yes & & & $16(21.3 \%)$ & $5(6.7 \%)$ & $28.0 \%$ & \\
\hline \multicolumn{7}{|c|}{$\mathrm{A} 1 \mathrm{c}>8 \%$} \\
\hline No & & & $36(54.5 \%)$ & $24(36.4 \%)$ & $90.9 \%$ & .682 \\
\hline Yes & & & $3(4.5 \%)$ & $3(4.5 \%)$ & $9.0 \%$ & \\
\hline \multicolumn{7}{|c|}{$\begin{array}{l}\text { Change in diabetes } \\
\text { plan }\end{array}$} \\
\hline No & .608 & 1 & 28 (37.3\%) & $15(20.0 \%)$ & $57.3 \%$ & .435 \\
\hline Yes & & & $18(24.0 \%)$ & $14(18.7 \%)$ & $42.7 \%$ & \\
\hline \multicolumn{7}{|c|}{ Insulin at discharge } \\
\hline No & .164 & 1 & 28 (37.3\%) & $19(25.3 \%)$ & $62.6 \%$ & .685 \\
\hline Yes & & & $18(24.0 \%)$ & $10(13.3 \%)$ & $37.3 \%$ & \\
\hline \multicolumn{7}{|c|}{ Caregiver in home } \\
\hline No & & & $7(9.3 \%)$ & $4(5.3 \%)$ & $14.6 \%$ & 1.000 \\
\hline Yes & & & 39 (52.0\%) & $25(33.3 \%)$ & $85.3 \%$ & \\
\hline \multicolumn{7}{|c|}{ Home care } \\
\hline No & .108 & 1 & 24 (32.0\%) & $14(18.7 \%)$ & $40.7 \%$ & .742 \\
\hline Yes & & & 22 (29.3\%) & $15(20.0 \%)$ & $49.3 \%$ & \\
\hline \multicolumn{7}{|c|}{$\begin{array}{l}\text { Difficulty with } \\
\text { medications }\end{array}$} \\
\hline No & 12.828 & 1 & 35 (46.7\%) & $10(13.3 \%)$ & $60.0 \%$ & $<.001$ \\
\hline Yes & & & $11(14.7 \%)$ & $19(25.3 \%)$ & $40.0 \%$ & \\
\hline \multicolumn{7}{|c|}{$\begin{array}{l}\text { Difficulty with other } \\
\text { chronic health } \\
\text { problem }\end{array}$} \\
\hline No & 16.999 & 1 & 32 (42.7\%) & $6(8.0 \%)$ & $50.7 \%$ & $<.001$ \\
\hline Yes & & & $14(18.7 \%)$ & $23(30.7 \%)$ & $49.4 \%$ & \\
\hline
\end{tabular}


Table 12. Chi $\left(X^{2}\right)$ Analysis of Dichotomous Variables Associated with Participant-reported Difficulty with Management of a Non-diabetes Chronic Illness after Discharge

\begin{tabular}{|c|c|c|c|c|c|c|}
\hline Variable & $X^{2}$ & $\mathrm{df}$ & $\begin{array}{c}\text { No } \\
\text { Difficulty }\end{array}$ & Difficulty & Total & $p$ \\
\hline \multicolumn{7}{|c|}{ Age $\geq 75$ years } \\
\hline No & 1.039 & 1 & $21(27.3 \%)$ & 17 (22.1\%) & $49.4 \%$ & .306 \\
\hline Yes & & & 17 (22.1\%) & 22 (28.6\%) & $50.7 \%$ & \\
\hline \multicolumn{7}{|l|}{ Gender } \\
\hline Female & .118 & 1 & $18(23.4 \%)$ & $20(26.0 \%)$ & $49.4 \%$ & .731 \\
\hline Male & & & $20(26.0 \%)$ & 19 (24.7\%) & $50.7 \%$ & \\
\hline \multicolumn{7}{|c|}{$\begin{array}{l}\text { Coronary artery } \\
\text { disease }\end{array}$} \\
\hline No & 1.052 & 1 & $17(22.1 \%)$ & 13 (16.9\%) & $39.0 \%$ & .305 \\
\hline Yes & & & $21(27.3 \%)$ & $26(33.8 \%)$ & $61.1 \%$ & \\
\hline \multicolumn{7}{|c|}{ Heart failure } \\
\hline No & 2.427 & 1 & 27 (35.1\%) & $21(27.3 \%)$ & $62.4 \%$ & .119 \\
\hline Yes & & & $11(14.3 \%)$ & $18(23.4 \%)$ & $37.7 \%$ & \\
\hline \multicolumn{7}{|l|}{ COPD } \\
\hline No & .046 & 1 & $30(39.0 \%)$ & $30(39.0 \%)$ & $78.0 \%$ & .830 \\
\hline Yes & & & $8(10.4 \%)$ & $9(11.7 \%)$ & $22.1 \%$ & \\
\hline \multicolumn{7}{|c|}{$\begin{array}{l}\text { Chronic kidney } \\
\text { disease }\end{array}$} \\
\hline No & 3.826 & 1 & $25(32.5 \%)$ & 17 (22.1\%) & $54.6 \%$ & .05 \\
\hline Yes & & & 13 (16.9\%) & 22 (28.6\%) & $45.5 \%$ & \\
\hline \multicolumn{7}{|c|}{$\begin{array}{l}\text { Cerebrovascular } \\
\text { disease }\end{array}$} \\
\hline No & 1.725 & 1 & $32(41.6 \%)$ & $28(36.4 \%)$ & $78.0 \%$ & .189 \\
\hline Yes & & & $6(7.8 \%)$ & $11(14.3 \%)$ & $22.1 \%$ & \\
\hline \multicolumn{7}{|c|}{$\begin{array}{l}\text { Peripheral vascular } \\
\text { disease }\end{array}$} \\
\hline No & .640 & 1 & 23 (29.9\%) & 27 (35.1\%) & $65.0 \%$ & .424 \\
\hline Yes & & & 15 (19.5\%) & $12(15.6 \%)$ & $34.1 \%$ & \\
\hline \multicolumn{7}{|c|}{ Neuropathy } \\
\hline No & .128 & 1 & $16(20.8 \%)$ & $18(23.4 \%)$ & $44.2 \%$ & .721 \\
\hline Yes & & & $22(28.6 \%)$ & $21(27.3 \%)$ & $55.9 \%$ & \\
\hline \multicolumn{7}{|c|}{$\begin{array}{l}\text { Cardiovascular } \\
\text { admission }\end{array}$} \\
\hline No & .027 & 1 & $26(33.8 \%)$ & 26 (33.8\%) & $67.6 \%$ & .869 \\
\hline Yes & & & $12(15.6 \%)$ & 13 (16.9\%) & $32.5 \%$ & \\
\hline \multicolumn{7}{|c|}{$\begin{array}{l}\text { General medical } \\
\text { admission }\end{array}$} \\
\hline No & 2.818 & 1 & $26(33.8 \%)$ & 33 (42.9\%) & $76.7 \%$ & .093 \\
\hline Yes & & & $12(15.6 \%)$ & $6(7.8 \%)$ & $23.4 \%$ & \\
\hline
\end{tabular}




\begin{tabular}{|c|c|c|c|c|c|c|}
\hline Variable & $X^{2}$ & $\mathrm{df}$ & $\begin{array}{c}\text { No } \\
\text { Difficulty }\end{array}$ & Difficulty & Total & $p$ \\
\hline \multicolumn{7}{|c|}{ Surgical admission } \\
\hline No & 1.628 & 1 & $24(31.2 \%)$ & $19(24.7 \%)$ & $55.9 \%$ & .202 \\
\hline Yes & & & $14(18.2 \%)$ & $20(26.0 \%)$ & $44.2 \%$ & \\
\hline \multicolumn{7}{|c|}{ Hospitalist } \\
\hline No & 1.821 & 1 & 25 (32.5\%) & 31 (40.3\%) & $72.8 \%$ & .177 \\
\hline Yes & & & $13(16.9 \%)$ & 8 (10.4\%) & $27.3 \%$ & \\
\hline \multicolumn{7}{|l|}{$\mathrm{A} 1 \mathrm{c}>8 \%$} \\
\hline No & & & $28(41.2 \%)$ & 33 (48.5\%) & $89.7 \%$ & 1.000 \\
\hline Yes & & & $3(4.4 \%)$ & $4(5.9 \%)$ & $10.3 \%$ & \\
\hline \multicolumn{7}{|c|}{$\begin{array}{l}\text { Change in diabetes } \\
\text { plan }\end{array}$} \\
\hline No & .017 & 1 & $22(28.6 \%)$ & 22 (28.6\%) & $57.2 \%$ & .895 \\
\hline Yes & & & $16(20.8 \%)$ & $17(22.1 \%)$ & $42.9 \%$ & \\
\hline \multicolumn{7}{|c|}{ Insulin at discharge } \\
\hline No & .105 & 1 & 23 (29.9\%) & 25 (32.5\%) & $62.4 \%$ & .746 \\
\hline Yes & & & $15(19.5 \%)$ & $14(18.2 \%)$ & $37.7 \%$ & \\
\hline \multicolumn{7}{|c|}{ Caregiver in home } \\
\hline No & & & $4(5.2 \%)$ & 7 (9.1\%) & $14.3 \%$ & .517 \\
\hline Yes & & & $34(44.2 \%)$ & 32 (41.6\%) & $85.5 \%$ & \\
\hline \multicolumn{7}{|c|}{ Home care } \\
\hline No & 1.063 & 1 & $22(28.6 \%)$ & 18 (23.4\%) & $52.0 \%$ & .303 \\
\hline Yes & & & $16(20.8 \%)$ & $21(27.3 \%)$ & $48.1 \%$ & \\
\hline \multicolumn{7}{|c|}{$\begin{array}{l}\text { Difficulty with } \\
\text { medications }\end{array}$} \\
\hline No & 19.667 & 1 & 32 (42.1\%) & 13 (17.1\%) & $59.2 \%$ & $<.001$ \\
\hline Yes & & & $6(7.9 \%)$ & 25 (32.9\%) & $40.8 \%$ & \\
\hline \multicolumn{7}{|c|}{$\begin{array}{l}\text { Difficulty with } \\
\text { diabetes control or } \\
\text { management }\end{array}$} \\
\hline No & 16.999 & 1 & $32(42.7 \%)$ & 14 (18.7\%) & $61.4 \%$ & $<.001$ \\
\hline Yes & & & $6(8.0 \%)$ & $23(30.7 \%)$ & $38.7 \%$ & \\
\hline
\end{tabular}


Table 13. Chi $\left(X^{2}\right)$ Analysis of Dichotomous Variables Associated with Participant-reported Difficulty with Medication Management

\begin{tabular}{|c|c|c|c|c|c|c|}
\hline Variable & $X^{2}$ & $\mathrm{df}$ & No Difficulty & Difficulty & Total & $p$ \\
\hline \multicolumn{7}{|c|}{ Age $\geq 75$ years } \\
\hline No & \multirow[t]{2}{*}{.002} & \multirow[t]{2}{*}{1} & 22 (28.9\%) & $15(19.7 \%)$ & $48.6 \%$ & \multirow[t]{2}{*}{.966} \\
\hline Yes & & & $23(30.3 \%)$ & $16(21.1 \%)$ & $51.4 \%$ & \\
\hline \multicolumn{7}{|l|}{ Gender } \\
\hline Female & \multirow[t]{2}{*}{.180} & \multirow[t]{2}{*}{1} & $21(27.6 \%)$ & $16(21.1 \%)$ & $48.7 \%$ & \multirow[t]{2}{*}{.672} \\
\hline Male & & & $24(31.6 \%)$ & $15(19.7 \%)$ & $51.3 \%$ & \\
\hline \multicolumn{7}{|c|}{$\begin{array}{l}\text { Coronary artery } \\
\text { disease }\end{array}$} \\
\hline No & \multirow[t]{2}{*}{3.385} & \multirow[t]{2}{*}{1} & $21(27.6 \%)$ & 8 (10.5\%) & $38.1 \%$ & \multirow[t]{2}{*}{.066} \\
\hline Yes & & & $24(31.6 \%)$ & $23(30.3 \%)$ & $61.9 \%$ & \\
\hline \multicolumn{7}{|c|}{ Heart failure } \\
\hline No & \multirow[t]{2}{*}{.317} & \multirow[t]{2}{*}{1} & 29 (38.2\%) & $18(23.7 \%)$ & $61.9 \%$ & \multirow[t]{2}{*}{.574} \\
\hline Yes & & & $16(21.1 \%)$ & $13(17.1 \%)$ & $38.3 \%$ & \\
\hline \multicolumn{7}{|l|}{ COPD } \\
\hline No & \multirow[t]{2}{*}{.074} & \multirow[t]{2}{*}{1} & 36 (47.4\%) & $24(31.6 \%)$ & $79.0 \%$ & \multirow[t]{2}{*}{.786} \\
\hline Yes & & & $9(11.8 \%)$ & $7(9.2 \%)$ & $21 \%$ & \\
\hline \multicolumn{7}{|c|}{$\begin{array}{l}\text { Chronic kidney } \\
\text { disease }\end{array}$} \\
\hline No & \multirow[t]{2}{*}{.004} & \multirow[t]{2}{*}{1} & 25 (32.9\%) & $17(22.4 \%)$ & $55.3 \%$ & \multirow[t]{2}{*}{.951} \\
\hline Yes & & & 20 (26.3\%) & $14(18.4 \%)$ & $44.7 \%$ & \\
\hline \multicolumn{7}{|c|}{$\begin{array}{l}\text { Cerebrovascular } \\
\text { disease }\end{array}$} \\
\hline No & \multirow[t]{2}{*}{.356} & \multirow[t]{2}{*}{1} & 36 (47.4\%) & $23(30.3 \%)$ & $77.7 \%$ & \multirow[t]{2}{*}{.551} \\
\hline Yes & & & $9(11.8 \%)$ & $8(10.5 \%)$ & $22.3 \%$ & \\
\hline \multicolumn{7}{|c|}{$\begin{array}{l}\text { Peripheral vascular } \\
\text { disease }\end{array}$} \\
\hline No & .964 & 1 & 27 (35.5\%) & 22 (28.9\%) & $64.4 \%$ & .326 \\
\hline Yes & & & 18 (23.7\%) & $9(11.8 \%)$ & $35.5 \%$ & \\
\hline Neuropat & & & & & & \\
\hline No & .004 & 1 & $20(26.3 \%)$ & $14(18.4 \%)$ & $44.7 \%$ & .951 \\
\hline Yes & & & 25 (32.9\%) & $17(22.4 \%)$ & $55.3 \%$ & \\
\hline $\begin{array}{l}\text { Cardiovas } \\
\text { admissior }\end{array}$ & & & & & & \\
\hline No & .010 & 1 & 30 (39.5\%) & $21(27.6 \%)$ & $67.1 \%$ & .922 \\
\hline Yes & & & 15 (19.7\%) & $10(13.2 \%)$ & $22.9 \%$ & \\
\hline $\begin{array}{l}\text { General n } \\
\text { admissior }\end{array}$ & & & & & & \\
\hline No & & & $31(40.8 \%)$ & 27 (35.5\%) & $76.3 \%$ & .088 \\
\hline Yes & & & 14 (18.4\%) & $4(5.3 \%)$ & $23.7 \%$ & \\
\hline
\end{tabular}




\begin{tabular}{|c|c|c|c|c|c|c|}
\hline Variable & $X^{2}$ & $\mathrm{df}$ & No Difficulty & Difficulty & Total & $p$ \\
\hline \multicolumn{7}{|c|}{ Surgical admission } \\
\hline No & 2.778 & 1 & 29 (38.2\%) & $14(18.4 \%)$ & $56.6 \%$ & .191 \\
\hline Yes & & & $16(21.1 \%)$ & $17(22.4 \%)$ & $43.5 \%$ & \\
\hline \multicolumn{7}{|c|}{ Hospitalist } \\
\hline No & & & $28(36.8 \%)$ & 27 (35.5\%) & $72.1 \%$ & .020 \\
\hline Yes & & & 17 (22.4\%) & $4(5.3 \%)$ & $27.8 \%$ & \\
\hline \multicolumn{7}{|c|}{$\mathrm{A} 1 \mathrm{c}>8 \%$} \\
\hline No & & & 34 (50.7\%) & $26(38.8 \%)$ & $89.5 \%$ & .692 \\
\hline Yes & & & $3(4.5 \%)$ & $4(6.0 \%)$ & $10.5 \%$ & \\
\hline \multicolumn{7}{|c|}{$\begin{array}{l}\text { Change in diabetes } \\
\text { plan }\end{array}$} \\
\hline No & 1.941 & 1 & $29(38.2 \%)$ & 15 (19.7\%) & $57.9 \%$ & .164 \\
\hline Yes & & & $16(21.1 \%)$ & $16(21.1 \%)$ & $42.2 \%$ & \\
\hline \multicolumn{7}{|c|}{ Insulin at discharge } \\
\hline No & .159 & 1 & 27 (35.5\%) & $20(26.3 \%)$ & $61.8 \%$ & .690 \\
\hline Yes & & & $18(23.7 \%)$ & $11(14.5 \%)$ & $38.2 \%$ & \\
\hline \multicolumn{7}{|c|}{ Caregiver in home } \\
\hline No & .116 & 1 & $6(7.9 \%)$ & $5(6.6 \%)$ & $14.5 \%$ & .734 \\
\hline Yes & & & 39 (51.3\%) & $26(34.2 \%)$ & $85.5 \%$ & \\
\hline \multicolumn{7}{|c|}{ Home care } \\
\hline No & .002 & 1 & 23 (30.3\%) & $16(21.1 \%)$ & $51.4 \%$ & .966 \\
\hline Yes & & & 22 (28.9\%) & $15(19.7 \%)$ & $48.6 \%$ & \\
\hline \multicolumn{7}{|c|}{$\begin{array}{l}\text { Difficulty with } \\
\text { diabetes control or } \\
\text { management }\end{array}$} \\
\hline No & 12.828 & 1 & 35 (46.7\%) & $11(14.7 \%)$ & $61.4 \%$ & $<.001$ \\
\hline Yes & & & $10(13.3 \%)$ & $19(25.3 \%)$ & $38.6 \%$ & \\
\hline \multicolumn{7}{|c|}{$\begin{array}{l}\text { Difficulty with } \\
\text { managing other } \\
\text { chronic health } \\
\text { problem }\end{array}$} \\
\hline No & 19.667 & 1 & 32 (42.1\%) & $6(7.9 \%)$ & $50.0 \%$ & $<.001$ \\
\hline Yes & & & $13(17.1 \%)$ & 25 (32.9\%) & $50.0 \%$ & \\
\hline
\end{tabular}


Table 14. $t$ tests of Continuous Variables Associated with Recidivism in First 30 Days Following Discharge

\begin{tabular}{|c|c|c|c|c|c|c|}
\hline Variable & $\begin{array}{c}\text { No Event } \\
\text { Recidivism }\end{array}$ & $\begin{array}{c}\text { Event } \\
\text { Recidivism }\end{array}$ & Sample & $t$ & $\mathrm{df}$ & $p$ \\
\hline \multicolumn{7}{|l|}{ Age } \\
\hline$n$ & 43 & 30 & 90 & -1.275 & 71 & .206 \\
\hline Mean years & 74.91 & 76.63 & 75.14 & & & \\
\hline$S D$ & 5.149 & 6.392 & 6.068 & & & \\
\hline Median & & & 75.0 & & & \\
\hline Range & & & $65-60$ & & & \\
\hline \multicolumn{7}{|c|}{$\begin{array}{l}\text { Total diabetes-related chronic } \\
\text { complications }\end{array}$} \\
\hline$n$ & 43 & 30 & 90 & .700 & 71 & .486 \\
\hline Mean & 2.84 & 2.57 & 2.64 & & & \\
\hline$S D$ & 1.758 & 1.406 & 1.560 & & & \\
\hline Median & & & 2.0 & & & \\
\hline Range & & & $0-6$ & & & \\
\hline \multicolumn{7}{|l|}{ Length-of-stay } \\
\hline$n$ & 43 & 30 & 90 & .353 & 71 & .725 \\
\hline Mean days & 6.44 & 6.13 & 6.16 & & & \\
\hline$S D$ & 3.990 & 3.170 & 3.636 & & & \\
\hline Median & & & 5.0 & & & \\
\hline Range & & & $2-18$ & & & \\
\hline \multicolumn{7}{|c|}{ Perceived discharge readiness } \\
\hline$n$ & 43 & 30 & 90 & 2.274 & 48 & .028 \\
\hline Mean & 193.44 & 183.93 & 187.88 & & & \\
\hline$S D$ & 13.707 & 19.856 & 19.286 & & & \\
\hline Median & & & 195.00 & & & \\
\hline Range & & & $105-210$ & & & \\
\hline \multicolumn{7}{|c|}{$\begin{array}{l}\text { Quality of discharge teaching - } \\
\text { content needed }\end{array}$} \\
\hline$n$ & 43 & 30 & 90 & -.397 & 71 & .693 \\
\hline Mean & 8.86 & 9.93 & 8.78 & & & \\
\hline$S D$ & 11.865 & 10.583 & 10.707 & & & \\
\hline Median & & & 5 & & & \\
\hline Range & & & $0-47$ & & & \\
\hline \multicolumn{7}{|c|}{$\begin{array}{l}\text { Quality of discharge teaching - } \\
\text { content received }\end{array}$} \\
\hline$n$ & 43 & 30 & 90 & .845 & 71 & .401 \\
\hline Mean & 34.84 & 31.90 & 32.71 & & & \\
\hline$S D$ & 14.284 & 15.073 & 14.761 & & & \\
\hline Median & & & 35.00 & & & \\
\hline Range & & & $1-60$ & & & \\
\hline
\end{tabular}




\begin{tabular}{|c|c|c|c|c|c|c|}
\hline Variable & $\begin{array}{c}\text { No Event } \\
\text { Recidivism }\end{array}$ & $\begin{array}{c}\text { Event } \\
\text { Recidivism }\end{array}$ & Sample & $t$ & df & $p$ \\
\hline \multicolumn{7}{|l|}{ Quality of discharge teaching - } \\
\hline$n$ & 113.53 & 109.80 & 110.28 & & & \\
\hline Mean & 7.601 & 14.361 & 13.334 & & & \\
\hline$S D$ & & & 112.50 & & & \\
\hline Median & & & $55-120$ & & & \\
\hline Range & & & & & & \\
\hline \multicolumn{7}{|l|}{$\begin{array}{l}\text { Quality of discharge teaching - } \\
\text { total }\end{array}$} \\
\hline$n$ & 43 & 30 & 90 & 1.264 & 46 & .245 \\
\hline Mean & 148.37 & 141.70 & 142.99 & & & \\
\hline$S D$ & 17.931 & 27.207 & 24.148 & & & \\
\hline Median & & & 148.0 & & & \\
\hline Range & & & $56-180$ & & & \\
\hline \multicolumn{7}{|l|}{ Perceived discharge quality } \\
\hline$n$ & 43 & 25 & 73 & 1.661 & 66 & .101 \\
\hline Mean & 71.18 & 62.90 & 68.31 & & & \\
\hline$S D$ & 18.636 & 21.786 & 20.08 & & & \\
\hline Median & & & 66.67 & & & \\
\hline Range & & & $0-100$ & & & \\
\hline \multicolumn{7}{|l|}{$\begin{array}{l}\text { Post-discharge coping } \\
\text { difficulty - } \\
7 \text { days }\end{array}$} \\
\hline$n$ & 43 & 23 & 73 & -1.071 & 64 & .288 \\
\hline Mean & 17.93 & 24.26 & 19.23 & & & \\
\hline$S D$ & 20.832 & 26.329 & 22.027 & & & \\
\hline Median & & & 10.00 & & & \\
\hline Range & & & $0-95$ & & & \\
\hline \multicolumn{7}{|l|}{$\begin{array}{l}\text { Post-discharge coping } \\
\text { difficulty - } 30 \text { days }\end{array}$} \\
\hline$n$ & 41 & 22 & 63 & -3.363 & 24.7 & .003 \\
\hline Mean & 8.98 & 30.14 & 16.37 & & & \\
\hline$S D$ & 11.376 & 28.317 & 21.412 & & & \\
\hline Median & & & 6.5 & & & \\
\hline Range & & & $0-82$ & & & \\
\hline
\end{tabular}


Table 15. $t$ tests of Continuous Variables Associated with Difficulties Managing Medications

\begin{tabular}{|c|c|c|c|c|c|}
\hline Variable & $\begin{array}{c}\text { No } \\
\text { Difficulty }\end{array}$ & $\begin{array}{c}\text { Yes } \\
\text { Difficulty }\end{array}$ & $t$ & $\mathrm{df}$ & $p$ \\
\hline \multicolumn{6}{|l|}{ Age } \\
\hline$n$ & 45 & 31 & -1.561 & 74 & .124 \\
\hline Mean years & 74.09 & 76.23 & & & \\
\hline$S D$ & 5.304 & 6.607 & & & \\
\hline \multicolumn{6}{|c|}{$\begin{array}{l}\text { Total diabetes-related chronic } \\
\text { complications }\end{array}$} \\
\hline$n$ & 38 & 40 & -1.604 & 76 & .113 \\
\hline Mean & 2.37 & 2.95 & & & \\
\hline$S D$ & 1.584 & 1.616 & & & \\
\hline \multicolumn{6}{|l|}{ Length-of-stay } \\
\hline$n$ & 45 & 31 & -1.284 & 74 & .203 \\
\hline Mean days & 5.69 & 6.74 & & & \\
\hline$S D$ & 3.496 & 3.540 & & & \\
\hline \multicolumn{6}{|c|}{ Perceived discharge readiness } \\
\hline$n$ & 45 & 31 & 1.072 & 50.8 & .289 \\
\hline Mean & 192.42 & 188.19 & & & \\
\hline$S D$ & 13.529 & 18.885 & & & \\
\hline \multicolumn{6}{|c|}{$\begin{array}{l}\text { Quality of discharge teaching - } \\
\text { content needed }\end{array}$} \\
\hline$n$ & 38 & 40 & -1.889 & 63.9 & .063 \\
\hline Mean & 6.63 & 11.23 & & & \\
\hline$S D$ & 7.76 & 13.15 & & & \\
\hline \multicolumn{6}{|c|}{$\begin{array}{l}\text { Quality of discharge teaching - } \\
\text { content received }\end{array}$} \\
\hline$n$ & 45 & 31 & 1.011 & 74 & .315 \\
\hline Mean & 113.24 & 110.13 & & & \\
\hline$S D$ & 6.238 & 14.984 & & & \\
\hline \multicolumn{6}{|c|}{$\begin{array}{l}\text { Quality of discharge teaching - } \\
\text { delivery }\end{array}$} \\
\hline$n$ & 45 & 31 & 1.094 & 37.23 & .281 \\
\hline Mean & 35.16 & 31.71 & & & \\
\hline$S D$ & 12.238 & 17.510 & & & \\
\hline \multicolumn{6}{|c|}{ Quality of discharge teaching - total } \\
\hline$n$ & 45 & 31 & 1.168 & 42.57 & .249 \\
\hline Mean & 148.40 & 141.84 & & & \\
\hline$S D$ & 15.660 & 28.447 & & & \\
\hline \multicolumn{6}{|c|}{ Perceived discharge quality } \\
\hline$n$ & 43 & 30 & 2.123 & 71 & .037 \\
\hline Mean & 72.38 & 62.48 & & & \\
\hline$S D$ & 18.25 & 21.41 & & & \\
\hline
\end{tabular}




\begin{tabular}{|c|c|c|c|c|c|}
\hline Variable & $\begin{array}{c}\text { No } \\
\text { Difficulty }\end{array}$ & $\begin{array}{c}\text { Yes } \\
\text { Difficulty }\end{array}$ & $t$ & $\mathrm{df}$ & $p$ \\
\hline \multicolumn{6}{|c|}{$\begin{array}{l}\text { Post-discharge coping difficulty - } \\
7 \text { days }\end{array}$} \\
\hline$n$ & 43 & 28 & -2.429 & 59 & .018 \\
\hline Mean & 15.01 & 26.75 & & & \\
\hline$S D$ & 19.519 & 24.431 & & & \\
\hline \multicolumn{6}{|c|}{$\begin{array}{l}\text { Post-discharge coping difficulty - } 30 \\
\text { days }\end{array}$} \\
\hline$n$ & 34 & 29 & & & \\
\hline Mean & 9.18 & 24.79 & -2.461 & 49 & .018 \\
\hline$S D$ & 18.195 & 22.107 & & & \\
\hline
\end{tabular}


Table 16. $t$ tests of Continuous Variables Associated with Difficulties Controlling or Managing Diabetes

\begin{tabular}{|c|c|c|c|c|c|}
\hline Variable & $\begin{array}{c}\text { No } \\
\text { Difficulty }\end{array}$ & $\begin{array}{c}\text { Yes } \\
\text { Difficulty }\end{array}$ & $t$ & $\mathrm{df}$ & $p$ \\
\hline \multicolumn{6}{|l|}{ Age } \\
\hline$n$ & 46 & 29 & -.234 & 72 & .816 \\
\hline Mean years & 74.74 & 75.07 & & & \\
\hline$S D$ & 5.98 & 5.89 & & & \\
\hline \multicolumn{6}{|c|}{$\begin{array}{l}\text { Total diabetes-related chronic } \\
\text { complications }\end{array}$} \\
\hline$n$ & 46 & 29 & .512 & .73 & .610 \\
\hline Mean & 2.72 & 2.52 & & & \\
\hline$S D$ & 1.72 & 1.53 & & & \\
\hline \multicolumn{6}{|l|}{ Length-of-stay } \\
\hline$n$ & 46 & 29 & -.233 & 73 & .816 \\
\hline Mean days & 6.04 & 6.24 & & & \\
\hline$S D$ & 4.38 & 3.729 & & & \\
\hline \multicolumn{6}{|c|}{ Perceived discharge readiness } \\
\hline$n$ & 46 & 29 & .269 & 73 & .789 \\
\hline Mean & 190.96 & 189.93 & & & \\
\hline$S D$ & 14.919 & 17.844 & & & \\
\hline \multicolumn{6}{|c|}{$\begin{array}{l}\text { Quality of discharge teaching - content } \\
\text { needed }\end{array}$} \\
\hline$n$ & 46 & 29 & .047 & 73 & .962 \\
\hline Mean & 9.20 & 9.07 & & & \\
\hline$S D$ & 11.09 & 11.51 & & & \\
\hline \multicolumn{6}{|c|}{$\begin{array}{l}\text { Quality of discharge teaching - content } \\
\text { received }\end{array}$} \\
\hline$n$ & 46 & 29 & .347 & 73 & .730 \\
\hline Mean & 34 & 32.79 & & & \\
\hline$S D$ & 14.48 & 14.82 & & & \\
\hline \multicolumn{6}{|c|}{ Quality of discharge teaching - delivery } \\
\hline$n$ & 46 & 29 & 1.287 & 73 & .202 \\
\hline Mean & 113.13 & 109.86 & & & \\
\hline$S D$ & 6.52 & 15.19 & & & \\
\hline \multicolumn{6}{|c|}{ Quality of discharge teaching - total } \\
\hline$n$ & 46 & 29 & .863 & 73 & .391 \\
\hline Mean & 147.13 & 142.66 & & & \\
\hline$S D$ & 18.69 & 26.181 & & & \\
\hline \multicolumn{6}{|c|}{ Perceived discharge quality } \\
\hline$n$ & 44 & 29 & .793 & 71 & .431 \\
\hline Mean & 69.82 & 66.0 & & & \\
\hline$S D$ & 18.16 & 22.83 & & & \\
\hline
\end{tabular}




\begin{tabular}{|c|c|c|c|c|c|}
\hline Variable & $\begin{array}{c}\text { No } \\
\text { Difficulty }\end{array}$ & $\begin{array}{c}\text { Yes } \\
\text { Difficulty }\end{array}$ & $t$ & $\mathrm{df}$ & $p$ \\
\hline \multicolumn{6}{|c|}{$\begin{array}{l}\text { Post-discharge coping difficulty - } \\
7 \text { days }\end{array}$} \\
\hline$n$ & 42 & 29 & -2.798 & 59 & .007 \\
\hline Mean & 14.00 & 19.248 & & & \\
\hline$S D$ & 27.83 & 23.888 & & & \\
\hline \multicolumn{6}{|c|}{$\begin{array}{l}\text { Post-discharge coping difficulty - } 30 \\
\text { days }\end{array}$} \\
\hline$n$ & 38 & 25 & -3.170 & 47 & .003 \\
\hline Mean & 8.76 & 27.92 & & & \\
\hline$S D$ & 16.26 & 23.74 & & & \\
\hline
\end{tabular}


Table 17. $t$ tests of Continuous Variables Associated with Difficulties Managing Other Chronic Illness

\begin{tabular}{|c|c|c|c|c|c|}
\hline Variable & $\begin{array}{c}\text { No } \\
\text { Difficulty }\end{array}$ & $\begin{array}{c}\text { Yes } \\
\text { Difficulty }\end{array}$ & $t$ & $\mathrm{df}$ & $p$ \\
\hline \multicolumn{6}{|l|}{ Age } \\
\hline$n$ & 36 & 40 & -.889 & 76 & .377 \\
\hline Mean years & 74.26 & 75.45 & & & \\
\hline$S D$ & 5.37 & 6.36 & & & \\
\hline \multicolumn{6}{|c|}{$\begin{array}{l}\text { Total diabetes-related chronic } \\
\text { complications }\end{array}$} \\
\hline$n$ & 38 & 40 & -1.604 & 76 & .113 \\
\hline Mean & 2.37 & 2.95 & & & \\
\hline$S D$ & 1.58 & 1.62 & & & \\
\hline \multicolumn{6}{|l|}{ Length-of-stay } \\
\hline$n$ & 38 & 40 & -1.376 & 76 & .173 \\
\hline Mean days & 5.61 & 6.73 & & & \\
\hline$S D$ & 3.48 & 3.70 & & & \\
\hline \multicolumn{6}{|c|}{ Perceived discharge readiness } \\
\hline$n$ & 38 & 40 & 1.942 & 66.3 & .056 \\
\hline Mean & 193.63 & 186.60 & & & \\
\hline$S D$ & 12.124 & 192.24 & & & \\
\hline \multicolumn{6}{|c|}{$\begin{array}{l}\text { Quality of discharge teaching - content } \\
\text { needed }\end{array}$} \\
\hline$n$ & 38 & 40 & -1.889 & 63.9 & .063 \\
\hline Mean & 6.63 & 11.23 & & & \\
\hline$S D$ & 7.78 & 13.15 & & & \\
\hline \multicolumn{6}{|c|}{$\begin{array}{l}\text { Quality of discharge teaching - content } \\
\text { received }\end{array}$} \\
\hline$n$ & 38 & 40 & -.307 & 76 & .758 \\
\hline Mean & 33.26 & 34.28 & & & \\
\hline$S D$ & 13.27 & 15.62 & & & \\
\hline \multicolumn{6}{|c|}{ Quality of discharge teaching - delivery } \\
\hline Mean & 38 & 40 & 1.266 & 55.4 & .203 \\
\hline \multirow[t]{2}{*}{$S D$} & 113.63 & 110.60 & & & \\
\hline & 6.19 & 13.462 & & & \\
\hline \multicolumn{6}{|c|}{$\begin{array}{l}\text { Quality of discharge teaching - total } \\
n\end{array}$} \\
\hline Mean & 38 & 40 & .411 & .76 & .683 \\
\hline \multirow[t]{2}{*}{$S D$} & 146.89 & 144.98 & & & \\
\hline & 16.25 & 25.86 & & & \\
\hline
\end{tabular}




\begin{tabular}{|c|c|c|c|c|c|}
\hline Variable & $\begin{array}{c}\text { No } \\
\text { Difficulty }\end{array}$ & $\begin{array}{c}\text { Yes } \\
\text { Difficulty }\end{array}$ & $t$ & $\mathrm{df}$ & $p$ \\
\hline Perceived discharge quality & 36 & 37 & .673 & 71 & .503 \\
\hline$n$ & 69.92 & 66.74 & & & \\
\hline Mean & 18.76 & 21.43 & & & \\
\hline$S D$ & & & & & \\
\hline \multirow{2}{*}{\multicolumn{6}{|c|}{$\begin{array}{l}\text { Post-discharge coping difficulty - } \\
7 \text { days }\end{array}$}} \\
\hline & & & & & \\
\hline$n$ & 37 & 34 & -2.457 & 59 & .017 \\
\hline Mean & 13.03 & 26.85 & & & \\
\hline$S D$ & 17.08 & 24.96 & & & \\
\hline \multicolumn{6}{|c|}{$\begin{array}{l}\text { Post-discharge coping difficulty - } 30 \\
\text { days }\end{array}$} \\
\hline$n$ & 29 & 34 & -2.391 & 47 & .021 \\
\hline Mean & 8.59 & 23.00 & & & \\
\hline$S D$ & 15.70 & 23.532 & & & \\
\hline
\end{tabular}


Table 18. Bivariate Correlations of Continuous Transition-Related Variables

\begin{tabular}{|c|c|c|c|c|c|c|c|}
\hline & Readiness & $\begin{array}{c}\text { Discharge } \\
\text { Content } \\
\text { Needed }\end{array}$ & $\begin{array}{c}\text { Discharge } \\
\text { Content } \\
\text { Received }\end{array}$ & $\begin{array}{c}\text { Quality } \\
\text { Content } \\
\text { Delivered }\end{array}$ & $\begin{array}{c}\text { Quality } \\
\text { Discharge } \\
\text { Teaching } \\
\text { Total }\end{array}$ & $\begin{array}{c}\text { Perceived } \\
\text { Transition } \\
\text { Quality }\end{array}$ & $\begin{array}{c}\text { Post } \\
\text { Discharge } \\
\text { Coping } \\
\text { Difficulty } \\
7 \text { day }\end{array}$ \\
\hline \multicolumn{8}{|l|}{ Discharge } \\
\hline \multirow{2}{*}{\multicolumn{8}{|c|}{$\begin{array}{l}\text { Content } \\
\text { Needed }\end{array}$}} \\
\hline & & & & & & & \\
\hline$r$ & -.314 & & & & & & \\
\hline$p$ & .003 & & & & & & \\
\hline$n$ & 90 & & & & & & \\
\hline \multicolumn{8}{|l|}{ Discharge } \\
\hline \multicolumn{8}{|l|}{ Content } \\
\hline \multicolumn{8}{|l|}{ Received } \\
\hline$r$ & .258 & .263 & & & & & \\
\hline$p$ & .014 & .012 & & & & & \\
\hline$n$ & 90 & 90 & & & & & \\
\hline \multicolumn{8}{|l|}{ Quality } \\
\hline \multicolumn{8}{|l|}{ Content } \\
\hline \multicolumn{8}{|l|}{ Delivered } \\
\hline$r$ & .556 & -.055 & 475 & & & & \\
\hline$p$ & $<.001$ & .604 & $<.001$ & & & & \\
\hline$n$ & 90 & 90 & 90 & & & & \\
\hline \multicolumn{8}{|l|}{ Quality } \\
\hline \multicolumn{8}{|l|}{ Discharge } \\
\hline \multicolumn{8}{|l|}{ Teaching } \\
\hline \multicolumn{8}{|l|}{ Total } \\
\hline$r$ & .465 & .130 & .874 & .843 & & & \\
\hline$p$ & $<.001$ & .221 & $<.001$ & $<.001$ & & & \\
\hline$n$ & 90 & 90 & 90 & 90 & & & \\
\hline \multicolumn{8}{|l|}{ Perceived } \\
\hline \multicolumn{8}{|l|}{ Transition } \\
\hline \multicolumn{8}{|l|}{ Quality } \\
\hline$r$ & .403 & -.193 & .333 & .451 & .444 & & \\
\hline$p$ & $<.001$ & .102 & .004 & $<.001$ & $<.001$ & & \\
\hline$n$ & 73 & 73 & 73 & 73 & 73 & & \\
\hline \multicolumn{8}{|l|}{ Post } \\
\hline \multirow{2}{*}{\multicolumn{8}{|c|}{$\begin{array}{l}\text { Discharge } \\
\text { Difficulty }\end{array}$}} \\
\hline \multirow{2}{*}{\multicolumn{8}{|c|}{$\begin{array}{l}\text { Difficulty } \\
7 \text { day }\end{array}$}} \\
\hline & & & & & & & \\
\hline$r$ & -.195 & .288 & .038 & -.058 & -.006 & -.286 & \\
\hline$p$ & .129 & .023 & .767 & .653 & .963 & .027 & \\
\hline$n$ & 62 & 62 & 62 & 62 & 62 & 60 & \\
\hline
\end{tabular}




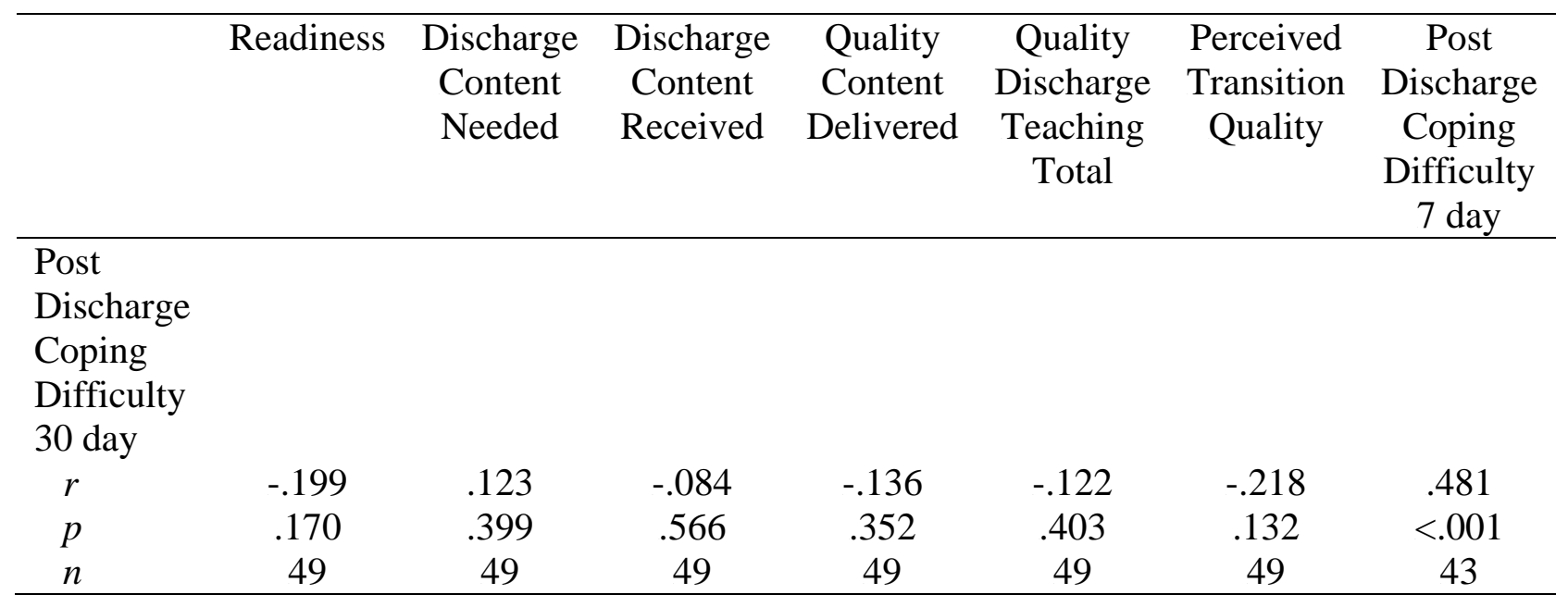


Table 19. Logistic Regression and Odds Ratios for Individual Chronic Condition Variables Total 30-Day Post-Discharge Recidivism

\begin{tabular}{|c|c|c|c|c|c|c|}
\hline Variable & Beta & $\mathrm{SE}$ & Wald $X^{2}$ & df & $p$ & $\begin{array}{c}\text { Odds Ratio } \\
\operatorname{Exp}(\mathrm{B})\end{array}$ \\
\hline Diabetes chronic complications & -.106 & .150 & .498 & 1 & .480 & .900 \\
\hline COPD & .056 & .541 & .011 & 1 & .917 & 1.058 \\
\hline DM Complications*COPD & -.077 & .177 & .191 & 1 & .662 & .926 \\
\hline
\end{tabular}

Table 20. Final Logistic Regression Model with Significant Predictors for Event of Recidivism within 30 Days of Discharge

\begin{tabular}{|c|c|c|c|c|c|c|}
\hline Variable & Beta & $\mathrm{SE}$ & Wald $\mathrm{X}^{2}$ & $\mathrm{df}$ & $p$ & $\begin{array}{c}\text { Odds Ratio } \\
\text { Exp (B) }\end{array}$ \\
\hline 7-day PDCDS Score & -.055 & .029 & 3.671 & 1 & .050 & .947 \\
\hline 30-day PDCDS Score & .088 & .034 & 6.723 & 1 & .010 & 1.092 \\
\hline $\begin{array}{l}\text { Difficulty managing other chronic } \\
\text { illness }\end{array}$ & 2.367 & .827 & 8.200 & 1 & .004 & 10.666 \\
\hline Constant & -2.559 & .721 & 12.598 & 1 & $<.001$ & .077 \\
\hline Test & $X^{2}$ & & & If & & $p$ \\
\hline $\begin{array}{l}\text { Overall model evaluation } \\
\text { Goodness-of-fit }\end{array}$ & 26.737 & & & 3 & & $<.001$ \\
\hline Hosmer \& Lemeshow & 7.061 & & & 8 & & .530 \\
\hline
\end{tabular}

Table 21. Classification Table for Logistic Regression Predicting Event of Recidivism

\begin{tabular}{lccc}
\hline Observed & $\begin{array}{c}\text { Predicted No Case of } \\
\text { Recidivism }\end{array}$ & $\begin{array}{c}\text { Predicted Case of } \\
\text { Recidivism }\end{array}$ & $\begin{array}{c}\text { Predicted \% } \\
\text { Correct }\end{array}$ \\
\hline $\begin{array}{l}\text { Participants } \\
\text { experiencing no event } \\
\text { of recidivism }\end{array}$ & 34 & 6 & 85.0 \\
$\begin{array}{l}\text { Participants } \\
\text { experiencing an event } \\
\text { of recidivism } \\
\text { Overall percentage }\end{array}$ & 7 & 13 & 65.0 \\
\hline
\end{tabular}




\section{References}

American Diabetes Association. (2013a). Economic costs of diabetes in the U. S. in 2012. Diabetes Care, 36, 1033-1046.

American Diabetes Association. (2013b). Standards of medical care in diabetes - 2013. Diabetes Care, 36 (Suppl 1), S12-S66.

American Geriatrics Society. (2012). Guiding principles for the care of older adults with multimorbidity: An approach for clinicians. Journal of the American Geriatrics Society, 60, E1-E-25.

Bobay, K., Jerofke, T. A., Weiss, M. E., \& Yakusheva, O. (2010). Age-related differences in perception of quality of discharge teaching and readiness for hospital discharge. Geriatric Nursing, 31, 178-187.

Borson, S., \& Scanlan, J. M. (2006). The accuracy of the Mini-Cog in screening low-educated elderly for dementia. Journal of the American Geriatrics Society, 54, 376-378.

Borson, S., Scanlan, J. M., Brush, M., Vitallano, P., \& Dokmak, A. (2000). The Mini-Cog: A cognitive vital signs measure for dementia screening in multi-lingual elderly. International Journal of Geriatric Psychiatry, 15, 1021-1027.

Borson, S., Scanlan, J. M., Chen, P., \& Ganguli, M. (2003). The Mini-Cog as a screen for dementia: Validation in a population-based sample. Journal of the American Geriatrics Society, 51, 1451-1454.

Borson, S., Scanlan, J. M., Watanabe, J., Tu, S., \& Lessig, M. (2005). Simplifying detection of cognitive impairment: Comparison of the Mini-Cog and Mini-Mental State Examination in a multiethnic sample. Journal of the American Geriatrics Society, 53, 871-874. 
Borson, S., Scanlan, J. M., Watanabe, J., Tu, S., \& Lessig, M. (2006). Improving identification of cognitive impairment in primary care. International Journal of Geriatric Psychiatry, 21, 349-355.

Brooten, D., Naylor, M. D., York, R., Brown, L. P., Munro, B. H., Hollingsworth, A. O., et al. (2002). Lessons learned from testing the quality cost model of advanced practice nursing (APN) transitional Care. Image: Journal of Nursing Scholarship, 34, 369-375.

Brorsson, B., \& Asberg, K. H. (1984). Katz Index of Independence in ADL: Reliability and validity in short-term care. Scandinavian Journal of Rehabilitative Medicine, 16, $125-132$.

Bull, M. J., Hansen, H. E., \& Gross, C. R. (2000a). Differences in family caregiver outcomes by their level of involvement in discharge planning. Applied Nursing Research, 13, 76-82.

Bull, M. J., Hansen, H. E., \& Gross, C. R. (2000b). Predictors of elder and family caregiver satisfaction with discharge planning. Journal of Cardiovascular Nursing, 14(3), 76-87.

Bull, M. J., \& Jervis, L. L. (1997). Strategies used by chronically ill older women and their caregiving daughters in managing post-hospital care. Journal of Advanced Nursing, 25, $541-547$.

Bull, M. J., Luo, D., \& Maruyama, G. M. (2000). Measuring continuity of elders' posthospital care. Journal of Nursing Measurement, 8, 41-60.

California Healthcare Foundation \& American Geriatrics Society on Improving Care for Elders with Diabetes. (2003). Guidelines for improving the care of the older person with diabetes mellitus. Journal of American Geriatrics Society, 51 (Suppl), S265-S279. 
Centers for Disease Control and Prevention. (2011). National diabetes fact sheet: National estimates and general information on diabetes and prediabetes, 2011. Atlanta, GA: U. S. Department of Health and Human Services.

Centers for Medicare and Medicaid. (2013). Readmission Reduction Program. Retrieved May 5, 2013, from http://www.cms.gov/Medicare/Medicare-Fee-for-ServicePayment/AcuteInpatientPPS/Readmissions-Reduction-Program.html

Charlson, M. E., Pompei, P., Ales, K. L., \& MacKenzie, C. R. (1987). A new method of classifying prognostic comorbidity in longitudinal studies: Development and validation. Journal of Chronic Disease, 40, 373-383.

Chatfield, M. D., Brayne, C. E., \& Matthews, F. E. (2005). A systematic literature review of attrition between waves in longitudinal studies in the elderly shows a consistent pattern of dropout between differing studies. Journal of Clinical Epidemiology, 58, 13-19.

Ciesla, J. R., Shi, L., Stoskopf, C., \& Samuels, M. E. (1993). Reliability of Katz's Activities of Daily Living Scale when used in telephone interviews. Evaluation \& the Health Professions, 16, 190-203.

Coleman, E. A. (2003). Falling through the cracks: Challenges and opportunities for improving transitional care for persons with continuous complex care needs. Journal of the American Geriatrics Society, 51, 549-555.

Coleman, E. A. (2006). Care Transition Measure (CTM-15). Retrieved March1, 2011, from http://www.caretransitions.org/documents/CTM-15.pdf

Coleman, E. A., \& Boult, C. (2003). Improving the quality of transitional care for persons with complex care needs. Journal of the American Geriatrics Society, 51, 556-557. 
Coleman, E. A., Mahoney, E., \& Parry, C. (2005). Assessing the quality of preparation for posthospital care from the patient's perspective: The care transitions measure. Medical Care, 43, 246-255.

Coleman, E. A., Min, S., Chomiak, A., \& Kramer, A. M. (2004). Posthospital care transitions: Patterns, complications, and risk identification. Health Services Research, 39, 1449-1465.

Coleman, E. A., Parry, C., Chalmers, S., \& Min, S. (2006). The care transitions intervention: Results of a randomized controlled trial. Archives of Internal Medicine, 166, 1822-1828.

Coleman, E. A., Parry, C., Chalmers, S. A., Chugh, A., \& Mahoney, E. (2007). The central role of performance measurement in improving the quality of transitional care. Home Health Care Services Quarterly, 26(4), 93-104.

Coleman, E. A., Smith, J. D., Frank, J., Eilersten, T. B., Thiare, J. N., \& Kramer, A. M. (2002). Development and testing of a measure designed to assess the quality of care transitions. International Journal of Integrated Care, 2, 1-9.

Congdon, J. G. (1994). Managing the incongruities: The hospital discharge experience for elderly patients, their families, and nurses. Applied Nursing Research, 7, 125-131.

Deeg, D. J. H., van Tilberg, T., Smit, J. H., \& de Leeuw, E. D. (2002). Attrition in the Longitudinal Aging Study Amsterdam: The effect of differential inclusion in side studies. Journal of Clinical Epidemiology, 55, 319-328.

Frincke, B. G., Clark, J. A., Linzer, M., Spiro, A., Miller, D. R., Lee, A., et al. (2005). Assessment of long-term complications due to type 2 diabetes using patient self-report: The diabetes complications index. Journal of Ambulatory Care Management, 28, 262273. 
Goldfield, N. I., McCullough, N. C., Hughes, J. S., Tang, A. M., Eastman, B., Rawlins, L. K., et al. (2008). Identifying potentially preventable readmission. Healthcare Financing Review, 30, 75-91.

Hall, M. J., DeFrances, C. J., Williams, S. N., Golosinskiy, A., \& Swartzman, A. (2010). National Hospital Discharge Survey: 2007 summary. National Health Statistics Reports, 29. Hyattsville, MD: National Center for Health Statistics.

Hartigan, I. (2007). A comparative review of the Katz ADL and the Barthel Index in assessing activities of daily living in older people. International Journal of Older People Nursing, 2, 204-212.

Huang, E. S., Sachs, G. A., \& Chin, M. H. (2006). Implications of new geriatric diabetes care guidelines for the assessment of quality of care in older patients. Medical Care, 44, 373377.

Jencks, S. F., Williams, M. V., \& Coleman, E. A. (2009). Rehospitalizations among patients in the Medicare fee-for-service program. New England Journal of Medicine, 360, 14181428.

Katz, S., Downs, T. D., Cash, H. R., \& Grotz, R. C. (1970). Progress in development of the Index of ADL. Gerontologist, 10, 20-30.

Law, M., \& Letts, L. (1989). A critical review of scales of activities of daily living. American Journal of Occupational Therapy, 43, 522-528.

LeClerc, C. M., Wells, D. L., Craig, D., \& Wilson, J. L. (2002). Falling short of the mark: Tales of life after hospital discharge. Clinical Nursing Research, 11, 242-266. 
Levit, K., Wier, L., Stranges, E., Ryan, K., \& Elixhauser, A. (2009). HCUP facts and figures: Statistics on hospital-based care in the United States, 2007. Rockville, MD: Agency for Healthcare Research and Quality.

Mahdi, O. Z., Blandford, R., Arter, M., \& Roche, J. (2007). Type 2 diabetes and the older adult. Geriatric Medicine, 37(9), 31.

Mahoney, J. E., Eisner, J., Havighurst, T., Gray, S., \& Palta, M. (2000). Problems of older adults living alone after hospitalization. Journal of General Internal Medicine, 15, 611-619.

Maloney, L. R., \& Weiss, M. E. (2008). Patients' perceptions of hospital discharge informational content. Clinical Nursing Research, 17, 200-219.

Marengoni, A., Angleman, S., Melis, R., Manglialasche, F., Karp, A., Garmen, A., et al. (2011). Aging with multimorbidity: A systematic review of the literature. Aging Research Reviews, 10, 430-439.

Marengoni, A., Rizzuto, D., Wang, H.-X., Winbland, B., \& Fratiglioni, L. (2009). Patterns of chronic multimorbidity in the elderly population. Journal of the American Geriatrics Society, 57, 225-230.

Medicare Payment Advisory Committee. (2007). Report to Congress: Promoting greater efficiency in Medicare. Washington, DC.

Meleis, A. I., Sawyer, L. M., Im, E., Messias, D. K. H., \& Schumacher, K. (2000). Experiencing transitions: An emerging middle-range theory. Advances in Nursing Science, 23, 12-28.

Members of the California Healthcare Foundation \&, American Geriatrics, Society Panel on Improving Care for Older Persons with Diabetes. (2003). AGS clinical practice guideline: Guidelines for improving care of the older person with diabetes mellitus. Journal of the American Geriatrics Society, 51, S265-S280. 
Miller, J. F., Piacentine, L. B., \& Weiss, M. (2008). Coping difficulties after hospitalization. Clinical Nursing Research, 17, 278-296.

Mistiaen, P., Duijunhouwer, E., Wijkel, D., de Bont, M., \& Veeger, A. (1997). The problems of elderly people at home one week after discharge from the acute care setting. Journal of Advanced Nursing, 25, 1233-1240.

Morse, J. M. \& Liehaus, L. (2007). Combining qualitative and quantitative methods for mixedmethod designs. In P. L. Munhall (Eds.), Nursing research: A qualitative perspective (pp. 541-554). Sudsbury, MA: Jones and Bartlett Publishers.

Munshi, M., Grande, L., Hayes, M., Ayres, D., Suhl, E., Capelson, R., et al. (2006). Cognitive dysfunction is associated with poor diabetes control in older adults. Diabetes Care, 29, 1794-1799.

Naylor, M. D. (2000). A decade of transitional care research with vulnerable elders. Journal of Cardiovascular Nursing, 14(3), 1-14.

Naylor, M. D., Brooten, D. A., Campbell, R. L., Maislin, G., McCauley, K. M., \& Schwartz, J. S. (2004). Transitional care of older adults hospitalized with heart failure: A randomized, controlled trial. Journal of the American Geriatrics Society, 52, 675-684.

Naylor, M. D., Kurtzman, E. T., Grabowski, D. C., Harrington, C., McClellan, M., \& Reinhard, S. C. (2012). Unintended consequences of steps to cut readmissions and reform payment may threaten care of vulnerable older adults. Health Affairs, 31, 1623-1632.

Parry, C., Coleman, E. A., Smith, J. D., Frank, J., \& Kramer, A. M. (2003). The care transitions intervention: A patient-centered approach to ensuring effective transfers between sites of geriatric care. Home Health Care Services Quarterly, 22(3), 1-17. 
Parry, C., Mahoney, E., Chalmers, S. A., \& Coleman, E. A. (2008). Assessing the quality of transitional care: Further applications of the care transitions measure. Medical Care, 46, 317-322.

Quadagno, J. (2008). Aging and the life course: An introduction to social gerontology (4th ed.). New York: McGraw Hill.

Russell, L. B., Valiyeva, E., Roman, S. H., Pogach, L. M., Suh, L. M., \& Safford, M. M. (2005). Hospitalizations, nursing home admissions, and deaths attributable to diabetes. Diabetes Care, 28, 1611-1617.

Schumacher, K. L., \& Meleis, A. I. (1994). Transitions: A central concept in nursing. Image: Journal of Nursing Scholarship, 26, 119-127.

Schumacher, K. L., Jones, P. S., \& Meleis, A. I. (1999). Helping elderly persons in transition: A framework for research and practice. In E. A. Swanson \& T. Tripp-Reimer (Eds.), Life transitions in the older adult: Issues for nurses and other health professionals (pp. 1-26). New York: Springer.

Shepperd, S., McClaren, J., Phillips, C., Lannin, N. A., Clemson, L. M., McCluskey, A., et al. (2010). Discharge planning from hospital to home. Cochrane Collaboration.

Snow, A. L., Cook, K. F., Lin, P., Morgan, R. O., \& Magaziner, J. (2005). Proxies and other external raters: Methodological considerations. Health Services Research, 40, 1676-1693.

Steinman, M. A., Lee, S. J., Boscardin, W. J., Miao, Y., Fung, K. Z., Moore, K. L., et al. (2012). Patterns of multimorbidity in elderly veterans. Journal of the American Geriatrics Society, 60, 1872-1880.

Suhl, E., \& Bonsignore, P. (2006). Diabetes self-management education for older adults: General principles and practical application. Diabetes Spectrum, 19, 234-240. 
Travis, S. S., Buchanan, R. J., Wang, S., \& Kim, M. (2004). Analyses of nursing home residents with diabetes at admission. Journal of the American Medical Directors Association, 5, 320-327.

Tsilimingras, D., \& Bates, D. W. (2008). Performance improvement. Addressing post-discharge adverse events: A neglected area. Joint Commission Journal on Quality \& Patient Safety, 34, 85-97.

van Walraven, C. J., Dhalla, I. A., Bell, C., Etchells, E., Stiell, I. G., Zarnke, K., et al. (2010). Derivation and validation of an index to predict early death or unplanned readmission from hospital to the community. Canadian Medical Association Journal, 182, 551-557.

Wallace, M., \& Shelkey, M. (2012). Katz Index of Independence with Activities of Daily Living (ADL). Retrieved April 1, 2012, from http://consultgerirn.org/uploads/File/trythis/try_this_2.pdf

Wallace, M., \& Shelkey, M. (2008). Monitoring functional status in hospitalized older adults. AJN, 108(4), 64-71.

Watkins, L., Hall, C., \& Kring, D. (2012). Hospital to home: A transition program for frail older adults. Professional Case Management, 17, 117-125.

Weiss, M., Johnson, N. L., Malin, S., Jerofke, T., Lang, C., \& Sherburne, E. (2008). Readiness for discharge in parents of hospitalized children. Journal of Pediatric Nursing, 23, 282295.

Weiss, M., Yakusheva, O., \& Bobay, K. (2010). Nurse and patient perceptions of discharge readiness in relation to postdischarge utilization. Medical Care, 48, 482-486.

Weiss, M. E., \& Piacentine, L. B. (2006). Psychometric properties of the Readiness for Hospital Discharge Scale. Journal of Nursing Measurement, 14, 163-180. 
Weiss, M. E., Piacentine, L. B., Lokken, L., Ancona, J., Archer, J., Gresser, S., et al. (2007). Perceived readiness for hospital discharge in adult medical-surgical patients. Clinical Nurse Specialist: The Journal for Advanced Nursing Practice, 21(1), 31-42.

Williams, M. A., Oberst, M. T., \& Bjorklund, B. C. (1994). Early outcomes after hip fracture among women discharged home and to nursing homes. Research in Nursing \& Health, 17, 175-183. 


\title{
CHAPTER FOUR: HOSPITAL-TO-HOME TRANSITION EXPERIENCES OF OLDER ADULTS DIAGNOSED WITH DIABETES - ANALYSIS OF QUALITATIVE DATA
}

\begin{abstract}
Older adults experience the highest rates of acute care hospitalization. The transition from hospital-to-home is a period of heightened vulnerability for the older adult. Following hospitalization an elder is at-risk for poor transition outcomes including medication errors, events of recidivism, and development post-discharge coping difficulties. Over $50 \%$ of older adults are affected by more than three concurrent chronic illnesses that may precipitate or complicate a hospitalization and the subsequent home recovery transition. Diabetes is a prototype of a chronic illness that affects millions of older adults and adds to the intricacies of the post-discharge transition.
\end{abstract}

A simultaneous quantitative/qualitative mixed methods design was used to provide enhanced description and specificity to the problems and difficulties encountered by older adults with diabetes and their family caregivers during the early and intermediate phases of the home recovery transition. Of the 96 hospitalized older adults with diabetes who enrolled in the core component of the study, 61participants or proxy caregiver respondents provided 219 free response comments to a questionnaire that measured post-discharge coping difficulties within the first week of the home recovery transition. Another 159 comments were offered by 52 participants 30 days following discharge.

The following four overarching themes emerged during supplementary content analysis of the free response data: "the daily stuff is difficult"; "engineering care at home is difficult”; "life is stressful”; and “difficulty managing complex health problems”. Respondents painted a portrait of individuals who were striving to attain self-sufficiency and a return to health while 
encountering obstacles created by physical and functional limitations, external personal and family stressors, and exacerbation of or emerging difficulties with pre-existing chronic health problems including diabetes. Difficulties managing comorbid health conditions including diabetes were more prevalent in the later transition period as participants experienced deterioration in stability of chronic illnesses, incorporated modifications in constantly changing treatment plans, and awaited results of follow-up diagnostic work-ups.

The following three subthemes related to problems managing complex health problems emerged: difficulty managing complex medication regimens; difficulty controlling glucoses or managing diabetes; and difficulty managing a chronic illness other than diabetes. Because of their potential relationship to recidivism, these subthemes were transposed into nominal level variables and included in statistical tests that examined factors related to post-discharge difficulties in the core component of the study.

The findings of this supplementary analysis revealed that the home recovery transition is dynamic and that the needs of elders and family caregivers change as they navigate the posthospitalization transition. The complexity of the home caregiving situation precluded diagnosisdriven identification of elders who were at risk for problems during the home recovery transition. While hospital discharge planning processes typically address immediate transition needs, the changes in health status that emerged during in the first month following discharge suggest that there is a need for ongoing support of elders and family caregivers during the later phases of the home recovery transition. 


\section{Background}

Millions of older adults are hospitalized each year as a result of the exacerbation or deterioration of a pre-existing chronic health problem (Condelius, Edberg, Jakobsson, \& Hallberg, 2008; Hall, DeFrances, Williams, Golosinskiy, \& Swartzman, 2010). Multimorbidity, defined as "the simultaneous presence of diseases/symptoms, cognitive and physical functional limitations”(Marengoni et al., 2011, p 431), affects over 50\% of people who are age 65 or older (American Geriatrics Society [AGS], 2012). Older adults affected by multimorbidity are more likely to develop functional impairments, suffer from poor quality of life, experience adverse events related to complex treatment regimens, and require short-term rehabilitation and longterm care placements (AGS, 2012; Marengoni et al., 2011). During a hospitalization, clinical management of the primary diagnosis may impact the stability of one or more comorbid illnesses (AGS, 2012). The occurrence of one chronic health condition has been associated with under treatment of other unrelated medical problems (Marengoni, Rizzuto, Wang, Winbland, \& Fratiglioni, 2009).

The intricacies of concurrently managing multiple health problems places significant selfmanagement burdens on many older adults and family caregivers and contributes to higher inpatient utilization by the elderly (AGS, 2012; Marengoni et al., 2011). Following a hospitalization, modifications of established treatment plans and introduction of new therapies for emerging health problems may significantly complicate post-discharge care in elders who experience multimorbidity. Patients typically recall less than $50 \%$ of information provided by health professionals during a healthcare encounter which may lead to difficulty in correctly implementing complex self-care activities after discharge (Brown \& Bussell, 2011). Inadequate health literacy that contributes to poor understanding of health conditions and their associated 
treatment plans has been linked to poor adherence with home medication regimens (Brown \& Bussell, 2011).

Diabetes is an example of a chronic illness that significantly contributes to the multimorbidity of over 12 million older adults (Centers for Disease Control and Prevention [CDC], 2011). The long-term systemic effects of diabetes place elders at risk for cardiovascular disease (CVD), hypertension, stroke, retinopathy, amputation, and chronic kidney disease (CKD) (American Diabetes Association [ADA], 2013a). Diabetes increases the risk for an elder to develop one or more geriatric syndromes such as functional disability, cognitive deficits, pain, and polypharmacy (ADA, 2013b).

Diabetes places significant self-management burdens on the older adult and caregiver. Community-dwelling elders with diabetes often must manage technically complex medication regimens that include problem-prone drugs such as insulin. Additionally, they must incorporate dietary restrictions for several conditions into daily meal plans, modify personal care practices, and coordinate medical follow-up appointments with specialty providers such as podiatrists and ophthalmologists (ADA, 2013a). Older adults with diabetes often require supplemental assistance with activities of daily living. They are two to three times more likely to have difficulty walking moderate distances, climbing steps, and performing basic household tasks (CDC, 2011). Hospitalization rates of elders with diabetes significantly exceed those of older adults who are not affected by the condition (ADA, 2013b). In 2012, older adults with diabetes utilized over 16.5 million hospital days and over 81 million nursing home or residential care days (ADA, 2013b).

Cardiovascular and general medical diagnoses such as infection most commonly precipitate hospital admission of an older adult with diabetes (ADA, 2013b). Diabetes typically 
presents as a secondary diagnosis during a hospitalization of an affected elder. Deterioration of diabetes control and development of disease-related complications such as impairment in renal function may occur during the course of a hospitalization and commonly require changes in established treatment plans at discharge (Chau \& Edelman, 2001).

Elders who suffer from multimorbidity are often reliant on the supplemental support of family and community resources to maintain their health status and to meet basic needs (van den Akker, Buntinx, Metsemakers, Roos, \& Knottnerus, 1998). The escalating care needs of an elder affected by multimorbidity often place time, physical, and emotional demands on family care providers and may even necessitate restructuring of the caregiver's lifestyle (van den Akker et al., 1998).

The transition from hospital to home is an exceptionally vulnerable period for older adults. Elders become particularly susceptible to poor transitions because they are often discharged with ongoing care needs that exceed those that preceded the hospitalization (Levine et al., 2006; Miller, Piacentine, \& Weiss, 2008; Mistiaen, Francke, \& Poot, 2007; Murtaugh \& Litke, 2002; Weiss et al., 2007). Demands on family members and other support structures typically increase during the home recovery transition. The escalating care needs of an elder affected by multimorbidity often place time, physical, and emotional demands on family care providers and may even necessitate restructuring of the caregiver’s lifestyle (van den Akker et al., 1998).

The needs of and problems experienced by aging families who care for elders with a preexisting chronic health problem as they progress through hospital-to-home transitions have been limitedly studied. Specifically, the transitional care needs of older adults with diabetes are not well-understood (ADA, 2013a). This analysis will explore the post-discharge transition needs 
and difficulties experienced by older adults with diabetes and those of their family caregivers during the early and intermediate phases of their home recovery transition.

\section{Purpose}

The purpose of this supplementary analysis of free-response data obtained in core component project on hospital-to-home transition outcomes of older adults with diabetes was to:

1. Describe and add specificity to the common problems and difficulties encountered by older adults with diabetes and their family caregivers during the early (7-day) and intermediate (30-day) post-discharge transition periods.

2. To determine if older adult and family caregiver problems and difficulties differ in the early (7 day) and intermediate (30 day) transitional periods following an acute hospitalization.

\section{Research Strategy}

A simultaneous quantitative-qualitative mixed methods design was used to better understand the specific issues that older adults and their family care providers encountered during the early and intermediate phases of the home recovery transition (Morse \& Niehaus, 2007). The core component of the project used a descriptive correlational design to examine factors related to post-hospitalization transition outcomes. This supplementary qualitative analysis of free-response survey data provided added description and specificity to recurring problems encountered by respondents during the home recovery transition. Three subthemes that emerged during qualitative analyses were subsequently transposed into quantitative variables and used in statistical testing of variables associated with recidivism and development of specific post-discharge coping difficulties. 
Participants were recruited from multiple in-patient medical-surgical and progressive care units of a 560-bed community medical center in east, central Florida. Permission to conduct the research project was received from the university institutional review board and administration at the research site. Informed consent from each participant was obtained by the principal researcher on the on the day of discharge. Inclusion criteria were: age 65 years or older; diagnosis of diabetes that predated the hospitalization; length-of-stay of 48 hours or longer for any medical-surgical diagnosis; ability to hear, speak, understand and read English; anticipated discharge within four hours of enrollment; planned home discharge; and telephonic availability for 30 days following discharge. Individuals were excluded from the study if they had a planned discharge to a facility or to hospice services. Individuals whose medical history or medication profiles were suggestive of a pre-existing cognitive deficit were additionally excluded from the study.

\section{Instruments}

The Post-Discharge Coping Difficulty Scale (PDCDS) assesses for the presence of problems encountered during the first weeks following a hospital-to-home transition and was used as a post-discharge outcome measure in the core component of the research project (Miller et al., 2008; Weiss \& Piacentine, 2006). The PDCDS includes ten items that address postdischarge stress, recovery and care challenges, help and emotional support needs, confidence in self-care and medical management, family difficulties, and personal adjustment (Miller et al., 2008). The PDCDS is scored using a 0 to 10 scale, and higher scores are indicative of greater difficulty with post-discharge coping. A Cronbach's alpha of 0.87 was previously reported in an adult medical-surgical population (Miller et al., 2008). Psychometric properties of the PDCDS in 
an older adult population and in individuals with specific disease states such as diabetes have not been reported. In the parent study, Cronbach's alpha reliability coefficients of .916 and .921 were observed respectively in the 7 and 30-day post-discharge interviews.

The PDCDS affords an opportunity for participants to provide free response to questions that describe difficulties encountered in the following areas: sources of stress; recovery; caring for self; management of the medical condition; and family issues (Miller et al., 2008). Responses to these questions provided the data for the current analysis of qualitative data.

\section{Data Collection}

Data were collected March, 2012 through January, 2013.The principal investigator consulted with nursing staff, participated in unit case management rounds, and utilized hospital informatics systems to screen for potential participants who met inclusion criteria. After obtaining informed consent, demographic data that addressed the participant's general health status, multimorbidity profile, diabetes history, functional status, cognitive status, and postdischarge resource availability were gathered through participant self-report and medical record review. Assessments of perceived readiness for hospital discharge and quality of discharge teaching were also obtained (Bobay, Jerofke, Weiss, \& Yakusheva, 2010; Weiss \& Piacentine, 2006; Weiss et al., 2007).

An appointment for telephone follow-up was made upon study enrollment. Participants were mailed a reminder letter with copies of the post-discharge surveys at least four days prior to the scheduled appointment. Participants were contacted telephonically 7 days and 30 days following discharge. Up to four attempts to contact each participant over a 7 day period were 
made. Participants not reached during the established follow-up period were considered lost follow-up.

A retired registered nurse with extensive experience in conducting telephone healthrelated surveys with older individuals used a standardized script to gather post-discharge data on recidivism, family care involvement, and home care support. She also administered the quantitative and free-response items of the PDCDS. Participants who declined participation in follow-up telephone surveys often described active problems with caregiving or personal healthmanagement as the rationale. These comments were documented and incorporated into the qualitative data analysis. The research assistant additionally recorded verbatim comments provided in response to PDCDS interview questions. A total of 219 comments were provided by 61 participants who completed the PDCDS and an additional 6 participants who declined survey completion at the 7-day follow-up. Fifteen participants completed the PDCDS without comment during the 7-day follow-up. A total of 159 comments were provided by 52 participants who completed the survey and 3 participants who deferred completion of the 30-day post-discharge interview. Sixteen participants completed the final survey without comment.

Survey data were gathered from both participants and proxy caregivers. Proxy report is appropriate when an objective outcome measure is available, when the elder cannot provide an accurate report, and when an alternative respondent, in this case the family caregiver, has the ability to provide important information on the phenomenon under investigation (Snow, Cook, Lin, Morgan, \& Magaziner, 2005). The instrument used in this study had been previously administered to proxy respondents. 


\section{Data Analysis}

Three databases were constructed to create a portrait of the personal transition difficulties encountered by study participants during the early and intermediate periods following discharge. Initially, each transcribed response was attributed to the associated PDCDS question and referenced to the temporal period in which the response was provided. These qualitative data were then organized by participant, and the content was analyzed. After multiple iterations, four overarching themes, each with three to four accompanying subthemes, emerged. As themes and subthemes presented, codes were created, and each response was subsequently categorized by the principal investigator. The categorized responses were then reviewed by the retired registered nurse who initially gathered the free-response data. She independently assigned each response to a category and concurred with the original categorizations provided by the principal investigator. She additionally commented that the themes and subthemes accurately captured the experiences shared by participants during the actual telephone interviews. The frequencies of each thematic category were summed and then compared by response period. Several participants described more than one difficulty in post-discharge coping and contributed data that described more than one theme or subtheme. The themes and subthemes are presented by frequency and temporal period in Table 22.

\section{Respondent Profile}

Free-response data were gathered from 67 participants during the 7-day follow-up period and 55 participants at the 30-day post-discharge time interval. The median age of the qualitative respondents was approximately 75 years $(n=67)$. Genders were equally represented during both data collection periods. Participants were primarily Caucasian which is consistent with 
community demographics. Almost half of study participants $(n=32)$ were admitted for noncardiovascular medical diagnoses. Over $85 \%(n=57 ; n=48)$ of participants had a pre-existing diagnosis of a chronic diabetes-related health condition. The most frequently reported chronic health conditions were coronary artery disease $(59.7 \% ; n=40 ; 60.0 \%, n=33)$, diabetic neuropathy $(n=37,55.2 \% ; 61.8 \%, n=34)$, chronic kidney disease $(41.8 \%, n=28 ; 43.6 \%, n=$ 24), and heart failure (35.8\%; $n=24 ; 35.4 \%, n=20)$. Most participants were experiencing acceptable glycemic control in the period that preceded admission. The median A1c of survey respondents was $6.7 \%(n=60)$. Over $40 \%(n=25)$ of participants experienced a change in the home diabetes treatment regimen at discharge. The preponderance of participants $(85.1 \%, n=$ $57 ; 89.1 \%=49$ ) had access to a caregiver in the home following discharge. Approximately half ( $n=35 ; n=28$ ) of all participants were receiving home care services at the time of the scheduled follow-up interviews. A summary of the demographic characteristics of participants who contributed qualitative data for this supplementary component of the research project is provided in Table 23.

\section{Results}

The following major themes emerged as descriptors of the post-discharge difficulties most frequently encountered by study participants during two data collection periods: "the daily stuff is difficult”; "engineering care at home is complex"; "life is stressful”; and "managing multiple complex health problems is difficult”. Each theme along with its associated subthemes and supporting exemplars will be discussed in conjunction with the temporal placement of the reported difficulty during the post-discharge transition process. 


\section{The Daily Stuff is Difficult}

Participants consistently described a desire for self-sufficiency in the post-discharge period but faced considerable obstacles in achieving this goal. A 69-year-old, married male who was discharged home after a ten-day hospitalization for heart failure exemplified this theme with the following statement, "I felt emotionally drained when I got home. I felt like I was starting from square one. The daily stuff is difficult.”

Over 50\% $(n=38)$ of respondents reported difficulty with managing daily personal tasks during the early transition period. Specifically, participants conveyed problems in the following areas: performing activities-of-daily living and basic household tasks (43.3\%, $n=29)$; walking and mobility $(17.9 \%, n=12)$; accessing transportation $(4.5 \%, n=3)$; and acquiring supplies and medications $(4.5 \%, n=3)$.

For many elders, problems with daily tasks were persistent at the time of the 30-day follow-up interview. Over 55\% $(n=31)$ of participants described ongoing issues meeting everyday needs. Respondents most commonly reported a latent requirement for at least stand-by assistance with hygiene $(41.8 \%, n=23)$ and help with mobility, particularly stair climbing $(18.2 \%, n=10)$. These difficulties were most prevalent in participants who underwent orthopedic surgical procedures such as knee replacement, hip replacement, and spinal surgery.

A 75-year-old woman who lived alone and underwent spinal fusion surgery reflected the theme, "the daily stuff is difficult", with the following statement: "My neighbor is checking on me three times per day. I get my meals by myself, but she helps to clean up and do errands. I was not told what I would need and getting supplies is difficult. I am having so much pain. I wish I went to rehab. I like being home, but it is so hard doing everything myself.” 
Another 71-year-old woman who was being treated for a diabetic foot ulcer described the difficulty of integrating medical treatments with personal care needs. She stated, "Having a wound vac is stressful. I can only bathe in the sink, and it takes so long. It takes 40 minutes to do my sponge bath.”

One 90-year-old male participant was hospitalized for heart failure and resumed his role as the primary caregiver for his wife who had dementia immediately upon discharge. The gentleman had experienced substantial declines in functional status that complicated his home recovery transition. He portrayed his home situation as follows:

My daughter came while I was in the hospital to drive my wife around. She is gone now, and now my wife is stressed. I am having trouble getting around, but my wife and I work together to do the cooking and housework. I am having trouble with my bladder which has been stressful. I had to learn how to do the laundry.

Lack of transportation can create significant problems in accessing follow-up medical care and in acquiring supplies, medications, and food for impacted individuals. Transportation problems were more frequently reported by participants $(12.7 \%, n=7)$ during later stages of home recovery as family caregivers resumed employment or returned home. The response of an 84-year-old woman who lived with an elderly roommate illustrated how lack of transportation complicated her home recovery transition experience with the following exemplar:

I am doing OK with my care and cooking, but I was having problems with the bus before I went into the hospital. The bus doesn't come on time, and I have to wait. I have to take the bus to the doctor and to get groceries... I am having pain in my leg and needed x-rays, but I don't have a ride to the hospital and couldn't get there. I am on new medicines, but it is difficult to get them. I shop for groceries every two weeks and carry them on the bus. How am I going to live?

\section{Engineering Care at Home is Difficult}

Older adults and individuals in their support network face a myriad of potential physical and psychosocial stressors as an elder leaves the hospital. One week following discharge, $52.2 \%$ 
$(n=35)$ of survey respondents reported difficulties with establishing a care environment that satisfied the mutual needs of the elder and, if available, lay care provider. Persistent issues with caregiving were expressed by $46.3 \%(n=24)$ of respondents during the 30-day post-discharge interview. Four subthemes that specifically described the intricacies and difficulties of providing care to a recently-hospitalized older adult emerged in the free responses. The identified subthemes included: "I put myself last”; "Doing it alone”; "mobilizing family and support resources"; and "This is rough on my family."

\section{Put Myself Last}

This subtheme specifically addressed the personal impact of hospitalization on an individual assuming or resuming a caregiving role. Difficulties with caregiving were experienced by family members who undertook the role of care provider for the recently-hospitalized elder as well as hospitalized older adults who were immediately returning home as a care provider for another individual. Five study participants reported that they were required to resume the role of caregiver for another immediately after discharge. One 76-year-old female participant who underwent a total hip replacement described her post-discharge experience as follows:

My husband has macular degeneration and is blind. He developed shortness of breath and had to go to the doctor. He is now on a nebulizer and home oxygen for his COPD. It is difficult trying to heal and take care of my husband. My hip condition is regressing according to my physical therapist because I am doing too much. I put myself last, and it is affecting my recovery.

An 84-year-old male who was admitted with pancreatic obstruction was discharged from the hospital on the same day as his wife who experienced a fall with injury during his hospitalization. He expressed the following frustrations with his home situation: "My wife was discharged on the same day that I was. I thought my son would give us more help than he has. I 
am exhausted.” Another elderly gentleman who was the primary caregiver for his wife was placed on a driving restriction following his hospitalization for a chronic subdural hematoma. He and his wife were subsequently involved in a motor vehicle crash as she attempted to drive him to a medical appointment during his first week at home.

Family caregivers reported personal health problems that affected their ability to provide care to the elder or to manage their own health needs. A 75-year-old woman who underwent a lumbar discectomy provided the following exemplar: "I can’t bend, lift or turn. My sister helps me with everything but my medications. My sister had an abdominal hernia repair with complications one month ago and is still recovering from her own surgery.” Another 77-year-old woman who was hospitalized with a pseudoaneurysm following an interventional cardiovascular procedure described family stress that emerged secondary to a change in the health status of her spouse:

My husband helps me with my care. He was just diagnosed with blockage of the carotid arteries. He is not a candidate for surgery. This has been so hard on my family. They are upset that I had to have two procedures. My husband is also in bad shape.

Competing demands of multigenerational family members was another challenge reported by five study participants. In addition to providing care to a recently hospitalized elder, these family members bore primary responsibility for the care of grandchildren, children, very elderly parents, and even friends with special needs. One participant stated, "My daughter is also caring for an 11-month-old. She gets no help from her sisters.” A 66-year-old participant who was hospitalized for pneumonia stated, "My daughter died four years ago, and I am the main caregiver for my 11 and 13-year-old grandchildren. I am having some difficulty caring for them, but my husband and I 'tag team' the children.” A 70-year-old male who was hospitalized with 
urosepsis also provided an exemplar describing his family’s experience with multigenerational caregiving during his 30-day interview:

My wife is a teacher's aide and will have to return to work soon, making transportation a problem for me. My wife and her sister care for my mother-in-law. They go to the nursing home three times per day. All of this is very rough on her.

A 71-year-old male who was discharged following cardiac surgery reported the following during his 30-day interview, "I am very concerned that my wife is so worried about me. She also cares for her mother who is in the hospital with a stroke.”

\section{Doing It Alone Is Difficult}

Respondents who returned home alone were limitedly represented in this study. A 65year-old female with long-standing type 1 diabetes who underwent an exploratory laparotomy was initially discharged into the care of her daughter who lived out of the area. She provided the following exemplar illustrating challenges she experienced during her 30-day post-discharge interview:

My daughter and friends have been helping me. My daughter gave up a week of work to be with me. She went home, and now I am dependent on friends to drive me to doctor appointments and to get groceries.

The previously-discussed woman who underwent lumbar laminectomy provide the following exemplar on latent caregiving issues faced by people who live alone during her 30-day follow-up interview:

My surgeon told me I would have no trouble, but I have no one at home to help me and had no idea how hard this would be. My neighbor who helps me is on vacation. She has been 'weaning' me from assistance. Doing my daily care and washing clothes has been hard since my back surgery. I figured out a new way to do it. 


\section{Mobilizing Family and Support Resources}

Participants enlisted help from a variety family and social resources when creating an environment to support their home recovery transition. Respondents reported receipt of assistance from children (both local and non-local), daughters-in-law, grandchildren, siblings, nieces, friends, neighbors, and church members. Almost 15\% of respondents $(n=10)$ described use of extended family and social network supports during the 7-day post-discharge time period. Twenty percent of respondents $(n=11)$ reported ongoing reliance on these resources one month after discharge. An 86-year-old female who was new to dialysis exemplified the creativity that families use to maintain a stable care environment in the following response: "My daughter hired a nurse so that she could go on vacation. My grandson is staying at the house with the nurse.” The extremes that families use to maintain elders with complex care needs in the home setting is described in the following exemplar provided by a 71-year-old female who was discharged on long-term intravenous therapy and a complex wound management program: “My son quit his job because he can’t work and care for me. The bills and medicines and infusions are expensive."

\section{This Is Rough on My Family}

Concern for the family caregiver was a subtheme that was expressed repeatedly by elderly care recipients. Over one-third $(n=23)$ of respondents described emotional and logistical challenges that were experienced by family members during the immediate post-discharge transition period. Almost 20\% $(n=10)$ of respondents reported ongoing family stressors during the 30-day interview. 
The stress experienced by family caregivers as they attempted to transition care responsibility back to an older adult was conveyed in responses that were provided by an 81year-old woman who was hospitalized for syncope and her daughter. The daughter described the early home recovery transition experience in the following exemplar: "She needed help with basic care and getting her strength and confidence back. I had to clarify her medicines and make sure she could do them herself to be safe at home. I worry about leaving her alone.” Thirty days following discharge the elder described the demands on her family as follows:

I am having trouble building confidence after the fall. I needed to go to my daughter's home for a few weeks. I am home alone now. My closest daughter lives 45-minutes away but checks on me by phone every day. My daughters have more responsibilities because they visit more than before. They bring my groceries and easy meals for me to heat up. The demands on family care providers were further exemplified by a 72-year-old male who underwent laparoscopic cholecystectomy. He stated, "My son flew down and drove me back to New York 2 days after I got out of the hospital. My family visits every day. My daughter has taken over a lot since my wife died in September.” The wife of an 82-year-old male with CHF provided the following additional exemplar on caregiver stress during the 7 day follow-up, "My husband was readmitted today. He needs more medicines for his kidneys and is starting dialysis. I have three more stops to make before I go back to the hospital. I am exhausted.”

\section{Life is Stressful}

In addition to the inherent stress associated with the hospital-to-home transition experience, recently-discharged older adults also must cope with newly-emerging and preexisting psychosocial stressors. Over 20\% $(n=15)$ of respondents described life stressors that were potentially impacting their early recovering. Psychosocial stressors were even more frequently reported during later follow-up interviews $(29.1 \%, n=16)$. "Family conflict”, "grief 
and depression”, and "anxiety and frustration" were the subthemes that emerged to illustrate common psychosocial stressors encountered by elders during the post-discharge transition.

\section{Family Conflict}

Family conflict was a source of stress that was reported by several participants. The following exemplar provided during the 30-day follow-up interview by a 72-year-old female who underwent a laparoscopic colectomy for ulcerative colitis portrayed the extreme personal and family stressors she experienced after discharge:

I am having bowel movements every 20 minutes all day long. My husband has to do the laundry. My husband and I are fighting. We are moving out of our house and into a trailer and having an estate sale. There are too many outside influences for me to take care of myself correctly.

Comments provided by an 80-year-old female who was 7-days post total knee

replacement further described stressors experienced by recovering elders: "My husband is trying to do everything. He expects more out of me and does not understand my pain.” Several other participants provided additional non-specific reports of "family stressors" during post-discharge interviews.

\section{Grief and Depression}

Reports of depression were most commonly expressed during the 30-day follow-up interviews $(12.3 \%, n=7)$. Two participants had children who were diagnosed with terminal health conditions during their post-discharge transition. Several other participants reported griefrelated depression from prior losses at the time of follow-up.

An 81-year-old female discharged following an exacerbation of COPD reported that daughter had been diagnosed with terminal cancer. She stated, "I have recovered from my 
illness, but I just found out that my daughter was diagnosed with stage IV brain cancer.” Another 68-year-old male who was discharged following a bout of pneumonia as a complication from a recent stem cell transplant exemplified the external stressors that older adults encounter after discharge during his 7-day follow-up interview: "I am very worried about my son. He has a problem with his pancreas and was just released from the hospital. My wife and I are very concerned.” When contacted for the final interview, the gentleman became distraught and reported that his son had passed away two weeks prior from pancreatic cancer.

The aforementioned woman who was the primary caregiver for her grandchildren confided that it was the anniversary of her daughter's death, and she was feeling quite emotional. Three respondents had suffered the loss of a spouse during the year that preceded their hospitalizations and were experiencing grief reactions. Several participants reported feelings of depression or "feeling down" secondary to self-perceived slow recovery, the duration of their dependency on others, and restrictions on activities such as attendance at senior center, driving, and mobility.

\section{Anxiety and Frustration}

Anxiety and frustration were reported in the early $(16.4 \%, n=11)$ and intermediate stages of recovery $(12.3 \%, n=7)$, though the etiologies varied temporally. Several respondents in the early phase of their home recovery transitions reported frustration with having to accept help from others and having an unmet transition expectation. One married woman who underwent an orthopedic surgical procedure provided the following exemplar: "This is totally different than what I thought it would be. The nursing care did not meet my expectations. I don't think I was prepared enough for home. You are on your own.” A 71-year-old male who 
underwent open heart surgery expressed anxiety secondary to a lack of trust in his home care provider. He stated, "The doctor found fluid in my chest during my routine follow-up check-up. It concerns me that the nurse did not identify this.” A 79-year-old male who had just relocated to the area reported health-related anxiety in the following exemplar: "I am having trouble wheezing and will be seeing a cardiologist. We just moved to the area, and I am learning a new medical system. I am very concerned.” Pain was also reported as a worry in the early recovery process by several participants.

Reports of anxiety and frustration in the later phase of the post-discharge transition clustered around persistent issues with dependency such as back precautions and concerns about ongoing clinical work-ups for newly-emerging health concerns. Several participants were awaiting results from diagnostic procedures or were planning for subsequent surgeries. This subtheme was exemplified in the following response provided by a 78-year-old female who was hospitalized for pneumonia: "I had an arteriogram last week because I may have a clot in my heart. I am very anxious because I will need surgery when I am well enough.” An 81-year-old gentleman who had been hospitalized with a transient ischemic attack reported similar concern in the following statement:

Life in general has been very difficult. I had to go to the nephrologist 2 weeks ago. Blood tests and urine tests were done. I will find out the results this week. My kidney function is causing worry for me and my family.

\section{Difficulties Managing Complex Health Problems}

Struggles encountered as elders and family caregivers attempted to self-manage multiple complex health problems emerged as the most-commonly reported theme related to postdischarge coping difficulty. Specifically, difficulties were reported in the following areas: controlling or managing diabetes; managing other chronic health problems such as hypertension; 
the complexity of medication regimens; and the lack of needed information. Interestingly, more reports of difficulties managing complex health problems were provided during the 30-day interview $(78.2 \%, n=43)$ than in the early stage $(52.4 \%, n=35)$ of the home recovery transition.

\section{Difficulty Controlling or Managing Diabetes}

Problems with glycemic control or diabetes management were described by $17.9 \%$ $(n=12)$ of respondents during the initial follow-up. Multimorbidity appeared to play a significant role in the development of diabetes-related post-discharge coping difficulties. Participants described significant elevations of glucose which they related to pain, medication changes such as the addition of steroids, or difficulties managing other chronic health conditions. Participants, most of who were admitted with acceptable glycemic control, often lacked skills to self-manage acute changes in their diabetes status.

A 70-year-old-male who had been admitted with a pneumomediastinum provided the following exemplar to describe difficulties he encountered with diabetes management during the early post-discharge transition: "My sugar has been up and down due to prednisone. I am having trouble finding the right balance between insulin and glucose. I am going to see an endocrinologist.” Likewise, a 77-year-old male discharged after a bout of pneumonia and a complex sinus infection reported the following struggles with glycemic regulation: "My blood sugar went over 400. It has never done that before. The doctor added glipizide. I am seeing him in two days.” A 70-year-old female who was post open-laparotomy for an abdominal abscess related to diverticular disease experienced difficulties secondary to inadequate information on how to manage a carbohydrate-controlled liquid diet. 
Troubles with glycemic control and diabetes management were more frequently reported during the 30-day interview $(37.3 \%, n=16)$. A 71-year-old female with acute renal failure described the following difficulties: "I know what to do if my sugar goes high, but have no idea how to manage it if is low. Diabetes medicines have been difficult. They have been changed.” A 79-year-old male who suffered a myocardial infarction enrolled in a diabetes self-management program due to problems with glycemic regulation following his hospitalization. He stated: "I am working with two diabetes educators at the VA on how to manage my carbs and on how much insulin I need. I am finally learning how to take care of my diabetes.” Several participants reported modification to diabetes medication regimens that included the addition of insulin, modification of insulin doses, and addition or changes in oral hypoglycemic medications.

\section{Difficulty Managing Other Chronic Health Problems}

Instability of a chronic health problem, often other than the index condition that led to hospitalization, contributed to difficulties that older adults faced during the early $(31 \%, n=19)$ and intermediate $(47.3 \%, n=26)$ home recovery transition periods. Interestingly, more respondents were experiencing issues with management of a chronic health problem at the time of the final follow-up interview, suggesting that multimorbidity may be a contributing factor to an individual's post-discharge transition experience. Although important elements in the postdischarge experience, pain and fatigue will not be included in the discussion of this subtheme because they are expected findings in many study participants, particularly those who have undergone surgical procedures.

Three respondents who were new to dialysis reported significant long-standing difficulties during the home recovery transition period. The caregiver of an 86-year-old female 
who was hospitalized for 18 days with acute renal failure exemplified the problems faced by transitioning elders with chronic kidney disease in the following response:

She is having trouble with dialysis, dressing and diet; she is exhausted. The dialysis is difficult. Her sugar level has been hard to maintain, and taking blood pressure medicines is difficult. I check her blood pressure four times per day and personally give her the blood pressure medicines. Dialysis three times per week and sorting out lots of medications have been tough.

Instability of cardiovascular conditions, specifically arrhythmias, coronary artery disease, and heart failure, was experienced by multiple participants. One gentleman who had been hospitalized for atrial fibrillation, experienced an episode of syncope which resulted in a fall within the first week of hospitalization. He subsequently fractured his femur and required surgical repair of the fracture and insertion of a pacemaker. He was residing in a short-term rehabilitation facility at the time of the 30-day follow-up. In addition to cardiovascular conditions and CKD, participants reported difficulty managing the following conditions during the home recovery transition: COPD; cerebrovascular disease in the form of transient ischemic attack; ulcerative colitis; malignant melanoma; arthritis; hypertension; osteomyelitis; lymphoma; and diverticulitis. Problems managing these conditions sometimes precipitated concurrent difficulties controlling diabetes.

\section{So Many Medicines}

Difficulties managing complex medication regimens were described by $16.4 \%(n=11)$ of participants during the early post-hospitalization transition period and by $10.9 \%(n=6)$ one month following discharge. Immediately upon returning home, difficulties centered on the need for clarification of medication recommendations, particularly relative to management of preexisting health conditions, acquisition of new prescriptions, and the sheer number of prescribed 
medications. A 72-year-old female provided the following exemplar of difficulties she encountered in managing medications for a pre-existing chronic illness: "I am unclear if I should take my ulcerative colitis medicines. My symptoms are getting worse.” One elderly gentleman described his difficulty with medication management in the following response: "I am on 18 medicines and get some from the VA. I have to wait 14 days to get the medicines through the mail.”

Changes in medications used in the management of chronic health problems presented challenges to elders during the later follow-up period. An 81-year-old woman who lived alone discussed her trials with medication management in the following exemplar: "Changing medications has been a problem.... when to take them and putting them in places where I will remember to take them on time.” An elderly gentleman who had been hospitalized for heart failure corroborated this theme with the following statement: "I am on 6 new pills. It is very hard to adjust these.” Multiple participants indicated that they had abdicated responsibility for medication management to a family member.

\section{Needed More Information}

Inadequate discharge information was a concern cited by $10.4 \%(n=7)$ of respondents during the first week of the home recovery transition. Participants perceived that they had received insufficient information on their health status and prognosis and, as previously discussed, self-management requirements in the areas of diet, medication management, and wound care. One woman who had a three-day length-of-stay following an elective colectomy with possible colostomy showed a significant lack of understanding of her condition with the following exemplar: 
I do not know what happened in surgery. I was given information while I was still asleep. I still don’t know what is going on. I have not been able to speak to my doctor about it my primary care doctor does not have the information.

A 71-year-old female who was hospitalized for acute renal failure also demonstrated a poor understanding of her changing health status with the following statement: “The doctor told me I have $18 \%$ of my kidney function. I don’t know what that means.”

A 69-year-old married male who was admitted with heart failure provided a portrait of the difficulties that acutely-ill older adults encounter while attempting to process the large amount of information provided during a hospitalization. His telling experience is encapsulated in the following exemplar:

I saw half-a-dozen health professionals every day in the hospital at all hours of the day and night. I know this is how a 24-hour operation runs, but it was difficult. I realized I was not grasping large amounts of information and had my wife spend the night to help with it all and to make sure I was not missing anything. It was daunting.

\section{Discussion}

Content analysis of the many free-response comments provided by participants and their caregivers offered insight into the specific difficulties that older adults with a pre-existing chronic illness encountered at home during the early and intermittent stages of the posthospitalization transition. Participants described the dynamic nature of the home recovery transition process and evolving needs of the older adult and family system as the transition progressed. The fragility of the post-discharge caregiving situation was displayed in comments that described the creative approaches that elders and family members used to maintain an older adult at home. 


\section{The Daily Stuff is Difficult}

The theme, "the daily stuff is difficult" portrays the difficulties that elders and family caregivers face in meeting declines in functional status that often follow a hospitalization. Early in the home recovery transition, elders were typically dependent upon a family caregiver to meet basic needs such as hygiene, housekeeping, meal preparation, and transportation. Post-surgical participants, in particular, were placed on activity restrictions that precluded them from independently meeting basic needs or experienced pain while attempting to perform personal care. The unexpected duration of these restrictions and pain were problematic for several respondents.

As the post-hospitalization transition progressed, respondents articulated a strong desire for self-sufficiency and expressed frustration with continued reliance on others particularly for stand-by assistance with bathing and transportation. For elders who lived alone, a family member or friend often provided support in the first weeks following discharge. The elder subsequently had to engage other resources from their social network, particularly for transportation to obtain groceries or to attend medical appointments, when the initial caregiver departed.

\section{Engineering Care at Home Is Complex}

The Merriam Webster dictionary (2013) defines the transitive verb “to engineer” as “to contrive or plan out; to guide the course of”. The action of “engineering” effectively conceptualizes the complexity of the personal, family, extended support, supply, and community resource integration that is necessary for an effective hospital-to-home transition. While hospital personnel may provide recommendations and referrals for care resources, it is ultimately the 
elder and individuals in his or her support system that operationalize the post-discharge care experience.

Responses revealed that the hospitalization of an older adult presented a family crisis that affected multiple individuals within the elder's social network. Older adults and their family members frequently solicited help from a variety of sources in order to operationalize a safe discharge into the home environment. Often, family members rearranged their personal lives in order to maintain the elder at home. Respondents reported that family caregivers had traveled great distances in order to provide post-discharge assistance. Alternately, some elders had relocated to the care provider's home during the early post-hospitalization transition. In one extreme circumstance, a caregiver had left employment in order to care for his mother. Some families provided daily visitation and supervision to a recently-discharged elder and described an obligation to provide ongoing support late into the home recovery transition. Recruitment of support from extended family members such as siblings, nieces, grandchildren, and daughters-inlaw was common.

Approximately half of the respondents reported that they had been referred to home care following discharge. While the assistance with care was appreciated, caregivers stated that scheduling of these resources was often challenging and limited the ability of the caregiver to leave the home to meet personal and family needs such as banking, medical appointments, and grocery shopping. Elders who were discharged with complex care needs typically received home care services from multiple disciplines. The inclusion of more than one discipline in care at home was particularly problematic for caregivers as they attempted to plan their daily schedules.

The hospitalization of an established family caregiver inflicted a tremendous stress on the recovering older adult and the family system. Participants who were required to resume the care 
of a dependent family member immediately after discharge reported high stress levels that impacted the perceived ability of the recently-hospitalized elder to recover.

Meeting the competing and, at times, conflicting demands of self and the care recipient was particularly difficult when the primary caregiver had personal health problems. Several of these caregivers reported the need for future surgical procedures and the presence of pre-existing orthopedic conditions such as chronic back problems and arthritis that affected their ability to serve as an effective physical care provider.

Multigenerational caregiving emerged as an extreme source of post-discharge strain in several families. In addition to having full care responsibility for the recently-discharge elder, several caregivers also had care obligations for another dependent individual. The term “sandwich generation” has been used to describe the competing demands exerted by work, childrearing, and care of elderly parents that are encountered by many middle-aged adults (Quadagno, 2008). The concept of “sandwich generation” was much broader for the respondents in this study and applied exclusively to female care providers. Several caregivers had dual accountability for grandchildren and an ill-spouse, while others carried the burden of concurrent responsibility for a husband and an old-old parent. At least two women experienced simultaneous admission of a spouse and parent during the data collection period.

Living alone presented unique challenges to elders following a hospitalization and necessitated the coordination of community and social resources. During recruitment activities, the principal investigator anecdotally noted that older adults who lacked a caregiver and experienced moderate to complex post-discharge care needs were typically transferred to shortterm rehabilitation facilities. Ten participants in the parent study reported living alone with no formal caregiver at the time of enrollment. Two of these participants were discharged to a 
rehabilitation setting after it was determined by physical therapy on the day of discharge that they were unsafe for relocation to an unsupervised environment. Another five of the participants who lived alone were lost-to-follow-up during the post-discharge period. Statements provided by participants who were navigating the post-discharge transition independently were limited but provide important insight into the experience of “doing it alone.” These respondents utilized creative approaches in eliciting support during their home recovery transitions and were typically reliant on social networks and community resources to meet their needs. Several felt that they were not physically ready for discharge and retrospectively stated they should have sought a short-term rehabilitation placement following discharge.

Care recipients were keenly aware of the sacrifices that care providers made in order to support them during their post-hospitalization transitions. They were conscious of the burden of care that their illness imposed on a loved one and expressed worry about their caregivers’ physical and mental health.

\section{Life is Stressful}

In addition to the innate stressors associated with post-hospitalization transitions, elders returned home to unique sets of external family stressors that had the potential to exert substantial impact on their recoveries. Respondents reported marital stress, worries about children, and financial concerns and intimated that these stressors were precluding them from focusing on their health. Acute and latent grief reactions were experienced by at least five respondents during the data collection period.

Mental health and coping problems were reported by at least one-fourth of participants. Depression and anxiety were particularly prevalent later in the home recovery transition. 
Frustration with self-perceived delays in recovery was common. New and existing health problems that developed or decompensated following discharge generated anxiety later in the transition process. Several participants were awaiting diagnostic results for conditions such as kidney and cardiovascular disease. A few respondents were scheduled for future surgeries after they recovered from the condition that led to hospitalization.

\section{Managing Multiple Complex Health Problems is Difficult}

The impact of multimorbidity on the home recovery transition was pervasive and was captured in the overarching theme of "managing multiple complex health problems is difficult". Participants regularly confronted difficulties in managing health problems that were not directly related to the index condition that precipitated the hospitalization. Respondents described concomitant problems with mobility, transportation secondary to medical restrictions, the emotional and physical demands of caregiving, maintenance of glycemic control, integrating treatment plans for multiple chronic conditions, the exacerbation of pre-existing health problems, and the complexity of medication regimens. Participants encountered more difficulty managing chronic health problems later in the post-discharge transition.

Three recurring subthemes that specifically portrayed the complexity of self-managing chronic health conditions were identified as having a potential direct relationship to events of recidivism. These subthemes included difficulty controlling or managing diabetes, difficulty managing chronic health problems other than diabetes, and difficulty managing medications in the post-discharge period. Discrete data variables that described the presence of absence of each of these problems were transposed into nominal level variables and subjected to statistical testing in the quantitative core component of the study. 
Unmet system-level needs, particularly inadequate discharge preparation, were reported by multiple participants. Anecdotally, the principal investigator noted that had many participants could not articulate post-discharge care requirements at the time of study enrollment, which was typically within several hours of discharge. Participants would commonly provide statements such as, "I am sure they will tell me what to do before I go home.” Additionally, respondents routinely voiced that they would rely on prior experience in managing a chronic health condition when operationalizing care at home. Review of case management notes revealed that the older adult was often the sole individual providing information on post-hospitalization care needs. Statements such as "My wife will manage it" or "My daughter takes care of things" were common.

\section{Implications}

This supplementary analysis of free-response data provided enlightening descriptions of problems encountered by elders affected by a pre-existing chronic illness during the immediate and intermediate periods of the home recovery transition.

\section{Clinical Practice}

Responses illustrated that elders and family care providers often encountered difficulties as they attempted to implement care in the home environment. The etiologies of problems confronted during the early and intermediate phases of the post-discharge transition varied. The findings of this analysis suggest that there is a need to appreciate the evolving care requirements of recently hospitalized elders as they progress through the post-hospitalization transition process. Systems to support recently elders and caregivers at multiple points of the home recovery transition are needed. The findings of this analysis support transitional care models that 
support older adults and their family care givers beyond the 30-day readmission threshold (Naylor et al., 2004; Transitional Care Model, 2009; Watkins, Hall, \& Kring, 2012).

Input on discharge disposition recommendations for study participants was typically sought from nursing, rehabilitation, medical, and social service professionals. Review of discharge planning records in this study revealed that no uniform, measureable criteria were used in formulating recommendations to guide families in selection of an appropriate post-discharge care setting. There is a great need for development of instruments that assist in risk-stratifying patients based upon a structured set of predictors for successful and unsuccessful posthospitalization transition outcomes.

Because family care providers are so integral to a successful home recovery transition, there is a need to better appreciate the post-discharge transition experience from the caregiver perspective. Expanded participation of family care providers in determination of discharge plans is required. Study respondents indicated that health and external stressors potentially impacted the experience of caregiving and recovery of the recently-discharged older adult. Pre-discharge assessment of family stress may be helpful in identifying elders and family caregiver who are at higher risk for post-discharge coping difficulty. Early identification of stress, anxiety, and depression in older adults and caregivers during follow-up provider visits may facilitate opportunities to discuss effective coping strategies and initiate mental health referrals as needed.

\section{Research}

The post-discharge needs of individuals with combined disease states are poorly understood. All participants in this study were affected by diabetes, and most had been diagnosed with several additional chronic health conditions. A number of participants experienced 
difficulty in integrating the care demands of multiple chronic conditions. None of the participants was admitted with diabetes, but changes in glycemic control that presented during the course of illness and recovery often resulted in changes in established diabetes treatment plans. The ADA has indicated that there is a need to better understand the specific discharge needs of individuals with diabetes (American Diabetes Association, 2013b). The findings of this research further suggest that there is a need to better understand the post-hospitalization needs of elders with multimorbidity.

Initiatives to improve medication reconciliation and information transfer practices have been a national trend in response to patient safety concerns (The Joint Commission, 2013). Because participants in this study were experiencing difficulty managing changing, complex medication regimens during both data collection periods, there is a need for further research on best practices for medication reconciliation within ambulatory care settings.

Responses provided by the limited number of participants who lived alone suggested that a solo living situation significantly increased the risk for post-discharge coping difficulties. During study recruitment, many elders who lived alone were transferred to a short-term rehabilitation facility following hospitalization. Most of these elders will eventually return home, many with residual care needs that may mirror those of respondents in this analysis. Discharge preparation resources in short-term rehabilitation facilities may be more limited than those available in hospitals. Thus, there is an opportunity to study the post-discharge needs of recently hospitalized older adults as they transition from hospital to home, hospital to rehabilitation facility, and rehabilitation facility back to home. 


\section{Health Policy}

The current national focus on outcome-based reimbursement for acute care services, which includes penalties for 30-day readmission for several diagnoses, has incentivized hospitals to implement disease-specific transitional care programs (Medicare Payment Advisory Committee, 2007; Naylor et al., 2012). Emphasis on condition-specific interventions, however, may not adequately identify the heightened discharge risk of older adults who are affected by multimorbidity but unaffected by the targeted conditions. Furthermore, the risk for postdischarge difficulties may be underestimated in elders with multiple complex health problems who are admitted for seemingly, unrelated elective surgical procedures. Current metrics that evaluate institutional performance on discharge outcomes should be expanded beyond events of recidivism to include measures that assess the transition quality from the perspective of patients and family caregivers.

\section{Limitations}

The opportunity to provide free response comments to items on the PDCDS was optional in this study. It was noted that participants who reported no post-discharge coping difficulties provided few free response comments, leaving no ability to compare the situational experiences of those who did and did not experience transition problems. Additionally, descriptions of postdischarge coping difficulties of individuals who were lost-to-follow-up were not available. It is possible that these participants, particularly those who lived alone or were readmitted, deferred follow-up because they did not want to report difficulties. Free response comments used in this analysis were obtained from both participants and proxy care providers. At times responses by one respondent may have reflected an opinion on how the other party was adjusting or coping 
with the transition. Responses were typically brief and the nature of the telephone interview precluded further probing on significant issues.

The demographic of survey respondents was unable to fully capture variations in transition experiences secondary to cultural or ethnic background and living situation. Due to the demographic profile of the community in which the study was conducted, there were few ethnic or cultural differences between study participants. Cultural mores and associated family expectations on elder care may potentially affect transitional care decision making. Finally, few respondents who provided responses in this study lived alone. The experience of "doing it alone" may be inadequately represented by participant responses in this study.

\section{Conclusion}

Hospitalization commonly precipitates a period of heightened vulnerability for older adults and individuals within their family networks. Respondents in this study provided comments that described difficulties encountered by older adults with a pre-existing chronic health problem as well as their family care providers during the early and intermediate transition from the hospital to home. Analysis of comments provided during the two data collection periods revealed that the transition from hospital to home is complex and potentially fraught with problems, particularly when elders are afflicted with multiple medical conditions, live alone, or are subjected to external family stressors such as serving as a caregiver for another.

The home recovery transition is dynamic, and the difficulties experienced by participants vary temporally. The study included participants with a variety of medical diagnoses, most of who were affected by multimorbidity. Emerging care models that target individuals with predetermined health conditions may inadequately identify elders who are not affected by an index 
condition but still have extensive needs. While hospital discharge planning processes typically address immediate transition needs, the changes in health status that emerged during in the first month following discharge suggest that there is a need for improved support of elders and family caregivers during the later phases of the home recovery transition.

\section{Tables}

Table 22. Summary of Themes and Subthemes by Frequency and Response Period

\begin{tabular}{|c|c|c|c|c|}
\hline \multirow[t]{2}{*}{ Thematic Category } & \multicolumn{2}{|c|}{$\begin{array}{c}\text { 7-day Follow-up } \\
n=67\end{array}$} & \multicolumn{2}{|c|}{$\begin{array}{l}\text { 30-day Follow-up } \\
n=55\end{array}$} \\
\hline & $\%$ & $n$ & $\%$ & $n$ \\
\hline "The daily stuff is difficult." & 56.7 & 38 & 56.3 & 31 \\
\hline - Personal care and household tasks & 44.3 & 29 & 41.8 & 23 \\
\hline - Walking and mobility & 17.9 & 12 & 18.2 & 10 \\
\hline - Transportation & 4.5 & 3 & 12.7 & 7 \\
\hline - Getting supplies and medicines & 4.5 & 3 & 0 & 0 \\
\hline Engineering care at home is complex & 52.2 & 35 & 43.6 & 24 \\
\hline - “I come last" & 20.9 & 14 & 25.5 & 14 \\
\hline - "Doing it alone is difficult." & 3.0 & 2 & 7.3 & 4 \\
\hline - Mobilizing family and support resources & 14.9 & 10 & 20.0 & 11 \\
\hline - “This is rough on my family." & 34.3 & 23 & 18.2 & 10 \\
\hline "Life is stressful." & 22.4 & 15 & 29.1 & 16 \\
\hline • “Too many outside influences.” & 6.0 & 4 & 9.1 & 5 \\
\hline - Grief and depression & 3.0 & 2 & 12.7 & 7 \\
\hline - Anxiety and frustration & 16.4 & 11 & 12.7 & 7 \\
\hline $\begin{array}{l}\text { Managing multiple complex health problems is } \\
\text { difficult }\end{array}$ & 52.2 & 35 & 78.2 & 43 \\
\hline • “My diabetes has been hard to control.” & 17.9 & 12 & 29.1 & 16 \\
\hline - Managing other chronic health problems & 31.3 & 21 & 47.3 & 26 \\
\hline & 16.4 & 11 & 10.9 & 6 \\
\hline
\end{tabular}




\begin{tabular}{ccccc}
\hline Thematic Category & \multicolumn{2}{c}{$\begin{array}{c}\text { 7-day Follow-up } \\
n=67\end{array}$} & $\begin{array}{c}\text { 30-day Follow-up } \\
n=55\end{array}$ \\
\cline { 2 - 4 } & $\%$ & $n$ & $\%$ & $n$ \\
\hline • "So many medicines.” & 13.4 & 9 & 1.8 & 1 \\
• "I needed more information." & & & & \\
\hline
\end{tabular}

**Participants frequently provided multiple comments representing different thematic categories 
Table 23. General Demographic and Health-Illness Characteristics of 7-day and 30-day Respondents

\begin{tabular}{|c|c|c|}
\hline & $\begin{array}{c}\text { 7-day } \\
\text { Respondents }\end{array}$ & $\begin{array}{c}\text { 30-day } \\
\text { Respondents }\end{array}$ \\
\hline Age & $n=67$ & $n=55$ \\
\hline Mean (SD) years & $75.22(6.112)$ & $75.65(5.901)$ \\
\hline Median years & 75.00 & 76.00 \\
\hline $64-74$ years $(\%, n)$ & $47.8,32$ & $41.8,23$ \\
\hline$\geq 75$ years $(\%, n)$ & $52.2,35$ & $58.2,32$ \\
\hline Gender & $n=67$ & $n=55$ \\
\hline Female $(\%, n)$ & $49.3,33$ & 50.9 \\
\hline Male $(\%, n)$ & $50.7,34$ & 49.1 \\
\hline Ethnicity & $n=67$ & $n=55$ \\
\hline Asian $(\%, n)$ & $1.5,1$ & $1.8,1$ \\
\hline Black $(\%, n)$ & $9.0,6$ & $12.7,7$ \\
\hline Caucasian $(\%, n)$ & $88.1,59$ & $83.6,46$ \\
\hline Latino $(\%, n)$ & $1.5,1$ & $1.8,1$ \\
\hline Admitting Diagnosis & $n=67$ & $n=55$ \\
\hline Cardiovascular condition $(\%, n)$ & $25.4,17$ & $30.9,17$ \\
\hline Non-cardiovascular medical condition $(\%, n)$ & $47.8,32$ & $45.5,25$ \\
\hline General surgical $(\%, n)$ & $26.9,18$ & $23.6,13$ \\
\hline Comorbidity Profile & $n=67$ & $n=55$ \\
\hline Coronary artery disease $(\%, n)$ & $59.7,40$ & $60.0,33$ \\
\hline Chronic kidney disease $(\%, n)$ & $41.8,28$ & $43.6,24$ \\
\hline Chronic obstructive pulmonary disease $(\%, n)$ & $22.4,15$ & $21.8,12$ \\
\hline Cerebrovascular disease $(\%, n)$ & $22.4,15$ & $21.8,12$ \\
\hline Diabetes chronic complication $(\%, n)$ & $85.1,57$ & $87.3,48$ \\
\hline Foot problems $(\%, n)$ & $9.0,6$ & $9.1,5$ \\
\hline Heart failure $(\%, n)$ & $35.8,24$ & $36.4,20$ \\
\hline Neuropathy $(\%, n)$ & $55.2,37$ & $61.8,34$ \\
\hline Peripheral vascular disease $(\%, n)$ & $31.3,21$ & $36.4,20$ \\
\hline \multicolumn{3}{|l|}{ Diabetes Status } \\
\hline $\mathrm{A} 1 \mathrm{c}(\%)$ & $n=60$ & $n=50$ \\
\hline Mean $(S D)$ & $6.82(1.06)$ & $6.78(.913)$ \\
\hline Median & 6.7 & 6.75 \\
\hline $\mathrm{A} 1 \mathrm{c} \geq 8(\%, n)$ & $10.1,7$ & 8.0, \\
\hline Insulin at discharge? $(\%, n)$ & $32.8,23$ & $40.0,22$ \\
\hline Change in diabetes treatment at discharge? $(\%, n)$ & $41.8,25$ & $47.3,26$ \\
\hline Length-of-stay (days) & $n=67$ & $n=55$ \\
\hline Mean $(S D)$ & $5.87(3.393)$ & $5.78(3.337)$ \\
\hline Median & 5.0 & 5.0 \\
\hline Hospitalist $(\%, n)$ & $28.4,19$ & $23.6,13$ \\
\hline Caregiver in home at discharge $(\%, n)$ & $85.1,57$ & $89.1,49$ \\
\hline Homecare at discharge $(\%, n)$ & $52.2,35$ & $50.9,28$ \\
\hline
\end{tabular}




\section{References}

American Diabetes Association. (2013a). Standards of medical care in diabetes - 2013. Diabetes Care, 36(Suppl 1), S12-S66.

American Diabetes Association. (2013b). Economic costs of diabetes in the U. S. in 2012. Diabetes Care, 36, 1033-1046.

American Geriatrics Society on Care of Older Adults with Multimobidity. (2012). Guiding principles for the care of older adults with multimorbidity: An approach for clinicians. Journal of the American Geriatrics Society, 60, E1-E-25.

Bobay, K., Jerofke, T. A., Weiss, M. E., \& Yakusheva, O. (2010). Age-related differences in perception of quality of discharge teaching and readiness for hospital discharge. Geriatric Nursing, 31, 178-187.

Brown, M. T., \& Bussell, J. K. (2011). Medication adherence: WHO cares? Mayo Clinic Proceedings, 86, 304-311.

Centers for Disease Control and Prevention. (2011). National diabetes fact sheet: National estimates and general information on diabetes and prediabetes, 2011. Atlanta, GA: U. S. Department of Health and Human Services.

Chau, D., \& Edelman, S. V. (2001). Clinical management of diabetes in the elderly. Clinical Diabetes, 19(4), 172-175.

Condelius, A., Edberg, K. A., Jakobsson, U., \& Hallberg, I. R. (2008). Hospital admissions among people 65+ to multimorbidity, municipal and outpatient care. Archives of Gerontology and Geriatrics, 46, 41-55.

Engineer. (2013). In Merriam-Webster's online dictionary. Retrieved from http://www.merriamwebster.com/dictionary/engineer 
Hall, M. J., DeFrances, C. J., Williams, S. N., Golosinskiy, A., \& Swartzman, A. (2010). National Hospital Discharge Survey: 2007 summary. National Health Statistics Reports, 29. Hyattsville, MD: National Center for Health Statistics.

Levine, C., Albert, S. M., Hokenstad, A., Halper, D. E., Hart, A. Y., \& Gould, D. A. (2006). "This case is closed": Family caregivers and the termination of home health care services for stroke patients. Milbank Quarterly, 84, 305-331.

Marengoni, A., Angleman, S., Melis, R., Manglialasche, F., Karp, A., Garmen, A., et al. (2011). Aging with multimorbidity: A systematic review of the literature. Aging Research Reviews, 10, 430-439.

Marengoni, A., Rizzuto, D., Wang, H. X., Winbland, B., \& Fratiglioni, L. (2009). Patterns of chronic multimorbidity in the elderly population. Journal of the American Geriatrics Society, 57, 225-230.

Medicare Payment Advisory Committee. (2007). Report to Congress: Promoting greater efficiency in Medicare. Washington, DC: MEDPAC.

Miller, J. F., Piacentine, L. B., \& Weiss, M. (2008). Coping difficulties after hospitalization. Clinical Nursing Research, 17, 278-296.

Mistiaen, P., Francke, A. L., \& Poot, E. (2007). Interventions aimed at reducing problems in adult patients discharged from hospital to home: A systematic meta-review. BMC Health Services Research, 7(47).

Morse, J. M., \& Niehause, L. (2007). Combining qualitative and quantitative methods for mixedmethods designs. In P. L. Munhall (Ed.), Nursing Research: A qualitative perspective (4th ed., pp. 541-554). Sudsbury, MA: Jones and Bartlett Publishers. 
Murtaugh, C. M., \& Litke, A. (2002). Transitions through post-acute and long-term care settings: Patterns of use and outcomes for a national cohort of elders. Medical Care, 40(3), 227236.

Naylor, M. D., Brooten, D. A., Campbell, R. L., Maislin, G., McCauley, K. M., \& Schwartz, J. S. (2004). Transitional care of older adults hospitalized with heart failure: A randomized, controlled trial. Journal of the American Geriatrics Society, 52(5), 675-684.

Naylor, M. D., Kurtzman, E. T., Grabowski, D. C., Harrington, C., McClellan, M., \& Reinhard, S. C. (2012). Unintended consequences of steps to cut readmissions and reform payment may threaten care of vulnerable older adults. Health Affairs, 31(7), 1623-1632.

Quadagno, J. (2008). Aging and the life course: An introduction to social gerontology (4th ed.). New York: McGraw Hill.

Snow, A. L., Cook, K. F., Lin, P., Morgan, R. O., \& Magaziner, J. (2005). Proxies and other external raters: Methodological considerations. Health Services Research, 40, 1676-1693.

The Joint Commission. (2013). National Patient Safety Guidelines effective January 1, 2013: Hospital Accreditation Program. Retrieved from http://www.jointcommission.org/assets/1/18/NPSG_Chapter_Jan2013_HAP.pdf

Transitional Care Model. (2009). Transitional Care Model. Retrieved from http://www.transitionalcare.info/index.html

van den Akker, M., Buntinx, F., Metsemakers, J. F. M., Roos, S., \& Knottnerus, J. A. (1998). Multimorbidity in general practice: Prevalence, incidence, and determinants of cooccurring chronic and recurrent diseases. Journal of Clinical Epidemiology, 51, 367-375. Watkins, L., Hall, C., \& Kring, D. (2012). Hospital to home: A transition program for frail older adults. Professional Case Management, 17(3), 117-125. 
Weiss, M. E., \& Piacentine, L. B. (2006). Psychometric properties of the Readiness for Hospital Discharge Scale. Journal of Nursing Measurement, 14, 163-180.

Weiss, M. E., Piacentine, L. B., Lokken, L., Ancona, J., Archer, J., Gresser, S., et al. (2007). Perceived readiness for hospital discharge in adult medical-surgical patients. Clinical Nurse Specialist: The Journal for Advanced Nursing Practice, 21, 31-42. 
APPENDIX A: IRB APPROVAL 


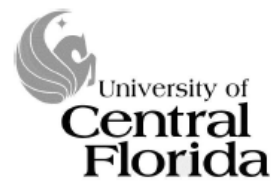

University of Central Florida Institutional Review Board

Office of Research \& Commercialization

12201 Research Parkway, Suite 501

Orlando, Florida 32826-3246

Telephone: $407-823-2901$ or $407-882-2276$

www.research.ucf.edu/compliance/irb.html

\title{
Approval of Human Research
}

\author{
From: $\quad$ UCF Institutional Review Board \#1 \\ FWA00000351, IRB00001138 \\ To: $\quad$ Jacqueline M Lamanna \\ Date: January 06, 2012
}

Dear Researcher:

On January 6, 2012, the IRB approved the following human participant research until 1/5/2013 inclusive:

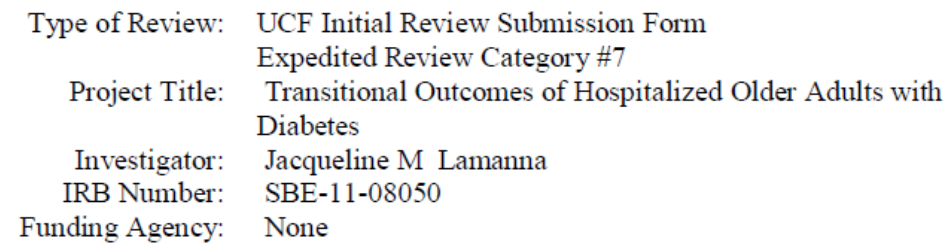

The Continuing Review Application must be submitted 30days prior to the expiration date for studies that were previously expedited, and 60 days prior to the expiration date for research that was previously reviewed at a convened meeting. Do not make changes to the study (i.e., protocol, methodology, consent form, personnel, site, etc.) before obtaining IRB approval. A Modification Form cannot be used to extend the approval period of a study. All forms may be completed and submitted online at https://iris.research.ucf.edu .

If continuing review approval is not granted before the expiration date of $1 / 5 / 2013$, approval of this research expires on that date. When you have completed your research. please submit a Study Closure request in iRIS so that IRB records will be accurate.

Use of the approved, stamped consent document(s) is required. The new form supersedes all previous versions, which are now invalid for further use. Only approved investigators (or other approved key study personnel) may solicit consent for research participation. Participants or their representatives must receive a signed and dated copy of the consent form(s).

In the conduct of this research, you are responsible to follow the requirements of the Investigator Manual

On behalf of Sophia Dziegielewski, Ph.D., L.C.S.W., CF IRB Chair, this letter is signed by:

Signature applied by Janice Turchin on 01/06/2012 02:16:39 PM EST

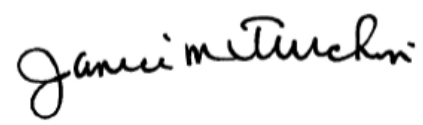

IRB Coordinator

Page 1 of 1 
Institutional Review Board (IRB)Authorization Agreement

\author{
Institution Providing IRB Review University of Central Florida IRB \#1 \\ ("Reviewing Institution"): \\ Providing Institution IRB Registration No.: RB00001138 \\ Providing Institution Federalwide Assurance (FWA) No.: FWA00000351
}

Institution Relying on Providing Institution IRB

("Relying Institution"):

Relying Institution FWA No.:

FWA00005314

The Officials signing below agree that the Relying Institution's IRB may depend upon the Reviewing Institution's IRB for review and continuing oversight of its human subjects research described below;

This agreement is limited to the following specific protocol(s):

SBE-11-08050 - Transitional Outcomes of Hospitalized Older Adults with Diabetes; Jacqueline Lamanna, Principal investigator

The Parties agree that Reviewing Institution's IRB shall:

1) providea copy of theprotocolto Relying Institution's IRB for a comment period lasting no longer than thirty (30) days,

2) receive Relying Institution IRB's comments to be considered in good faith, and

3) provide a copy of the final approved protocol.

The parties shall mutually agree upon the final review protocol. Relying institution's IRB shall have the final approval authority regarding whether to proceed with the human subject research described above. Reviewing Institution's IRB shall follow written procedures for reporting its findings and actions to appropriate officials at Relying Institution's IRB. Relevant minutes of Reviewing Institution IRB meetings shall be made available to Relying Institution upon request. Reviewing Institution's IRB shall use all reasonable efforts toconform with the human subject protection requirements and policies of Relying Institution's Office for Human Research Protections ("OHRP") approved FWA.Relying Institution's IRB remains responsible for ensuring compliance with Reviewing Institution'sIRB determinations and with the terms of its OHRP-approved FWA. This document must be kept on file by both parties and provided to OHRP upon request.

Providing Institution has full accreditation from the Association for the Accreditationof Human Research Protection Programs, Inc. ("AAHRPP") for its human research protection programs and warrants that it will maintain its full accreditation with AAHRPP in good standing and report immediately to Relying Institution any change in its accreditation status. Providing Institution shall also promptly report the results of any OHRP or Federal Food and Drug Administration investigations into research at Providing Institution to Relying Institution.

(Signature Page immediately follows this Page.) 
SIGNATURES OF SIGNATORY OFFICIALS OF THE PARTIES

Reviewing Institution

University of Central Florida IRB \#1

By:

Title: Associate V/ce Pressident for Research Print Full Name: Thomas O'Neal
Relying Institution:

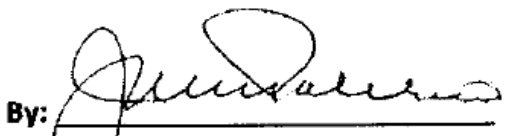

Title: CMO, VP Quality and Protection of Human Subjects in Research

Print Full Name: James V. Palermo, M. D.

(The Remainder of this Page Intentionally Left Blank.) 
APPENDIX B: INFORMED CONSENT FORM 


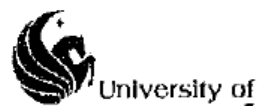 \\ Central \\ Florida
}

\section{Transitional Outcomes of Hospitalized Older Adults with Diabetes \\ Informed Consent}

\author{
Principal Investigator(s): Jacqueline M. LaManna, MSN, ARNP-BC, ADM, CDE \\ Faculty Supervisor: $\quad$ Karen Dennis, PhD, RN, FAAN
}

Investigational Site(s):

Introduction: Researchers at the University of Central Florida (UCF) study many topics. To do this we need the help of people who agree to take part in a research study. You are being invited to take part in a research study which will include about 156 people in east Central Florida. You have been asked to take part in this research study because you are an adult age 65 or older with a history of diabetes and because you are being discharged to home after at least a 2 day stay in the hospital.

Jacqueline LaManna, the person doing this research, is a doctoral student at the University of Central Florida, College of Nursing.

Because the researcher is a graduate student, she is being guided by Dr. Karen Dennis, a UCF faculty supervisor in the College of Nursing.

\section{What you should know about a research study:}

- Someone will explain this research study to you.

- A research study is something you volunteer for.

- Whether or not you take part is up to you.

- You should take part in this study only because you want to.

- You can choose not to take part in the research study. 
- You can agree to take part now and later change your mind.

- Whatever you decide it will not be held against you.

- Feel free to ask all the questions you want before you decide.

Purpose of the research study: The purpose of this study is find out what factors affect your adjustment to home and how you care for your diabetes after you are discharged from the hospital.

\section{What you will be asked to do in the study:}

- You will be asked to give permission for the researcher to review your hospital record. The researcher will gather information on your hospitalization, health history, diabetes history, diabetes treatment plan, and general discharge instructions.

- You will meet with the researcher on the day you are scheduled to leave the hospital. You will be asked questions about your health and your diabetes. You will be asked to complete a short memory screening test. You also will be asked to complete one survey on your readiness for discharge and another on how you perceive the quality of your hospital discharge teaching. This procedure will take no more than 30 minutes.

- Seven days after you return home, the researcher or a research assistant will contact you by telephone. You will be asked 15 questions about the quality of your hospital discharge. You also will be asked 10 questions to see if you have experienced any problems since returning home from the hospital.. This telephone interview should take no more than 15 minutes.

- Thirty days after you return home, you will be contacted by telephone and asked the same ten questions about after-discharge problems. You also will be asked 15 questions about how you have managed your diabetes since returning home. This telephone interview should take no more than 15 minutes.

\section{Location:}

- The face-to-face interview will be held in your hospital room. The remainder of the study will be conducted on the telephone.

Time required: We expect that you will be in this research study for 30 days.

\section{Risks:}

- It is possible that you could become tired during interviews. 
- People who have completed the surveys in this study have not reported emotional distress. However, it is possible that you could experience anxiety or emotional concerns during the interviews.

- All attempts will be made to protect your confidential information, but there is a small risk that there could be a breach in confidentiality.

\section{Benefits:}

You will not get any personal benefit from taking part in this study. Your willingness to take part, however, may help hospital staff to better understand and/or treat others who have diabetes in the future.

\section{Compensation or payment:}

There is no compensation or other payment to you for taking part in this study.

\section{Confidentiality:}

We will limit your personal data collected in this study to people who have a need to review this information. While all attempts will be made to protect your privacy, we cannot promise complete secrecy.

Your information will be combined with the information from other people taking part in the study. When we write about the study to share it with other researchers, we will write about the combined information we have gathered. You will not be identified in these written materials. We may publish the results of this study; however, we will keep your name and other identifying information private.

We will make every effort to prevent anyone who is not on the research team from knowing that you gave us information, or what that information is. For example, your name will be kept separate from the information you give, and these two files will be stored in different places under lock and key. The information provided will be coded with a number assigned to you alone. Only the researcher will have access to this number. All information will be stored on a computer that is password protected in a file that is also password provided. Data will be backed up on a password protected USB device.

All interviews will be conducted in a private environment. Follow-up telephone interviews will be conducted on a cell phone that is dedicated only to this project. The researcher or research assistant will be in a private environment when conducting these interviews. 
We will limit your personal data collected in this study to people who have a need to review this information. Organizations that may inspect and copy your information include the UCF Institutional Review Board, other representatives of UCF, and personnel from Holmes Regional Medical Center and Health First, Inc.

\section{Study contact for questions about the study or to report a problem:}

If you have questions, concerns, or complaints, or think the research has hurt you, talk to Jacqueline LaManna, Graduate Student, College of Nursing, (321) 433-7855 or Dr. Karen Dennis, Faculty Supervisor, College of Nursing, (407) 832-1832 or by email at karen.dennis@ucf.edu.

IRB contact about your rights in the study or to report a complaint: Research at the University of Central Florida involving human participants is carried out under the oversight of the Institutional Review Board (UCF IRB). This research has been reviewed and approved by the IRB. For information about the rights of people who take part in research, please contact: Institutional Review Board, University of Central Florida, Office of Research \& Commercialization, 12201 Research Parkway, Suite 501, Orlando, FL 32826-3246 or by telephone at (407) 823-2901. You may also talk to them for any of the following:

- Your questions, concerns, or complaints are not being answered by the research team.

- You cannot reach the research team.

- You want to talk to someone besides the research team.

- You want to get information or provide input about this research.

\section{Withdrawing from the study:}

If you decide to take part in the study at this time, you still have the right to decide at any time that you no longer want to continue. If you decide to leave the study, contact the investigator so that the investigator can remove your from the follow-up phone call list. You will not be treated differently if you decide to stop taking part in the study.

The individuals conducting the study may need to withdraw you from the study without your approval. This may occur if you are not able to follow the directions they give you or if there are significant communication problems on the telephone. Also, if the researcher cannot reach you within 7 days of each telephone follow-up appointment, you will be withdrawn from the study.

\section{HIPAA AUTHORIZATION TO RELEASE INFORMATION FOR RESEARCH}

Privacy laws, including the Health Insurance Portability \& Accountability Act (HIPAA) and other federal and state laws, rules, and regulations, protect your individually identifiable health information (also called Protected Health Information or PHI). The privacy laws require you to sign an Authorization that describes your rights and explains how your Protected Health Information (PHI) will be used and disclosed for this research study. 
By signing this informed consent, you are authorizing the principal investigator, his/her research staff, and the sponsor to use and disclose your PHI for the purnoses described below. You also authorize your doctors, health care services at , and individuals who provide described below.

to disclose your PHI for the purposes

This Authorization does not have an expiration date.

This study includes personnel from

and the University of

Central Florida. They may use your health information and share it with others. We want you to know who may use this information and how they may use it.

We also want to tell you about your rights concerning the use of your personal information before you agree to take part in the study.

Who may use and give out information about you?

The Investigator and research staff will have information about your health that tells us your identity. They may give this information to others during and after the study.

\section{Who may see this information?}

The following people, agencies and businesses may get information from us that show who you are.

- The researcher conducting the study

- The research assistant who will contact you after discharge

$-$

- UCF College of Nursing supervisory personnel

- UCF Institutional Review Board

- Accreditation organizations

What information may be used and shared?

If you volunteer to take part in this research study you have the right to know that others may know your identity. In addition, medical information that identifies you and relates to your participation will be created. Study information may identify you in the following ways:

- Name

- Telephone number

- Information obtained from the procedures used to find out whether you are eligible to take part in this study. This may include physical examinations, blood and urine tests, $\mathrm{x}$-rays and other procedures or tests, and any other information that you may release to us, including information about your health history.

- Information obtained in the course of the study including information about your response to any study treatments you receive, information related to study visits and phone calls, physical

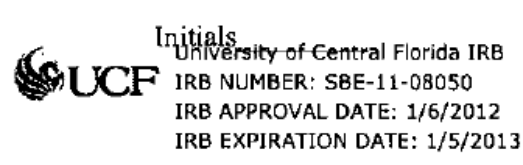


examinations, blood and urine tests, $x$-rays and other tests or procedures that may be performed, and other medical information relating to your participation in this study.

Why will this information be used and/or shared?

Information about you and your health, that might identify you, may be given to others to carry out the research study. The sponsor will analyze and evaluate the results of the study

The results of this research may be published in scientific journals or presented at medical meetings, but your identity will not be disclosed.

auditing roles.

representatives may review this research in their oversight and

What if $I$ decide not to give permission to use and give out my health information? By signing this consent form, you are giving permission to use and give out the health information listed above for the purposes described above. If you refuse to give permission, you will not be able to be in this research.

May I review or copy the information obtained from me or created about me?

You have the right to review and copy your health information. However, if you decide to be in this study and sign this permission form, you will not be allowed to look at or copy your information until after the research is completed.

May I withdraw or revoke (cancel) my permission?

Yes, but this authorization (permission) will never expire (end) unless you revoke (cancel) it in writing.

You may withdraw or take away your permission to use and disclose your health information at any time. You do this by sending written notice to the principal investigator. If you withdraw your permission, you will not be able to continue being in this study.

When you withdraw your permission, no new health information that might identify you will be gathered after that date. Information that has already been gathered may still be used and given to others. This would be done if it were necessary for the research to be reliable.

Is my health information protected after it has been given to others?

If you give permission to give your identifiable health information to a person or business, the information may no longer be protected. There is a risk that your information will be released to others without your permission.

Your personal information may be disclosed if required by law.

\section{How long is my information kept?}

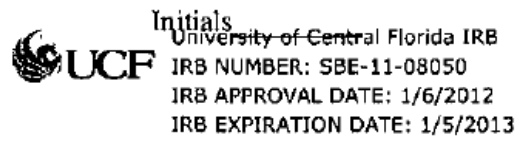


Files related to a research study are stored for at least seven (7) years after the research study has been closed.

Whether or not you choose to sign this authorization and participate in the research study, may not condition (withhold or refuse) treating you.

Do not sign this consent form unless a member of the research team has reviewed the study and this informed consent with you and until you have had a chance to ask questions and have received satisfactory answers to all of your questions.

If you agree to participate in this study, you will receive a signed and dated copy of this consent form for your records.

\section{DO NOT SIGN THIS FORM AFTER THE IRB EXPIRATION DATE BELOW}

Your signature below indicates your permission to take part in this research and to the use and disclosure of your protected health information:

Name of participant

Signature of participant

Signature of person obtaining consent
Date

Date

Printed name of person obtaining consent 
APPENDIX C: HUMAN SUBJECTS PROTECTION TRAINING 


\title{
CITI Collaborative Institutional Training Initiative
}

\author{
Human Research Curriculum Completion Report \\ Printed on 5/20/2013
}

Learner: Jacqueline LaManna (username: jlamanna2)

Institution: University of Central Florida

Contact Information

Group 1.Biomedical Research Investigators and Key Personnel:

Stage 4. Refresher Course Passed on 03/30/11 (Ref \# 5540086)

\begin{tabular}{|l|c|c|}
\hline Required Modules & $\begin{array}{c}\text { Date } \\
\text { Completed }\end{array}$ & Score \\
\hline Biomed Refresher 2 - History and Ethical Principles & $03 / 30 / 11$ & no quiz \\
\hline Biomed Refresher 2 - Regulations and Process & $03 / 30 / 11$ & $1 / 1(100 \%)$ \\
\hline Biomed Refresher 2 - Regulations and Process & $03 / 30 / 11$ & $1 / 1(100 \%)$ \\
\hline Biomed Refresher 2 - Informed Consent & $03 / 30 / 11$ & $1 / 1(100 \%)$ \\
\hline $\begin{array}{l}\text { Biomed Refresher 2 - SBR Methodologies in Biomedical } \\
\text { Research }\end{array}$ & $03 / 30 / 11$ & $2 / 2(100 \%)$ \\
\hline Biomed Refresher 2 - Genetics Research & $03 / 30 / 11$ & $1 / 1(100 \%)$ \\
\hline Biomed Refresher 2 - Genetics Research & $03 / 30 / 11$ & $1 / 1(100 \%)$ \\
\hline Biomed Refresher 2 - Records-Based Research & $03 / 30 / 11$ & $1 / 1(100 \%)$ \\
\hline Biomed Refresher 2 - Records-Based Research & $03 / 30 / 11$ & $1 / 1(100 \%)$ \\
\hline Biomed Refresher 2 - Records-Based Research & $03 / 30 / 11$ & $1 / 1(100 \%)$ \\
\hline $\begin{array}{l}\text { Biomed Refresher 2 - Research Involving Vulnerable } \\
\text { Subjects }\end{array}$ & $03 / 30 / 11$ & $1 / 1(100 \%)$ \\
\hline Biomed Refresher 2 - Vulnerable Subjects - Prisoners & $03 / 30 / 11$ & $1 / 1(100 \%)$ \\
\hline Biomed Refresher 2 - Vulnerable Subjects - Prisoners & $03 / 30 / 11$ & $1 / 1(100 \%)$ \\
\hline Biomed Refresher 2 - Vulnerable Subjects - Children & $03 / 30 / 11$ & $1 / 1(100 \%)$ \\
\hline Biomed Refresher 2 - Vulnerable Subjects - Children & $03 / 30 / 11$ & $1 / 1(100 \%)$ \\
\hline Biomed Refresher 2 - Vulnerable Subjects - Children & $03 / 30 / 11$ & $1 / 1(100 \%)$ \\
\hline $\begin{array}{l}\text { Biomed Refresher 2 - Vulnerable Subjects - Pregnant } \\
\text { Women, Human Fetuses, Neonates }\end{array}$ & $03 / 30 / 11$ & $0 / 1(0 \%)$ \\
\hline $\begin{array}{l}\text { Biomed Refresher 2 - Vulnerable Subjects - Pregnant } \\
\text { Women, Human Fetuses, Neonates }\end{array}$ & $03 / 30 / 11$ & $1 / 1(100 \%)$ \\
\hline $\begin{array}{l}\text { Biomed Refresher 2 - Conflicts of Interest in Research } \\
\text { Involving Human Subjects }\end{array}$ & $03 / 30 / 11$ & $3 / 3(100 \%)$ \\
\hline Biomed Refresher 2 - FDA-Regulated Research & $03 / 30 / 11$ & $1 / 1(100 \%)$ \\
\hline Biomed Refresher 2 - FDA-Regulated Research & $03 / 30 / 11$ & $2 / 2(100 \%)$ \\
\hline $\begin{array}{l}\text { Biomed Refresher 2 - HIPAA and Human Subjects } \\
\text { Research }\end{array}$ & $03 / 30 / 11$ & $2 / 2(100 \%)$ \\
\hline
\end{tabular}




\begin{tabular}{|l|c|c|}
\hline $\begin{array}{l}\text { Biomed Refresher } 2 \text { - Conflicts of Interest in Research } \\
\text { Involving Human Subjects }\end{array}$ & $03 / 30 / 11$ & $1 / 2(50 \%)$ \\
\hline $\begin{array}{l}\text { How to Complete the CITI Refresher Course and } \\
\text { Receive a Completion Report }\end{array}$ & $03 / 30 / 11$ & no quiz \\
\hline
\end{tabular}

For this Completion Report to be valid, the learner listed above must be affiliated with a CITI participating institution. Falsified information and unauthorized use of the CITI course site is unethical, and may be considered scientific misconduct by your institution.

Paul Braunschweiger Ph.D.

Professor, University of Miami

Director Office of Research Education

CITI Course Coordinator 
Commitment Statement of an Individual Investigator, Not Covered

by an Institutional Federalwide Assurance, to UCF Institutional

Human Subject Protection Policies and IRB Oversight

\title{
Cy UCF IRB Individual Investigator Agreement
}

\author{
Name of Institution with the Federalwide Assurance (FWA): University of Centrai Florida \\ Applicable FWA \#: 00000351 \\ Individual Investigator's Name (Non-UCF): \\ Marilyn Burton
}

Specify Research Covered by this Agreement: Research Assistant in dissertation of Jacqueline LaManna entitled "Transition Outcomes of Hospitalized Older Adults with Diabetes"

(1) The above-named Individual Investigator has reviewed: 1) The Belmont Report: Ethical Principles and Guidelines for the Protection of Human Subjects of Research [or other internationally recognized equivalent; see section B.1. of the 'Terms of the Federalwide Assurance (FWA) for International (Non-U.S.) Institutions]; 2) the U.S. Department of Health and Human Services (HHS) regulations for the protection of human subjects at 45 CFR part 46 [or other procedural standards; see section B.3. of the Terms of the FWA for International (Non-U.S.) Institutions]; 3) the FWA and applicable Terms of the FWA for the institution referenced above; and 4) the relevant institutional policies and procedures for the protection of human subjects.

(2) The Investigator understands and hereby accepts the responsibility to comply with the standards and requirements stipulated in the above documents and to protect the rights and welfare of human subjects involved in research conducted under this Agreement.

(3) The Investigator will comply with all other applicable federal, international, state, and local laws, regulations, and policies that may provide additional protection for human subjects participating in research conducted under this agreement.

(4) The Investigator will abide by all determinations of the University of Central Florida Institutional Review Board (UCF IRB) designated under the above FWA and will accept the final authority and decisions of the UCF IRB, including but not limited to directives to terminate participation in designated research activities.

(5) The Investigator will complete any educational training required by the UCF IRB prior to initiating research covered under this Agreement.

(6) The Investigator will report promptly to the UCF IRB any proposed changes in the research conducted under this Agreement. The investigator will not initiate changes in the research without prior UCF IRB review and approval, except where necessary to eliminate apparent immediate hazards to subjects. 
(7) The Investigator will report immediately to the UCF IRB any unanticipated problems involving risks to subjects or others in research covered under this Agreement.

(8) The Investigator, when responsible for enrolling subjects, will obtain, document, and maintain records of informed consent for each such subject or each subject's legally authorized representative as required under HHS regulations at 45 CFR part 46 and stipulated by the UCF IRB.

(9) The Investigator acknowledges and agrees to cooperate in the UCF IRB's responsibility for initial and continuing review, record keeping, reporting, and certification for the research referenced above. The Investigator will provide all information requested by the IRB in a timely fashion.

(10) The Investigator will not enroll subjects in research under this Agreement prior to its review and approval by the UCF IRB.

(11) Emergency medical care may be delivered without UCF IRB review and approval to the extent permitted under applicable federal regulations and state law, but the Investigator shall notify the UCF IRB within 5 working days of the administration of such care.

(12) This Agreement does not preclude the Investigator from taking part in research not covered by this Agreement.

(13) The Investigator acknowledges that he/she is primarily responsible for safeguarding the rights and welfare of each research subject, and that the subject's rights and welfare must take precedence over the goals and requirements of the research.

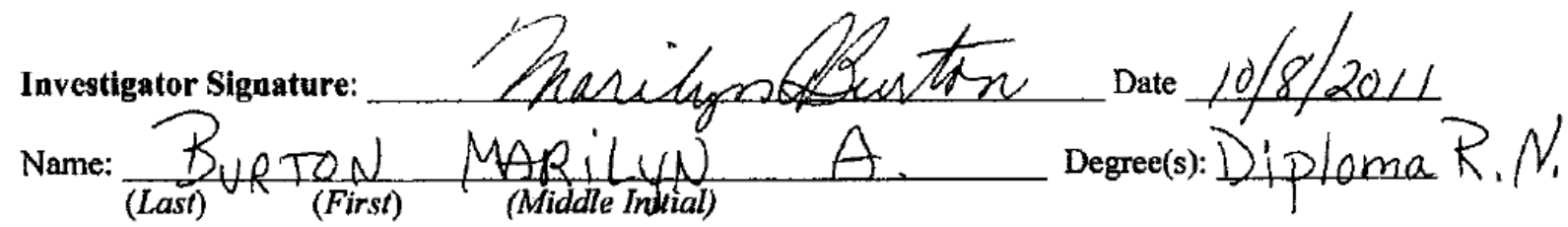

Company:

Address: phone \#:

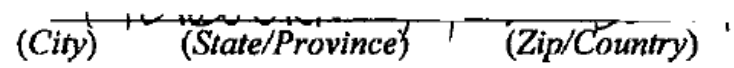

UCF FWA Official (or Designee) Signature:

Date

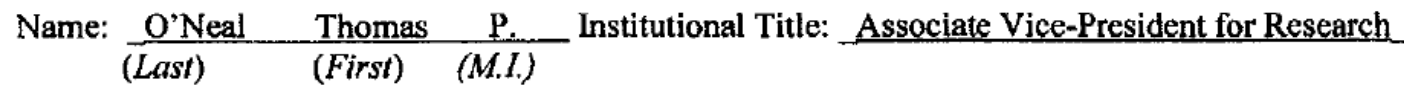

Address: UCF, Office of Research \& Commercialization, 12201 Research Parkway, Suite 501

phone \#: $407-823-2901$

Orlando

FL USA 


\title{
CITI Collaborative Institutional Training Initiative
}

\author{
Human Research Curriculum Completion Report \\ Printed on 10/7/2011
}

Learner: Marilyn Burton (username: mburton41)

Instifutlon: University of Central Florida

Contact

Information

Department: Nursing

Group 2.Social / Behavioral Research Investigators and Key Personnel:

Stage 1. Basic Course Passed on 10/07/11 (Ref \# 6828766)

\begin{tabular}{|c|c|c|}
\hline Required Modules & \begin{tabular}{|c|} 
Date \\
Completed
\end{tabular} & Score \\
\hline Introduction & $10 / 05 / 11$ & no quiz \\
\hline History and Ethical Principles - SBR & $10 / 07 / 11$ & $3 / 4(75 \%)$ \\
\hline Defining Research with Human Subjects - SBR & $10 / 07 / 11$ & $5 / 5(100 \%)$ \\
\hline $\begin{array}{l}\text { The Regulations and The Social and Behavioral } \\
\text { Sciences - SBR }\end{array}$ & $10 / 07 / 11$ & $5 / 5(100 \%)$ \\
\hline $\begin{array}{l}\text { Assessing Risk in Social and Behavioral Sciences - } \\
\text { SBR }\end{array}$ & $10 / 07 / 11$ & $4 / 5(80 \%)$ \\
\hline Informed Consent - SBR & $10 / 07 / 11$ & $5 / 5(100 \%)$ \\
\hline Privacy and Confidentiality - SBR & $10 / 07 / 11$ & $5 / 5(100 \%)$ \\
\hline Research with Prisoners - SBR & $10 / 07 / 11$ & $4 / 4(100 \%)$ \\
\hline Research with Children - SBR & $10 / 07 / 11$ & $4 / 4(100 \%)$ \\
\hline $\begin{array}{l}\text { Research in Public Elementary and Secondary Schools } \\
\text { - SBR }\end{array}$ & $10 / 07 / 11$ & $4 / 4(100 \%)$ \\
\hline International Research - SBR & $10 / 07 / 11$ & $3 / 3(100 \%)$ \\
\hline Internet Research - SBR & $10 / 07 / 11$ & $4 / 4(100 \%)$ \\
\hline Research and HIPAA Privacy Protections & $10 / 07 / 11$ & $5 / 5(100 \%)$ \\
\hline $\begin{array}{l}\text { Conflicts of Interest in Research Involving Human } \\
\text { Subjects }\end{array}$ & $10 / 07 / 11$ & $4 / 5(80 \%)$ \\
\hline$\overline{U C F}$ & $10 / 07 / 11$ & no quiz \\
\hline
\end{tabular}

For this Completion Report to be valid, the learner listed above must be affiliated with a CITI particlpating institution. Falsifled information and unauthorized use of the CITI course site is unethical, and may be considered scientific misconduct by your institution.

Paul Braunschweiger Ph.D.

Professor, University of Miami

Director Office of Research Education

CITI Course Coordinator 
APPENDIX D: DATA COLLECTION FLOW 


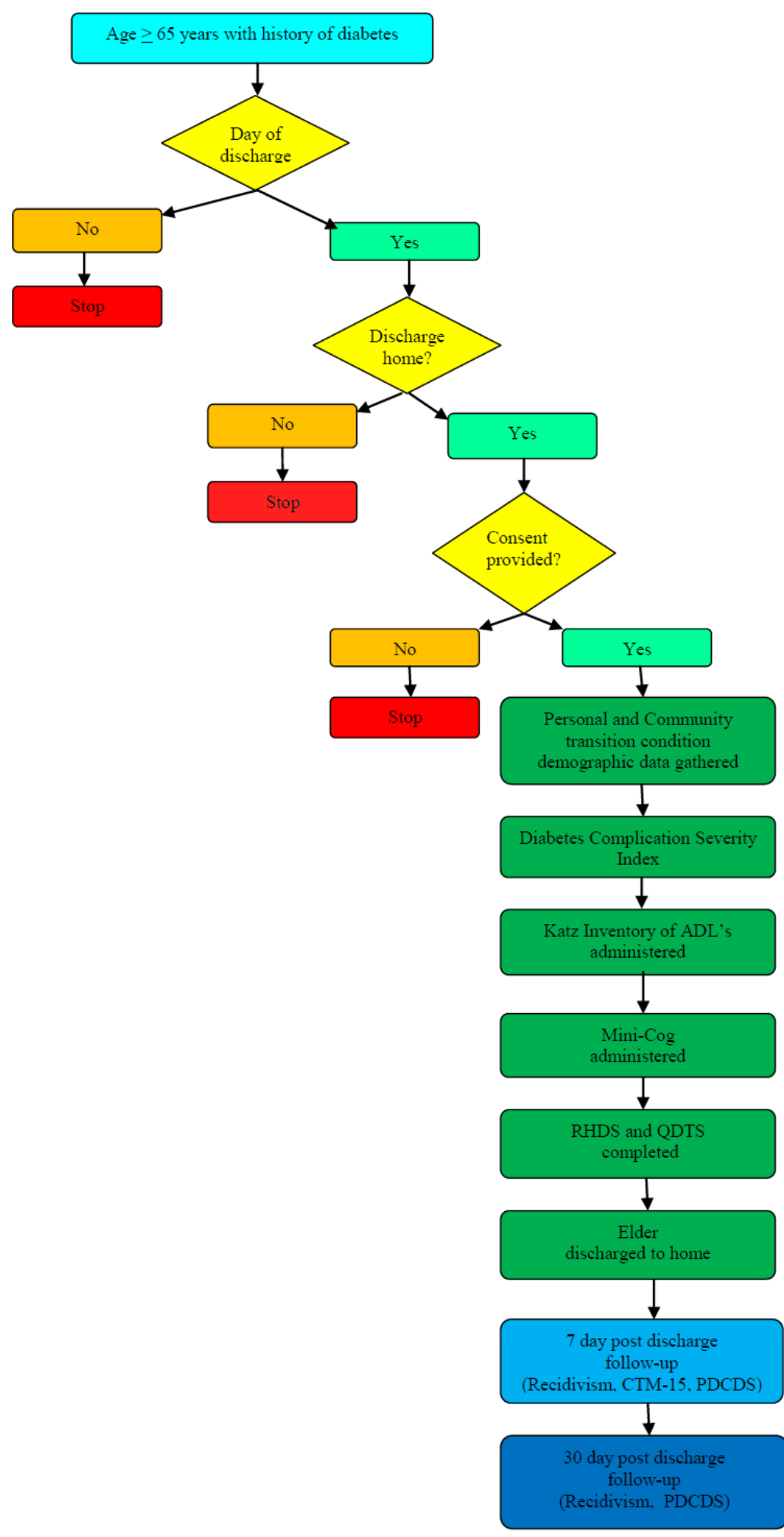


APPENDIX E: DATA COLLECTION FORMS 
Transition Experiences of Older Adults with Diabetes Data Collection Form Intake/Enrollment Information

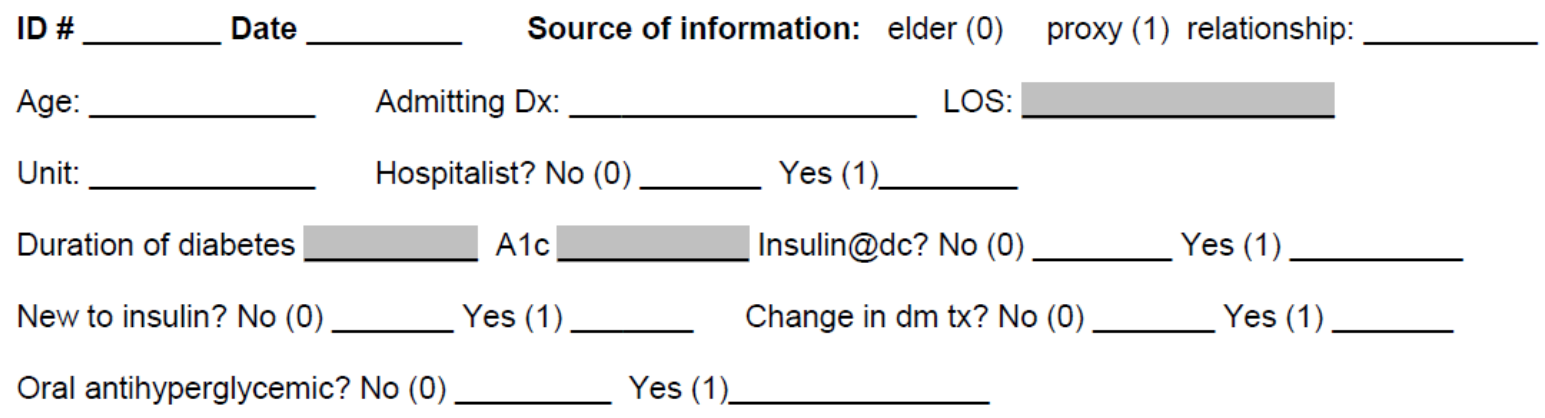

Chronic Illness Burden (Charlson Comorbidity Index) Chart data

Weight

1

2

4

6

\author{
Condition \\ COPD \\ Rheumatologic disease \\ Renal disease \\ Diabetes with chronic complications
}

$\mathrm{CHF}$

Dementia

Mild liver disease

Hemiplegia or paraplegia

Any malignancy including lymphoma/leukemia

Moderate/severe liver disease

HIVIAIDS

Metastatic solid tumor

Total Charlson Score (24 possible)

\section{Mini-Cog Score}

Administer following described protocol

Word recall points ( 1 point per recalled word/3 possible)

Clock draw points ( 0 points abnormal; 2 points normal)

Total Mini-Cog___ points ( 0 to 5 points; 0 to 2 high likelihood dementia)

Katz Independence with ADLs Score

Interview patient

Katz Score points (range 0 to 6 ) 


\section{Diabetes Complication Index}

$\begin{array}{lll}\text { Interview participant - see form } & \\ \text { CAD } & \text { Yes (1) } & \text { No (0) (includes CAD, angina and/or MI) } \\ \text { Cerebrovascular Dis } & \text { Yes (1) } & \text { No (0) (includes stoke and/or TIA) } \\ \text { PVD } & \text { Yes (1) } & \text { No (0) (includes dx PVD or calf pain with walking) } \\ \text { Neuropathy } & \text { Yes (1) } & \text { No (0) (includes peripheral and/or autonomic) } \\ \text { Foot problems } & \text { Yes (1) } & \text { No (0) (includes ulcers, hx gangrene or amputation) } \\ \text { Eye problems } & \text { Yes (1) } & \text { No (0) (includes cataracts, retinopathy) }\end{array}$

Total $\mathrm{DCl}$ score __ (Range 0 to 6 )

\footnotetext{
Readiness for Hospital Discharge Scale Scores

Administer to participant - may assist if needed

Personal Status Subscale score (range 0 to 60 )

Knowledge Subscale score (range 0 to 90 )

Coping Ability Score (range 0 to 30 )

Expected Support Score (range 0 to 40 )

Total Score All RDHS Subscales (range 0 to 220)

\section{Quality of Discharge Teaching Scale Scores}

Administer to participant - may assist if needed

- Content needed: Items 1a, 2a, 3a, 4a, 5a, 6a

- Content received: Items $1 b, 2 b, 3 b, 4 b, 5 b, 6 b$

- Delivery: Items $7,8,9,10,11,12,13,14,15,16,17,18$.

- Total Score: (Add scores content needed and delivery)
} 


\section{Caregiver at Discharge?}

No (0) Yes (1)

If yes, relationship:

If yes, present in home?

Homecare at Discharge?

No (0) Yes (1) 


\section{Transition Experiences of Older Adults with Diabetes Data Collection Form \\ Follow Up 1 - Day 7 (Week 1)}

Participant ID Date

\section{Recidivism: Total events of recidivism}

Since leaving the hospital, have you (or the person to whom you provide care) been admitted back to the hospital?
Yes (1)
No $(0)$
Date:
Reason:

Since leaving the hospital, have you (or the person to whom you provide care) been seen in the emergency department?
Yes (1)
No $(0)$
Date:
Reason:

Since leaving the hospital, have you (or the person to whom you provide care) required an unscheduled visit to a doctor or care provider?
Yes (1)
No $(0)$
Date:
Reason:

Do you currently have a family member, friend, or other individual assisting with your care?
Yes (1)
No $(0)$
If yes, relationship:

If yes, is the care provider currently staying in the home?

Are you (or the person to whom you provide care) currently receiving home health care services?

Yes (1) No (0)

Perceived Discharge Quality Score

Administer Care Transition Measure -15 telephonically to elder or caregiver following directions and scoring rubrics

CTM-15 calculated score:

Post-Discharge Coping Difficulty Scale Score

Administer Post-Discharge Coping Difficulty Scale telephonically to elder or caregiver

PDCD Scale calculated score: 


\section{Transition Experiences of Older Adults with Diabetes Data Collection Form}

\section{Follow Up 2 - Day 30 (Week 2 to 4)}

\section{Participant ID}

\section{Recidivism: Total Events of Recidivism}

During the past 3 weeks, have you (or the person to whom you provide care) been admitted back to the hospital?
Yes (1)
No $(0)$
Date:
Reason:

During the past 3 weeks, have you (or the person to whom you provide care) been seen in the emergency department?
Yes (1)
No $(0)$
Date:
Reason:

During the past 3 weeks, have you (or the person to whom you provide care) required an unscheduled visit to a doctor or care provider?
Yes (1)
No $(0)$
Date:
Reason:

\section{Do you currently have a family member, friend, or other individual assisting with your care?}

Yes (1) No (0) If yes, relationship:

If yes, is the care provider currently staying in the home?

\section{Are you (or the person to whom you provide care) currently receiving home health care services?}

Yes (1) No (0)

\section{Post-Discharge Coping Difficulty Scale Score}

Administer Post-Discharge Coping Difficulty Scale telephonically to elder or caregiver

\section{PDCD Scale calculated score:}

Diabetes Self-Management Behaviors

Administer Self-Care Inventory-Revised to elder or caregiver limiting to past 1 month as time frame

Average of items: $1,2,5,6,7,8, \& 13$

\section{SCI-R calculated score:}


APPENDIX F: DIABETES COMPLICATION INDEX AND PERMISSION TO USE 


\section{CORONARY ARTERY DISEASE}

Scoring of coronary artery disease (CAD): 1 on $\mathrm{CAD}$ and/or angina pectoris and/or myocardial infarction $=1 ; 0$ on all three $=0$

\section{Coronary artery disease}

a. Has a doctor ever told you that you have a blockage in the blood flow to your heart, also called CAD? Such blockage can lead to chest pain, also called angina. Scoring of CAD: yes $=1 ;$ no $=0$

\section{Angina pectoris}

a. In the past 6 months have you had chest pain or pressure?

b. Was the chest pain or pressure brought on by physical activity or stress?

c. Was the chest pain or pressure relieved by rest or nitroglycerine?

Scoring of angina: yes to all $=1$; no to $a$ or $b$ or $c=0$

\section{Myocardial infarction}

a. Has a doctor ever told you that you had a heart attack?

Scoring of myocardial infarction: yes $=1$; no $=0$

\section{CEREBROVASCULAR DISEASE}

Scoring of cerebrovascular disease: 1 on stroke and/or transient ischemic attack $=1$; 0 on both $=0$

\section{Stroke}

a. Have you ever been told by a doctor that you have had a stroke?

Scoring of stroke: yes $=1 ;$ no $=0$

\section{Transient ischemic attack}

a. Has a doctor ever told you that you have had a TIA? This is also called "Transient Ischemic Attack" or "warning stroke."

b. Have you ever developed sudden, strokelike symptoms, for example, weakness on one side of your body, difficulty speaking, drooping of one side of your mouth, drooling, or trouble seeing, which completely returned to normal within a day?

Scoring of transient ischemic attack: yes on $a$ and/or $b=1$

\section{PERIPHERAL VASCULAR DISEASE}

Scoring of peripheral vascular disease: yes on $a$ and/or $b=1$; no on both $=0$

a. Has a doctor ever told you that you have blockages in the blood vessels, arteries to your legs, also called peripheral vascular disease?

b. During the past 6 months, have you had leg cramps or pain in your calf while walking, which was relieved by rest?

\section{NEUROPATHY}

Scoring of neuropatby: 1 on peripheral and/or autonomic neuropathy $=1 ; 0$ on both $=0$

\section{Peripheral neuropathy}

a. During the past 6 months, have you had no feeling or numbness in your feet?

Scoring of peripberal neuropatby: yes $=1$, no $=0$

\section{Autonomic neuropathy}

a. During the past 4 weeks, how often have you had loss of bowel control or diarrhea 
while sleeping? Never, 1 or 2 times, about once a week, 2 or 3 times a week, most of the time.

Scoring of autonomic neuropatby:

$>$ never $=1 ;$ never $=0$

\section{FOOT PROBLEMS}

Scoring of foot problems: yes on $a$ and/or $b$ and/or $c=1$; no on all three $=0$

a. During the past 6 months, have you had ulcers on your toes, feet, or lower legs?

b. Have you ever had gangrene on any of your toes?

c. Have you ever had any part of your toes or feet amputated because of diabetes?

\section{EYE PROBLEMS}

Scoring of eye problems: yes on $a$ and/or $b=1 ;$ no on both $=0$ a. Do you now have cataracts?

b. Has a doctor ever told you that you have retinopathy or diabetic eye disease?

\section{Missing values}

Subjects with missing values are included only if the missing values prevent determination of whether 1 of the 6 complications is present or absent. For example, a "yes" answer to either of the 2 eye questions makes it possible to determine that an eye problem is present, even if the answer to the other question is missing. Therefore, this subject would be included. On the other hand, if the answer to that question were "no" and the answer to the other question were missing, it would not be possible to determine whether an eye problem is present or absent and the subject would be excluded. In practice, this means that subjects with missing values are included when it is still possible to calculate the DCI score, but excluded when it is not. 


$\begin{array}{ll}\text { From: } & \text { Graeme Fincke } \\ \text { To: } & \text { Jacqueline Lamanna } \\ \text { Subject: } & \text { Re: Request to Use Diabetes Complication Index Instrument } \\ \text { Date: } & \text { Monday, September 12, 2011 8:11:24 PM }\end{array}$

Jacqueline,

Yes, please feel free to use the Diabetes Complications Index.

Good luck with your study and congratulations in advance on your doctorate.

(Benjamin) Graeme Fincke

On Sep 12, 2011, at 7:24 PM, Jacqueline Lamanna wrote:

Dr. Fincke,

I am currently a doctoral student at the University of Central Florida College of Nursing. I am in the dissertation phase of the program and will be defending my proposal shortly. My dissertation research will examine hospital-to-home transition experiences of older adults with pre-existing diabetes. I believe that the Diabetes Complications Index will provide a excellent means of understanding the diabetesspecific disease burden of the study sample. With your permission, I would like to use this tool in my research study.

Thank you for your consideration.

Sincerely,

Jacqueline LaManna

Jacqueline LaManna, MSN, ARNP-BC, ADM, CDE

Instructor, Campus Coordinator

UCF College of Nursing

Brevard Campus 
APPENDIX G: PERMISSION TO USE INSTRUMENTS 
Hi Jacqueline - glad to hear you are progressing.

I have resent all instruments - see the psychometrics documents on the RHDs for the only change we are recommending based on a recent study of 1500 patients.

I am just writing the psychometrics paper that updates the QDTS and RHDS but the psychometrics are essentially the same. I think we include new alphas in the following references. We have a paper in revision right now that is the final report of the study that is referred to in the following 2 papers. I think I reported some psychometrics in those as well. We also know that others are finding similar results from use. Watch for a paper by Alice Coffey from Ireland - she just defended and she used the RHDS with elderly - psychometrics were fine and $p$ value for relationship to readmission was .07. I also know there was a paper submitted in Thailand - I will see if I can find it.

I have also attached the permission form. I would appreciate it if you would complete it if you choose to use the instruments - You certainly have permission to use them, I'm just trying to track who is using and the patient populations. I get a lot of requests and the requestors often ask if I know anyone else doing work in the area.

References for our 2 most recent papers are:

2010 Weiss, M.E., Yakusheva, O, \& Bobay, K.L. Nurse and patient perceptions of discharge readiness in relation to post-discharge utilization.

Medical Care, 48(5), 482-486.

2010 Bobay, K., Jerofke, T, Weiss, M., \& Yakusheva, O. Age-related

differences in perception of quality of discharge teaching and readiness for hospital discharge. Geriatric Nursing, 31(3), 178-187.

Good luck with your work. I look forward to hearing about it.

Marianne Weiss, DNSc, RN

Associate Professor and

Wheaton Franciscan Healthcare, St. Joseph / Sister Rosalie Klein Professor of Women's Health

Marquette University College of Nursing

PO Box 1881

From: Jacqueline Lamanna [jlamanna@mail.ucf.edu]

Sent: Friday, February 18, 2011 1:45 PM

To: Weiss, Marianne

Cc: jlamanna@knights.ucf.edu; Karen Dennis

Subject: Permission to Use Quality of Discharge Teaching Scale

Dr. Weiss,

I am a PhD student at the University of Central Florida College of Nursing. I am currently in the proposal stage of dissertation. My dissertation will explore transitional outcomes of older adults with diabetes who are hospitalized for an acute medical problem. Dr. Karen Dennis is my chair. I have been following your 
research over the past 2 years as I have moved from the course work to the dissertation phase of my program.

I wrote to you about 2 years ago to request (and you granted) permission to use the Readiness for Hospital Discharge Scale and Post-Discharge Coping Difficulty Scale in my psychometrics paper. I would also like to use both of these instruments and the Quality of Discharge Teaching Scale in my dissertation if you are agreeable.

If you could provide me with the most recent copy of each instrument and any updated data on psychometrics of the measures I would be most appreciative. I believe you asked for submission of a permission document in your last email. I had not submitted one at that time because I was still completing course work and was not sure of the direction of my dissertation at the time.

Thank you for your consideration and time.

Jacqueline LaManna 


\section{PERMISSION FOR USE AGREEMENT \\ READINESS FOR HOSPITAL DISCHARGE SCALE (RHDS) \\ QUALITY OF DISCHARGE TEACHING SCALE (QDTS) \\ POST-DISCHARGE COPING DIFFICULTY SCALE (PDCDS) Marianne Weiss, DNSC, RN, author}

You may use the RHDS/QDTS/PDCDS for clinical practice or research purposes under the following conditions: You agree to provide me with

1. a brief description of the study and/or clinical population for which it is used

2. a summary of any results from use of the instrument; for example, reliability coefficients, differences among groups, correlations, predictors, and/or outcomes

3.. where possible, a copy of RHDS/QDTS AND/OR PDCDS data for inclusion in an instrument database for further analysis of psychometric properties (not required for permission to use)

\section{Please complete the following questions:}

1. Your name: Jacqueline LaManna, MSN, ARNP-BC

2. Your organization: University of Central Florida College of Nursing

3. Your address:

4. Your telephone number: 321-XXX-XXXX

5. Your e-mail address:

6. Purposes(s) for using the instrument(s):

[ ] clinical practice

$x$ research, If yes, will you use the instrument(s)for [ ]master's thesis

$\mathrm{x}$ PhD dissertation

7. Which linstrument(s) do you plan to use in your research?

$x$ RHDS $\quad x$ QDTS $x$ PDCDS

Which version of the instrument(s) do you plan to use?

[ ] New mothers form(s) x Adult medical-surgical form(s) [] Parent of hospitalized

child form(s)

8. Describe how you plan to use the instrument? (If research, please briefly describe the Research questions and methods)

Dissertation research entitled "Hospital-to-Home Transition Experiences of Older Adults with Diabetes. 
Study objectives are:

- To determine whether personal (health-illness factors, diabetes-related factors, and discharge readiness) and community (hospital-related transition factors, family caregiver involvement, family caregiver involvement, and use of home care resources) transition conditions impact short-term (perceived discharge quality and post-discharge coping difficulties) and intermediate hospital-to-home transition outcomes (post-discharge coping difficulties and disease-specific self-management skills) in hospitalized older adults with diabetes.

- To ascertain whether personal and community transition conditions impact older adults' participation in diabetes self-management activities following hospital discharge.

Will be using with convenience sample of 150 older adults with diabetes on day of discharge with planned home discharge disposition. Participants will be hospitalized on medical/surgical and progressive care units. Site is $\mathbf{5 5 0}$ bed community medical center in east central Florida.

RHDS and QDTS will be administered prior to discharge and the PDCDS will be administered 7 and 30 days after discharge - participants will be mailed survey and then survey will be reviewed by phone

9. Describe the patients who will complete the instrument(s).

Inclusion criteria are: age 65 and older, diagnosis of diabetes pre-dating hospital admission, hospitalized at least 2 days for any diagnosis, planned home discharge disposition, within 4 hours of expected discharge

Exclusion criteria: discharge to hospice, diagnosis of dementia or cognitive impairment, visual or hearing impairment, lack of access to telephonic communication.

Signature: Jacquetine LaManna, MSN, ARNP (electronic) Date: 1/5/12

Please e-mail this form to Dr. Marianne Weiss. 
APPENDIX H: READINESS FOR HOSPITAL DISCHARGE SURVEY AND SCORING INFORMATION 


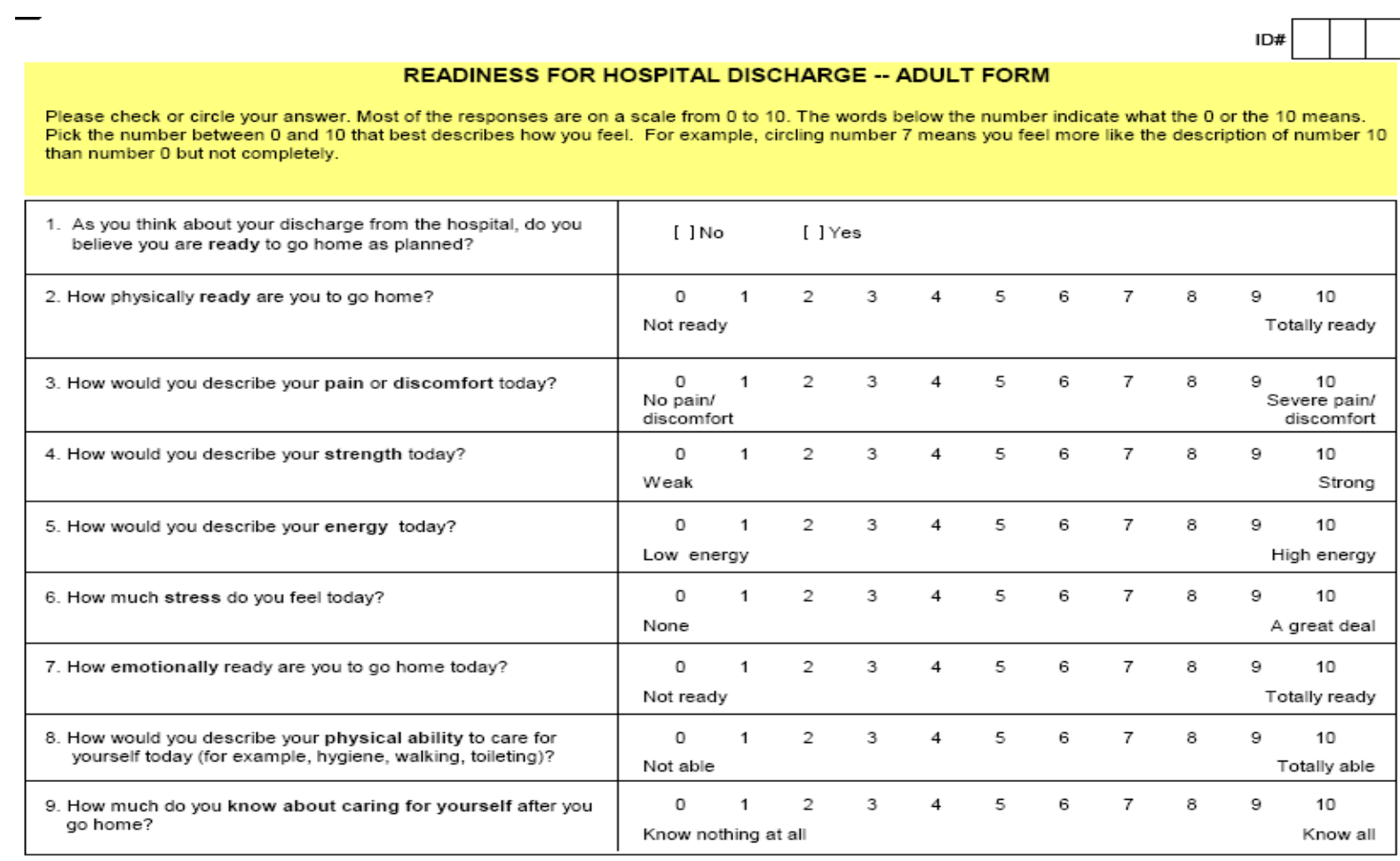




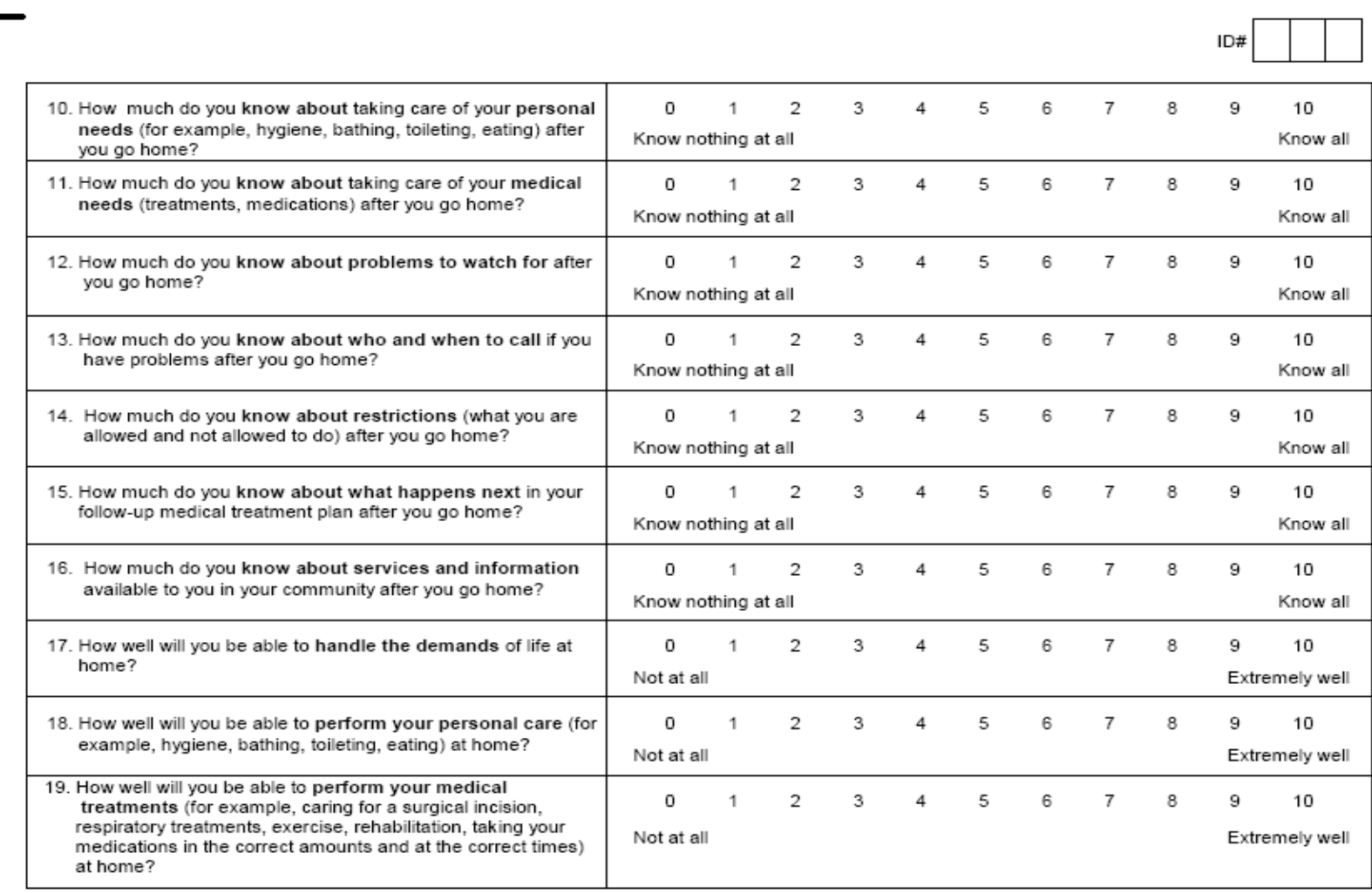




\section{RHDS Scoring Sheet - Original Version}

Participant ID Number:

\begin{tabular}{|l|l|l|}
\hline \multicolumn{1}{|c|}{ Question } & \multicolumn{1}{|c|}{ Item Score } & Calculated Scale Score \\
\hline 1 Ready to go home & & \\
\hline 2 Description physical readiness & (reverse code) & \\
\hline 3 Description of comfort & & \\
\hline 4 Description of strength & Exclude & \\
\hline 5 Description of energy & & \\
\hline 6 Description of stress & & \\
\hline 7 Description emotional readiness & & \\
\hline Personal Status Subscale Score & Total Scores Items 2-7 & \\
\hline 8 Physical ability for self-care & & \\
\hline 9 Knowledge of care needs & & \\
\hline 10 Knowledge personal needs & & \\
\hline 11 Knowledge medical needs & & \\
\hline 12 Knowledge problems to watch & & \\
\hline 13 Knowledge of who to call & & \\
\hline 14 Knowledge of restriction & & \\
\hline 15 Knowledge of follow-up & & \\
\hline 16 Knowledge of services & & \\
\hline Knowledge Subscale Score & Total Score Items 8-16 & \\
\hline 17 Ability to handle demands & & \\
\hline 18 Ability to perform personal care & & \\
\hline 19 Ability to perform medical tx & & \\
\hline Coping Ability Score & Total Score Items 17-19 & \\
\hline 20 Amount of emotional support & & \\
\hline 21 Help with personal care & & \\
\hline 22 Help with household activities & & \\
\hline 23 Help with medical care needs & & \\
\hline Expected Support Score & Total Score Items 20-23 & \\
\hline & & \\
\hline
\end{tabular}


APPENDIX I: QUALITY OF DISCHARGE TEACHING SCALE AND SCORING INFORMATION 
QUALITY OF DISCHARGE TEACHING SCALE - ADULT FORM

Please check or circle your answer. Most of the responses are on a scale from 0 to 10 . The words below the number indicate what the 0 or the 10 means. Pick the number between 0 and 10 that best describes how you feel. For example, circling number 7 means you feel more like the description of number 10 than number 0 but not completely.

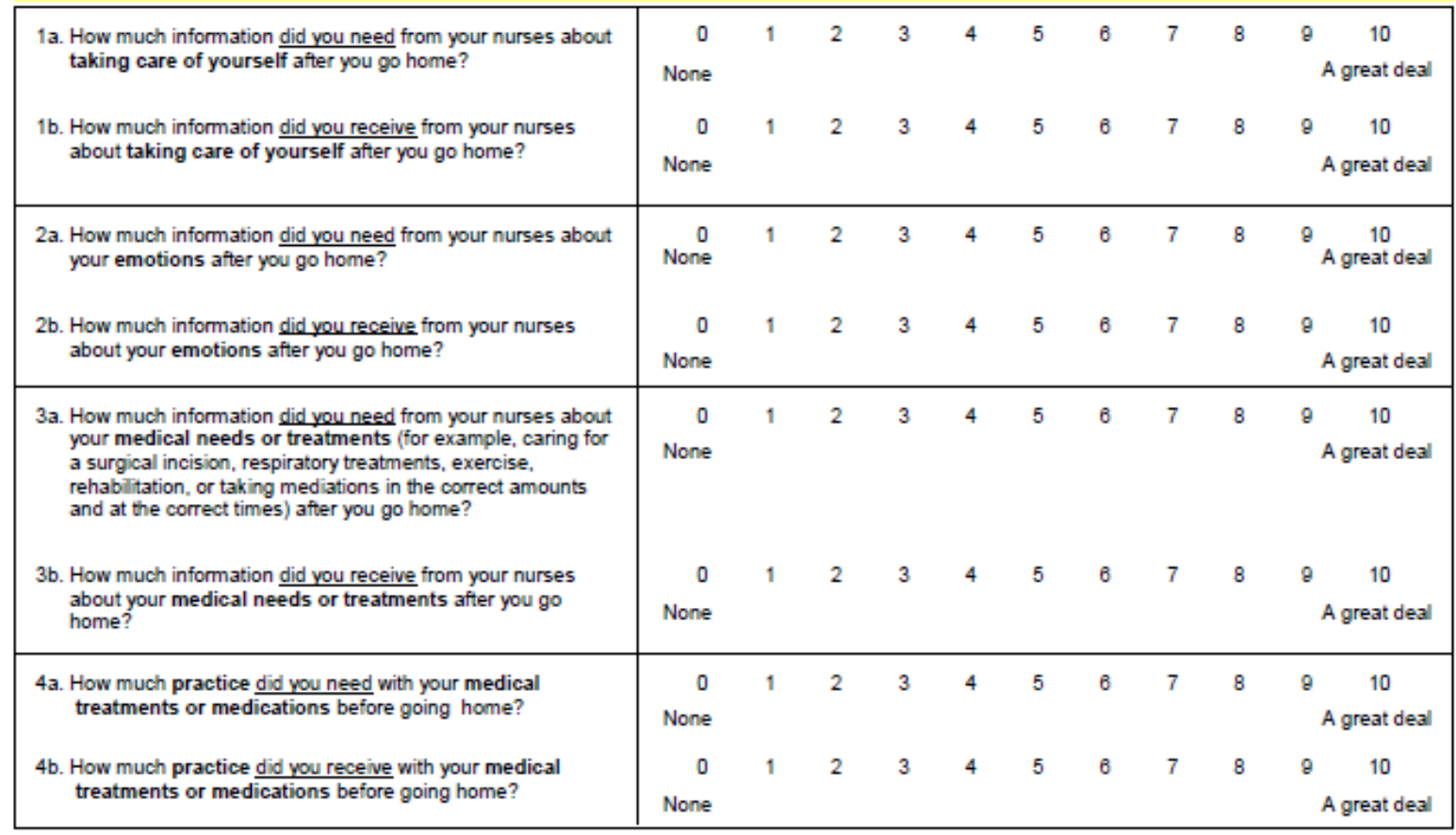




\begin{tabular}{|c|c|c|c|c|c|c|c|c|c|c|c|}
\hline $\begin{array}{l}\text { 5a. How much information did you need from your nurses about } \\
\text { who and when to call if you have problems after you go } \\
\text { home? }\end{array}$ & None & 1 & 2 & 3 & 4 & 5 & 6 & 7 & 8 & \multicolumn{2}{|c|}{ A great deal } \\
\hline $\begin{array}{l}\text { 5b. How much information did you receive from your nurses } \\
\text { about who and when to call if you have problems after you } \\
\text { go home? }\end{array}$ & None & 1 & 2 & 3 & 4 & 5 & 6 & 7 & 8 & \multicolumn{2}{|c|}{ A great deal } \\
\hline $\begin{array}{l}\text { 6a. How much information did your family member(s) or others } \\
\text { need about your care after you go home from the hospital? }\end{array}$ & $\begin{array}{c}0 \\
\text { None }\end{array}$ & 1 & 2 & 3 & 4 & 5 & 6 & 7 & 8 & $\theta$ & $\begin{array}{l}10 \\
\text { eat deal }\end{array}$ \\
\hline $\begin{array}{l}\text { 6b. How much information did your family member(s) or others } \\
\text { receive about your care after you go home from the hospital? }\end{array}$ & $\begin{array}{r}0 \\
\text { None }\end{array}$ & 1 & 2 & 3 & 4 & 5 & 6 & 7 & 8 & $\theta$ & $\begin{array}{l}10 \\
\text { eat deal }\end{array}$ \\
\hline $\begin{array}{l}\text { 7. How much did the information provided by your nurses answer } \\
\text { your specific concerns and questions? }\end{array}$ & $\begin{array}{c}0 \\
\text { Not at all }\end{array}$ & 1 & 2 & 3 & 4 & 5 & 6 & 7 & 8 & 9 & $\begin{array}{l}10 \\
\text { eat deal }\end{array}$ \\
\hline 8. How much did your nurses listen to your concerns? & $\begin{array}{c}0 \\
\text { Not at all }\end{array}$ & 1 & 2 & 3 & 4 & 5 & 6 & 7 & 8 & 9 & $\begin{array}{l}10 \\
\text { eat deal }\end{array}$ \\
\hline $\begin{array}{l}\text { 9. Were your nurses sensitive to your personal beliefs and } \\
\text { values? }\end{array}$ & $\begin{array}{c}0 \\
\text { Not at all }\end{array}$ & 1 & 2 & 3 & 4 & 5 & 6 & 7 & 8 & 9 & $\begin{array}{l}10 \\
\text { eat deal }\end{array}$ \\
\hline $\begin{array}{l}\text { 10. Did you like the way nurses taught you about how to care for } \\
\text { yourself at home? }\end{array}$ & $\begin{array}{c}0 \\
\text { Not at all }\end{array}$ & 1 & 2 & 3 & 4 & 5 & 6 & 7 & 8 & 9 & $\begin{array}{l}10 \\
\text { eat deal }\end{array}$ \\
\hline $\begin{array}{l}\text { 11. Was the information your nurses provided about caring for } \\
\text { yourself presented to you in a way you could understand? }\end{array}$ & $\begin{array}{c}0 \\
\text { Not at all }\end{array}$ & 1 & 2 & 3 & 4 & 5 & 6 & 7 & 8 & $\theta$ & $\begin{array}{l}10 \\
\text { Always }\end{array}$ \\
\hline $\begin{array}{l}\text { 12. Did your nurses check to make sure you understood the } \\
\text { information and instructions? }\end{array}$ & $\begin{array}{c}0 \\
\text { Not at all }\end{array}$ & 1 & 2 & 3 & 4 & 5 & 6 & 7 & 8 & 9 & $\begin{array}{l}10 \\
\text { eat deal }\end{array}$ \\
\hline $\begin{array}{l}\text { 13. Did you receive consistent (the same) information from your } \\
\text { nurses, doctors, and other health workers? }\end{array}$ & $\begin{array}{c}0 \\
\text { Not at all }\end{array}$ & 1 & 2 & 3 & 4 & 5 & 6 & 7 & 8 & 9 & $\begin{array}{l}10 \\
\text { Always }\end{array}$ \\
\hline
\end{tabular}




\begin{tabular}{|c|c|c|c|c|c|c|c|c|c|c|c|}
\hline $\begin{array}{l}\text { 14. Was the information about caring for yourself given to you at } \\
\text { times that were good for you? }\end{array}$ & $\begin{array}{c}0 \\
\text { Not at all }\end{array}$ & 1 & 2 & 3 & 4 & 5 & 6 & 7 & 8 & 9 & $\begin{array}{l}10 \\
\text { Always }\end{array}$ \\
\hline $\begin{array}{l}\text { 15. Was the information you received from your nurses provided } \\
\text { at times when your family member(s) or others could } \\
\text { attend? }\end{array}$ & $\begin{array}{c}0 \\
\text { Not at all }\end{array}$ & 1 & 2 & 3 & 4 & 5 & 6 & 7 & 8 & 9 & $\begin{array}{l}10 \\
\text { Always }\end{array}$ \\
\hline $\begin{array}{l}\text { 16. Did your nurses help you to feel confident in your ability to } \\
\text { care for yourself at home? }\end{array}$ & Not at all & 1 & 2 & 3 & 4 & 5 & 6 & 7 & 8 & 9 & $\begin{array}{l}10 \\
\text { eat deal }\end{array}$ \\
\hline $\begin{array}{l}\text { 17. How confident do you feel that you would know what to do } \\
\text { in an emergency? }\end{array}$ & $\begin{array}{c}0 \\
\text { Not at all }\end{array}$ & 1 & 2 & 3 & 4 & 5 & 6 & 7 & 8 & 9 & $\begin{array}{l}10 \\
\text { eat deal }\end{array}$ \\
\hline $\begin{array}{l}\text { 18. Did the information your nurses provided about your care at } \\
\text { home decrease your anxiety about going home? }\end{array}$ & $\begin{array}{c}0 \\
\text { Not at all }\end{array}$ & 1 & 2 & 3 & 4 & 5 & 6 & 7 & 8 & 9 & $\begin{array}{l}10 \\
\text { eeat deal }\end{array}$ \\
\hline
\end{tabular}

Thank you for responding to our survey. 
Quality of Discharge Teaching Scale Description and Scoring (Weiss, M., 2012) The Quality of Discharge Teaching Scale (QDTS) was developed to measure patients' perceptions of the discharge teaching received from nursing staff in preparation for discharge. Discharge teaching was conceptualized as the composite of teaching provided by nurses over the course of hospitalization to prepare the patient for managing their own care and recovery in the post-hospitalization period. The QDTS is a measure of the receiver characteristics of the nursing process of discharge teaching. Three formats of the tool have been developed for use in 3 separate populations: adult medical-surgical, new mother, and parents of hospitalized children. The QDTS consists of 24 items that are common across the 3 formats of the QDTS.

Administration Instructions:

o The QDTS is designed to be self-administered but can be read to a patient if visual or motor impairments preclude independent completion by the patient.

o The instrument is completed on the day of discharge after the decision to discharge is made and within 4 hours of the patient's projected discharge time.

o The instrument takes approximately 10 minutes to complete.

Scoring Instructions:

0 The instrument consists of 3 subscales:

- Content needed: Items 1a, 2a, 3a, 4a, 5a, 6a

- Content received: Items 1b, 2b, 3b, 4b, 5b, 6b

- Delivery: Items 7,8,9,10,11,12,13,14,15,16,17,18.

o Subscale scores are created by summing the item scores 
0 Total scale score is calculated by adding the 'content received' and 'delivery' subscale scores (the total scale score contains 18 items)

O A 'content difference' subscale score can be computed by creating a difference score for each content item (for example $1 \mathrm{diff}=1 \mathrm{~b}-1 \mathrm{a}$ ) then summing the 6 difference scores.

o Based on a study of 1800 patients completed in 2009 ( manuscript in process), we are recommending the use of subscale scores rather than total scores in analyses. The scales perform differently in predictive analyses.

Weiss, M.E., et al., (2007). Perceived readiness for hospital discharge in adult medicalsurgical patients. Clinical Nurse Specialist, 21 (1), 1-12.

Maloney, L.R. \& Weiss, M.E. (2008)Patients' perception of hospital discharge informational needs. Clinical Nursing Research, 17. 200-219. 
APPENDIX J: POST-DISCHARGE COPING DIFFICULTY SCALE AND SCORING INFORMATION 
Study ID

Post-Discharge Coping Difficulty Scale Adult

Since you have been home from the hospital:

\begin{tabular}{llllllllllll}
\hline 1. How stressful has your life been? & 0 & 1 & 2 & 3 & 4 & 5 & 6 & 7 & 8 & 9 & 10
\end{tabular}

Not at all

Extremely

What has been stressful?

\begin{tabular}{llllllllllll}
\hline 2. How much difficulty have you had with & 0 & 1 & 2 & 3 & 4 & 5 & 6 & 7 & 8 & 9 & 10
\end{tabular} your recovery?

None at all

A great deal

What has been difficult?

\begin{tabular}{llllllllllll}
\hline 3. How much difficulty have you had with & 0 & 1 & 2 & 3 & 4 & 5 & 6 & 7 & 8 & 9 & 10
\end{tabular} caring for yourself?

None at all

A great deal

What has been difficult?

4. How much difficulty have you had with $\quad \begin{array}{llllllllllll}0 & 1 & 2 & 3 & 4 & 5 & 6 & 7 & 8 & 9 & 10\end{array}$
managing your medical condition?

None at all

A great deal

What has been difficult?

5. How difficult has the time been for your $\quad \begin{array}{lllllllllll}0 & 1 & 2 & 3 & 4 & 5 & 6 & 7 & 8 & 9 & 10\end{array}$ family members or other close persons?

Not at all

Extremely

What has been difficult?

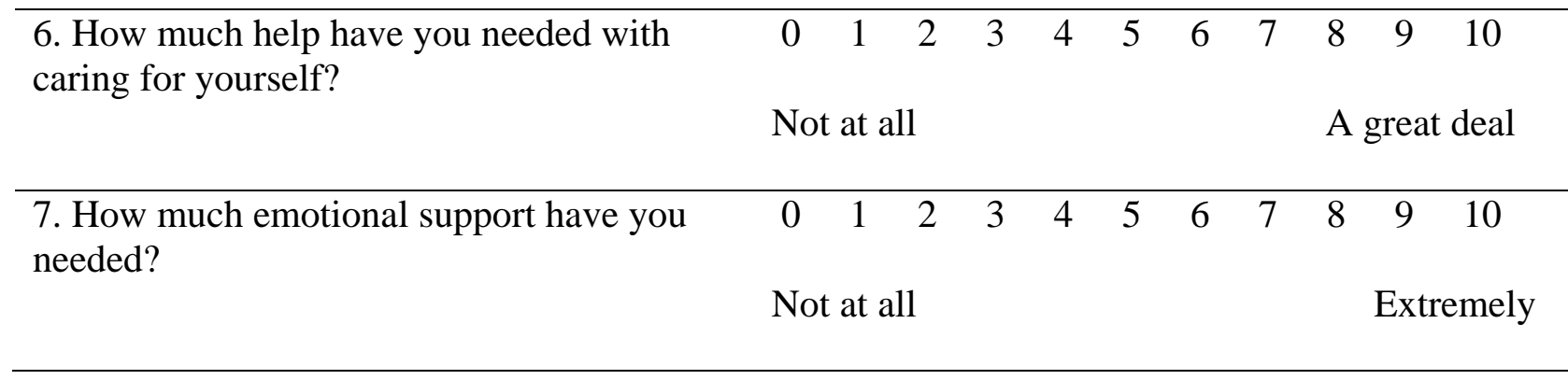


8. How confident have you felt in your ability to care for your own needs? $\begin{array}{lllllllllll}0 & 1 & 2 & 3 & 4 & 5 & 6 & 7 & 8 & 9 & 10\end{array}$

Not at all

Completely
9. Have you been able to take care of your medical needs such as medications or treatments?

$\begin{array}{lllllllllll}0 & 1 & 2 & 3 & 4 & 5 & 6 & 7 & 8 & 9 & 10\end{array}$

Not at all

10. How well have you adjusted to being at home since your hospitalization?

$\begin{array}{lllllllllll}0 & 1 & 2 & 3 & 4 & 5 & 6 & 7 & 8 & 9 & 10\end{array}$

Not at all

Extremely well

Thank you for participating in our study. 
PDCDS scoring instructions(M. Weiss, 2011)

The PDCDS is a 10 item instrument that measures the concept of coping difficulty following hospital discharge.

To score the instrument:

a. Reverse code items 8, 9, 10

b. Sum the responses to items $1,2,3,4,5,6,7$ and the reverse coded items 8, 9, and 10

Higher scores represent greater coping difficulty. 
APPENDIX K: CARE TRANSITION MEASURE AND SCORING INFORMATION 


\section{CARE TRANSITIONS MEASURE (CTM-15)}

Patient Name: Date:

Who completed interview? $\theta$ Patient $\theta$ Caregiver

The first few statements are about the time you were in the hospital ...

1. Before I left the hospital, the staff and I agreed about clear health goals for me and how these would be reached.

\begin{tabular}{|c|c|c|c|c|}
\hline $\begin{array}{l}\text { Strongly } \\
\text { Disagree }\end{array}$ & Disagree & Agree & $\begin{array}{c}\text { Strongly } \\
\text { Agree }\end{array}$ & $\begin{array}{l}\text { Don't Know/ } \\
\text { Don't Remember/ } \\
\text { Not Applicable }\end{array}$ \\
\hline
\end{tabular}

2. The hospital staff took my preferences and those of my family or caregiver into account in deciding what my health care needs would be when I left the hospital.

\begin{tabular}{|c|c|c|c|c|}
\hline $\begin{array}{l}\text { Strongly } \\
\text { Disagree }\end{array}$ & Disagree & Agree & $\begin{array}{l}\text { Strongly } \\
\text { Agree }\end{array}$ & $\begin{array}{l}\text { Don't Know/ } \\
\text { Don't Remember/ } \\
\text { Not Applicable }\end{array}$ \\
\hline
\end{tabular}

3. The hospital staff took my preferences and those of my family or caregiver into account in deciding where my health care needs would be met when I left the hospital.

\begin{tabular}{|c|c|c|c|c|}
\hline $\begin{array}{l}\text { Strongly } \\
\text { Disagree }\end{array}$ & Disagree & Agree & $\begin{array}{c}\text { Strongly } \\
\text { Agree }\end{array}$ & $\begin{array}{l}\text { Don't Know/ } \\
\text { Don't Remember/ } \\
\text { Not Applicable }\end{array}$ \\
\hline
\end{tabular}

The next set of statements is about when you were preparing to leave the hospital ...

4. When I left the hospital, I had all the information I needed to be able to take care of myself.

$\begin{array}{lccc}\begin{array}{c}\text { Strongly } \\ \text { Disagree }\end{array} \quad \text { Disagree } & \text { Agree } & \begin{array}{c}\text { Strongly } \\ \text { Agree }\end{array} & \begin{array}{c}\text { Don't Know/ } \\ \text { Don't Remember/ } \\ \text { Not Applicable }\end{array}\end{array}$

5. When I left the hospital, I clearly understood how to manage my health.

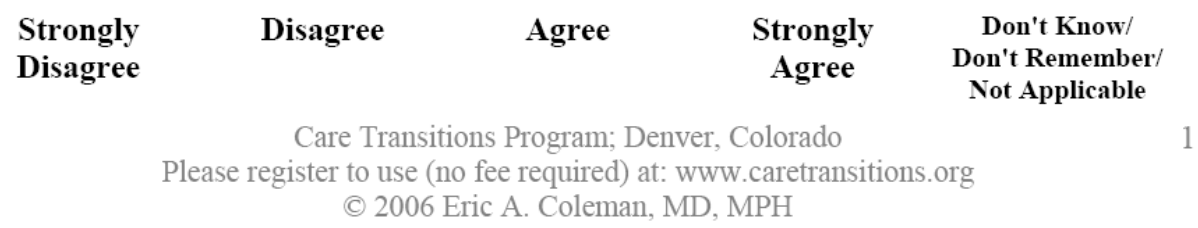


6. When I left the hospital, I clearly understood the warning signs and symptoms I should watch for to monitor my health condition.

\begin{tabular}{|c|c|c|c|c|}
\hline $\begin{array}{l}\text { Strongly } \\
\text { Disagree }\end{array}$ & Disagree & Agree & $\begin{array}{c}\text { Strongly } \\
\text { Agree }\end{array}$ & $\begin{array}{l}\text { Don't Know/ } \\
\text { Don't Remember/ } \\
\text { Not Applicable }\end{array}$ \\
\hline
\end{tabular}

7. When I left the hospital, I had a readable and easily understood written plan that described how all of my health care needs were going to be met.

\begin{tabular}{|c|c|c|c|c|}
\hline $\begin{array}{l}\text { Strongly } \\
\text { Disagree }\end{array}$ & Disagree & Agree & $\begin{array}{c}\text { Strongly } \\
\text { Agree }\end{array}$ & $\begin{array}{l}\text { Don't Know/ } \\
\text { Don't Remember/ } \\
\text { Not Applicable }\end{array}$ \\
\hline
\end{tabular}

8. When I left the hospital, I had a good understanding of my health condition and what makes it better or worse.

\begin{tabular}{|c|c|c|c|c|}
\hline $\begin{array}{l}\text { Strongly } \\
\text { Disagree }\end{array}$ & Disagree & Agree & $\begin{array}{c}\text { Strongly } \\
\text { Agree }\end{array}$ & $\begin{array}{c}\text { Don't Know/ } \\
\text { Don't Remember/ } \\
\text { Not Applicable }\end{array}$ \\
\hline
\end{tabular}

9. When I left the hospital, I had a good understanding of the things I was responsible for in managing my health.

\begin{tabular}{|c|c|c|c|c|}
\hline $\begin{array}{l}\text { Strongly } \\
\text { Disagree }\end{array}$ & Disagree & Agree & $\begin{array}{c}\text { Strongly } \\
\text { Agree }\end{array}$ & $\begin{array}{l}\text { Don't Know/ } \\
\text { Don't Remember/ } \\
\text { Not Applicable }\end{array}$ \\
\hline
\end{tabular}

10. When I left the hospital, I was confident that I knew what to do to manage my health.

\begin{tabular}{|c|c|c|c|c|}
\hline $\begin{array}{l}\text { Strongly } \\
\text { Disagree }\end{array}$ & Disagree & Agree & $\begin{array}{c}\text { Strongly } \\
\text { Agree }\end{array}$ & $\begin{array}{l}\text { Don't Know/ } \\
\text { Don't Remember/ } \\
\text { Not Applicable }\end{array}$ \\
\hline
\end{tabular}

11. When I left the hospital, I was confident I could actually do the things I needed to do to take care of my health.

\begin{tabular}{|c|c|c|c|c|}
\hline $\begin{array}{l}\text { Strongly } \\
\text { Disagree }\end{array}$ & Disagree & Agree & $\begin{array}{c}\text { Strongly } \\
\text { Agree }\end{array}$ & $\begin{array}{c}\text { Don't Know/ } \\
\text { Don't Remember/ } \\
\text { Not Applicable }\end{array}$ \\
\hline
\end{tabular}


The next statement is about your follow-up doctors' appointments ...

12. When I left the hospital, I had a readable and easily understood written list of the appointments or tests I needed to complete within the next several weeks.

\begin{tabular}{|c|c|c|c|c|}
\hline $\begin{array}{l}\text { Strongly } \\
\text { Disagree }\end{array}$ & Disagree & Agree & $\begin{array}{c}\text { Strongly } \\
\text { Agree }\end{array}$ & $\begin{array}{l}\text { Don't Know/ } \\
\text { Don't Remember/ } \\
\text { Not Applicable }\end{array}$ \\
\hline
\end{tabular}

The next set of statements is about your medications...

13. When I left the hospital, I clearly understood the purpose for taking each of my medications.

\begin{tabular}{|c|c|c|c|c|}
\hline $\begin{array}{l}\text { Strongly } \\
\text { Disagree }\end{array}$ & Disagree & Agree & $\begin{array}{l}\text { Strongly } \\
\text { Agree }\end{array}$ & $\begin{array}{l}\text { Don't Know/ } \\
\text { Don't Remember/ } \\
\text { Not Applicable }\end{array}$ \\
\hline
\end{tabular}

14. When I left the hospital, I clearly understood how to take each of my medications, including how much I should take and when.
Strongly
Disagree
Agree
Strongly
Don't Know/
Disagree
Agree
Don't Remember/
Not Applicable

15. When I left the hospital, I clearly understood the possible side effects of each of my medications.

\begin{tabular}{|c|c|c|c|c|}
\hline $\begin{array}{l}\text { Strongly } \\
\text { Disagree }\end{array}$ & Disagree & Agree & $\begin{array}{c}\text { Strongly } \\
\text { Agree }\end{array}$ & $\begin{array}{l}\text { Don't Know/ } \\
\text { Don't Remember/ } \\
\text { Not Applicable }\end{array}$ \\
\hline
\end{tabular}




\section{Scoring the CTM-15}

Overall Quality of Care Transition Score: This score reflects the overall quality of the care transition, with lower scores indicating a poorer quality transition, and higher scores indicating a better transition.

\section{Scoring Protocol}

Step 1: Code responses as Strongly Disagree $=1 ;$ Disagree $=2 ;$ Agree $=3 ;$ Strongly Agree $=4$.

Step 2: Assign code (e.g., 9) to missing responses, and a different code (e.g., 99) to Don't Know/Don't Remember/Not Applicable. These will not be counted as answered questions for Step 3a, as the 9 and 99 codes are not included in the 4 point Likert scale and therefore will not contribute to the CTM score. You can, however, get a count of 99's in order to calculate a percentage of these responses relative to questions answered (step 3a.)

Step 3: Compute a mean score for each respondent based only on the questions answered. To do this:

- Step 3a: For each respondent count the number of questions answered. (In SPSS, Step 3a is accomplished with the Count command in the Transform menu and Step $3 \mathrm{~b}$ by a Compute command).

- Step 3b: For each respondent obtain a summated score by adding Step 1 values across answered questions.

- Step 3c: Obtain mean for each respondent by dividing Step 3b result by Step 3a result. The name of this value is mean.

Step 4: Perform a linear transformation of the result of Step 3c to obtain a user-friendly 0-100 score. Use the following formula:

- $0-100$ CTM Score for each respondent $=[(\text { Step } 3 \mathrm{c} \text { result }-1) / 3]^{*} 100$.

- In SPSS Syntax this computation is:

COMPUTE CTM15_0_100 = ( ( (ctm15) $-(1)) /(3)) * 100$. EXECUTE . 
APPENDIX L: CURRICULUM VITAE 
Jacqueline LaManna, MSN, ANP, BC-ADM, CDE

\author{
University of Central Florida College of Nursing \\ 1519 Clearlake Road \\ Cocoa, FL 32922 \\ (321) 433-7855-Office \\ (321) 433-7863-Fax \\ jacqueline.lamanna@ucf.edu
}

\title{
EDUCATION
}

\begin{tabular}{|c|c|c|c|c|}
\hline Year & Degree & Institution & Clinical Major & Role Preparation \\
\hline $\begin{array}{l}\text { In } \\
\text { progress }\end{array}$ & $\mathrm{PhD}(\mathrm{c})$ & University of Central Florida, Orlando, FL & Nursing & Research \\
\hline 1991 & MSN & University of Florida, Gainesville, FL & Adult Health & Nurse Practitioner \\
\hline 1985 & BSN & Purdue University, West Lafayette, IN & Nursing & \\
\hline 1983 & $\mathrm{ADN}$ & Purdue University, West Lafayette, IN & Nursing & \\
\hline
\end{tabular}

\section{LICENSURE/CERTIFICATION}

$\begin{array}{ll}\text { ARNP } & \text { Florida, 1636342 } \\ \text { Adult NP } & \text { ANCC, Expires December, 2016 } \\ \text { Advanced Diabetes } & \text { NCBDE, Expires February, 2015 } \\ \text { Management NP } & \\ \begin{array}{l}\text { Certified Diabetes } \\ \text { Educator }\end{array} & \text { NCBDE, Expires, September, 2013 }\end{array}$

\section{EMPLOYMENT}

\section{ACADEMIC APPOINTMENTS:}

2007-present Brevard Regional Campus Manager, University of Central Florida College of

Nursing, Southern Regional Campus, Cocoa

2005-present Instructor and Lab Coordinator, University of Central Florida School of Nursing

Fall, 2004; Fall $\quad$ Clinical Preceptor, University of Central Florida, RN to BSN Program

2003; Fall, 2001

Spring, 1998

Fall, 1991; Fall,

1993; Fall 1996

1983-1984

Clinical Preceptor, University of Florida, MSN/Adult Nurse Practitioner Program

Adjunct Faculty - Health Assessment/School of Nursing, University of Central Florida, School of Nursing, Cocoa, FL

RN Nursing Skills Lab Assistant, Purdue University, West Lafayette, IN

\section{CLINICAL APPOINTMENTS:}

1998-2005

1997-1998

$1992-1997$

1990-1992

1990

$1986-1990$
Diabetes Nurse Practitioner/Manager, Health First Diabetes Center, Health First. Inc., Melbourne, FL

Adult Nurse Practitioner, HOPE Clinical Services, Health First, Inc., Melbourne, FL Clinical Nurse Specialist, Medicine, Holmes Regional Medical Center, Health First, Inc., Melbourne, FL

Education Coordinator, Holmes Regional Medical Center, Melbourne, FL

Staff Nurse Post Anesthesia Care Unit (per diem) - Holmes Regional Medical Center, Melbourne, FL

Staff Nurse/Nurse Clinician Progressive Care Unit - Holmes Regional Medical Center, Melbourne, FL 
1985-1986 Home Care Nurse - Trico Home Health Services, Melbourne, FL

1984-1985 Staff Nurse Labor and Delivery, Home Hospital, Lafayette, IN

PUBLICATIONS

NON-REFEREED JOURNALS OR PUBLICATIONS: (* Data-based articles)

LaManna, J. (2003-2005). Health First Health Plans Diabetes Newsletter, Quarterly Publication

LaManna, J. (2005). Fine tuning your diabetes: Beginning Symlin therapy [Patient Learning Module]. Melbourne, FL: Health First, Inc.

LaManna, J. (2005). Fine tuning your diabetes:Beginning Byetta therapy [Patient Learning Module]. Melbourne, FL: Health First, Inc.

LaManna, J. (2005). Fine tuning your diabetes medicines. (2nd ed.) [Patient Learning Module]. Melbourne, FL: Health First, Inc.

LaManna, J. (2005). Fine tuning your diabetes: Intensifying your insulin regime (3rd ed.) [Patient Learning Module] Melbourne, FL: Health First, Inc.

LaManna, J. (2005). Fine tuning your insulin (4th ed.) [Patient Learning Module]. Melbourne, FL Health First, Inc.

LaManna, J. (2005). Staying well with diabetes $\left(7^{\text {th }}\right.$ ed.) [Patient Learning Module]. Melbourne, FL: Health First, Inc.

LaManna, J (2005). Staying well with diabetes: Comprehensive ADA program cunriculum ( $7^{\text {th }}$ ed.). Melbourne, FL: Health First, Inc.

LaManna, J. (2004). Fine tuning your exercise program. [Patient Learning Module]. Melbourne, FL: Health First, Inc.

LaManna, J. (2003). Fine tuning your diabetes monitoring [Patient Learning Module]. Melbourne, FL: Health First, Inc.

LaManna, J. (2000.). Nursing exemplar: When no one cares. Melbourne, FL: Health First, Inc.

LaManna, J. (1993). Care of the hospitalized elder. [SLM\}. Melbourne, FL: Holmes Regional Medical Center.

LaManna, J. (1993). Patient education resource guide. Melbourne, FL: Holmes Regional Medical Center.

LaManna, J. (1992). Stepped skill instruction manual for patients and caregivers .Melbourne, FL: Holmes Regional Medical Center.

LaManna,, J. (1992). Preventing medication errors. (SLM) Melbourne, FL: Health First, Inc.

LaManna, J. (1991). Factor's associated with the development of femoral artery cannulation complications. Gainesville, FL: University of Florida (master's thesis).

\section{BOOK CHAPTERS:}

LaManna, J. \& Amidei, C. (2013). Endocrine alterations. In M. L. Sole, D. G. Klein \& M. J. Moseley (Eds.). Introduction to critical care mursing (6th ed.). St. Louis: Elsevier.

LaManna, J. (2013). QSEN best practice exemplars. In M. L. Sole, D. G. Klein \& M. J. Moseley (Eds.). Introduction to critical care nursing (6th ed.). St. Louis: Elsevier.

LaManna, J. (2013). Endocrine alterations. In M. L. Sole, D. G. Klein \& M. J. Moseley (Eds.). Instructor manual to accompany introduction to critical care mursing (6th ed.). St. Louis: Elsevier.

LaManna, J. (2009). End-of-life in the critical care unit. In M. L. Sole, D. G. Klein \& M. J. Moseley (Eds.). Instructor manual to accompany introduction to critical care nursing (5th ed.). St. Louis: Elsevier.

LaManna, J. (2009). Endocrine alterations. In M. L. Sole, D. G. Klein \& M. J. Moseley

(Eds.). Instructor manual to accompany introduction to critical care mursing (5th ed.). St. Louis: Elsevier. 
RESEARCH and GRANTS

\begin{tabular}{|c|c|c|c|c|c|}
\hline Date & Role & Title & Agency & Type & Amount \\
\hline $\begin{array}{l}\text { In } \\
\text { process }\end{array}$ & PI & $\begin{array}{l}\text { Hospital-to-Home Transition } \\
\text { Experiences of Older Adults with } \\
\text { Diabetes }\end{array}$ & $\begin{array}{l}\text { University of Central } \\
\text { Florida College of } \\
\text { Nursing }\end{array}$ & Dissertation & Not funded \\
\hline 2007 & $\begin{array}{l}\text { Co- } \\
\text { investigator }\end{array}$ & $\begin{array}{l}\text { College of Nursing Predictive } \\
\text { Admission Criteria }\end{array}$ & $\begin{array}{l}\text { University of Central } \\
\text { Florida College of } \\
\text { Nursing }\end{array}$ & Intramural & Not funded \\
\hline 2004 & Co-PI & $\begin{array}{l}\text { An Analysis of Pregnancy } \\
\text { Outcomes for Women with the } \\
\text { Diagnosis of Gestational Diabetes } \\
\text { Who Participate in a Coordinated } \\
\text { Community Gestational Diabetes } \\
\text { Program }\end{array}$ & Health First & Intramural & Not funded \\
\hline 1997 & $\begin{array}{l}\text { Site } \\
\text { coordinator }\end{array}$ & Project Thunder & $\begin{array}{l}\text { American Association of } \\
\text { Critical Care Nurses }\end{array}$ & Extramural & Not funded \\
\hline 1992 & PI & $\begin{array}{l}\text { Effect of Hands on Caregiver } \\
\text { Education on Home Care } \\
\text { Outcomes of High Risk Elders }\end{array}$ & $\begin{array}{l}\text { Holmes Regional } \\
\text { Medical Center; Florida } \\
\text { Institute of Technology }\end{array}$ & Joint grant & $\$ 2000$ \\
\hline 1991 & PI & $\begin{array}{l}\text { Factors Associated with the } \\
\text { Development of Femoral Artery } \\
\text { Cannulation Complications }\end{array}$ & University of Florida & Thesis & Not funded \\
\hline
\end{tabular}

\section{PRESENTATIONS-NATIONAL/INTERNATIONAL}

\begin{tabular}{|l|l|l|l|l|}
\hline Date & Type & Title & Conference Title, City/State & $\begin{array}{l}\text { Refereed/ } \\
\text { Invited }\end{array}$ \\
\hline $02 / 12 / 2009$ & Poster & $\begin{array}{l}\text { An Examination of Insulin Usage } \\
\text { Patterns in Older Adults }\end{array}$ & $\begin{array}{l}\text { Southern Nursing Research } \\
\text { Society annual conference, } \\
\text { Baltimore, MD }\end{array}$ & Refereed \\
\hline $02 / 22 / 2008$ & Poster & Transitions in Older Adulthood & $\begin{array}{l}\text { Southern Nursing Research } \\
\text { Society annual conference, } \\
\text { Birmingham, AL }\end{array}$ & Refereed \\
\hline $05 / 31 / 1998$ & Poster & $\begin{array}{l}\text { Interdisciplinary High Risk } \\
\text { Geriatric Team and Critical } \\
\text { Pathway }\end{array}$ & $\begin{array}{l}\text { American Association of Critical } \\
\text { Care Nurses National Teaching } \\
\text { Institute, Los Angeles, CA }\end{array}$ & Refereed \\
\hline
\end{tabular}

\section{PRESENTATIONS-LOCAL/REGIONAL/STATE}

04/11/13 Hospital to Home Transition Needs of Older Adults; Health First Clinical Nurse Educators

10/08/11 Hospital to Home Transition Experiences of Older Adults with Diabetes; UCF Southern Regional Campus Brown Bag, Cocoa, FL

01/04/11 Quality and Safety in Nursing Education: An Overview; co-presented with Leslee D'Amato-Kubiet, UCF College of Nursing Lunch and Learn, Orlando, FL

07/10/10 Nursing Care of the Hospitalized Patient with Diabetes; Wuesthoff Hospital GN Program, Rockledge, FL

4/2008 Transitions in Older Adulthood, poster presented at Sigma Theta Tau Research Day, Orlando Florida

4/2007 Technological Competence as Caring: A Middle Range Theory, poster presented at UCF 
$01 / 27 / 07$

$10 / 14 / 06$

05/10/06

09/06/05

08/31/05

$08 / 29 / 05$

$06 / 21 / 05$

$06 / 16 / 05$

$04 / 12 / 05$

$11 / 10 / 04$

$10 / 27 / 04$

$10 / 15 / 04$

08/18/04

$12 / 13 / 03$

$10 / 24 / 03$

$12 / 16 / 02$

$10 / 20 / 02$

$09 / 04 / 02$

$06 / 29 / 02$

06/27/02

05/08/02

$09 / 28 / 01$

$09 / 12 / 01$

$11 / 18 / 00$

$10 / 12 / 00$

1992-

2000

College of Nursing Research Day, Orlando, FL

Diabetes Medications, Health First Rehabilitation Update; Cocoa Beach, FL

Diabetes and Heart Disease, Concerned Hearts Support Group; Melbourne, FL

The Changing Face of Childhood Diabetes, University of Central Florida/Winter Park

Health Foundation, Orlando, FL

Promoting Exercise Safety in People with Diabetes, Pro Health and Fitness Center, Palm Bay, FL

Milestones in Life: Diabetes Through the Lifespan, Health First, Inc., Melbourne, FL Repeated 3 times per year

School Management of Diabetes, Brevard Public School Wellness Conference, Satellite Beach, Florida

Intensifying Insulin: Taking Insulin to the Next Level, Health First Home Care, Palm Bay, FL

Critical Care Management of Endocrine Disturbances, Health First, Inc,

Melbourne, FL; Repeated annually

Fine Tuning Your Diabetes Exercise Program, Pro Health and Fitness Center,

Melbourne, FL

Diabetes in Children (guest lecturer), Keiser College, Melbourne, FL

What's New in Diabetes? Health First Home Care, Merritt Island, FL

Management of Acute Diabetes Complications (guest lecturer), Keiser College, Melbourne, FL

Fitting the Pieces of the Puzzle: Medication Management in Type 2 Diabetes, Health First, Inc, Melbourne, FL (repeated quarterly)

Management of the Surgical Patient with Diabetes, Health First, Inc., Melbourne, FL

The Numbers Game: Lab Implication of Diabetes, Florida East Coast Point of Care Conference, Cape Canaveral, FL

Medications that Affect Diabetes Control, American Diabetes Association Central Florida Chapter Diabetes Expo, Satellite Beach, FL

Diabetes in African American Women, Greater Faith Temple COGIC, Cocoa Beach, FL Medication Management of Type 2 Diabetes, HOPE Clinical Services, Melbourne, FL

Management of Diabetes Medications: What is New on the Horizon, American Diabetes Association Central Florida Region Expo, Melbourne, FL

Metabolic Crisis in Diabetes, Cape Canaveral Hospital, Cocoa Beach, FL

The Pathway to Higher Education, Nursing Professional Development Fair, Melbourne, FL Gestational Diabetes, Health First Women and Children's Center, Melbourne, FL

Diabetes Clinical Update, Health First, Inc. Melbourne, FL

New Diabetes Equipment and Devices, American Diabetes Association Expo Central Florida Affiliate, Melbourne, FL

Nurses Who Make a Difference Exemplar Presentation, Health First, Melbourne, FL

Numerous continuing education program for professional and community continuing education programs on disease/case management, physical assessment, fluid/electrolyte management, cardiovascular care, respiratory care, long term mechanical ventilation, medical-surgical graduate nurse preparation and geriatric care issues

\section{HONORS/AWARDS}

\begin{tabular}{|l|l|l|}
\hline Date & Award & Organization/Group \\
\hline 2012 & Knightengale Schloar & University of Central Florida, College of Nursing \\
\hline 2010 & $\begin{array}{l}\text { University of Central Florida College of Nursing } \\
\text { Undergraduate Teaching Excellence } \\
\text { Award }\end{array}$ & University of Central Florida, College of Nursing \\
\hline 2008 & Merit Award, Poster & Sigma Theta Tau Research Day, Orlando, FL \\
\hline 2003 & Team Award, Diabetes Evidenced Based & Health First, Inc, Melbourne, FL \\
\hline
\end{tabular}




\begin{tabular}{|l|l|l|}
\hline Date & Award & Organization/Group \\
\hline & Practice & \\
\hline 2003 & Team Award, NCQA Preparation & Health First, Inc, Melbourne, FL \\
\hline 2003 & Nominee, Golden Eagle Award & Health First, Inc, Melbourne, FL \\
\hline 2000 & Clinical Excellence Award & Health First, Inc, Melbourne, FL \\
\hline 1995 & $\begin{array}{l}\text { Baxter Award for Quality Innovation in Health } \\
\text { Care, (Subject: Partners in Quality: A Nursing } \\
\text { Home Quality Action Team - authored paper for } \\
\text { organization) }\end{array}$ & American Association of Nurse Executives \\
\hline 1985 & University Top Woman Scholar Award & Purdue University, West Lafayette, IN \\
\hline
\end{tabular}

\section{PROFESSIONAL ACTIVITIES \& COMMUNITY SERVICE}

PROFESSIONAL ORGANIZATIONS:

\begin{tabular}{|l|l|l|}
\hline Date & Organization & Role \\
\hline 2011,2012 & National Certification Board for Diabetes Educators & $\begin{array}{l}\text { Item writer for revised advanced } \\
\text { diabetes management exam }\end{array}$ \\
\hline 2009-present & American Association of Diabetes Educators & Program reviewer \\
\hline 2005-2010 & American Nurses' Credentialing Center & $\begin{array}{l}\text { Expert Panel, Advanced Diabetes } \\
\text { Management Exam }\end{array}$ \\
\hline 1996-2008 & Health First Institutional Review Board & $\begin{array}{l}\text { Affiliated then transitioned to non- } \\
\text { affiliated member }\end{array}$ \\
\hline 1984-present & Sigma Theta Tau, Theta Epsilon Chapter & Member \\
\hline 1993-present & American Association of Diabetes Educators & Member \\
\hline 1993-present & American Diabetes Association & Member \\
\hline 1990-1998 & American Association of Critical Care Nurses & Member \\
\hline $1991-1995$ & Space Coast Association of Critical Care Nurses & Member \\
\hline $1991-1995$ & American Nurses' Association & Member \\
\hline $1991-1995$ & Florida Nurses' Association, District 31 & $\begin{array}{l}\text { District Board Member, Vice- } \\
\text { President, and Newsletter Editor }\end{array}$ \\
\hline
\end{tabular}

COMMUNITY SERVICE:

\begin{tabular}{|c|c|c|}
\hline Date & Organization & Role \\
\hline 2009-2011 & $\begin{array}{l}\text { Brevard Healthcare Forum, Behavioral Health } \\
\text { Subcommittee }\end{array}$ & College representative \\
\hline 2007-present & Astronaut High School Health Advisory Committee & College representative \\
\hline $2005-2007$ & $\begin{array}{l}\text { Ascension Catholic Church Health/Parish Nursing } \\
\text { Advisory Board }\end{array}$ & Member \\
\hline $1997-2008$ & Girl Scouts of Citrus Council & Co-Leader Girl Scout Troop 257 \\
\hline 2006-present & Central Florida Boy Scouts of America & Merit badge counselor \\
\hline Fall, 2004 & Brevard County Emergency Management & $\begin{array}{l}\text { Volunteer, Bayside Special Needs } \\
\text { Shelter - Hurricane Frances and } \\
\text { Jeanne }\end{array}$ \\
\hline $1998-2005$ & Adults with Diabetes Support Group & Facilitator \\
\hline $1998-2005$ & Young Adults with Diabetes/Insulin Pump Support Group & Facilitator \\
\hline
\end{tabular}




\begin{tabular}{|l|l|l|}
\hline Date & Organization & Role \\
\hline 2004 & Central Florida Affiliate, American Diabetes Association & $\begin{array}{l}\text { Planning Committee, Brevard } \\
\text { Walk }\end{array}$ \\
\hline 2003 & $\begin{array}{l}\text { Partners in Quality Nursing Home Community Action } \\
\text { Team }\end{array}$ & Member \\
\hline
\end{tabular}

CONSULTATION:

\begin{tabular}{|l|l|l|}
\hline Date & Consulting Organization/Individuals & Consultation Role \\
\hline August, 2009 & Hibiscus OB-GYN & $\begin{array}{l}\text { Gestational diabetes program } \\
\text { development }\end{array}$ \\
\hline July, 2006 & Sebastian River Medical Center & $\begin{array}{l}\text { Establishment of ADA Recognized } \\
\text { Diabetes Self-Management } \\
\text { Program }\end{array}$ \\
\hline February, 2006 & Ascension Catholic School & School management of diabetes \\
\hline Spring, 2002 & City of Melbourne Fire Rescue & Diabetes management in the field \\
\hline
\end{tabular}

\section{UNIVERSITY ACTIVITIES}

UNIVERSITY SERVICE: (Cummulative)

\begin{tabular}{|l|l|l|l|}
\hline Date & Level & Committee & Role \\
\hline 2011-2012 & College & $\begin{array}{l}\text { Undergraduate Annual Evaluation, } \\
\text { Standards and Procedures Task Force } \\
\text { (ad hoc) }\end{array}$ & Member \\
\hline 2011 & College & Undergraduate Search Committee & Member \\
\hline 2007-present & College & Basic BSN Cocoa Campus & Program Manager \\
\hline 2006-present & College & Basic BSN Cocoa Campus & Lab Coordinator \\
\hline 2006-present & College & Brevard Campus Advisory Committee & Chairperson (2007-present) \\
\hline $2007-$ present & College & $\begin{array}{l}\text { Undergraduate Admission, Progression } \\
\text { and Graduation Committee }\end{array}$ & Member \\
\hline $\begin{array}{l}2006, \\
2009-2011\end{array}$ & College & Undergraduate Curriculum Committee & Member \\
\hline $2009-2010$ & College & Strategic Planning Committee (ad hoc) & Member \\
\hline
\end{tabular}

DISSERTATION / THESIS / RESEARCH PROJECT ADVISING:

\begin{tabular}{|l|l|l|l|l|}
\hline Dates & Student & Title & Level & Role \\
\hline 2012-2013 & Samuel Foarde & $\begin{array}{l}\text { Support Systems in Adolescents } \\
\text { with Type 1 Diabetes Mellitus and the } \\
\text { Relationship to Diabetes-Related } \\
\text { Stress, Conflict, and Metabolic Control }\end{array}$ & $\begin{array}{l}\text { Honors in the } \\
\text { Major }\end{array}$ & Chair \\
\hline $2011-2012$ & $\begin{array}{l}\text { Samantha } \\
\text { Bainbridge }\end{array}$ & $\begin{array}{l}\text { Hospital Experiences of Older Adults } \\
\text { with Dementia }\end{array}$ & $\begin{array}{l}\text { Honors in the } \\
\text { Major }\end{array}$ & Chair \\
\hline 2010 & Cindy Houser & $\begin{array}{l}\text { Impact of Personal Opinions and } \\
\text { Attitudes of Health Care Providers on } \\
\text { the Quality of Care Provided to the } \\
\text { Homeless Population }\end{array}$ & $\begin{array}{l}\text { Honors in the } \\
\text { Major }\end{array}$ & Chair \\
\hline 2010 & Barbara Green & $\begin{array}{l}\text { An Analysis of the Effectiveness of } \\
\text { Common Nursing Interventions in the } \\
\text { Prevention of Pressure Ulcer } \\
\text { Development }\end{array}$ & $\begin{array}{l}\text { Honors in the } \\
\text { Major }\end{array}$ & Chair \\
\hline $2009-2010$ & Kelly Sullivan & $\begin{array}{l}\text { Improving Nursing Care of Women } \\
\text { Who Suffer Miscarriage }\end{array}$ & $\begin{array}{l}\text { Honors in the } \\
\text { Major }\end{array}$ & Chair \\
\hline
\end{tabular}




\begin{tabular}{|l|l|l|l|l|}
\hline Dates & Student & Title & Level & Role \\
\hline 2009-2010 & Jennifer Watts & $\begin{array}{l}\text { A Comparative Analysis of the Effect } \\
\text { of Critical Care Nursing Interventions } \\
\text { on Acute Outcomes in Patients with } \\
\text { Traumatic Brain Injury }\end{array}$ & $\begin{array}{l}\text { Honors in the } \\
\text { Major }\end{array}$ & Chair \\
\hline 2009-2010 & Jessie Cameron & $\begin{array}{l}\text { Family Presence During Resuscitation } \\
\text { of Adult Patients }\end{array}$ & $\begin{array}{l}\text { Honors in the } \\
\text { Major }\end{array}$ & Chair \\
\hline
\end{tabular}

\section{COURSES TAUGHT:}

\begin{tabular}{|c|c|c|c|c|}
\hline Semester & Course & Course Name & Enrollment & Role \\
\hline Spring, 2013 & NUR 42270070 & Nursing Care of the Adult II & 26 & Co-instructor \\
\hline Spring 2013 & NUR 3634L 0070 & Community Health Nursing Clinical & 12 & Co-instructor \\
\hline Spring 2013 & NUR 3755L 0073 & Essentials of Nursing Clinical & 9 & Co-instructor \\
\hline Spring 2013 & NUR 3028L 0071 & Essentials of Nursing Lab & 19 & Instructor \\
\hline Spring 2013 & NUR 3028L 0070 & Essentials of Nursing Lab & 20 & Instructor \\
\hline Spring 2013 & NUR 30280070 & Essentials of Nursing & 40 & Instructor \\
\hline Fall, 2012 & NGR 62012L 0011 & Adult II Primary Care Clinical & 5 & Instructor \\
\hline Fall, 2012 & NGR 6342L 0012 & Gender Health for APN's Clinical & 4 & Instructor \\
\hline Fall, 2012 & NUR 32250070 & Nursing Care of the Adult II & 25 & Instructor \\
\hline Fall, 2012 & NUR 31450070 & Pharmacology for Nursing Practice & 25 & Instructor \\
\hline Summer 2012 & NUR $3125 \mathrm{C} 070$ & Pathophysiology for Nursing Practice & 35 & Instructor \\
\hline Summer 2012 & NUR 4227L C071 & Nursing Practicum & 11 & Instructor \\
\hline Summer 2012 & NUR 4227L C072 & Nursing Practicum & \begin{tabular}{|l|l|}
7 & 1 \\
\end{tabular} & Instructor \\
\hline Spring 2012 & NUR $3028 \quad 0070$ & Essentials of Nursing Practice & 36 & Instructor \\
\hline Spring 2012 & NUR $4227 \quad 0 \mathrm{M} 70$ & Nursing Care of the Adult II & 33 & Co-instructor \\
\hline Spring 2012 & NUR 3634L 0072 & Community Health Nursing Clinical & 12 & Instructor \\
\hline Fall 2011 & NGR 6242L 0014 & Adult II Clinical for APNs & 4 & Instructor \\
\hline Fall 2011 & NGR 69410014 & Advance Practice Practicum & 7 & Instructor \\
\hline Fall 2011 & NUR $3145 \quad 0070$ & Pharmacology for Nursing Practice & 34 & Instructor \\
\hline Fall 2011 & NUR $3225 \quad 0070$ & Nursing Care of the Adult I & 35 & Co-instructor \\
\hline Fall 2011 & NUR $3905 \quad 0070$ & Independent Study & 1 & Instructor \\
\hline Summer 2011 & NUR $3125 \quad \mathrm{C} 070$ & Pathophysiology for Nursing Practice & 38 & Instructor \\
\hline Summer 2011 & NUR 4945L C071 & Nursing Practicum & 9 & Instructor \\
\hline Summer 2011 & NUR 4945L C072 & Nursing Practicum & 9 & Instructor \\
\hline Spring 2011 & NUR 3028L 0070 & Essentials of Nursing Practice & 37 & Instructor \\
\hline Spring 2011 & NUR $4227 \quad 0 \mathrm{M} 70$ & Nursing Care of the Adult II & 30 & Co-instructor \\
\hline Spring 2011 & NUR $3145 \quad 0001$ & Pharmacology for Nursing Practice & 117 & Instructor \\
\hline Spring 2011 & NUR 3634L 0071 & Community Health Nursing Clinical & 12 & Instructor \\
\hline Spring 2011 & NUR 3028L 0072 & Essentials of Nursing Clinical & 13 & Co-instructor \\
\hline Spring 2011 & NUR $3905 \quad 0070$ & Independent Study & 1 & Instructor \\
\hline Fall 2010 & NGR 69410014 & Advance Practice Practicum & 5 & Instructor \\
\hline Fall 2010 & NGR $6941 \quad 0043$ & Advance Practice Practicum & 2 & Instructor \\
\hline Fall 2010 & NUR $3145 \quad 0070$ & Pharmacology for Nursing Practice & 28 & Instructor \\
\hline Fall 2010 & NUR $3225 \quad 0070$ & Nursing Care of the Adult I & 29 & Co-instructor \\
\hline Summer 2010 & NUR $3125 \quad \mathrm{C} 070$ & Pathophysiology for Nursing Practice & 37 & Instructor \\
\hline Summer 2010 & NUR 4945L C071 & Nursing Practicum & 12 & Instructor \\
\hline Summer 2010 & NUR 4945L C072 & Nursing Practicum & 10 & Instructor \\
\hline Spring 2010 & NUR $3028 \quad 0070$ & Essentials of Nursing Practice & 41 & Instructor \\
\hline Spring 2010 & NUR 3028L 0071 & Essentials of Nursing Practice Lab & 21 & Instructor \\
\hline Spring 2010 & NUR 3634L 0071 & Community Health Nursing Clinical & 14 & Instructor \\
\hline Spring 2010 & NUR $4227 \quad 0070$ & Nursing Care of the Adult II & 37 & Co-Instructor \\
\hline
\end{tabular}




\begin{tabular}{|c|c|c|c|c|}
\hline Semester & Course & Course Name & Enrollment & Role \\
\hline Fall 2009 & NGR 6240L 0011 & Adult I Clinical (NP) & 10 & Instructor \\
\hline Fall 2009 & NUR $3145 \quad 0070$ & Pharmacology for Nursing Practice & 33 & Instructor \\
\hline Fall 2009 & NUR $3225 \quad 0070$ & Nursing Care of the Adult I & 36 & Co-Instructor \\
\hline Fall 2009 & $\begin{array}{lll}\text { NUR } 3905 \quad 0070 \\
\end{array}$ & Independent Study & 3 & Instructor \\
\hline Summer 2009 & NUR $3125 \quad$ C071 & Pathophysiology for Nursing Practice & 35 & Instructor \\
\hline Summer 2009 & NUR 4945L C072 & Nursing Practicum & 10 & Instructor \\
\hline Summer 2009 & NUR 4945L C073 & Nursing Practicum & 7 & Instructor \\
\hline Spring 2009 & NUR $3028 \quad 0070$ & Essentials of Nursing Practice & 38 & Instructor \\
\hline Spring 2009 & NUR 3028L 0071 & Essentials of Nursing Practice Lab & 19 & Instructor \\
\hline Spring 2009 & NUR 3755L 0072 & Essentials of Nursing Practice Clinical & 13 & Instructor \\
\hline Spring 2009 & NUR 3634L 0074 & Community Health Nursing Clinical & 12 & Co-Instructor \\
\hline Spring 2009 & NUR $4227 \quad 0$ T70 & Nursing Care of the Adult II & 26 (ITV) & Co-Instructor \\
\hline Fall 2008 & NUR $3145 \quad 0070$ & Pharmacology in Nursing Practice & 33 & Instructor \\
\hline Fall 2008 & NUR $3225 \quad$ 0T70 & Nursing Care of the Adult I & 34 (ITV) & Co-Instructor \\
\hline Summer 2008 & NUR $3125 \quad$ C071 & Pathophysiology in Nursing Practice & 34 & Instructor \\
\hline Summer 2008 & NUR 4945L C072 & Nursing Practicum & 11 & Instructor \\
\hline Summer 2008 & NUR 4945L C072 & Nursing Practicum & 6 & Instructor \\
\hline Spring 2008 & NUR $3028 \quad 0070$ & Essentials of Nursing Practice & 37 & Instructor \\
\hline Spring 2008 & NUR 3028L 0070 & Essentials of Nursing Practice Lab & 17 & Instructor \\
\hline Spring 2008 & NUR $4227 \quad 0070$ & Nursing Care of the Adult II & 27 & Co-Instructor \\
\hline Fall 2007 & NUR $3125 \quad 0070$ & Pathophysiology for Nursing Practice & 33 & Instructor \\
\hline Fall 2007 & NUR $3145 \quad 0070$ & Pharmacology for Nursing Practice & 33 & Instructor \\
\hline Fall 2007 & NUR 3225L 0072 & Nursing Care of the Adult I Clinical & 8 & Co-instructor \\
\hline Fall 2007 & NUR 3225L 0072 & Nursing Care of the Adult I Clinical & 9 & Co-Instructor \\
\hline Summer 2007 & NUR 6482L C012 & Women's Health Clinical (NP) & 7 & Instructor \\
\hline Summer 2007 & NUR $3940 \quad$ C072 & Nursing Internship & 7 & Instructor \\
\hline Summer 2007 & NUR $4835 \quad \mathrm{C} 071$ & Role Transition & 40 & Instructor \\
\hline Summer 2007 & NUR 4945L C071 & Nursing Practicum & 10 & Instructor \\
\hline Summer 2007 & NUR 4945L C072 & Nursing Practicum & 10 & Instructor \\
\hline Spring 2007 & NGR 6242L OM13 & Adult II Clinical (NP) & 7 & Instructor \\
\hline Spring 2007 & $\begin{array}{|ll|}\text { NUR } 3028 \quad 0070 \\
\end{array}$ & Essentials of Nursing & 34 & Instructor \\
\hline Spring 2007 & NUR 3028L 0072 & Essentials of Nursing Lab & 17 & Instructor \\
\hline Spring 2007 & NUR 3028L 0073 & Essentials of Nursing Lab & 17 & Instructor \\
\hline Fall 2006 & NUR $3235 \quad 0$ T70 & Promoting Physical and Mental Health & 38 (ITV) & Co-Instructor \\
\hline Fall 2006 & NUR 3235L 0070 & $\begin{array}{l}\text { Promoting Physical and Mental Health } \\
\text { Clinical }\end{array}$ & 12 & Instructor \\
\hline Summer 2006 & NUR $3940 \quad$ C072 & Internship & 3 & Instructor \\
\hline Summer 2006 & NUR 4945L C072 & Nursing Practicum & 14 & Instructor \\
\hline Summer 2006 & NUR 4945L C073 & Nursing Practicum & 11 & Instructor \\
\hline Spring 2006 & NUR $3825 \quad 0070$ & Role of the Professional Nurse & 37 & Instructor \\
\hline Spring 2006 & NUR 3026L 0071 & Therapeutic Interventions & 19 & Instructor \\
\hline
\end{tabular}

